Routledge Studies in Communication, Organization, and Organizing

\title{
WHISTLEBLOWING, \\ COMMUNICATION AND \\ CONSEQUENCES
}

LESSONS FROM THE NORWEGIAN NATIONAL LOTTERY

\author{
Edited by \\ Peer Jacob Svenkerud, Jan-Oddvar Sørnes \\ and Larry Browning
}

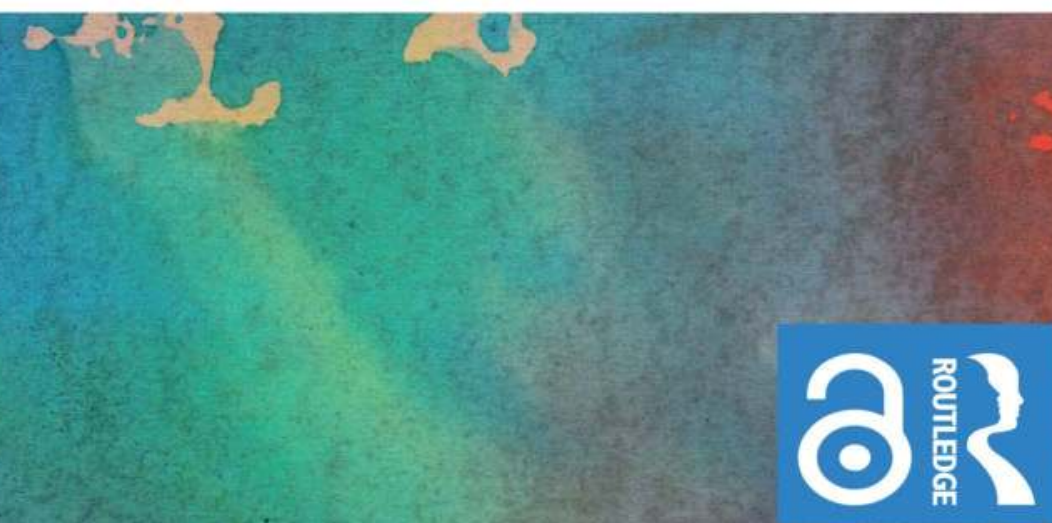




\section{Whistleblowing, Communication and Consequences}

Whistleblowing, Communication and Consequences offers the first in-depth analysis of the most publicized, and morally complex, case of whistleblowing in recent Scandinavian history: the Norwegian national lottery, Norsk Tipping.

With contributions from the whistleblower himself, as well as from key voices in the field, this book offers unique perspectives and insights into not only this fascinating case, but also into whistleblowing and wrongdoing in organizations more broadly. An international team of scholars use 14 different theoretical lenses to show the complex and multi-faceted nature of whistleblowing. The book begins with an ethnographic account by the whistleblower story and proceeds into an analysis of the literature and conceptual topics related to that whistleblowing incident to present the lessons that can be learned from this extreme example of institutional failure.

This fascinating, complex, and multi-theoretical book will be of great interest to scholars, students, and industry leaders in the areas of public relations, corporate communication, leadership, corporate social responsibility, whistleblowing, and organizational resistance.

Peer Jacob Svenkerud, Ph.D., Ohio University, Professor and Dean at the School of Business and Social Sciences, Inland University of Applied Sciences, Norway.

Jan-Oddvar Sørnes, Ph.D., Norwegian University of Science and Technology, Organizational Communication, Nord University, Business School.

Larry Browning, Ph.D., The Ohio State University, Professor Emeritus, William P. Hobby Centennial Professor of Communication, Department of Communication Studies, University of Texas at Austin, Moody College of Communication and Adjunct Professor of Management, Nord University Business School, Bodø, Norway. 


\section{Routledge Studies in Communication, Organization, and Organizing \\ Series Editor: François Cooren}

The goal of this series is to publish original research in the field of organizational communication, with a particular-but not exclusive-focus on the constitutive or performative aspects of communication. In doing so, this series aims to be an outlet for cutting-edge research monographs, edited books, and handbooks that will redefine, refresh, and redirect scholarship in this field.

The volumes published in this series address topics as varied as branding, spiritual organizing, collaboration, employee communication, corporate authority, organizational timing and spacing, organizational change, organizational sense making, organization membership, and disorganization. What unifies this diversity of themes is the authors' focus on communication, especially in its constitutive and performative dimensions. In other words, authors are encouraged to highlight the key role communication plays in all these processes.

Authority and Power in Social Interaction

Methods and Analysis

Edited by Nicolas Bencherki, Frédérik Matte and François Cooren

Organizing Inclusion: Moving Diversity from Demographics

to Communication Processes

Edited by Marya L. Doerfel and Jennifer L. Gibbs

Whistleblowing, Communication and Consequences

Lessons from The Norwegian National Lottery

Edited by Peer Jacob Svenkerud, Jan-Oddvar Sørnes

and Larry Browning

For more information about this series, please visit: www.routledge.com/ Routledge-Studies-in-Communication-Organization-and-Organizing/ book-series/RSCOO 


\section{Whistleblowing, \\ Communication and \\ Consequences \\ Lessons from The Norwegian \\ National Lottery}

Edited by Peer Jacob Svenkerud,

Jan-Oddvar Sørnes and

Larry Browning 
First published 2021

by Routledge

52 Vanderbilt Avenue, New York, NY 10017

and by Routledge

2 Park Square, Milton Park, Abingdon, Oxon, OX14 4RN

Routledge is an imprint of the Taylor \& Francis Group, an informa business

(C) 2021 Taylor \& Francis

The right of Peer Jacob Svenkerud, Jan-Oddvar Sørnes and Larry Browning to be identified as the authors of the editorial material, and of the authors for their individual chapters, has been asserted in accordance with sections 77 and 78 of the Copyright, Designs and Patents Act 1988.

The Open Access version of this book, available at www.

taylorfrancis.com, has been made available under a Creative Commons Attribution-Non Commercial-No Derivatives 4.0 license.

Trademark notice: Product or corporate names may be trademarks or registered trademarks, and are used only for identification and explanation without intent to infringe.

Library of Congress Cataloging-in-Publication Data

A catalog record for this book has been requested

ISBN: 978-0-367-42133-5 (hbk)

ISBN: 978-0-367-82203-3 (ebk)

Typeset in Sabon

by Apex CoVantage, LLC 


\section{Contents}

List of Figures viii

List of Tables ix

List of Contributors $\quad \mathrm{x}$

Preface xiii

PART I

Introduction 1

1 Alone Against the Organization-Peer's Whistleblower Story 3 PEER JACOB SVENKERUD

2 Whistleblowing, Voice, and Monomythology: The Prospect for Analysis

LARRY BROWNING, JAN-ODDVAR SØRNES, AND PEER JACOB SVENKERUD

\section{PART II}

What Goes Wrong?

3 Truth-Telling and Organizational Democracy: The Rhetoric of Whistleblowing as an Act of Parrhesia

RONALD WALTER GREENE, DANIEL HORVATH, AND

LARRY BROWNING

4 Smothered by Paradoxes and Swamped by Procedures: The Legal Context of the Case

ANNE OLINE HAUGEN

5 Whistleblowing, Identity Construction, and Strategic Communication 
vi Contents

PART III

How Does It Happen?

6 Sensemaking and Whistleblowing

KARL E. WEICK

7 Ethical Blindness as an Explanation for Non-Reporting of Organizational Wrongdoing

EINAR ØVERENGET AND ÅSE STORHAUG HOLE

8 Chronotopic Distinctions in Whistleblowing Events: X-Rays of Power and Sustaining Values

SARAH AMIRA DE LA GARZA

9 Whistleblowing: Making a Weak Signal Stronger BJØRN T. BAKKEN AND THORVALD HÆREM

PART IV

What Makes Whistleblowing a Risky Business?

10 Blowing the Whistle Is Laden With Risk JOSEPH McGLYNN

11 Hero or "Prince of Darkness"? Locating Peer Jacob Svenkerud in an Attributions-Based Typology of Whistleblowers

BRIAN K. RICHARDSON

12 Norsk Tipping's Loneliest Stakeholder: Crisis, Issues, and the Stakeholder Voice

AUDRA DIERS-LAWSON

PART V

How to Encourage Employees to Report Wrongdoing

13 The Influence of Psychological Contracts on DecisionMaking in Whistleblowing Processes

ÅSE STORHAUG HOLE AND THERESE E. SVERDRUP

14 Culture Eats Control for Breakfast: The Difficulty of Designing Management Systems for Whistleblowing 
15 Whistleblowing as a Means of $(\operatorname{Re})$ Constituting an Organization

WILLIAM ROTHEL SMITH III, JEFFREY W. TREEM, AND

JOSHUA B. BARBOUR

\section{PART VI}

Epilogue

16 Epilogue: God and Devil, Hero and Villain, and the Long Journey Ahead

RITA L. RAHOI-GILCHREST

Index 


\section{Figures}

11.1 Typology of Whistleblowers 154

12.1 Examples of Some of Norsk Tipping's Stakeholders 169

12.2 The Stakeholder Relationship Management Model 171

13.1 The Whistleblowing Process 188 


\section{Tables}

2.1 Campbell's Monomyth 22

14.1 Management Control Systems Package 203 


\section{Contributors}

Bjørn T. Bakken, Ph.D., BI Norwegian Business School. Associate Professor of Crisis Management, Inland Norway Business School (Campus Rena), Inland Norway University of Applied Sciences, Elverum, Norway. bjorn.bakken@inn.no

Joshua B. Barbour, Ph.D., The University of Illinois at Urbana-Champaign. Associate Professor, Department of Communication Studies, University of Texas at Austin, Moody College of Communication, barbourjosh@utexas.edu

Larry Browning, Ph.D., The Ohio State University. Professor Emeritus, William P. Hobby Centennial Professor of Communication, Department of Communication Studies, University of Texas at Austin, Moody College of Communication and Adjunct Professor of Management, Nord University Business School, Bodø, Norway. lbrowning@mail. utexas.edu

Corey Bruno, B.A. Communication, Texas A\&M University, Operations Manager, Abraham Logistics LLC, cjbruno13@gmail.com

Charles Conrad, Professor of organizational communication and organizational rhetoric in the Department of Communication at Texas A\&M University, cconrad@tamu.edu

Sarah Amira de la Garza, Ph.D., University of Texas at Austin, Associate Professor, Southwest Borderlands Scholar, Hugh Downs School of Human Communication, Affiliated Faculty in School of Transborder Studies and School of Social Transformation, Arizona State University, Tempe.delagarza@asu.edu

Audra Diers-Lawson, Ph.D., University of Texas at Austin. Senior Lecturer at Leeds Beckett University, United Kingdom. audra.lawson@ leedsbeckett.ac.uk

June Borge Doornich, Ph.D., Associate Professor in Strategy and Control at Nord University Business School, Bodø, Norway. June.b.doornich. nord.no 
Ronald Walter Greene, Ph.D., The University of Illinois at UrbanaChampaign. Professor and Chair, Department of Communication Studies, University of Minnesota (Twin Cities), green179@umn.edu.

Thorvald Hærem, Ph.D., Copenhagen Business School, Professor of Organizational Psychology, Norwegian School of Management, thorvald.harem@bi.no

Anne Oline Haugen, Cand. Jur., Professor of Law, Inland School of Business and Social Sciences, Inland Norway University of Applied Sciences, Department of Law and Norwegian University of Science and Technology, Faculty of Architecture and Design, Department of Design, anne.haugen@inn.no

Åse Storhaug Hole, Cand Scient., Norwegian School of Sports. MPA, University of Karlstad. Professor at the Department of Organization, Leadership and Management, Inland Norway School of Business and Social Sciences, Inland Norway University of Applied Sciences (INN), ase.storhaug@inn.no

Daniel Horvath, Ph.D., University of Minnesota (Twin Cities). Part-time faculty, California State University, Stanislaus, dhorvath@csustan.edu

Joseph McGlynn, Ph.D., The University of Texas at Austin. Assistant Professor, Department of Communication Studies, College of Liberal Arts and Social Sciences, University of North Texas, Joseph.McGlynn@unt. edu.

Einar Øverenget, Ph.D. in philosophy, Boston College, USA. Professor at the Department of Organization, Leadership and Management, Inland Norway School of Business and Social Sciences, Inland Norway University of Applied Sciences (INN), einar.overenget@inn.no

Rita L. Rahoi-Gilchrest, Ph.D., Ohio University. Associate Dean, College of Liberal Arts, Professor of Communication Studies, and Adjunct Professor, Healthcare Leadership and Administration, College of Nursing and Health Sciences, Winona State University, rrgilchrest@ winona.edu

Brian K. Richardson, Ph.D., The University of Texas at Austin. Professor, Department of Communication Studies, University of North Texas, richardson@unt.edu

William Rothel Smith III, Ph.D., The University of Texas at Austin. Assistant Professor, School of Communication, Illinois State University, wrsmit1@ ilstu.edu

Jan-Oddvar Sørnes, Ph.D., Norwegian University of Science and Technology, Organizational Communication, Nord University, Business School, Jan-Oddvar.Sornes@nord.no 


\section{xii Contributors}

Peer Jacob Svenkerud, Ph.D., Ohio University. Professor and Dean at the School of Business and Social Sciences, Inland University of Applied Sciences, Norway. peer.svenkerud@inn.no

Therese E. Sverdrup, Ph.D., Associate Professor at the Department of Strategy and Management and Vice Rector for Innovation and Development at Norwegian School of Economics (NHH), therese.sverdrup@ nhh.no

Jeffrey W. Treem, Ph.D., Northwestern University. Associate Professor, Department of Communication Studies, University of Texas at Austin, Moody College of Communication, jtreem@austin.utexas.edu

Karl E. Weick, Ph.D., The Ohio State University, Rensis Likert Distinguished University Professor of Organizational Behavior and Psychology, and Emeritus Professor of Psychology at the University of Michigan,karlw@umich.edu 


\section{Preface}

What could be more important, in these times of turbulence, than the investigation into the phenomenon of whistleblowing? We focus on one particular story-that of Peer Jacob Svenkerud (hereafter, PJS) in the hopes and beliefs that greater understanding will lead to increased effectiveness in responding to, seeing the warning signs, and establishing cultures that respond to whistleblowing. In this book, our aim is to investigate, through various theoretical approaches, one narrative, one data set, from the actual experiences of a whistleblower.

This book grew out of an ethnographic chapter that Peer Jacob Svenkerud (PJS) contributed to an earlier book, edited by Soelberg, Browning, and Sørnes, titled High North Stories in a Time of Transition. Based on his experience with articulating his story in ethnographic form, PJS invited the second and third editors to participate in developing a book with a multi-dimensional focus on his experience as a whistleblower. His goal, rather than simply sensationalizing his story, was to use it to showcase theoretical development. Our question, in inviting writers for chapters, was this: How does your theoretical stance as a scholar inform the data that PJS developed from his experience?

One of our goals was to enjoy the experience while we did the work. In service of that goal, work sessions occurred in delightful places: Crestone, Colorado; San Pancho, Mexico; Bodo, Norway; and at PJS's farm northeast of Oslo. These work sessions allowed us to complete 26 hours of interviews and to translate documents central to the whistleblowing event, including news articles, annual reports, governmental reports, and official investigative formal reports contracted by Norsk Tipping. These are the data provided to the chapter writers as a basis for their analysis.

As we elaborate in Chapter 2, the total data set was posted on a website; the chapter writers used the website to access these documents as the data for their analysis. Our goal was to generate independent interpretations of the data.

Several grants enabled us to complete this book. We thank Inland Norway University of Applied Sciences and Nord University for their generous support through research grants for traveling, transcription, and translation that allowed us to complete the project. 
We also thank Åse Storhaug Hole and Anne Oline Haugen, as they were pivotal in initiating the project and securing funding at Inland University; John Trimble, distinguished teaching professor of English, emeritus, University of Texas at Austin for editing the final copy; François Cooren, for supporting our efforts in securing a contract with Routledge; and Victoria Hoch for taking a final sweep through the galley proofs. As always, we thank Wencke and Victoria for keeping the home fires burning. Following is the rationale and outline for this book.

\section{A Rationale and Outline}

This book, Whistleblowing, Communication and Consequences: Lessons from The Norwegian National Lottery, offers the first in-depth analysis of a highly publicized, and morally complex, case of whistleblowing - the take-down of Norsk Tipping (hereafter, NT), Norway's national lottery, by one of the firm's senior officials, Peer Jacob Svenkerud, (hereafter, PJS) the Senior Vice President Information and External Relations. It took 29 months for NT's wrongdoings to be resolved. Meanwhile, PJS was asked to stay in place as a confidential informant and, ironically, also to help create the firm's communication strategy for responding to the very illegalities he had privately revealed. He agreed to become a double agent and to live a life of secrecy for the 29 months it took for PJS's identity to become public knowledge.

PJS himself gets the opening chapter here to tell us his story from his own viewpoint. The second chapter, which PJS co-writes with his editing partners, turns to a theoretical interpretation of voice and heroism to set expectations for the chapter contributors. Then, in the succeeding chapters, 13 scholars take turns viewing the same incident, but each through his or her own theoretical lens, the better to reveal the case's multi-dimensional complexity. The book is synthesized with Rita L. Rahoi-Gilchrest's epilogue.

What can we learn from their dissecting of this example of institutional failure? It turns out, plenty.

Whistleblowing, Communication and Consequences: Lessons from The Norwegian National Lottery lays out a single case, that of PJS blowing the whistle while the Senior Vice President Information and External Relations. Our inspiration for this strategy comes from several places: James G. March and his colleagues urge us to learn from samples of one or fewer by trading the analysis of multiple cases to the depth of multiple analyses of a single case. ${ }^{1}$ François Cooren follows this model by asking contributors to analyze a single board meeting from multiple perspectives. ${ }^{2}$ The body of the book follows March's insistence and Cooren's example by submitting PJS's outlier case to 13 different theoretical lenses to show its complex and multi-faceted nature. Our aim is to offer fresh takes on what might be learned about wrongdoing in organizations. What follows is an outline of the chapters and the contributing authors. 


\section{Part I: Introduction}

1. Alone Against the Organization: Peer's Whistleblower Story. Peer J. Svenkerud, Inland Norway University of Applied Sciences.

2. Whistleblowing, Voice, and Monomythology: The Prospect for Analysis. Larry Browning, Nord University and University of Texas at Austin; Jan-Oddvar Sørnes, Nord University; and Peer J. Svenkerud, Inland Norway University of Applied Sciences

\section{Part II: What Goes Wrong?}

What triggers a sense that something has gone desperately wrong? How does communication change when wrongdoing happens? Greene, Horvath, and Browning's opening chapter on the rhetoric of wrongdoing introduces this three-chapter grouping by locating whistleblowing as a persuasive act articulated in a local culture, with blame and gain activated within a micropolitical context. Anne Oline Haugen then addresses Norway's legal system, especially as to whether its laws support and defend whistleblowers. Corey Bruno and Charles Conrad cap the section by showing how the story demonstrates the autonomous choice of the whistleblower-especially how PJS's corporate knowledge and communication style distinguish his story.

3. Truth-Telling and Organizational Democracy: The Rhetoric of Whistleblowing as an Act of Parrhesia. Ronald Walter Greene, University of Minnesota; Daniel Horvath, California State University, Stanislaus; and Larry Browning, Nord University and the University of Texas at Austin.

4. Smothered by Paradoxes and Swamped by Procedures: The Legal Context of the Case. Anne Oline Haugen, Inland Norway University of Applied Sciences.

5. Whistleblowing, Identity Construction, and Strategic Communication, Corey Bruno and Charles Conrad, Texas A\&M University.

\section{Part III: How Does It Happen?}

Why do some organization members fail to see wrongdoing, let alone report it? It is hardly uncommon: "Employees, perhaps sensing that managers will not welcome complaints, often do not speak up." ${ }^{3}$ It's much easier to look past the misconduct; blowing the whistle requires a lot of energy and effort, and people are often punished for it. ${ }^{4}$ But how, exactly, does an organization's culture repress or express what to consider wrongdoing? How do people decide what to look past and what to report? Karl E. Weick's lead-off chapter of this four-set grouping shows us that sensemaking occurs when something is set apart from the routine and singled out as worth noticing and then interpreting. Sensemaking is 
a way to question this situation, to ask, "What's happening here?" Next, Einar Øverenget and Åse Storhaug Hole argue that ethical blindness consists of closing one's eyes to avoid seeing what is clearly wrongdoing-in effect, it is blindness by choice. For the authors, moral neutralization occurs not when looking past the behavior but instead when seeing and interpreting what is directly visible and common enough to be explicable and acceptable-in short, rationalized and normalized. De la Garza contributes to this section by applying the concept of the chronotope to trace the time-space relations of PJS's story and how then spatio-temporal sequences relate to De la Garza's own experience with whistleblowing. Finally, Bjørn T. Bakken and Thorvald Hærem apply the concept of weak signals to this whistleblowing case and suggest how a person and organization might move from weak to strong signals.

6. Sensemaking and Whistleblowing. Karl E. Weick, University of Michigan.

7. Ethical Blindness as an Explanation for Non-Reporting of Organizational Wrongdoing. Einar Øverenget and Åse Storhaug Hole, Inland Norway University of Applied Sciences.

8. Chronotopic Distinctions in Whistleblowing Events: X-Rays of Power and Sustaining Values. Sarah Amira de la Garza, Arizona State University.

9. Whistleblowing: Making a Weak Signal Stronger. Bjørn T. Bakken, Inland Norway University of Applied Sciences, and Thorvald Hærem, Inland Norway Business School.

\section{Part IV: What Makes Whistleblowing a Risky Business?}

The three chapters in this part focus on the things that pique attention and stand apart whenever whistleblowing occurs. What happens when an organization is jolted out of the norm by an individual? Joseph McGlynn shows us that risk invariably increases for the person who blows the whistle, especially since others may shrink from taking the same risk. Brian K. Richardson, in his chapter on heroes and villains, shows us that organizations don't automatically see the whistleblower as a symbol of justice and fairness; instead, they'll often question the person's motives. Or they'll ask: Why does he or she act the morally superior hero while I choose to remain quiet as a morally average person? ${ }^{5}$ Audra Diers-Lawson shows us that crisis communication typically treats whistleblowing as simply another kind of problem that requires clarity about who the organization's stakeholders are and what it takes to satisfy them.

10. Blowing the Whistle Is Laden With Risk. Joseph McGlynn, University of North Texas. 
11. Hero or "Prince of Darkness"? Locating Peer Jacob Svenkerud in an Attributions-Based Typology of Whistleblowers. Brian K. Richardson, University of North Texas.

12. Norsk Tipping's Loneliest Stakeholder: Crisis, Issues, and the Stakeholder Voice. Audra Diers-Lawson, Leeds Beckett University.

\section{Part V: How to Encourage Employees to Report Wrongdoing}

Organizations often want to control behavior to increase productivity or to establish a culture. But what about a culture that opposes wrongdoing? The three chapters in this section come to grips with why wrongdoing proves hard to control and whistleblowing is so difficult to support-especially in strong cultures. Åse Storhaug Hole and Therese E. Sverdrup take up the psychological contract-the expectations-between the organization and a person. They describe the obligations that keep the structures of conformity intact. June Borge Doornitch's chapter on internal control systems explores this inquiry: Is it possible to structure a fool-proof organization in such a way that wrongdoing is always handled internally? Can processes be made seamless, so that decision-makers can rectify a problem without the pressure of external controls? Finally, William Rothel Smith III, Jeffrey W. Treem, and Joshua B. Barbour interrogate the concept of authority by analyzing how it is communicated by key players at NT.

13. The Influence of Psychological Contracts on Decision-Making in Whistleblowing Processes. Ase Storhaug Hole and Therese E. Sverdrup, Inland Norway University of Applied Sciences and Norwegian School of Economics (NHH).

14. Culture Eats Control for Breakfast: The Difficulty of Designing Management Systems for Whistleblowing. June Borge Doornich, Nord University.

15. Whistleblowing as a Means of (Re)Constituting an Organization. William Rothel Smith III, Jeffrey W. Treem, and Joshua B. Barbour, University of Texas at Austin.

\section{Part VI: Epilogue}

16. Epilogue: God and Devil, Hero and Villain, and the Long Journey Ahead. Rita L. Rahoi-Gilchrest, Winona State University.

\section{Notes}

1. March, J. G., Sproull, L. S., \& Tamuz, M. (1991). Learning from samples of one or fewer. Organization Science, 2(1), 1-13.

2. Cooren, F. (Ed.). (2007). Interacting and organizing: Analyses of a board meeting. Mahwah, NJ: Lawrence Erlbaum. 


\section{xviii Preface}

3. Miceli, M. P., Near, J. P., \& Dworkin, T. M. (2009). A word to the wise: How managers and policy-makers can encourage employees to report wrongdoing. Journal of Business Ethics, 86(3), 379-396.

4. Kenny, K. (2019). Whistleblowing: Toward a new theory. Cambridge, MA: Harvard University Press.

5. Fishkin, J. S. (1982). The Limits of Obligation. Binghampton, NY: Yale University Press; Archer, A. (2015). Saints, heroes and moral necessity. Royal Institute of Philosophy Supplements, 77, 105-124. 


\section{Part I}

\section{Introduction}




\title{
1 Alone Against the Organization-Peer's Whistleblower Story
}

\author{
Peer Jacob Svenkerud
}

Throughout most of my adulthood I had felt as if a shadow were following me-a feeling of general unhappiness about where my life had taken me, a sense of not belonging, and of failing to accomplish anything meaningful. I had spent countless hours wondering why I felt like this and thinking that the feeling would never go away, that it had simply become a part of me. It took many years before I found a solution, and my story is about that journey.

There's a tiny bus stop between the rural towns of Elverum and Hamar, almost lost in the vast pine forests in that part of Norway. I had gotten used to stopping there daily to vomit in its solitude, hoping to quiet my churning stomach. The obstacles confronting me seemed intractable. More than two years earlier, in 2007, I had blown the whistle on the CEO of my own organization, and it had seemed to cost me as dearly as it had him.

Whenever I now pass that bus stop, I see it as a symbol of a transformative period in my life, a symbol of a place and time when the question of who I was and who I wanted to become was essential for my development.

I remember my parents telling me that unrest and impatience were always major features of my personality, so when, in 1994, I announced my decision to study abroad, in the American West, it surprised no one. It was just another sign of my impatience and need to discover. I ended up spending many years in the U.S., concluding at the University of New Mexico. By then I had been blessed to meet and work with Everett Rogers, one of the most famous communication researchers in the world. My time with him gave me new confidence, encouragement, and support. His work, on the diffusion of innovations, centered on how new practices and ideas spread, and I knew it would have a real impact, for it had already had that on me. Empowered by it, I had become more focused and ambitious, and I was now doing things that were appreciated and important. I had stumbled into the right place at the right time.

But my unrest and yearning for a sense of belonging never seemed to go away. And year after year, those feelings became ever stronger and more bothersome, whittling away at my well-being. On the surface, work 


\section{Peer Jacob Svenkerud}

was largely fulfilling, and my private life was fine. But my unsettledness pressed on me, urging me to make some sort of radical life change, possibly even like moving back home to Norway and changing my career. But what job could I find there? Having now spent many years abroad, my network was small and my knowledge of Norwegian working life was limited.

But in the summer of 1998, I was lucky to be offered a well-paying job with Burson-Marsteller, a global public relations and communications firm headquartered in New York City. Delighted, I accepted it. Soon I found myself living back in Oslo, doing enjoyable work on a nice salary, and getting to travel business class internationally. A new career path began to form, and my anxiety abated. I was living the dream.

I was involved in creating training programs in intercultural competence; giving speeches on corporate social responsibility, strategy, and leadership; and writing editorials about them. I was building a name for myself in the corporate world, even doing so well that I was invited to teach part time at the Norwegian School of Economics and serve on a university board. Headhunters kept me abreast of exciting possibilities.

My specialty became issues involving corporate social responsibility. I focused on the idea of "doing good" and "doing well" simultaneouslythat is, showing that it was possible for businesses both to have a positive societal impact and make a good profit. But being a consultant meant that I essentially just moved from task to task, billing as many hours for Burson-Marsteller as possible. There was no sense of ownership or being part of a company culture. I yearned to be the leader that I was telling others to be.

So in the fall of 2000, I Ieft Burson-Marsteller and started working for the international telecommunications operator Telenor, one of the largest corporations in Norway. The work involved the responsibility of building international leadership competence by establishing a corporate university. It was exciting. The work took me all over the world. I traveled with former colleagues to places such as Bangladesh, where I wrote case studies for Instead, a French business school, about Telnor's operations in Bangladesh and its economic effect on the Bengali population. ${ }^{1,2,3} \mathrm{~A}$ highlight was our meeting with Dr. Mohammad Yunus, founder of Grameen Bank and co-partner of Telenor (and later a Nobel Peace Prize Laureate), in his simple office in Dhaka, a picture of Gandhi on the wall behind him. There, he said something I will never forget. We were telling him about our work on ethics and business practices. Yunus mostly listened.

"Yes," he finally said, "I agree. Doing good and doing well seem to go hand in hand. However, remember one thing, Mr. Svenkerud: we all have to be truthful to ourselves. Corporate social responsibility and ethics aren't something that you practice in church every Sunday by passing the collection plate. They must always be with you. They're like a backpack you never remove." 
Consultants are notorious for not practicing what they preach, so I will forever remember his comment on consistency. His words were timely because just months later, Telenor, our company, was involved in a labor scandal in Bangladesh. One of Telenor's sub-suppliers had been engaged in child labor. It brought the Norwegian company into crisis, and my existential crisis returned as well.

But just after Christmas 2002, I was offered a position with Norsk Tipping (NT), the Norwegian National Lottery, and promptly took it, thinking it would resolve my crisis. The company was doing exceptionally well. Led by a charismatic CEO, it had transformed, in just a few years, from a traditional operator of basic lottery games such as Lotto and classic sports-betting into a modern, high-tech enterprise with a broad portfolio. The business had skilled, mostly locally based employees and a multiplicity of products, all of which were very popular and created fantastic profits, netting billions of Norwegian kroner every year.

Not only that, but it had also received top ratings on responsibility measures, too. NT was a monopoly with a social mission: to channel gaming through one responsible operator that minimized addictive gambling by offering responsible products and funding good causes. In short, it was a company on the move and seemed a perfect fit for me. It was even headquartered in Hamar, a town just 30 kilometers from where I grew up, so I could move home and find my "place," yet still feed my corporate ambitions.

My new job had me responsible for all internal and external communications, national TV drawings, and external sponsorships. I reported directly to the CEO and was part of the top leadership group. I enjoyed opportunities I had never imagined so close to home.

The world suddenly seemed to be more in balance. My internal unrest could take a well-deserved break. It promised to be a joyous time, with problems that could be easily solved. I had found my place.

But I was to discover a dark personal nightmare awaiting me on the horizon.

Our company's commitment to corporate modesty was a national watchword. Gøran Persson, the former Swedish prime minister, once told me, "You know, Mr. Svenkerud, in modern monopolies you drink your coffee from paper cups!" In short, a monopoly, being granted a playing field without competitors, and getting the right to handle other people's money, must live up to that trust by keeping a strict focus on costs and efficiency. Moreover, companies, especially publicly owned ones, had all started to realize that they were in the midst of a paradigm shift, a new age of transparency, and that society expected a degree of disclosure in which agreements, dealings, practices, and transactions were open to public verification. So corporate practices that might have been acceptable ten years ago weren't acceptable today-and especially in an organization in which gaming risks and lots of money were prominent. 
The new era forged difficult changes in many previous practices. For example, companies like the one I worked for were now expected to report on internal expenses, like fringe benefits, and to select their suppliers based on objective criteria and open competition. We were to be as transparent as possible in all our business transactions. For state-owned organizations that enjoyed a monopoly, such as Norsk Tipping, these expectations were especially important.

Given that I enjoyed the use of a corporate car, an impressive budget, and a grand office on the second floor of a bronze-plated office building, my feeling of internal conflict came creeping back. But this time the signals were different and had more force. Something was terribly wrong. Was our company synchronous with its time? Did our practices pass the acid tests demanded by the age of transparency?

One day in the fall of 2005 , we received a call from an investigative journalist working for one of the largest financial newspapers. She had questions about the awarding of a 2004 contract, worth 800 million Norwegian kroner, to a small Swedish manufacturer to produce a new type of slot machine for the Norwegian market. That manufacturer, whom I knew well, basically had just one customer-Norsk Tipping. And its CEO was a close friend of my boss. The intimate ties my company had with the Swedish supplier had spurred many discussions internally, but the critical voices had been silenced. The journalist wanted to know about the personal relations between the two CEOs. And she had a specific question: Was it true that my CEO had been the best man at the other CEO's wedding? I immediately went to ask my boss. He responded: "No! That is not true!" I reported his disclaimer to the journalist and was puzzled when she chose not to pursue the matter further. The CEO later confided to me that he was at the wedding, yes, but not as the best man. "I was toastmaster," he said, laughing.

In the months to come, more colleagues and outsiders started to raise questions like that journalist's; the circle around the CEO and the company kept tightening. My efforts to communicate this to the CEO seemed fruitless. Even people from top management voiced their concerns. One director of marketing said to me: "Do you know about the gardening work that is taking place at the CEO's house? Is that something the company really is paying for?" Another employee working with logistics informed me that the CEO demanded that one of the company truck drivers was to be freed from his duties in order to serve as his private driver. An executive in the Norwegian Athletic Association asked me, "Is it true that your CEO has his own private chauffeur?"

The company was flying high on the expense side. This I knew for a fact. The many extravagant meetings and events were noticed by outsiders, including the media. Phone calls from the media asking about spending and the apparent lack of transparency became harder and harder to answer. So far, the "big" story had not emerged, but I became increasingly convinced that it was just a matter of time. 
Our CEO was a very charismatic and highly public figure. His 18 -year tenure gave him tremendous internal positioning and lots of supporters. He had thrived on the company's modernization and economic success. His strong will and the intense respect directed toward him combined to make him both loved and feared.

In an endless number of leadership classes, we had often been warned of what could happen to leadership and the quality of decision-making when no one ever spoke up and challenged decisions or practices. One of our lecturers, Phyllis Perlow, had written an impactful article, "When Silence Is Killing Your Company," 4 in which she noted that silence in a company can be associated with virtues such as modesty, respect for others, prudence, and decorum, and that under such ingrained rules of etiquette, people will often silence themselves to avoid embarrassment, confrontation, and other dangers. Was that happening in this company?

What happens to the decision-making process in a company when critical voices are suppressed, ${ }^{5}$ when there is a feudal company culture that people quietly follow because the risk of speaking out seems too complicated and too consequential? Was ours a culture of pacification that invited wrong decisions because no one ever challenged the dominant voice or present practices? Did individuals who raised critical questions against their own organization or the CEO run the risk of punishment?

Our CEO was so oblivious to the issue that many had begun to question his leadership. Stories started to circulate about the leadership of the company and particularly the CEO. There were tales of excessive spending, questionable sponsorship contracts, and expensive trips to exotic locations for which suppliers paid. At first, they were easy to dismiss as coincidences, but they started to come with increasing frequency. To my distress as communications director, the CEO's practices began to gain increasing external attention. The public and the media were on the track of "something," and my job was to defend or redirect attention. But the nefarious activities became increasingly difficult to defend. Moreover, my knowledge of and involvement in the specifics grew only deeper over time.

It was difficult not to notice what happened to people who broke the silence about some of the practices. One individual, a middle-level manager in our security department, had repeatedly questioned work that had been done at the CEO's house and billed to the company. "The vice CEO asked me to change the invoice so that it was untraceable," he told me. "And I refused." He was about to give up when he came into my office. I sympathized and told him I would attempt to bring attention to the matter. A few months later he quit the company. Others who protested came back subdued, and sometimes frightened. One manager told me, "I was told to shut up and cool down-and that I would be put in another position if I continued." A former executive told me directly that he lost his leading position because he had asked too many questions. The situation was getting worse and worse. 


\section{Peer Jacob Svenkerud}

Was I a part of something that was unhealthy, and that, if it became public, would be a disaster? I had been with the company for more than five years by then so the responsibility was also on me. As part of the top leadership group, I knew, given my role, about most of the controversial practices going on. The notion of being part of a leadership culture that needed to change became more and more evident, and being part of a silent culture was no longer a sustainable option. "You are responsible," a friend told me. "You cannot be ignorant to this situation. What about your own values? How can you defend and hide these things in the company where you are supposed to be a leader?"

I had no adequate answers, so I initiated what seemed like an endless number of conversations with both the CEO and the executive group addressing my concerns. I never made any threats; I simply attempted to bring critical issues to the table. The weekly top-executive meeting was usually the place where I tried to raise such issues, often in connection with a growing number of critical articles written about the company by the media, or when presenting external surveys which showed that the company had challenges meeting public expectations. I felt my arguments were often met with ridicule. It became a laughing matter when one of the executives named me "the prince of darkness." The name stuck. I had become a somber, problem-oriented individual who brought important things into focus, namely things other than that of making money. I felt out of place, in the wrong place. My efforts seemed to lead nowhere. Pressure mounted as the outside media and other stakeholders kept on digging into possible "company secrets." I was there, defending them with rapidly increasing discomfort. My own moral and ethical questions were staring me in the face. Did I pass the ethical tests that all companies and their employees should abide by and that had become my mantra in business? If all other options were exhausted, what choice was left but to blow the whistle? Alternatively, was I simply negotiating my personal ethics with those found in the dominant organizational culture over issues that would not commonly be recognized as corruption? ${ }^{6}$

It was difficult to face my own fundamental ethical platform. Would blowing the whistle mean giving up a comfortable and prestigious life? Would I be able to get another job? Did I even have a choice now, given that I was working for a governmentally owned operation that had a monopoly on a tremendously profitable market? Was the only option to finally face myself and live with the consequences? Moreover, was a failure to face myself the real reason for the internal disorder that had shadowed me for years?

It looked as if I had three options: pretend like nothing was happening, pray that things would go away, or find another job. The latter was possible but would probably not resolve my internal commotion. I was obviously beyond the point of pretending. I was a man who knew too much, and I had reached a point where non-action was no longer an 
ethical option. To think that it would all go away was unrealistic. I had experienced this first-hand. I too had been told repeatedly about obvious ethical practices. To ignore or pretend to escape this reality would further push the necessity of facing myself.

It was now early August 2007 and an unusually hot summer. Norwegians typically take the whole month of July off to enjoy the warm weather, but, for me, it had been far from joyous. I was just as stuck as my brand new, but unused, boat anchored on the dock of beautiful Lake Mjøsa, only a few kilometers beyond the office in Hamar.

One day, a friend who knew my dilemma persuaded me to join him for an afternoon cruise on that boat. For a long time, he was the only person with whom I had discussed my options. He was concerned, and his description of me was accurate: an unhappy individual dominated by internal anguish. It was painful to be told how he saw me, but he had a lot of credibility. He was a colleague at NT and someone who for years had consistently expressed his own concern about the CEO's behavior and the company's leadership.

I opened up, telling him about my upset stomach and the choice that seemed like the only solution but which would in all likelihood destroy my career. "Well, do you really have a choice?" he said. "Will your internal unrest ever go away if you do not finally face yourself?" He did not seem to want to do it himself. It was easy to see that he thought the risks were too high for him. Further, I was convinced he was correct when he said a person in the top leadership group would probably be more effective when addressing the chair of the board than anyone else.

What Do You Want to Stand for, Peer Jacob? Perhaps that was the real question. I remembered Yunus's subtle message from years ago that ethics was no removable backpack. Was that the question and solution, to finally come to terms with your own internal values and be true to them regardless of the challenges you face in life? I had to blow the whistle. McKenna says that whistleblowing is the last resort, for, once done, your effectiveness as an internal positive change agent is finished. ${ }^{7}$ The prospect for success seemed as tiny as a mustard seed, but there was no other choice. The boat trip turned me into a whistleblower, and now the circus started for real.

An old Norwegian children's song speaks of individuals who go behind people's backs and talk about them. Basically, it conjures up the image of an invisible person with a knife who is ready to stab you from behind. ${ }^{8}$ The song is the scariest children's song of all time and for many became a symbol of a whistleblower: a person you cannot trust, someone invisible, ready to backstab you at any moment. Was I the person in this song? Would people think of me this way?

Cut to two weeks later, in late August 2007. I'm in the house of the board's chair, who supervised the CEO, in the town of Lillehammer, about an hour's drive from my workplace. I informed him of my worries 


\section{0}

and provided a list of real cases, including trips the CEO had taken with suppliers with private planes to exotic locations for salmon fishing; sponsorship agreements with close liaisons of the CEO such as sponsoring cross-country tracks around the CEO's getaway cabin in the Norwegian mountains; sponsoring events with no strategic purpose yet having close ties negotiated by the CEO himself; questionable contracts to suppliers awarded to friends and associates; extravagant spending in contacts with outsiders exceeding official limits; use of company personnel to serve as private chauffeurs; work done on the CEO's private property that was subsequently billed to the company, etc. All these cases were well known to the administration, and I and others had raised them on several occasions. My body trembled with tension as I talked to him. He listened in complete silence. He just sat there and took notes. When I was finished, he finally spoke. "You will hear from me," he said. "I will look into it." The meeting was over. Later, when backing out of his parking lot, I was shaking so much that I rammed a row of mailboxes, denting my car and splintering the rack.

Soon, however, that splintered rack was the least of the things that had started to come undone. In late September at a top leadership meeting, the president and vice president stated that the organization had a problem. The vice CEO said in almost biblical terms: "We have an unfaithful servant. Do any of you know who this individual is?" No one spoke. The chair of the board must have taken some kind of action. It was clear that they did not have a particular suspect. Everyone was a suspect. And everyone in the room knew that the company leadership would bring to bear all its powers to find the source and silence it. The moment looked like a scene from a movie. The CEO went around the table in the executive boardroom. Each person in the top leadership group was asked directly if he or she knew something about the case. Each responded "No," myself included, I confess. I was discovering that my earlier caution was not baseless. Soon, meetings with "suspects" all over the company took place. The situation had turned into a desperate hunt for the "unfaithful servant." The crisis was clearly escalating.

Weeks passed and I remained silent. In early October 2007, the chair of the board summoned me to a meeting in Oslo. The board had received answers from the administration on the various accounts that had been reported, all involving the CEO.

A close liaison and corruption expert had advised me as to what was going to happen:

The administration and board will attempt to undermine and minimize the significance of your case. Be prepared. Imagine the feeling of being alone in a small boat, downstream on a small river, meeting a supertanker. That is how you will feel from now on. It will be you against everyone else! 
He was right. I met with the chair and the vice chair at an office in Oslo. In the meeting, case after case was dismissed with the explanation that it was impossible to prove, that they lacked written evidence, that, yes, it was serious and warranted a "warning" and change of practice, but that no further action was required. Each case ended with "Are you satisfied with the answer?"

One of the latter claims was about cutting grass.

Many knew that the CEO for years had had a gardener do horticultural work at his estate and that the company had picked up the bill. Several employees had warned him numerous times about the unethical nature of this practice. They were told either to stay away from the issue or that the issue was being handled. It was easy to see the frustration on their faces when they came into my office to tell me about their failed attempts. I was left with the impression that they wanted me to do something.

Not surprisingly, the chairman proceeded to dismiss this claim as well. Yes, this was a practice that must end, he allowed. But it had been approved by the board that the CEO would have the help, a few hours each week, of a maintenance person from within the company, given the CEO's extensive world travel and his consequent absence from home.

"Are you happy with this answer?" the chair asked me.

"The question is really whether you are comfortable with the answer you got, as well as the other answers you have received," I replied.

From my backpack, I handed over an envelope of receipts totaling approximately 10,000 USD, all from a local gardening company, not in-house maintenance, and all work related to renovating the CEO's property, including cutting the grass-all paid by NT. ${ }^{9}$

The skin color of the chair and vice chair of the board changed, and there was a long moment of silence. "We need a moment," they said. I was asked to leave the room.

That moment was pivotal. Later that day, I was informed that further investigations had to take place.

Just weeks later, on October 22, the CEO resigned. Further internal and external investigations followed. The chair stayed on and supervised the various investigations on behalf of the board. In April 2008, he also resigned. The office of the auditor general of Norway took on the case and launched a major investigation into the company's activities based on the cases I had forwarded in the initial charges.

For months, the company was turned upside down. Everyone was a suspect. The organizational climate stumbled to the edge of collapse. No one knew, except my close confidant within NT, who had turned so many people's lives upside down. The new chair of the board and the interim CEO knew about my role, and both of them expressed support, assuring me "You did the right thing" and "We will protect you." But those assurances failed to blot out my acute sense of isolation, nor did my guilt go away. I frequently went to that same quiet bus stop to assuage my upset stomach. 


\section{Peer Jacob Svenkerud}

In October 2008, a permanent CEO came on board. His mission? "To clean up!" During the elections of September 2009, the old chair of the board became Norway's Minister of Finance and left the board, and a new chair was appointed in November 2009. Naturally, they both wanted to put the case behind them and focus on the future. By this time, the case had dominated the company for more than two years. At that time, the office of the auditor general of Norway was close to concluding its investigation. It had found serious malfunctions with the company, most of which were connected to the former CEO and were all issues with which I was familiar. As a result, the auditor general of Norway decided to submit a special document to the Norwegian Parliament outlining this issue, and further, the issue was to be debated in a special council with the protocol committee of the Norwegian Parliament in May 2010. ${ }^{10}$

The protocol committee was very critical of Norsk Tipping and its previous practices, and also praised the whistle-blower. ${ }^{11}$ The story dominated the national press for days.

Then, one day in October 2010, now almost three years later, the national media somehow learned who the whistleblower was. Within 15 minutes, two of the largest newspapers in the country called me. Obviously, someone had tipped them off! My picture was plastered all over the front pages of national and regional newspapers. You might think this would cause me still further turmoil, but actually it brought me incredible relief. I was finally out of hiding. After almost three years, it was no longer my best-kept secret. Some of the squishy feeling in my stomach disappeared instantly. At the same time, I had a new feeling. Was this also going to be my exit from the company?

My fear grew stronger the next morning. The phone rang at 7:30 a.m. It was the CEO. He told me that he had called a meeting with all leaders in the company at 8.30 a.m., as the news about the identity of the whistleblower was now printed in a two-page story in Norway's largest financial newspaper.

I entered the meeting five minutes late; my 40-minute car ride had zipped by in about 20 minutes in my attempt to be there on time for the meeting. There was no applause, only somber, sad, and tired faces. The CEO led the meeting, and the topic was the whistleblowing case. To my shocked surprise, the discussion did not revolve around the exposure of right and wrong or the need for a company culture that encouraged people to speak. Instead, it seemed to deal with my future role in the company as the director for communications and external affairs.

My anxieties were quickly replaced by pure anger. How could the CEO, who had been brought in specifically to clean up the "mess," raise doubts about my credibility as Senior Vice President Information and External Relations? His claim was that there were different views on the case, both internally and externally, and that my role would be scrutinized in the time to come. Maybe so, but I had expected to be defended, not put in 
jeopardy. The CEO informed the group that I was to continue in my job but not be involved in the whistleblowing case in the future.

Fortunately, it was possible for me to leave the company for a few months and take a breath. Several months earlier I had been accepted to a three-month top leadership program at the Norwegian War College. But once I returned to work, it quickly became clear that the CEO no longer wanted me aboard. "You are doing a very good job, but your time here is over," he said. "You need to move on. If you do not, I will redesign your role and remove you from leadership in the company."

It was hard to comprehend that he actually gave me that ultimatum. I refused his order and demanded an explanation. He gave none.

I remained in my job, buying time, and the pressure on me continued. The CEO would regularly summon me to his office and demand a "plan of action." I offered none. In our final meeting, he demanded a specific exit date. I refused. The situation seemed absurd. Another dilemma had to be confronted: to fight the situation or contact a lawyer to help guide me. With the latter, the natural consequence was to leave the company with severance pay. It was not a pleasant option, but what else could I do? I could no longer stand in this situation by myself.

So I went out and hired one of the best labor-rights lawyers in the country. He couldn't believe what was happening, though he conceded that it was far from uncommon. He produced to the new CEO letters in which my rightful claims for such demands were presented. The CEO repeated his previous demands, also claiming that I had for a long time expressed an interest in leaving the company and that he needed "dedicated long-term-thinking” individuals to help lead his organization.

Clearly, my time at Norsk Tipping had come to an end. It was now just about making the exit as smooth as possible. So we forwarded our claims, which included severance pay plus coverage of all judicial expenses. The company met the demands fairly quickly.

But suddenly there was no job to go to. Unemployment seemed to be the next phase of my life. Fortunately, it turned out differently. A new job emerged within days, and a new career was about to start for me. Still, my feelings of bitterness were growing by the day. Was it naiveté that had led me to believe that it would be possible to continue a career at the Norwegian National Lottery? Instead, I was in a job with lower pay and a change of direction I had not chosen. My story would undoubtedly follow me for the rest of my life. Who would dare to trust a whistleblower?

Nevertheless, something within me had changed. Not only had the constant tormented feeling of internal unrest gone away, but also a different kind of balance had set in. With more certainty, it started to become clear to me that my self-confidence and ability to walk with my head held high in all kinds of situations had become easier.

It almost felt that the question of finding out who I wanted to be had been answered. Slowly but surely, a new feeling of self-contentment 
started to emerge. Yes, my experiences and doings at Norsk Tipping probably meant that many future opportunities would not come as easily and that some people would always treat me with suspicion, as a person who never could be truly trusted to stand on the hill and battle. But that did not matter as much anymore. What was of real importance was finally facing myself and asking and answering the question of who I really wanted to be as a person. This had been the cause of my unrest.

Yunus, who had won the Nobel Prize for Peace three years after we had briefed him on ethics, only to have him brief us back, was right, of course. You are your own value platform. Your value and sense of being is not something you can take on and off and practice as you please. It is something that is part of you, something you not only carry, but must face.

\section{Notes}

1. Malaviya, P., Singhal, A., Svenkerud, P. J., \& Srivastava, S. (2004). Telenor in Bangladesh: The prospect of doing good and doing well. Case study. Fontainebleau, FR: INSEAD.

2. Malaviya, P., Singhar, A., \& Svenkerud, P. J. (2004). Telenor in Bangladesh (B): Achieving multiple bottom lines at GrameenPhone. Fontainebleau, FR: INSEAD, 304-147.

3. Malaviya, P., Singhal, A., Svenkerud, J. P., \& Srivastava, S. (2004). Telenor in Bangladesh (C): The way forward. Fountainbleu, FR: INSEAD.

4. Perlow, L., \& Williams, S. (2003). Is silence killing your company? IEEE Engineering Management Review, 31(4), 18-23

5. Perlow, L. (2003). When you say yes but mean no: How silencing conflict wrecks relationships and companies ... and what you can do about it. New York: Crown Business.

6. Tran, C. K. (2011). An ethnographic analysis of the current whistleblowing landscape in the Canadian public service. Doctoral dissertation. Ottawa: Carleton University.

7. McKenna, B. (2008). Melanoma whitewash: Millions at risk of injury or death because of sunscreen deceptions. In Killer commodities: A critical anthropological examination of the corporate production of harm. Thousand Oaks, CA: AltaMira.

8. Munthe, M., \& Engebrigtsen, O. (2003). Kom skal vi synge. Oslo: Cappelen Forlag.

9. A final review showed that the company had been billed a total of 425.000 Norwegian kroner for work in the CEO's garden, approximately 78.000 USD (based on currency rates in 2007).

10. Riksrevisjonen. (2009). Riksrevisjonens utvidede revisjon av Norsk Tipping AS. Dokument nr. 3:14 (2008-2009) Riksrevisjonsrapport. Oslo: Riksrevisjonen.

11. Munthe, M., Nærum, K., \& Hovdenak, E. (2010). Bukke nikke neie. Oslo: Cappelen Damm. 


\title{
2 Whistleblowing, Voice, and Monomythology
}

\author{
The Prospect for Analysis
}

\author{
Larry Browning, Jan-Oddvar Sørnes \\ and Peer Jacob Svenkerud
}

Whistleblowing events seem made for storytelling because they involve a character, an ethical challenge, and the fraught search for its resolution. But the story we tell here is especially dramatic because it features a Dostoyevskian mix of power, transgression, charisma, secrecy, moral judgment, and sacrifice. And it's notable because it's set in Norway, long recognized for managing whistleblowing incidents with enviable skill and transparency. So what went wrong here? Why and how did the Norwegian whistleblowing model for resolving issues fail so egregiously?

The whistleblower here was Peer Jacob Svenkerud, or "PJS," who in 2007 blew the whistle on Norsk Tipping, the government-owned company operating Norway's national lottery. ${ }^{1}$ Our rationale for drawing on 14 scholars to help analyze his story follows Norman Denzin's (2017) strategy of triangulation, which recommends using multiple viewpoints to achieve a more comprehensive understanding of any complex research subject. It's particularly appropriate here because of the case's "complex nature due to the various actors being involved" (Culiberg \& Mihelič, 2017, p. 787), not to mention their shape-shifting roles as they tumble through the story's timeline in unpredictable ways.

Consider the following five narrative sequences that propelled PJS from being autonomous and in control to being isolated and out of control: (1) He approaches his board of directors and blows the whistle on the misuse of funds by his charismatic boss, the CEO; (2) the board takes his disclosures seriously and agrees to act on them; (3) at that same meeting where his accusations of wrongdoing are accepted, he offers to leave the organization-he has a job lined up elsewhere-and asks the chair of the board if he should take the outside position; (4) the chair discourages that idea and instead asks him to stay on as Norsk Tipping's Senior Vice President of Information and External Relations but also to remain unidentified as the whistleblower so he can assist in the firm's moral recovery; and (5) within a few weeks, NT's leadership learns that there's an internal, not an external, whistleblower. But instead of welcoming the challenge to clean house, the CEO via the leadership group declares biblically, "We have an unfaithful servant," and opens a search to locate the person. 
As Devine reminds us, "The first commandment of retaliation is to make the whistleblower, instead of his or her message, the issue: obfuscate the dissent by attacking the source's motives, credibility, professional competence, or virtually anything else that will cloud the issue" (1997, p. 28). This commandment is followed precisely by Norsk Tipping's leadership. In a special meeting of the leadership team, each person is asked if he or she is the whistleblower. Panicked, PJS declares that no, he is not. In our interviews with him, he candidly says, "I lied." That self-indictment reflects his sense of having lost, or at least badly compromised, his moral high ground. And his range of options for leadership had quickly narrowed, too. He had gone from acting with integrity and autonomy, to being called a traitor and a hunted man in his own organization-and to being complicit in his own cover-up.

The conflicts at Norsk Tipping (NT) emerged from philosophical, as well as moral, differences. Whereas his company was accustomed to certain material comforts and lax values that its culture either supported or at least tolerated, PJS saw himself as an agent of change-a man professionally committed to helping organizations, like his own, critique themselves and achieve a greater good. Before taking his position at Norsk Tipping, he had, in several roles, promoted that high-minded program on the topic of corporate social responsibility (CSR). Its goal was to expand the client organization's focus beyond profitability to a wider set of ecological and cultural goals while still remaining profitable-a corporate mission called "doing well while doing good." CSR proved easy to espouse as a value, but equally easy to set aside when the accustomed culture reasserted its dominance.

PJS's initial difference with NT was over the self-interested direction taken by the organization, especially how it defined, approached, and promoted its goals. But his position was further complicated by the demands of his role. As Senior Vice President of Information and External Relations, he was expected to match internal communication practices with what he communicated publicly about NT. Despite the legitimacy of valuing such a balance, what goes on internally and what is said publicly are often inconsistent communications. Initially, because PJS's differences with NT were over its direction—-not over wrongdoing — he first used strategies to move toward CSR-like goals without making an issue of past practices. It was not about critiquing the past but about redirecting and planning for a better future. So he began his tenure very much as a loyalist.

In the next section we offer a theory that explains how PJS's loyalty gravitates toward his finding a critical voice.

\section{Exit, Voice, Loyalty, and Monomythology}

As a way of presenting the whistleblowing story for our chapter writers/theorists, we offered them two conceptual frameworks: Albert 
Hirschman's (1970) Exit, Voice, and Loyalty: Responses to Decline in Firms, Organizations, and States and Joseph Campbell's (1972) articulation of monomyth as outlined in his book The Hero with a Thousand Faces. When the Hirschman and Campbell positions are aligned, they produce an innovative frame for understanding the complex iteration of PJS's whistleblowing story as it progresses, in time, across the features of Campbell's monomyth. We look at Hirschman first, saving Campbell for the next, separate section.

Hirschman's unique contribution reflects his training as an economist. His economic premise here is that people exit a market or an organization and move into another one if it better represents their values. Exiting from bad to better conditions helps account for the rise and fall of organizations. It is a replacement model—one trades the stability of the old for the possibility of something better. Exit is a natural option to wrongdoing because "irregularity increases the price of membership within the organization." (Pittroff, 2016, p. 705). Yet, in practice, the exit option is problematic. While an exit is unequivocal-there is no doubt about who has left-it offers little or no information concerning how the exited organization might have improved.

PJS's whistleblowing story is a prime example of Hirschman's' Exit, Voice, and Loyalty, which has dominated whistleblowing theory ever since the book was published. The book argues that conditions decline when "the normally bought product or the organization to which one belongs begins to deteriorate" (Hirschman, p. 87). And it analyzes what happens in markets and organizations under conditions of poor performanceespecially how they might recover. Hirschman sees whistleblowing as a response to decline. In the whistleblowing literature that relies on Exit, Voice, and Loyalty, whistleblowing is invariably equated to voice. In the PJS case, the management deteriorated by its misuse of funds and cronyism, and PJS, instead of exiting, loyally stayed on and voiced his criticisms of the CEO to the board of directors. These three rubrics-exit, voice, and loyalty-beautifully help define the essential issues of whistleblowing, especially how to speak truth to power, how to have a voice.

As an alternative to exit, Hirschman conceptualizes voice, in which the person speaks up for changes that might improve the organization, which results in the possibility of new and improved leadership. Hirschman views voice as the political alternative to the economics of exit. Whistleblowers typically promote transformational change (Kenny, 2019). Voice is attractive because it appeals to communicating via persuasive argumentation, but Hirschman warns that voice is also messy for several reasons. For example, what is seen as troubling by one person may simply be seen, by another, as a cultural given that requires acceptance to get the work done. Also, individuals who are more troubled by organizational practices are likely to exit early, leaving a diminished population that supports change, making them even more fringe players. 
But what about differences in voice? Bashshur and Oc (2015) note that a limitation of Hirschman's formulation is that it fails to distinguish different types of voice, especially with respect to their level of seriousness. As Hirschman at best acknowledges, it can range from "faint grumbling to violent protest" (1970, p. 16). But voice can vary in significance-from, say, complaining about the lousy coffee in the employee break room vs. bringing charges of malfeasance against the organization's leadershipso each example of voice must be weighed in relation to its context. And there are other considerations, too. Is the whistleblowing worth the effort? What are the costs and benefits of it? In our case, the whistleblowing ultimately did transform some aspects of the organization, but at great personal cost to all concerned.

Once whistleblowing became equated to voice, analyzing whistleblowing in relation to all three of Hirschman's categories enlivened whistleblowing analysis (Bashshur \& Oc, 2015). The categories are used frequently now because the main concepts are so clean and easy to grasp-exit is leaving, voice is speaking up, and loyalty is staying but not speaking up, with the latter including letting conditions deteriorate (Rusbult, Farrell, Rogers, \& Mainous, 1988). Voice has remained a chief theme in whistleblowing research, (Lee \& Varon, 2016) appearing, for example, in studies of the effect of silence (Brinsfield, 2014; Verhezen, 2010); how whistleblowing affects job satisfaction (Rusbult et al., 1988); how whistleblowing's effectiveness depends on the governmental structure above it (Pittroff, 2016); how to improve whistleblowing procedures (MacGregor, Robinson, \& Stuebs, 2014; Zhang, Pany, \& Reckers, 2013); how some voices are honored and others subordinated (Putnam, 2001); and how the perceived value of voice in whistleblowing can change across time, from useful to risky (Bashshur \& Oc, 2015).

The PJS case proves an exemplary fit with the literature on whistleblowing because it includes all four of Miceli and Near's (1985) research basics: the whistleblower (PJS), the wrongdoing (misuse of funds), the wrongdoer (the CEO of Norsk Tipping), and the reporting recipient (the chair and vice chair of the board at Norsk Tipping). The "reporting recipient" is central to this case, for the literature makes a point of distinguishing two kinds of whistleblowing. One kind is internal whistleblowing, which "refers to disclosing an observed wrongdoing to an entity within the organization through a confidential hotline or an individual in the organization." The second kind is external whistleblowing, which occurs when the complaint goes outside the organization (Culiberg \& Mihelič, 2017, p. 798). The distinction is crucial for this case because everyone, including PJS, accepts the generic label of whistleblowing, when technically the event was an internal matter that PJS only brought to the attention of the NT board. His issues could have been resolved within the Norwegian model quietly and without fanfare. 
Exit, voice, and loyalty are all relevant here, though PJS actually combined voice and loyalty, which isn't a major thrust of Hirschman's formulation. In Chapter 1 of the book, he paints exit and voice as complementary and loyalty as submission to silence in exchange for the right to remain in the organization. In a later chapter he offers an exception to the conclusion that silence is given in exchange for loyalty by articulating the effect of personal power on loyalty. He asserts that the ability to have an influence will increase one's loyalty to the organization: "the likelihood of voice increases with the degree of loyalty" (Hirschman, p. 77). He elaborates it in this way, employing the generic "he" still common in the era in which he was writing:

A member with a considerable attachment to a product or organization will often search for ways to make himself influential, especially when the organization moves in what he believes to be the wrong direction; conversely, a member who wields (or think he wields) considerable power in an organization and is therefore convinced that he can get it "back on track" is likely to develop a strong affection for the organization in which he is powerful (Hirschman, p. 77-78).

This fits our case because loyalty and voice are co-acting, thus co-evolutionary. PJS not only presumed he had power, he advanced the CSR paradigm of change that he had communicated from the outset with Norsk Tipping. In PJS's case, "voice signals commitment and concern for the organization" (Bashshur \& Oc, 2015, p. 1533). Yet, the commitment is complicated by PJS's expressing voice, and then accepting a vow to secrecy about his voice from the board of directors, and also remaining as a committed, loyal, and active employee in Norsk Tipping. Thus, he embodies the thesis of the present book-voice and loyalty are a paradox. PJS's case is narratively dramatic because he voices semi-publicly but does not exit the organization. His only departure is from transparency and from telling the truth. And he only steps away to remain in secrecy for the months that it took for the problem to be resolved-all the while remaining on the leadership team.

\section{Campbell's Monomyth}

Campbell's monomyth is applicable to this case because it became evident from our week of interviews with PJS, during which he fleshed out his story, that the various details flowed naturally, if inadvertently, into the sequences of a monomyth. At one point we asked him to comment on those concepts. He initially resisted the monomyth formulation because it implied that we were labeling him a hero, a very un-Norwegian characterization, for Norwegians valorize humility. But upon reviewing the 
specific monomyth sequences, PJS now concedes that the first part of the monomyth is accurate, though the finale is inaccurate because at the end he is not welcomed home from a foreign land as the hero who saved the kingdom. Instead, his story ends in contention, and he feels forced to move on to another organization.

Joseph Campbell's Hero with a Thousand Faces, which was initially published in 1949, served for decades as a primer to track the heroe's journey through the movement from the normal world, to accepting an external call for action, through trials, tribulations, and sacrifice before the story concludes. After years as a narrative textbook, it became an international bestseller after George Lucas, creator of the Star Wars movie series, made a point of saying that Campbell's monomyth-there is one universal hero story with minor variations-was the guiding light for the movies' sequences.

PJS enacts a "familiar narrative of the whistle-blower as a good and heroic individual who does the right thing and speaks up to challenge a clear wrong" (Kenny, 2019, p. 8). PJS's path into secrecy, aloneness, stress, and (dis)honesty ambles forward in varied combinations as he moves from the beginning of the story until the ending, when he leaves NT. And while he doesn't go on a journey to a foreign land to slay a monster, his narrative sequence follows Campbell's monomyth as he moves into a surreal and secret world away from the "world of common day" (Campbell, P. 30). He hears a call to adventure, to accomplish a mission, when his Nobel Peace Prize mentor says to him, oracularly, "Your integrity is a backpack that you can never take off." PJS initially refuses the call-as the Senior Vice President of Information and External Relations, he had observed and taken part in five years of organizational decision-making that he had resisted but participated in enough that he, too, is implicated. $\mathrm{He}$ is eventually propelled by the higher calling, traverses the threshold, and accepts the mission. PJS's response to the call "signifies that destiny has summoned the hero and transferred his spiritual center of gravity from within the pale of his society to an unknown zone" (Campbell, P. 58). That zone was secrecy. Yet, he faced many tribulations that tested his mettle throughout the mission. On one contentious occasion, PJS passed out cold on the floor of the hall in the executive suite, only to recover and persist. PJS had a helper, someone who produced the magic object-here, a collection of hard-copy payment receipts retrieved in darkness from the headquarter's basement-that confirmed the truth of his disclosures and moved the story forward at a critical juncture. The helper is motivated by the hero. In Campbell's words, "The hero to whom such a helper appears is typically one who has responded to the call” (Campbell, P. 73). PJS's will is magnified by a helper; the challenge becomes a two-person project, with the whistleblowing mission as the reason for their relationship.

The Campbell model holds up through the first two thirds of the monomyth sequence, but later interviews paint a conclusion far different from 
Campbell's model. Once PJS is outed as the whistleblower, his hero's welcome in Norsk Tipping is over. Rather than undergoing a supreme ordeal and gaining "his reward" (Campbell, P. 246), he is soon set up by organizational leadership with public events that are structured to shame him. Community members criticize him as being "biased" and unfit to continue as the spokesman for NT.

What is left for him is a series of negotiated exchanges among himself, his peers, and his supervisors-all oriented toward producing a positional advantage over one another. So his story is a monomyth with a ragged ending. Rather than heroic, it ends as a confusing and legally driven agreement.

In Table 2.1, we outline the variations of exit, voice, and loyalty that PJS experienced as they track forward on Campbell's monomyth.

The PJS story departs from Campbell's monomyth in two ways that may explain its disconnect from the model at the ending. In the Campbell model, the hero goes on a journey into a foreign land; he hopes to complete his mission and return home-an odyssey ends back where it began. In narrative theory, time and space are paramount (Browning \& Morris, 2012, Chapter 4). In contrast, PJS's story begins when he returns home from the foreign lands of international work to take on an executive job that, to his surprise, becomes an ethical challenge. His quest not only begins at home, but also his story is driven by the desire to complete the mission while remaining at home. PJS's commitment to remaining home accounts for how the story ends.

The object of the challenge also differentiates PJS's story from Campbell's monomyth. Rather than fighting off a strange beast to protect his homeland, PJS faces the unforgiving authority of his own home organization. "Whistleblowing" has a dual meaning. It is not only a conflict about a problem, but also it is a conflict about hierarchy and authority. PJS's whistleblowing is "opposition to authority" that takes place "within a context of political conflict" (Perrucci, Anderson, Schendel, \& Trachtman, 1980, p. 149). To resist one's own structure is a battle of a different kind (Mumby, Thomas, Martí, \& Seidl, 2017). The story ending looks like a tag-team fight in the wrestling ring, with PJS standing alone in the middle of the ring against organization members who take turns opposing him and shaming him, until he leaves.

\section{The Materials for the Chapter Writer/Theorists}

The 14 invited scholars who contributed chapters for this book were asked to examine five different data sets (plus any others they chose) for their interpretation of PJS's story: interviews, annual reports, newspaper articles, photographs, and external inspection reports, all in English. 


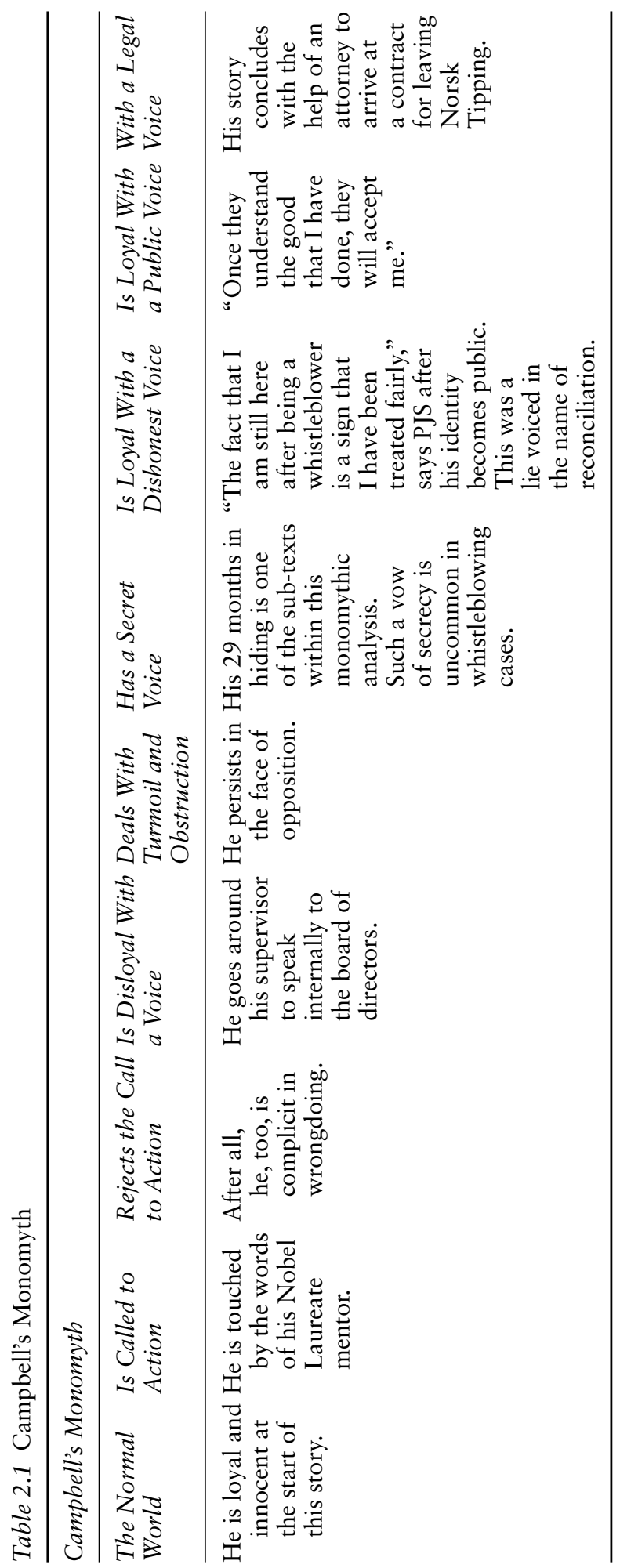




\section{Interviews}

The chief source was a series of in-depth interviews with PJS that were collected two months after he had completed the first draft of the ethnography that became Chapter 1 of this book. Over a week, and during 18 different sessions, ranging from a few minutes to almost an hour, Browning and Sørnes interviewed PJS in English and digitally recorded his story on a cell phone. The recordings were subsequently transcribed into Word documents. Besides verifying PJS's Chapter 1 story, the interviews also covered additional events. For example, we asked him to recall what exactly was said at crucial moments of communication between him and the different voices of authority at NT.

Another difference between his chapter and the interviews is the occasional theoretical turn in the interview content. As the theme of the interviews developed over the week, we began to ask for PJS's own theoretical interpretation of his case. Because he was a fellow Ph.D. in organizational communication, we asked for concepts as well as data. For example, at our urging, in one of our final interviews, PJS assigned the events of his story to Campbell's features of the monomyth. That interview shows the sequences mapped on to Campbell's listing. We make use of Campbell's monomyth to organize the interviews into five narrative sequences: (1) the normal world, interview 1 ; (2) the challenge and calling, interviews $2-4$; (3) the crisis of the whistleblowing event, interviews $5-8$; (4) the aftermath, interviews 9-17; and (5) monomythology, interview 18. Sørnes, a long-time friend of PJS, had been his supporter throughout this event and served as a national cultural check. He followed up by asking for details about Norwegian athletics and specific names of leaders who had a decision-making role in this case. Sørnes's questions and assessments were from a position of having witnessed the scandal play out in real time. He thus served as a check on the local meaning of the PJS story.

Another noteworthy feature of the 18 interviews is PJS's extended account of his leaving Norsk Tipping. While he commented on it in Chapter 1, our later interviews revealed the ending to be the most painful part of his entire story. Though he had prevailed by successfully managing the whistleblowing and the secrecy, he suffered badly once the truth was out. While he received the Inland Norway Communication Association's Person of the Year Award and was making selected presentations on his whistleblowing story, he was not being supported in his own organization. Instead, on the job he was being told, in various ways, that there wasn't a consensus of support for his continuing at Norsk Tipping.

We coded these interviews as the "end game," and this phase of the story began the day the Norwegian financial newspaper, Dagens Naeringsliv, made public that PJS was the whistleblower at Norsk Tipping. Once outed, PJS presumed he could relax and finally breathe freely again, but the opposite occurred: he was once again gasping for air and had anxiety 


\section{Larry Browning et al.}

attacks. The most significant addition to the story in these interviews is the more detailed account of how his professional life at Norsk Tipping came to an end. The chapter writers for this book use the interviews copiously and refer to them to build their case.

\section{Annual Reports}

The second major data source for the chapter writers was the eight years of NT annual reports that were produced during PJS's tenure as Senior Vice President of Information and External Relations. The documents are notable for their high quality. Our co-editor Sørnes claims they are superior to the ones that came before and after PJS's time at NT. PJS modestly explains in his interview that he had such a gigantic budget for the reports that it made producing quality easy.

Annual reports are important because the initial paradox of this story intersects the role of the Senior Vice President of Information and External Relations with that of the whistleblower. The whistleblower says, "There is something seriously wrong with this organization," whereas the Senior Vice President Information and External Relations states that NT is excellent, that its productivity and its contribution to the culture of Norway are beyond outstanding-that it is a joy to work there. PJS also says in the annual reports that NT "is living the dream!"

The annual report is a major way the organization is seen by the public. It is a record of performance verified by an external accountant. It is also a rhetorical document designed to communicate a coordinated message to the public as well as its own 322-person membership in 2007. Employees are attentive to the annual report and other public representations of their organization. They might ask the question of narrative fidelity: "Is this like us? Is this true for us?”

A major event in the PJS story is the brouhaha over using a gymnast on a balance beam for the cover of the 2003 annual report. While PJS had coordinated it with his CEO, a significant portion of the organization seemed to object. PJS's whistleblowing story is fraught with ironies: PJS both speaks for the organization and speaks against it. PJS officially charges NT with wrongdoing and then publicly defends the same organization when asked.

The annual reports are additionally relevant because they help to highlight the outlier nature of this case. As one of the government-provided advisors said about PJS's whistleblowing, "It is odd that someone in your professional position is the whistleblower." By position and profession, PJS was a veteran participant in mass media. He knew how to diffuse an innovation. He knew how to employ euphemistic and hopeful language to sweeten harsh data. He knew how to call a press conference and manage it as an event. He knew the shelf life of a political story. He could manage the response to an NT program disaster. He knew how 
to best frame a story's angle for the media. He knew how to satisfy the audience with a mild version of the truth. He could estimate how long confidential data would remain a secret. He knew how to anticipate the responses of his opponents and how to defend himself. All of these practices were enacted at the executive level between himself and the organization, especially the CEO he reported to. But his official responsibility during all of this was to shape and sign off on the annual report. Thus, his role, his productivity, and his value are demonstrated in the annual reports, and his role as the whistleblower can be interpreted in the context of them.

\section{News Articles}

The third set of texts the chapter writers could study were major news reports covering the era. All these documents were originally published in Norwegian, but we translated each of them into English. These news stories paint a critical picture of NT. For example, one reporter estimated that NT had paid double the actual value for the slot machines that were to become a public issue because they caused gambling addiction for a portion of users. More scandalous still, the slot machines didn't function properly and had to be scrapped at great cost. Such waste and the possibility of contract favoritism were two of the big news items made available to chapter writers. They might reasonably ask: How was whistleblowing written about in Norwegian media? What was the gravity of the case? How was the whistleblower treated? The news accounts also covered the outing of PJS and his boss's comments to the newspapers. We also included selected newspaper articles to give a frame of reference to the attention the case caused in the Norwegian media. Before it broke, one reporter, for instance, argued that the contract for the new slot machines, which were designed to lessen gaming dependency, had been awarded to a close friend of the CEO. Other articles give a description of the actual whistleblowing and the media's reactions to it. Further, we included media reactions to the various investigations that took place.

\section{Photographs}

We also offered photographs of PJS and his family farm because the farm plays such complex roles in his whistleblowing story. We offered photographs of it for analysis because descriptions of it hardly do it justice. Around PJS's farm home is a complete community, including a larder, a blacksmith shop, several hay barns, and a foreman's home.

The photographs were important because the farm, though an anchor for PJS, is also a burden to him-a noble responsibility he cannot unyoke himself from, though he'd prefer to walk away from it. At the start of the story, he searches for a job near the farm so he can both 
rehabilitate the place-it had grown derelict in his years of absenceand yet have the professional life he so deeply values. The beauty and panorama of the farm and farmhouse are apparent in the photographs. There is an upstairs ballroom lined with original oil paintings of his ancestors peering out on all who walk the floor in front of them. The burden of the story arises from his family's recent history of the farm and what it takes to maintain it. His role is that of a good neighbor; he sponsors a community effort to use his log splitter to cut enough wood for his neighbors' winter. In addition to that obligation is the history to overcome. PJS's father had almost failed in running the farm and completely lost it. But now, as the former Norwegian secretary of agriculture showed up to publicly announce at a party for PJS's fiftieth birthday, "The farm is once again in good hands."

For PJS, it's an effort to keep it that way. The farm continues to anchor PJS's story. When things fell apart at NT, PJS's position was that he deserved to be treated fairly by the company and, by extension, the country of Norway. To him, fairness meant supporting his professional goals-and at the same time allowing him to remain on the family farm. NT had seemed a perfect match for him, but the perfection of this match was hard to maintain. The photographs help to tell this part of the story.

\section{External Reviews From the Norwegian Auditor General and Deloitte}

The third set of texts available to the chapter writers were major texts that covered the case, including reports and selected newspaper articles. All these documents were originally published in Norwegian, but we translated into English.

Chief among them are executive summaries of the two major investigations. The first summary was that of the Norwegian auditor general (NAG). NAG audits all sizeable Norwegian state-owned organizations, including Norsk Tipping. After the whistleblowing went public, NAG decided to do an extensive audit of the company, which culminated in a report to the Protocol Committee of the Norwegian Parliament. We provided an executive summary of it. The second, by Deloitte, was commissioned by Norsk Tipping itself when it became known that the Auditor General's report contained details that were of such a grave nature that certain elements had been forwarded to the Norwegian National Authority for Investigation and Prosecution of Economic and Environmental Crime (Økokrim).

Deloitte was asked to further investigate those issues for the period 2000-2007. In Deloitte's report, NT's management team is criticized for improperly blurring personal interests and the company's financial interests, and for developing a "bad" culture (ukultur) in connection with the 
implementation of various contractual relationships. It specifically noted that a Norsk Tipping employee had taken a leave of absence to work for a supplier between 2004 and 2005, and then returned to Norsk Tipping as an employee. In summary, while no criminal offenses were identified, the report revealed events that provided grounds for harsh criticism of the company and its former senior management.

\section{Note}

1. For simplicity, we use "PJS" to refer to Peer Jacob Svenkerud throughout this book because Norwegians typically use a person's first and middle name even in informal conversation.

\section{References}

Bashshur, M. R., \& Oc, B. (2015). When voice matters: A multilevel review of the impact of voice in organizations. Journal of Management, 41(5), 1530-1554.

Brinsfield, C. T. (2014). Employee voice and silence in organizational behavior. In A. Wilkinson, J. Donaghey, T. Dundon, \& R. B. Freeman (Eds.), Handbook of research on employee voice (pp. 114-131). Edward Elgar Publishing. https:// doi.org/10.4337/9780857939272.00015

Browning, L. D., \& Morris, G. H. (2012). Stories of life in the workplace: An open architecture for organizational narratology. New York: Routledge.

Campbell, J. (1972). The hero with a thousand faces. Princeton, NJ: Bollingen.

Culiberg, B., \& Mihelič, K. K. (2017). The evolution of whistleblowing studies: A critical review and research agenda. Journal of Business Ethics, 146(4), 787-803, p. 787.

Denzin, N. K. (2017). The research act: A theoretical introduction to sociological methods. New Brunswick, NJ: Transaction Books.

Devine, T. (1997). The whistleblower's survival guide. Courage without martyrdom (p. 28). Washington, DC: The Fund for Constitutional Government.

Hirschman, A. O. (1970). Exit, voice, and loyalty: Responses to decline in firms, organizations, and states (Vol. 25). Cambridge, MA: Harvard University Press.

Kenny, K. (2019). Whistleblowing: Toward a new theory. Cambridge, MA: Harvard University Press.

Lee, J., \& Varon, A. L. (2016). Employee exit, voice, loyalty, and neglect in response to dissatisfying organizational situations: It depends on supervisory relationship quality. International Journal of Business Communication, 7(1), 30-51.

MacGregor, J., Robinson, M., \& Stuebs, M. (2014). Creating an effective whistleblowing environment. Strategic Finance, 95(9), 35.

Miceli, M. P., \& Near, J. P. (1985). Characteristics of organizational climate and perceived wrongdoing associated with whistle-blowing decisions. Personnel Psychology, 38(3), 525-544.

Mumby, D. K., Thomas, R., Martí, I., \& Seidl, D. (2017). Resistance redux. Organization Studies, 38(9), 157-1183.

Perrucci, R., Anderson, R. M., Schendel, D. E., \& Trachtman, L. E. (1980). Whistleblowing: Professionals' resistance to organizational authority. Social Problems, 28(2), 149-164. 


\section{Larry Browning et al.}

Pittroff, E. (2016). Whistle-blowing regulation in different corporate governance systems: An analysis of the regulation approaches from the view of path dependence theory. Journal of Management \& Governance, 20(4), 703-727.

Putnam, L. L. (2001). Shifting voices, oppositional discourse, and new visions for communication studies. Journal of Communication, 51(1), 38-51.

Rusbult, C. E., Farrell, D., Rogers, G., \& Mainous III, A. G. (1988). Impact of exchange variables on exit, voice, loyalty, and neglect: An integrative model of responses to declining job satisfaction. Academy of Management Journal, 31(3), 599-627.

Ukultur i Norsk tipping. Retrieved from www.dn.no/nyheter/politikkSamfunn/ 2010/09/01/laquoukulturenraquo-i-norsk-tipping-dokumentert.

Verhezen, P. (2010). Giving voice in a culture of silence: From a culture of compliance to a culture of integrity. Journal of Business Ethics, 96(2), 187-206.

www.norsk-tipping.no/26819/ekstern-granskning-av-norsk-tipping-over.

www.tv2.no/a/3279505/.

Zhang, J., Pany, K., \& Reckers, P. M. (2013). Under which conditions are whistleblowing "best practices” best? Auditing: A Journal of Practice \& Theory, 32(3), 171-181. 


\section{Part II}

\section{What Goes Wrong?}




\title{
3 Truth-Telling and Organizational Democracy
}

\author{
The Rhetoric of Whistleblowing \\ as an Act of Parrhesia
}

\section{Ronald Walter Greene, Daniel Horvath and Larry Browning}

In this chapter, we combine the theoretical work of the first and second authors with the third author's summary of the story he had collected as Peer Jacob Svenkerud's (PJS) interviewer and that serves as the data set for this book.

Whistleblowing, as popularly defined by Near and Miceli (1985, p. 4), is "the disclosure by organization members (former or current) of illegal, immoral, or illegitimate practices under the control of their employers, to persons or organizations that may be able to effect action." This chapter aims to add specificity, and historical context, to their word "disclosure." We view the whistleblower's disclosure as an example of what the ancient Greeks called parrhesia, a particular type of free speech that is especially bold, risky, and, most importantly, truth-telling. Kenny's (2019) treatise on whistleblowing in the financial community contrasts parrhesia with its far more common counterpart-cooperating for the sake of going along, being unwilling to critique the dominant narrative, or worrying what it means for your retirement pay (see Chapter 5).

We contend that whistleblowing is at its most rhetorical when it is approached as disclosure of organizational wrongdoing. Three related questions require attention: (1) What exactly is parrhesia? (2) How is whistleblowing a modern form of parrhesia? and (3) What does a more roundabout approach to going public-in this case going around the chief executive officer (CEO) to the board of directors (BOD)-reveal about the democratic power of parrhesiastic speech like whistleblowing?

We begin with a literature review tracing the relationship between whistleblowing and parrhesia to more fully appreciate whistleblowing as an effort to circulate a claim of wrongdoing beyond the immediate supervisor's organizational control. Whistleblowing is made powerful as a constitutive process of addressing a level in the hierarchy that might be mobilized to attend to organizational wrongdoing. In this case, the whistleblowing was an internal attempt to solve the problems with the least damage to PJS's own organization. It was an effort to form a "rhetorical audience" (Bitzer, 1968) beyond normal organizational control 


\section{Ronald Walter Greene et al.}

that, we argue, provided the democratic value of whistleblowing as parrhesia. Consequently, whistleblowing as a modern form of parrhesia becomes paradigmatically rhetorical when it attends to the complexity of modern public and democratic life. We contend that the public character of whistleblowing is potentially a mechanism by which whistleblowing transforms itself from a micro-act of resistance into a potentially collective act of change made legitimate by the democratic power of speech.

The first part of our chapter approaches whistleblowing in general and PJS in particular from within the study of organizational communication. The second part re-specifies PJS's whistleblowing as a form of democratic parrhesia. We conclude by discussing how whistleblowing as parreshia can improve the normative infrastructure necessary for organizational democracy.

\section{Whistleblowing as Organizational Communication}

Communication scholars, especially those interested in organizational rhetoric, will readily see that whistleblowing-the disclosure of organizational wrongdoing to those who might effect change-is, at bottom, your stock communicative process. A speaker (an organization member, former or current) speaks (discloses some wrongdoing under the control of their employer) to an audience (persons or organizations that may be able to effect action). As such, whistleblowing was initially approached as a species of superior-subordinate communication. The claim of wrongdoing was conceptualized as a question of information flow mediated by organizational hierarchy (Stewart, 1980). Vestiges of the superiorsubordinate relationship are, of course, evident in the present case. Our whistleblower, PJS, was subordinate to the CEO and blew the whistle on him by going around him to the chairman of the board $(\mathrm{COB})$ to register his complaint. Stewart viewed the typical communicative situation of whistleblowing as having an internal organizational component sometimes coupled with an external public component: "When potential whistleblowers attempt to take their concerns through an organizational hierarchy, they may be attempting to increase, or at least alter, the upward flow of information. They express their concerns directly to the public when they feel they cannot alter the flow of information or get a suitable response from the organization" (p. 97). At first, PJS was sufficiently satisfied with the response of the COB that he sanguinely accepted the man's invitation to remain in the organization and protect it. Three things are worth noticing about this initial configuration of the communicative process. First, whistleblowing was approached as an organizational rhetoric that was usually both internal and external to the organization. PJS and others had voiced concerns internally and gotten nowhere. Only after this, indeed much later, did he decide to go to the COB. Second, the audience of address-here, the $\mathrm{COB}$ - can change: from subordinate to 
superior to an organization member. The different audiences for PJS variously included close colleagues who shared his dismay over how things were handled; his mother; his external advisors; his former boss; and the COB. All of them deserved and received different message formations. Third, the pivots among audiences showed that PJS as whistleblower had encountered a non-responsive organization. He went to the COB only as a last resort. Stewart would conclude his analysis with a call for future research in organizational dissent, implying that whistleblowing was one genre of it (p. 99).

Five years later, Charles Redding (1985) would explicitly agree with that suggestion. Redding distinguished two figures of organizational dissent: "boat rockers" and "whistleblowers" (p. 246). "Boat rockers," he said, voice their complaints within the organization, whereas the whistleblower "voices his or her protest to people outside" it (p. 246). Redding, then, would label PJS a boat rocker, not a whistleblower. But Redding wrote in 1985. By PJS's time, the label "boat rocker" was unknown to Norsk Tipping (NT) (see Chapters 1 and 2). There, all parties simply called it "whistleblowing," and the term stuck (see Chapter 13).

Unlike Stewart (1980), who saw whistleblowing as both a constructive and a destructive process that might be managed with better internal communication, Redding, something of a boat rocker himself, advocated for a more politically active kind of organizational communication that would promote even more boat rockers and whistleblowers. Organizational dissent, he felt, should be an important proactive goal of organizational communication (and of communication studies, too, for that matter) in order to push back against the "dominant organizational ideology" (p. 249) that demands conformity to the internal hierarchy and the elitist notion that "management knows best" (p. 250). NT seemed to have an organizational culture with zero tolerance for boat-rocking. The CEO was an imperious boss whom others seemed unwilling to confront for fear of retribution. Hence, a culture of silence, of craven acceptance. And it was confirmed to varying degrees in the external investigations recounted in Chapter 2. But PJS's answer to "management knows best" was to contest it internally. Ironically, he was a manager himself, officing in the executive suite, but he was also an outlier by moral conviction and courage.

It's worth our noticing another difference between Redding and Stewart, this one in the audience that the whistleblower addressed. Redding's distinction between boat-rocking and whistleblowing makes the latter a public process (i.e., speaking external to the organization), whereas Stewart construed whistleblowing as having both an internal and (sometimes) an external component. Stewart's position seems to have gained ascendancy. Except in a few writers, both internal and external accusations get labeled "whistleblowing." In PJS's case, of course, the focus was definitely internal, not external. As Hirschman (1970) would 


\section{Ronald Walter Greene et al.}

have seen it, it was an act of loyalty. PJS was essentially saying, "These things need to be fixed, and I'm on board for leading the effort to fix them." We must concede, then, that "whistleblowing" is an inherently ambiguous term. What it means to the layman and what it means in organizational practice can be two distinctly different things.

In the end, Redding pulls back some, saying that whistleblowing should be a rare practice, one reserved for disclosing "intolerable evils" (p. 246). By "intolerable," he means things that absolutely cannot be accepted, that insist on being confronted. Bruno and Conrad's analysis (Chapter 5) contends that lavish benefits are typical in high-level government jobs to offset their comparatively modest salaries. For PJS, chief among the intolerables were chummy contacts with outside vendors and the CEO's use of influence to choose outside sponsorship partners who didn't align with the company's avowed values. PJS saw these issues as internal matters and thus went to the COB rather than to the Norwegian media.

As such, the disclosure of wrongdoing is not just any wrongdoing but should be of such a magnitude- "an intolerable evil" - that a turn away from the organization and toward the public is warranted. We ourselves contend that if it can be managed internally, going public is not necessary. Elsewhere in this book (see Chapter 13) we find agreement with our position. Handling whistleblower complaints internally is not only preferable but also a sign that managers can resolve problems constructively, without fanfare-one of the goals of good management (see Chapter 2). PJS tried to make his complaints internal, to the BOD. There was no public announcement until he was outed by Norway's major financial newspaper, Dagens Noeringsliv.

Redding's call for a more politically active approach to organizational communication became the warrant for "critical organizational communication studies" (Mumby, 1993, p. 8). As such, the question of organizational power and resistance emerged as the primary objects of study. This is shown in PJS's hesitance to work with the COB's own consulting firm, which had PR contracts and event management fees with the same organization he oversaw from his position on the board.

Recognizing Redding's point that organizational communication is all too easily perceived as a species of management discourse, critical organizational scholars have tried to better account for whistleblowing as a species of organizational resistance (Mumby, Thomas, Martí, \& Seidl, 2017). They catalogued whistleblowing as a case of insubordination (p. 1169). Well, "insubordination" is a pretty mild term for how PJS's whistleblowing was actually viewed at NT. A full-press search for the whistleblower occurred there. In one news article, the first CEO exclaimed, histrionically, that he'd been "stabbed in the back with a rusty knife." The entire leadership group was interrogated: "Are you the whistle-blower?" PJS recalls in his interviews that there was an active search to identify the "unfaithful servant." 
Like others kinds of insubordination, whistleblowing is imagined as a public form of individual, or micro, resistance to organizational power. For that reason, whistleblowing is increasingly aligned with Foucault's notion of parrhesia, or frank speech (Mumby et al., 2017, p. 169; Weiskopf \& Tobias-Miersch, 2016). It's important to note, once again, the public character of whistleblowing; its insubordination gains leverage to change organizational behavior when it achieves escape velocity beyond "organizational control" (p. 1170). That's reached in this case when the $\mathrm{COB}$ and vice $\mathrm{COB}$ go forward with PJS's complaint, leading to two investigations and a revamping of how NT would now handle whistleblowing.

Why might it be important that the public character of whistleblowing escape organizational control? Gabriel (2005) provides one answer: As organizations become more public-facing and therefore act in a context "dominated by spectacle, images, and pictures" (p. 311), whistleblowing becomes increasingly threatening because it may damage an "organization's image and reputation" (p. 311). In the name of brand protection, organizations are motivated to be responsive to any whistleblower who goes public. At NT, though, brand protection seems to have been secondary, for the immediate response to the whistleblowing there was reprisal-get this person, this backstabber.

At the same time, however, the media increased the ability of whistleblowing to generate radical change. In fact, media drove the change in this whistleblowing case, repeatedly coaxing PJS to answer questions about NT's practices. Such coaxing allowed PJS to claim, "The public will not accept this." Norwegian media often had the inside track on many of NT's issues, and they pressed for answers. The plot of this story formed over PJS's unwillingness to offer media justification for the CEO's behavior.

\section{Whistleblowing as Parrhesia}

\section{Parrhesia Then: Speaking Truth to Power}

Michel Foucault's (2001) interest in the classical history of parrhesia prompted much of our current discussions of whistleblowing as a modern example of truth-telling. Foucault, Gros, Ewald, Fontana, and Burchell (2010) found a cluster of meanings embedded in the Greco-Latin use of parrhesia, including "saying everything," "speaking frankly," "stating the truth," and/or "frank-spokenness" (p. 43). Foucault's history tracks the movement of parrhesia from the Athenian Assembly (the Periclean moment) as its theatre of deployment, to the Prince's soul as psychagogy (the Platonic/ Socratic moment), and, then slowly, to the streets, where it was viewed as a way to live a true life, embodied there in the practice of the cynics.

Foucault (2001) understands parrhesia as "a kind of verbal activity" that's distinguished in four ways: "the speaker has a specific relation to truth through frankness, a certain relationship to his own life through 
danger, a certain type of relation to himself or other people through criticism (self-criticism or criticism of other people), and a specific relation to moral law through freedom and duty" (p. 19). Frankness, danger, criticism, and duty-all deserve unpacking, and all appear in our present case of whistleblowing.

"Frankness," as Foucault glosses it, means saying everything one has in mind-that is, holding back nothing-so it's a seamless, one-to-one "relationship between the speaker and what he says"; moreover, what he says "is his own opinion" (Foucault, 2001, p. 12). Glossing frankness's relation to "truth," Foucault explains that aletheia, ancient Greek for "truth," also has four defining characteristics: (1) "that which, not being hidden, not concealed, is given to view in its entirety, is completely visible, no part of it being concealed or secret," (2) that "which is not added to or supplemented ... not altered by any foreign element which would thus distort it and end up concealing what it is in reality," (3) "that which is straight ... direct," and, finally (4) "that which exists and remains beyond any change, which remains in its identity, immutability, and incorruptibility" (Foucault, 2011, p. 219). In other words, "the unconcealed, the unalloyed, the straight, and the unchanging and incorruptible" (p. 220). For Foucault, this fourfold understanding of truth can be applied not only to the logos itself but also to the ways of being, to modes of actions and conduct. So, for Foucault, logos alethes is not simply that which is true empirically, "a set of propositions which turn out to be exact and can take the value of truth," but also is "a way of speaking in which, first, nothing is concealed ... second, neither the false, nor opinion, nor appearance is mixed with the true; [third], it is a straight discourse, in line with the rules and the law; and finally ... a discourse which remains the same, does not change, or become debased, or distorted, and which can never be vanquished, overturned, or refuted" (2011, p. 220). Foucault's definition and explanation fit this case because the principal effort after PJS's whistleblowing was to discern the veracity of his claims. Was he telling the truth? Except for the hard copies of the gardening bills that PJS's helper hived out of NT's basement records (see Chapter 2), there was little to distinguish the veracity of PJS's claims. It had all been said before.

As Foucault contends, the danger "comes from the fact that the said truth is capable of hurting or angering the interlocutor" (2001, p. 17). The function of parrhesia, adds Foucault, "is not to demonstrate the truth to someone else, but has the function of criticism" (p. 17). The parrhesiastes, aka truth-teller, "is always less powerful than the One with whom he speaks," meaning that parrhesia "comes from 'below' ... and is directed 'above"' (p. 18). Whistleblowing, too, typically comes from below and is directed to someone above. Such a flow of direction-from down to up-is the oldest presumption in organizational communication. Critical information moves slowly, if at all, from the bottom to the top. And whistleblowing is no exception. 
In personal relations, says Monoson (2000), parrhesia operated (and indeed still operates) as "candid speech among friends," whereas in the classical comedies, it got expressed as "hurling insults at identifiable individuals and ridiculing Athens," while in oratory, "speakers also utter blunt, and at times nasty criticisms of policy and of specific people" (p. 63). In all these contexts, Monoson notes, "parrhesia is consistently and closely associated with two things: criticism and truth-telling" (p. 63). Speaking with parrhesia "was to confront, oppose, or find fault with another individual or a popular view in a spirit of concern for illuminating what is right and best" (p. 63). Markovits (2008) adds danger to the mix: "to have the quality of parrhesia, a speech must criticize someone who has the power to somehow injure the speaker" (p. 66). For Saxonhouse (2006), parrhesia, when (mis)understood simply as free speech, "ties the word too strongly to the passive language of rights rather than the active expression of one's true beliefs" (p. 86). Saxonhouse argues that the anachronistic language of rights conceals "the daring and courageous quality of the practice ... the exposure of one's true thoughts, the resistance to hiding what is true because of deference to a hierarchical social and political world or a concern with how one appears before the gaze of others, that is shame" (p. 88).

All of these definitions point to criticism as a defining feature. Indeed, if anything, parrhesia is dangerous speech because its frankness puts the speaker at risk of the target's reaction to being criticized. And we see just that in the present case. PJS's speaking up created tremendous upheaval-literally. He recalls how he would travel to a rural bus stop to relieve his stomach every day on his way home from work. But even that relief wasn't enough. He eventually felt compelled to leave the company (Conrad, Chapter 5).

Still, if you're a true parrhesiastes, like PJS, you'll see it as your duty to disclose. As Foucault notes, parrhesia "is a verbal activity in which a speaker expresses his personal relationship to truth, and risks his life because he recognizes truth-telling as a duty to improve or help other people (as well as himself)" (2001, p. 19). PJS acted out of duty, even though the pushback he incurred had been predicted by his personal advisors. Markovits (2008) similarly sees in parrhesia a notion that emphasizes "not just the right to speak but also the duty to speak the truth" (pp. 65-66). As Saxonhouse notes, "freedom of speech is enshrined not for the benefit or freedom of the individual; it exists in the vision of these orators for the sake of the city" $(2006$, p. 96). In this case the "city" is Norway, and its benefits the resources generated by the national lottery (NT) that fund sports and culture throughout that country.

As Foucault (2001) notes, however, there are many and diverse modalities of telling the truth. Speaking specifically about ancient Greek culture, he points to prophecy, wisdom, and teaching as, alongside parrhesia, modes of veridiction. As for representatives of each-the prophet, the 
sage, the teacher, the parrhesiastes-he says that all four can be truthtellers, but how many actually face danger? How about the teacher, for example-the man of tekhne, of technical knowledge, whatever the kind, even his own kind (for he himself was a teacher)? Foucault has a quickperhaps too quick-flat answer: "Clearly this teacher, this man of tekbne, of expertise and teaching, does not take any risk in the truth-telling" (2011, p. 24). (Young teachers facing tenure might disagree.) For Foucault, then, "someone is said to use parrhesia and merits consideration as a parrhesiastes only if there is a risk or danger for him in telling the truth" (2001, pp. 15-16). So the proof of one's sincerity, he contends, is courage. "The fact that a speaker says something dangerous-different from what the majority believes-is a strong indication that he is parrhesiastes" (Foucault, 2001, p. 15). On that score, PJS certainly qualified. One of his advisors had warned him what would lie ahead: "Expect a situation when you are sitting in a rowboat, meeting a supertanker head-on-that is the kind of resistance you will meet."

So, yes, PJS certainly qualified. "There is always parrhesia," says Foucault, when the fact of telling the truth "will, may, or must entail costly consequences for those who have told it" (2010, p. 65). The danger of telling the truth entails a parrhesiastic pact "of the subject with himself" in which the speaker binds him- or herself to the content of the statement and to the act of making that statement (Foucault, 2010, p. 65). As we learned in Chapter 1, PJS felt he had three choices: Leave, accept the status quo, or speak out. The ultimate challenge for him was foreseen by Muhammad Yunus several years earlier-the challenge of being true to himself.

When one states the truth, one states what one knows and believes to be true; at the same time, one binds oneself to the act of stating the truth given that stating the truth entails risk. To put it differently, "the parrhesiastes is someone who emphasizes his own freedom as an individual speaking" (Foucault, 2010, p. 67). For PJS, his freedom from the dominating culture also freed him both to think critically and to speak. Parrhesia brings to the forefront a fundamental philosophical question: the connection between freedom and truth. Foucault again: "How and to what extent is the obligation of truth-the 'binding oneself to the truth,' 'binding oneself by the truth and by truth-telling'-at the same time the exercise of freedom, and the dangerous exercise of freedom?" (2010, p. 67). Parrhesia is a way of telling the truth, a way of entailing a risk, binding the speaker to the statement of truth and to the act of stating it in the form of a courageous act. That reads like a summary of the story of this book: PJS risks to tell the truth, and his statement is so dangerous that he is bound to secrecy for 29 months, to enact the courage via solace and a network of secrecy. Also noteworthy in Foucault's stance is the possible interplay of secrecy and privacy that the course of this case takes. 


\section{Parrhesia Now: Whistleblowing}

Parrhesia's constitutive elements-truth, frankness, criticism, danger, courage, duty, and freedom-are useful for describing the rhetorical interventions of outspoken critics of oppressive regimes, conscientious objectors, national-security leakers, and corporate whistleblowers. To imagine the whistleblower as one who binds him- or herself to a truth of organizational wrongdoing is useful for respecting the dangers that such a speech act entails. Mansbach (2009) describes whistleblowers as truth-tellers who "re-appropriate speech in the workplace in their struggle to shape their identity and the way in which they are identified by others" (p. 369). Mansbach (2009) and Mumby et al. (2017) share the transformational character of this re-appropriation of speech as an end to voluntary subordination to organizational hierarchy and the inauguration of a critical act of resistance or insubordination to the speech norms regulating organizational life. PJS was a high-level leader of an organization that required everyone to treat it as one you had no reason to complain about. Only a fool (it implied) would upset the munificent environment it offered. Yet, PJS felt obliged to speak the truth even though it was costly for him to do so.

Over the past couple of decades, viewing whistleblowing as a contemporary example of parrhesia is a central organizing theme of the whistleblowing literature (Kenny, 2019). How does whistleblowing work to inaugurate a "game" between truth-telling and the exercise of freedom? Or, in the more current language of critical organizational studies, how does it express a speech act of resistance?

First, leading scholarship in business ethics imagines the parrhesiastic relationship between the whistleblower and the authorities from within the organization. For example, Vandekerckhove and Langenberg (2012) describe the truth-telling of whistleblowers as a rupture in the normal flow of communication. They describe the parrhesiastic character of whistleblowing as generating a "disorganization of the organizational dynamic" (p. 40). From within the organization, whistleblowing generates a "parrhesiastic chain" that implicates different sets of speakers and hearers as the claim of wrongdoing moves through the chain of command. For PJS, breaking the chain of command meant going around the $\mathrm{CEO}$ directly to the BOD in a private meeting, making claims, and providing proof that said something had to be done. What is important is not simply the "courage" of the whistleblower but the responsiveness of the person who receives or hears the difficult news. When PJS pushed the $\mathrm{COB}$ into a corner, basically giving him no choice but to act, the COB responded by coaxing PJS into continuing in his official role as Senior Vice President Information and External Relations.

In some organizations, procedures are in place that allow for implementing an immediate planned response to a wrongdoing once it's disclosed. But no such procedures were in place in 2007 when PJS blew 
his whistle (see Chapter 4). The organization was caught flat-footed. PJS was almost equally unprepared. How could he have ever guessed that he would be invited to stay on and act as an undercover agent? Worth noting is that the company actually did implement such procedures after the fact.

It's also possible that the audience of a whistleblowing will fail to "hear truth" and help protect the organization (see Chapter 7). When that happens, the whistleblower is in danger of retaliation. But sometimes the whistleblower will activate a sense of courage in their hearer/audience. At NT, when top management learned of the whistleblowing, they started a search for his identity, determined to penalize him for his apostasy. At this point, a disorganizing process moved up the ladder, multiplying the need for a parrhesiastic relationship at every level of the hierarchy as organizational decision-makers were called on to be brave and support the apostate. Kenny (2019) similarly argues for a new conceptualization of whistleblowing that departs from viewing whistleblowers in a narrow frame, as "lone operators," since it discourages "ideas of commonality and collective action" (p. 3). She advocates for rethinking whistleblowers as part of a collective entity that enrolls others in speaking up when organizational wrongdoing is witnessed and impacts more than one individual. Such a perspective, though informed by the critical spirit of parrhesia, works within the context of upward communication flows that are associated with subordinate and superior communication.

A positive outcome of whistleblowing is the correction of organizational wrongdoing from within the organization. This case is an exception to the need for upward communication because PJS was the Senior Vice President Information and External Relations at NT; he reported directly to the CEO. He chooses to go around his direct report to the COB. This correction transforms the disorganizing work of parrhesia into a moment of re-organization so that the organization might move forward. For Vandekerckhove and Langenberg (2012), the parrhesiastic chain allows for a re-organization of the organization when a new set of procedures "establish a receptive determinacy" (p. 40). Is the critical spirit of parrhesia attenuated by the courage of management to be responsive to the speech of the whistleblower?

This model of the parrhesiastic chain is an argument for how the organization might benefit by keeping the claim of wrongdoing under its organizational control (Henderson, 2007). By keeping the whistleblowing within NT, it allowed the organization through the COB to keep the secret for 29 months following the whistleblowing. As long as the truth-telling remains under organizational control, the organization is likely able to fend off more collective critiques of its norms, practices, and behaviors. PJS's purpose in his internal whistleblowing was to change the organization with as little outside interference as possible. After all, PJS was a senior official of the same organization he was criticizing. As this 
book demonstrates, he intended to both critique the organization and to be part of the solution.

The emphasis on the courage of speaker and hearer as actors located within the organization often participates in the replication of a moral story of individual heroes challenging organizational wrongdoing, or, in the case of a responsive management, a story of organizational repair and re-form, (see Chapter 5). Parrhesia, imaged as a series of courageous conversations, multiplies the number of discursive interactions generating new opportunities for transforming speakers and hearers into parrhesiastes, but it does so at the expense of maintaining organizational control over the circulation of the claim of wrongdoing. A responsive management obviates the need to go public. An organization's ability to prevent the public circulation of wrongdoing is a good rhetorical explanation for understanding how the resistant character of whistleblowing is brought back under the control of the organization. Moreover, an overemphasis on demonstrating the courageous character of whistleblowing risks limiting the critical spirit of parrhesia to a virtue psychology.

\section{Regimes of Truth and the Rhetoric of Danger}

As an antidote to moral psychology and in an effort to secure whistleblowing as a critical practice, Mansbach (2009) and others (Perry, 1998; Weiskopf \& Willmott, 2013; Weiskopf \& Tobias-Miersch, 2016) have advocated the whistleblowing/parrhesia relationship to be one that amplifies how whistleblowing participates in the contestation over the practices and regimes of truth. The regimes of truth in contest here were the CEO's claim that nothing was wrong and PJS's claim that numerous things were wrong and demanded attention. The emphasis on truth does not so much displace the subjective elements of parrhesia as it refashions the ethical character of truth-telling as being "contingent on the development of a critical self-relation that allows the subject to resist specific normative demands and to act and intervene in power relations that are perceived as "intolerable" (Weiskopf \& Willmott, 2013, p. 485). Put differently, regimes of truth are always already contextual and speaking initiates the replication of the norms and/or, possibly, their means of transformation. For example, the voluntary subordination of organizational life is made possible by a regime of truth-in this case, treating the CEO's actions as normal and defensible, but so too the duty that inaugurates an act of whistleblowing generating a contest of truth regimes. To isolate whistleblowing as a practice that participates in a contestation over regimes of truth puts in suspension the validity of the truth claim made by the act of whistleblowing. Yet, the contextual character of truth regimes suggests that organizations might also be held accountable to regimes of truth. It is from within a regime of truth that the subjective element of parrhesia appears in a way that might escape a notion of whistleblowing 
as a virtue ethics for organizational management, but instead, appreciate how whistleblowing participates in a set of procedures and mechanisms that establish how its revelation of wrongdoing might necessitate action (see Chapter 4). Put differently, the responsiveness desired by an act of whistleblowing is itself subject to participation in a regime of truth that makes hearing the truth possible.

The tendency of rhetorical scholars approaching whistleblowing as parrhesia is to approach parrhesia as an ethic that underwrites rhetorical performance. Parrhesia is activated as a way to evaluate rhetorical performances defined by courageous frankness in the face of danger. As a critical standard of judgment and/or as a way to assert rhetorical agency, rhetorical critics can avoid the question of the classical relationship between rhetoric and parrhesia. According to Chu (2016), the public narratives and arguments about whistleblowing tend to draw a distinction between the moral decision to act and a question of rhetoric embedded in discussions concerning how to disclose, to whom, with what effect, and with what impact on oneself. This case involved the same bundle of moral and practical issues. Chu (2016) advances the claim that government and military whistleblowers are the paradigmatic cases of parrhesia because "unlike conventional whistleblowers, who are able to rely on legal and civil protections, the primary defense of whistleblowers like Ellsberg, Snowden, and Manning is the strength of their evidence and their ability as orators and storyteller to communicate that truth to the public" (p. 241). In contrast, PJS intended in this instance to use the least force possible, to draw the least public attention possible. Yet, his is a parrhesiastic action that risked retaliation. One point to emphasize about the danger of retaliation, if whistleblowing is to remain a form of parrhesia, is that the danger of retaliation must be present; it cannot be legislated away or be managed away through better procedures for disclosing wrongdoing. Otherwise, it is not parrhesia. As Haugen (see Chapter 4) states, it is the goal of the Norwegian state to support whistleblowing, yet like much of the rest of the world the evidence shows that the whistleblower, in the main, is punished, which means that it remains parrhesiastic speech (Kenny, 2019).

The rhetorical character of whistleblowing is expressed in the enactment of the revelation, its choice of audience, its effect, and the public defense or attack on the revelation. These questions are rhetorical because they are strategic considerations that implicate the act of truth-telling into a rhetorical calculation about the "methods best suited to tell the truth" (Chu, p. 232). Given the heightened sense that a public revelation of wrongdoing will initiate a higher threat of retaliation, one should take seriously how the decision to go public becomes a central rhetorical problem (Near \& Miceli, 1996; Mesmer-Magnus \& Viswesvaran, 2005). PJS's strategy for publicizing the wrongdoing was to (1) go internal, as an example of Redding's (1985) boat rocker rather than a whistleblower; 
(2) commit to a vow of secrecy that he was the whistleblower; and (3) act as the point of the arrow in defending the organization from the abuses he had claimed in his whistleblowing. As Skivenes and Trygstad (2010) note about Norway, the willingness to go public, or in this case private, is often an effect of contextual variables associated with models of labor relations inscribed in law (see Chapter 4).

\section{Conclusion: Organizational Resistance and Democracy}

To magnify the focus of whistleblowing as a public effort to escape organizational control orients scholars toward a more nuanced understanding of the rhetorical dimensions of parrhesia. Rhetorical decisions as to the methods of "rocking the boat" instead of going public reveal a complex processual infrastructure that activates and constrains the responsiveness desired by the whistleblower. The strategy here was to privately place a variety of concerns on the COB's agenda, knowing that the hard copy evidence of payments to the gardener changed the story. PJS's use of negotiation skills, to hold the strongest evidence until it is necessary, meant that PJS was a particularly strategic communicator.

By entering into a cross-current of textual circulation, whistleblowing brings about the possibility of a public being attentive to the truth-telling of the whistleblower. The strategic need of a whistleblower is to invent and activate a rhetorical audience with the agential power to correct organizational wrongdoing. In this way, whistleblowing's status as fearless speech is more than a micro-individualized act; it calls forth a collective "we" that demands organizational responsiveness often in combination with state actors or other public forms (like social movements). Going public, therefore, activates core principles of accountability that extend democratic values to organizational wrongdoing (state or corporate) (Mansbach, 2011). The Norwegian National Lottery (NT) was especially attentive to accountability because it was a public monopoly and had to emphasize discipline to show its consciousness. In ancient Athens, the use of parrhesia in public discourse did ideological work by buttressing a particular understanding of democracy, of the relation among citizens, and it was deployed as a specific practice of celebrating freedom and righting tyranny through speech (Monoson, 2000). Monoson demonstrates that the Athenian "coupling of freedom and parrhesia in the democratic selfimage ... functioned to assert two things: the critical attitude appropriate to a democratic citizen, and the open life promised by democracy" (p. 55). Whistleblowing often serves similar ideological work today as it links truth-telling to the promise of a democracy that can hold organizations responsible for their wrongdoing. Whistleblowing as a kind of parrhesia offers insight into how individuals negotiate asymmetrical relationships of power to make public organizational wrongdoing (Novak, 2006). 


\section{References}

Bitzer, L. (1968). The rhetorical situation. Philosophy \& Rhetoric, 1(1), 1-14.

Chu, A. (2016). In tradition of speaking fearlessly: Locating a rhetoric of whistleblowing in the parrhēsiastic dialectic. Advances in the History of Rhetoric, 19(3), 231-250.

Foucault, M. (2011). The courage of truth (the government of self and others II): Lectures at the Collège de France, 1983-1984. Houndmills, Basingstoke, Hampshire, New York: Palgrave Macmillan.

Foucault, M., Gros, F., Ewald, F., Fontana, A., \& Burchell, G. (2010). The government of self and others: Lectures at the Collège de France 1982-1983. Houndmills, Basingstoke, Hampshire; New York: Palgrave Macmillan; St Martin's Press.

Foucault, M., \& Pearson, J. (2001). Fearless speech. Semiotext(e) Foreign Agents Series. Los Angeles, CA: Semiotext(e) [Distributed by MIT Press].

Gabriel, Y. (2005). Glass cages and glass palaces: Images of organization in image-conscious times. Organization, 12, 9-27.

Henderson, G. (2007). The "parrhesiastic game": Textual self-justification in spiritual narratives of early modern women. Rhetoric Society Quarterly, 37(4), 423-451.

Hirschman, A. O. (1970). Exit, voice, and loyalty: Responses to decline in firms, organizations, and states (Vol. 25). Cambridge, MA: Harvard University Press.

Kenny, K. (2019). Whistleblowing: Toward a new theory. Cambridge, MA: Harvard University Press.

Mansbach, A. (2009). Keeping democracy vibrant: Whistleblowing as truth-telling in the workplace. Constellations, 16(3), 363-376.

Mansbach, A. (2011). Whistleblowing as fearless speech: The radical democratic effects of late modern parrehsia. In D. Lewis \& W. Vandekerckhove (Eds.), Whistleblowing and democratic values (pp. 12-26). E-book: International Whistleblowing Research Network.

Markovits, E. (2008). The politics of sincerity: Plato, frank speech, and democratic judgment. University Park, PA: Pennsylvania State University Press.

Mesmer-Magnus, J., \& Viswesvaran, R. (2005). Whistleblowing in organizations: An examination of correlates of whistleblowing intentions, actions, and retaliation. Journal of Business Ethics, 62(3), 277-297.

Monoson, S. (2000). Plato's democratic entanglements: Athenian politics and the practice of philosophy. Princeton, NJ: Princeton University Press.

Mumby, D. K. (1993). Critical organizational communication studies: The next 10 years. Communication Monographs, 60(1), 18-25.

Mumby, D., Thomas, R., Martí, I., \& Seidl, D. (2017). Resistance redux. Organization Studies, 38(9), 1157-1183.

Near, J., \& Miceli, M. (1996). Whistle-blowing: Myth and reality. Journal of Management, 22(3), 507-526.

Near, J., \& Miceli, P. (1985). Organizational dissidence: The case of whistleblowing. Journal of Business Ethics, 4(1), 1-16.

Novak, D. (2006). Engaging parrhesia in a democracy: Malcolm X as a truthteller. Southern Communication Journal, 71(1), 25-43.

Perry, N. (1998). Indecent exposures: Theorizing whistle-blowing. Organizational Studies, 19, 235-257. 
Redding, C. W. (1985). Rocking boats, blowing whistles, and teaching speech communication. Communication Education,34(3), 245-258.

Saxonhouse, A. (2006). Free speech and democracy in ancient Athens. Cambridge and New York: Cambridge University Press.

Skivenes, M., \& Trygstad, S. (2010). When whistle-blowing works: The Norwegian case. Human Relations, 63(7), 1071-1097.

Stewart, L. (1980). "Whistle blowing”: Implications for organizational communication. Journal of Communication (pre-1986), 30(4), 90.

Vandekerckhove, W., \& Langenberg, S. (2012). Can we organize courage? Implications of Foucault's parrhesia. Electronic Journal of Business Ethics and Organization Studies, 17(2), 35-44.

Weiskopf, R., \& Tobias-Miersch, Y. (2016). Whistleblowing, parrhesia and the contestation of truth in the workplace. Organization Studies, 37(11), 1621-1640.

Weiskopf, R., \& Willmott, H. (2013). Ethics as critical practice: The "Pentagon Papers”, Deciding responsibly, truth-telling, and the unsettling of organizational morality. Organization Studies, 34(4), 469-493. 


\title{
$4 \quad$ Smothered by Paradoxes and Swamped by Procedures \\ The Legal Context of the Case
}

\author{
Anne Oline Haugen
}

Imagine an employee who has spotted possible irregularities in his hospital's registration of data. Worried, he looks into the problem further, discusses it with some colleagues, then looks into it yet again. With the months passing, and still worried, he eventually approaches a manager about his concerns. The manager assures him that the registration is done correctly and that he needn't worry. Unpersuaded, the employee decides to contact the Privacy Protection authorities. It's now a year and a half since he first started worrying. The Privacy Protection authorities look into the matter and, after another full year, conclude that the employee's concerns are justified: the hospital's registration of data is indeed illegal. Meanwhile, not only has our employee been shunted to another office, he has also been denied an expected raise in salary. Worse still, he is then asked to resign. Why? Because his position has been declared "redundant." It is now two and a half years since he first started worrying. And now he faces a brand new problem: Should he sue the hospital because of how he's been treated? The outcome of a trial will be uncertain, he knows. Besides, being emotionally spent, how can he summon the strength to keep fighting? We will leave our employee here, but the point is, it's not enough to be right; you also have to be very persistent.

Peer Jacob Svenkerud's (PJS) story is about certain actions-or, more specifically, good deeds-that are supposed to be protected by legislation. PJS finds that the protection was not strong enough to shield him.

The legislation of whistleblowing aims to protect any individuals who find the courage to expose organizational wrongdoing that is harmful to society. In this story, the whistleblower blew the whistle about the use of public funds that he considered illegitimate. No one disputed the justness of his charges, but he still received no protection from recrimination. How could this happen?

Whether it involves going to court or making new legislation, the law is all about stories and human behavior. Stories always have a message, plus central characters (Bruner, 2002, p. 7; Horn, 2010). A legal story is usually told before a court of law (Bruner, 2002, p. 37), but often the main character, as in PJS's story, decides not to go to court. Whether you go to court 
or not, the two opposing characters, or "parties," will tell their own version of what happened, so the two stories invariably contradict each other. Both stories will consist of supposed facts of supposed legal relevance. Our story is told by just one of the parties, namely PJS. His story is about how he observed questionable incidents at the workplace, discussed them with both colleagues and senior management, and concluded that the incidents were indeed wrongdoing. His views, and his actions based on his views, had severe consequences for his future career in the organization.

\section{Norwegian Law as It Relates to This Case}

The law has some distinctive features, especially when compared with the stories found in the social sciences, literature, and theory, none of which share its gravity. For example, each nation's laws are its own, hence truly national. But they also operate within a larger legal context-that of the world (Evju, 2010, pp. 239-253). We have human rights, the European Union (EU) convention, and in Europe, the vastly influential EU court (Mikkola, 2016, p. 430). Throughout Europe, the national courts of its member countries will always look to the EU court. But they will, of course, also look principally to their own court decisions, especially those from their nation's supreme court. In legal research, national supreme court decisions are important documents. In addition, we have parliamentary documents, which are part of the lawyers' and courts' so-called preliminary work, as they help clarify how the laws themselves are to "be understood" (Lewis \& Trygstad, 2009, pp. 374-384). When it comes to different kinds of juridical evaluations of the law, the broad legal literature, and not only national law, is taken into consideration (Vaughn, 2014, pp. 239-266; also Lewis, Devine, \& Harpur, 2014, p. 350, and Weltzien, 2017, pp. 31-49). These juridical evaluations of the law are important in whistleblowing cases. But the central question comes down to this: Does the legislation work?

This chapter takes a legal point of view, hence only the facts of legal relevance are included here. For example, I ignore any reasons for why PJS became a whistleblower-explanations connected to him as a person or his tasks at work. I also skip over how PJS describes the way the pressure on him mounted and how he was tagged "the prince of darkness." I just focus on facts relevant to interpreting the legislation. Of course, it's hardly obvious which facts are actually the most relevant. As Jerome Frank once observed, "But the law as we have it is uncertain, indefinite, subject to incalculable changes" (Frank, 1931).

\section{Labor Law in General}

Because this story is about whistleblowing, it's important that Norway's whistleblowing legislation be set in a legal context, specifically its labor law (Skivenes \& Trygstad, 2017, p. 136). That focus is necessary to 
appreciate just how fully a whistleblower is theoretically protected because any weaknesses in the whistleblowing legislation may be compensated by other labor-law protections. The Norwegian Working Environment Act (WEA), which relates to the working environment, working hours, and employment protection, is an important factor in the safeguarding of the employee, for as a rule, this legislation cannot be set aside by a contract.

A central part of its protection is that the employee "cannot be dismissed unless this is objectively justified" (WEA, $\mathbb{S} 15-7$ ). In short, it must be clear that the employee has not fulfilled his or her obligation according to the contract agreed upon with their employer. Suppose, for example, you sell trade secrets to a competitive company. A disgruntled Coca-Cola employee once tried to do just that-sell top-secret Coke documents to Pepsi. It cost him a guilty verdict and eight years in prison.

The employee also has the right to be given adequate notice of dismissal, ranging from one to six months. There are also formal requirements with regard to that notice of dismissal (WEA, $\mathbb{S} \mathbb{S} 15-3$ and 15-4). For example, the dismissal must be in writing, and it also must be delivered by hand or registered mail. In addition, the dismissal must contain the right to demand negotiation and to institute legal proceedings. This law also protects against harassment in general (WEA, $\mathbb{S} 4-3$ ), the latter covered under Norway's discrimination act.

Also important in the Norwegian model are the collective agreements (Skivenes \& Trygstad, 2017, p. 122), which also provide further protection. As Skivenes and Trygstad state, $80 \%$ of all employees in the public sector are members of a trade union, while $37 \%$ of employees in the private sector are also members. That means that a large portion of employees have additional protections, such as ones governing the period of dismissal and part-time employment. (See the collective agreement between the union of communities and the labor organizations, Hovedtariffavtalen kapittel 2). Additionally, Skivenes and Trygstad emphasize the importance of an enterprise's obligation to have a safety representative, elected by and among its employees (WEA, $\mathbb{S} 6-1$ ), whenever it has more than ten employees. The public sector also is governed by the principles of unfairness. For example, an employee who blows the whistle and is then treated differently than his colleagues is considered unfairly treated (Eckhoff \& Smith, 2018, p. 404, and Moen, 2018, p. 341). Together, the legislation and the collective agreements are a part of the protection of employees.

Even beyond these safeguards, however, there are special rules concerning whistleblowing. To them we turn next.

\section{Legislation About Whistleblowing}

The background for Norway's legislation about whistleblowing starts with the hallowed rights of freedom of speech and freedom of expression, both of them enshrined in its national constitution. Article 10 in The 
European Convention of Human Rights also articulates the right to freedom of expression, as does Article 19 of the United Nations International Covenant on Civil and Political Rights (Mikkola, 2016, p. 430). The connection between Norway's legislation about freedom of speech and its legislation about whistleblowing (Boe, 2009, pp. 67-92) is an important one to consider. Freedom of speech is guaranteed in the constitution and is unlimited there. But later legislation has enacted some limitations, such as on hateful speeches. The purpose for legislation about whistleblowing is to protect whistleblowers against retaliation when they exercise their freedom of speech. Any limitations in employees' freedom of speech are grounded only in assumptions of loyalty to their employer, not as a limitation in the legislation. For if an employee is to enjoy unabridged freedom to practice his freedom of speech in the workplace, the legislation's protection is important. That's especially so in the public sector, where promoting whistleblowing can also serve as a weapon against criminal offense in the area of economy, such as blowing the whistle on embezzlement (Eriksen, 2014, p. 177, and also Brown \& Dworkin, 2013, pp. 652-713). We find some of these arguments in the preliminary works to the Norwegian legislation, where the need to expose misuse of public funds is an argument for protecting the whistleblower (Ot. prp. nr. 84, 2005-2006, p. 17; also NOU, 1999: 27). The misuse of public funds is looked upon by the legislator as more serious than the misuse of private ones. In the United States, the Civil Service Act of 1978 covers nearly all public-policy misconduct by the federal government. Examples include disclosures of illegality, abuse of authority, substantial and specific danger to public health or safety, and gross waste and gross mismanagement, to name a few (Lewis et al., 2014, pp. 351-380).

In today's academic literature, whistleblowing is defined as the disclosure by organization members (including former members and job applicants) of "illegal, immoral, or illegitimate practices (including omissions) under the control of their employers, to persons or organizations who may be able to effect action" (Near \& Miceli, 1985, pp. 1-16, and Near \& Miceli, 2013, p. 183). This definition departs somewhat from how whistleblowing is defined by the Norwegian legislation, especially regarding morality. For example, it holds that there may be immoral practices that are not punishable. To act disloyally to a colleague may be immoral but not punishable. The Norwegian legislation will above all cover actions that are punishable. But its definition is so similar to the prevailing academic one that it is still useful for our purpose.

These rules don't protect whistleblowers against every kind of retaliation. To enjoy protection, they must follow an appropriate procedure, which includes following certain rules. As long as they do, they get to enjoy this constitutional right of freedom of speech.

Compared with employees in other countries, Norwegians score high on whistleblowing activity and effectiveness, and also low on 


\section{0}

retaliation. The Nordic labor-market model, plus Norway's approach to whistleblowing as found in the legislation, helps explain these scores (Skivenes \& Trygstad, 2017, p. 136). The WEA affirms one's right to report misconduct, and workers who report misconduct shall be protected from retaliation. The model we find in the WEA exhibits such features as "high degree of unionization and centralized agreement and co-ordinated bargaining at several levels" (Skivenes \& Trygstad, 2010, p. 1073). Together, both employees' unions and the organizations on the employers' side are part of a public decision-making system. Yet, this only begins to tell the story. Legislation typically aims to have precise, clear rules to protect employees who blow the whistle. Even so, those employees may be running a risk (Dworkin, 2006, p. 1757). It can be difficult for them to decide whether the conditions for whistleblowing are severe enough to be fulfilled; then they must balance that assessment against their loyalty - whether to their employer, colleagues, or the workplace. They may ask themselves, "Should I overlook this incident? Is it worth the effort? What will it cost my colleagues who had no role in it?" Internal whistleblowing will therefore often be an easier choice to make than external claims of wrongdoing (Lewis \& Vandekerckhove, 2012, pp. 253-264). What kind of protection will the employee have (Tsahuridu \& Vandekerckhove, 2008, pp. 108-118)? What are the risks? What are the consequences of different actions for the whistleblower (Callahan \& Dworkin, 1992, p. 273)? This also includes the action of not blowing the whistle. What responsibility will I have for the wrongdoing? What about my conscience? Will it be possible to continue as a part of the leadership team after I've blown the whistle? Is it possible to minimize such uncertainties? All of these questions were central to PJS's decision-making.

The PJS story is an example of internal whistleblowing and retaliation, and this story will focus on the enforcement of the legislation.

Mind that Norway's legislation, rather than referring to "the workplace," often uses the more general term "the undertaking." (See further in WEA, $\mathbb{2}$ A-1.) That's significant, because it means that the rules cover more than the immediate workplace (Gimmingsrud, 2017, p. 808). If a person works in, say, the local government administration, the undertaking will be the township (EMD Langner v. Germany application no. 14464/11; see also Eggen, 2004, pp. 2-24). The consequence of this is that a whistleblower enjoys protection not only with respect to incidents at his own workplace, but also at the whole undertaking. If, for example, you work in some department at a huge hospital and become aware of the theft of medicine in another department of that same hospital, you will still have the whistleblower's legal protection. You do not have to stay in your lane when reporting wrongdoing.

Although the legislation gives the employee protection, several Norwegian investigations show that many employees choose not to blow 
the whistle after observing censurable conditions. Possibly it's because of their aversion to conflict, or maybe it's out of their respect for loyalty. Though legislation typically aims to provide very specific rules to protect them, they still may be running a risk if they speak out (Dworkin, 2006, p. 1757). That fear is genuine, say Trygstad and Ødegård (2016, p. 55). Their report reveals that employees are afraid of retaliation, great unpleasantness toward themselves, great personal strain, and even "destroying my career" (Trygstad \& Ødegård, 2016, p. 37). The same investigations show, alarmingly, that increasing numbers of employees have been subject to retaliation. For example, from 2006 to 2016, retaliation has more than doubled, from $12 \%$ to $25 \%$. What explains this? Trygstad and Ødegård's investigation documents the increasing numbers of whistleblowers who got negative reactions when whistleblowing, and the falling numbers who got positive reactions. Norwegian working life is clearly changing in a negative way for whistleblowing, and there are reasons to be worried about that development. You would think that given the additional focus on protecting whistleblowers, retaliation would decrease, but, sadly, the opposite has happened, despite Norway's giving employees' better legal protection than several other countries (Skivenes \& Trygstad, 2017, p. 136). On the other hand, we don't know enough yet to state that this protection makes it easier to blow the whistle in Norway. We need comparative studies of "wrongdoing and whistleblowing, especially comparative studies conducted under different labor market models" (Skivenes \& Trygstad, 2014, p. 113).

Two factors that may play into these trends, according to Dahle-Olsen (2015), are globalization and increasing competition among companies over borders.

\section{Conditions for Protection}

While we've established that Norway's whistleblowers will have protection, we haven't yet spelled out which conditions must be fulfilled to give them this protection. The Norwegian legislation expressly addresses this in WEA, $\mathbb{2}$ A-1. First, the whistleblower can blow the whistle only about "censurable conditions." These include "punishable actions, other illegal actions that are not punishable and unethical and damaging activity" (Ot. prp. nr. 49, 2004-2005, pp. 132 and 305).

Take the case of a division economist who was dismissed because of alleged curtailed operations-or so his employer argued. The employee responded that his dismissal was not objectively justified and that the real reason for the dismissal was outside consideration. The court's finding? The dismissal wasn't reasonably justified. The court decided that there were indeed outside considerations. The employee had first notified the group about irregularities in prices in an agreement with the ministry of defense. The court found that the dismissal was retaliatory. After the 


\section{Anne Oline Haugen}

dismissal, the whistleblower notified the media, and his dismissal was voided. In addition, he was awarded 1.5 million Norwegian kroner in compensation (TOSLO-2004-99016).

Harassment and discrimination are also censurable conditions. So are actions that conflict with a business's ethical routines (Auglend \& Jakhelln, 2017, pp. 183-291). But it can sometimes be difficult to decide whether the conditions are actually "censurable," both because the employee may not have known all of the relevant facts, and also because it's difficult to anticipate just how the court will consider those facts. In one Norwegian court case, an employee blew the whistle about the lack of his company's security routines, which had consequences for customers' privacy (Rt. 2003-1614). The court held that the consequences for the private parties were correctly described. But it also held that an email sent to all the company's employees alleging fraud by the company's leaders was enough to justify the employee's dismissal. The moral? You can rightly identify a problem, but if you then give it an inflammatory label and assign blame, you lose your protection.

The second condition is that the employee must carefully follow the appropriate procedure (LB- 2009-70215 and comments by Sønsteli \& Stueland, 2015, p. 121). In one case, a professor found a mistake in an examination's results. He made a note of this and gave it to a student, who then forwarded it. According to the court, the professor acted inappropriately. He should have simply informed the management or the board. But a case with an opposite result was the one (LB, 2009-36995) in which the court found that the employee did follow appropriate procedures. The court concluded that an NDT technician- "NDT" is short for "non-destructive testing" - had exposed a number of highly criticized and illegal conditions at the company's branch office in Oslo, all of them involving violations of the Radiation Protection Regulations. The court found that several of the proven conditions were very serious because in working with radioactive material, one can run the risk of major health damage. The employee's warning had indeed been sound, as was his handling of it. He had first notified the head of the department at the Oslo office, then the CEO, and finally the Norwegian Labor Inspection Authority. For this, he had several times been subjected to illegal retaliation from the head of the department in Oslo. He was thus awarded compensation.

It's important to understand that "appropriate procedure" is not meant to limit the right to blow the whistle. The demand of appropriate procedure is based on, or is a prolonging of, the principle of employees' loyalty toward their employer (Ot. prp. nr. 84, 2005-2006, p. 51). The employer's right to rule is mirrored by the employee's duty to be loyal and to obey the employer's instructions. There are, of course, several limitations in the legislations addressing this principle, and one of them concerns the rules of whistleblowing. 
The legislation about whistleblowing states that an employee is free to speak, and any limitations to that right must be argued for (WEA, $\mathbb{S}$ $2 \mathrm{~A}-1)$. An example of the need to constrain speech is the demand that an employee act responsibly, which is to say loyally, and that is a limitation in freedom of speech. After all, in PJS's case, disloyalty was the CEO's first charge. What might irresponsibility look like? I mentioned earlier the court decision about the professor who handed out a note to a student criticizing the censorship. The court found that his involving the student was irresponsible. There were several other ways he could have handled it - for example, by delivering it directly to the board. An important point is whether the interests of the employer are unnecessarily damaged (Ot. prp. nr. 84, 2005-2006, p. 51). Could the whistleblower have handled the situation in any other way-say, by blowing the whistle internally-to avoid destroying the reputation of the institution and at the same time solving the problem? In short, having the same aim, but with less damage? If the employee makes comments on Twitter and other social media about his leader and his negative qualities-for example, that he is afraid of making decisions, or that he lacks the necessary qualifications-it may damage the employer's interests and even the company's interests.

To follow the appropriate procedure, a whistleblower should also blow the whistle internally (WEA, $2005 \$ 2 \mathrm{~A}-1$ ). The legislation states that an employee has the right to notify in accordance with the undertaking's routines for whistleblowing, and to notify supervisory authorities or other public authorities. Such notification would be appropriate, and the whistleblower is then entitled to protection.

\section{The Difficulty of Following Procedures}

Following organizational procedures made by the undertaking will therefore always be seen as appropriate. This sounds as if it is not complicated, but it may be. First, it's a challenge to frame organizational procedures that are clear, straightforward, and consistent with the corresponding legislation. A Norwegian public administrative body once drafted guidelines for whistleblowing that ran 47 pages! Luckily, the document was not confirmed, and they had to rewrite it. If, as an employee, you have to read and understand 47 pages before you dare to blow the whistle, you probably won't bother. How sad, because the guidelines are meant to help ensure that whistleblowing happens, and that it happens correctly. Second, the procedures, if stricter than the legislation, are of course not legal. For example, they may demand that you do your whistleblowing in writing. After the Norwegian legislation was enacted, that is not necessary. On the other hand, the whistleblower may want to put his or her complaints in writing, just to have proof that they blew the whistle. But that is another story. The rights of the 


\section{Anne Oline Haugen}

employee must not be minimized in the procedures. These procedures must also be well publicized in the organization, and readily available. The rules concerning retaliation are also important here, for evidence rules can have a "significant effect on how rights can be asserted" (Fasterling, 2014, pp. 331-349). Importantly, the employer bears the burden of proof that notification has been made "in breach of this provision" (WEA, $\mathbb{2}$ A-1, number 3).

When our story took place, did PJS's workplace have such procedures? I checked with PJS while writing this chapter, and he says that as far as he recalls, they had none, and that procedures were added shortly after the whistleblowing incident took place. I have gone through their reports and found none myself. Of course, I can't know for sure. On the other hand, if they did have such procedures and the procedures weren't freely available to the employees, how could the employees be expected to follow them? How could they know what the "appropriate procedure" was? In 2007, the government published guidelines spelling out how governmental companies should make local procedures for whistleblowing. That year, 2007, was the same year that PJS blew the whistle. Although the undertaking did not have the same clear obligations as the legislation demands today, the workplace did have this obligation if the circumstances in the undertaking implied it, and it probably did (WEA $\$ 3-6$ ) - but again only from 2007. Why Norsk Tipping (NT) didn't develop these routines, one can only speculate. Since 2017 the legislation states that every workplace with more than five employees has to have routines, and those routines must be easily available for all its employees (Prop. 72 L, 2016-2017). This has several implications. The lack of routines made it more difficult for PJS to blow the whistle the right way. On the other hand, he could not be criticized for not following the routines.

As stated earlier, it will nearly always be correct to blow the whistle internally. But what about external whistleblowing? External whistleblowing covers whistleblowing to the media, blogging, websites, and other communications channels with several receivers. It also includes emailing the information to several receivers outside the company (Jakhelln \& Løne, 2017, p. 131). In which situations can this be responsible behavior or appropriate procedure? Well, it can be connected to various issues-accidents, the environment, and safety for employees and other groups, such as patients (Dege, 2009, p. 855). The main rule, according to the preliminary work, is that the employee must blow the whistle internally first before going public with it (Jakhelln \& Løne, 2017, p. 131). But is this an absolute demand according to the law? What if there are no supervisory authorities? What if management on all levels is involved in the censurable conditions, and these conditions can endanger people's health? What if big sums of money are involved? In such situations, contacting the media is justified (Devine, 2017, pp. 59-76). For financial incentives for whistleblowers against corporate fraud, see Faunce, Crow, Nikolic, \& Morgan Jr, 2014, pp. 381-401. What about anonymous contact with the 
media (TOSLO-2004-99016 Siemens Business Services)? What will happen if the media contact the whistleblower? Will there be the same restrictions on the whistleblower's freedom of speech as if he himself contacts them? The preliminary works state that if the whistleblowing concerns censurable conditions, and if internal whistleblowing has already been tried, and if the whistleblowing meets the standard of common interest, external whistleblowing is justified (Jakhelln \& Løne, 2017, p. 131).

\section{What Are Employees Protected From?}

Exactly what protection will whistleblowers be accorded (Tsahuridu \& Vandekerckhove, 2008, pp. 108-118)? What are their risks? What are the consequences of different actions by them (Callahan \& Dworkin, 1992, p. 273)? Is it possible to minimize these uncertainties for them?

The legislation states that any unfavorable treatment that occurs as a consequence of, or a reaction to, whistleblowing shall be counted as retaliation (Ot. prp. nr. 49, 2004-2005, p. 306). Examples include harassment, change of workplace, and reduced salary. In PJS's case, it was the pressure on him to get him to resign. Expressions such as "your mission is complete" and "new blood is needed" are unequivocal.

As mentioned, it's important to remember that the employee enjoys general protection against retaliation thanks to WEA, $\mathbb{} 2 \mathrm{~A}-2$.

\section{Our Story}

We have looked into the legislation governing PJS's situation, including the conditions that must be met to ensure whistleblower protection, such as censurable conditions and following the appropriate procedures.

But here's an important point: employees themselves will not necessarily ask, as a lawyer surely would, "Are these censurable conditions?" True, they might wonder if certain actions qualify as wrongdoings, but not necessarily in the same terms as the legislation. However, after a short while, PJS noticed several worrisome incidents at NT. The number of these incidents grew rapidly. In time, he felt certain that they counted as censurable conditions.

The employee may, as in our story, wonder if he is part of something that is "unhealthy, and that, if it became public, would be a disaster." Later on, the employee may wonder if he should blow the whistle. The whole picture of protection becomes important at such moments of bewilderment. In our story, the whistleblower mentions examples such as questionable contracts, extravagant spending, trips with suppliers, and different kinds of questionable sponsoring. Neither the company nor the chairman of the board contradicted the content of PJS's claims or argued that these were not censurable conditions. With this background, it would be natural for the whistleblower to conclude that the conditions of censurable conditions were fulfilled. PJS had several conversations with the CEO and the 
executive group about his concerns. That may not have counted as whistleblowing per se, but perhaps as more just an attempt to clarify what was going on. The board's chairman, who supervised the CEO, was informed by PJS about the incidents mentioned earlier; he was also given PJS's documentation. This act must be viewed as whistleblowing. According to PJS, when he met with the chairman of the board, he handed over documentation of approximately $\$ 10,000$ USD spent on the CEO's property. The investigation stimulated by PJS's whistleblowing showed that amount to be approximately $\$ 77,000$ USD (2007 currency value). PJS's interactions with the board must also be considered internal whistleblowing.

As mentioned, an employee is entitled to blow the whistle about censurable conditions as long as he or she proceeds responsibly and follows the appropriate procedures. The legislation states that whistleblowing, when it respects the company's own routines, will always count as acting responsibly. But according to PJS, the company didn't have its own routines for whistleblowing. The preliminary work of the legislation also states that internal whistleblowing is nearly always responsible. PJS had met with the CEO, the executive group, and the board's chairman. These contacts would all count as internal whistleblowing. But did PJS damage the working environment? Apparently not. PJS was acting as responsibly as the legislation stipulates. When these conditions are fulfilled, as here, retaliation is forbidden.

What happened to PJS after he blew the whistle? Was he exposed to retaliation? He relates several incidents. The most interesting of them, from a legal point of view, concerns the correspondence between PJS's lawyer and PJS's workplace. PJS's lawyer references statements from the management such as "Your time is over, it is time for new blood, we will redesign your role, remove you from leadership." True, this is not an outright dismissal in action, but it surely can be viewed as pressure on PJS to resign. Any pressure to resign would clearly constitute retaliation. It's also important to remember that at this point, PJS had been under severe pressure for a long, long time. As mentioned earlier, it's not enough to be persistent; you also have to be very persistent. In reality, PJS deserved the protection guaranteed by the legislation. One problem here, though, is how it's enforced. How, in other words, to make the protection actually function? Significantly, PJS was encouraged by his legal support simply to take the deal to leave- a conservative response, and maybe a sensible one, too. Even with protection in the legislation, a process in court could well prove too costly to him.

\section{Conclusion}

PJS blew the whistle properly, just as the legislation requires, and that guaranteed him protection against retaliation. The conversations with the new chairman of the board and the interim CEO gave PJS full support. 
But then what happened? Eventually PJS experienced retaliation. The Norwegian legislation is unambiguous: retaliation is forbidden. $\mathrm{Ah}$, but to prove retaliation, you have to go to court. PJS declined to do that, partly because of the legal advice he got. It was impossible for his lawyers, or him, to divine what the final outcome of going to court would be. He might in fact lose the case. As a whistleblower, he had been under enormous pressure. For him to then take his case to court and face an uncertain outcome was a major decision to make-the grinding pressure would simply continue, perhaps for months, perhaps even for years. This shows how, as a whistleblower, you are the driving character in your own story. You are in fact a lonely traveler. Whistleblowing is almost always done alone, rather than in a group. Yes, the system offers support, but no guarantees of justice. You bear the burden of fate on your own shoulders.

\section{References}

Auglend, R., \& Jakhelln, H. (2017). Varslingsrett, rapporteringsplikt og taushetsplikt. Lov og Rett, 2017, 183-291.

Boe, E. M. (2009). Nye toner om offentlig ansattes ytringsfrihet og varslerrett. In H. Aune, O. K. Fauchald, K. Lilleholt, \& D. Michalsen (Eds.), Arbeid og rett. Festskrift til Henning Jakhellns 70-årsdag. Oslo: Cappelen Damm Akademisk.

Brown, A. J., \& Dworkin, T. M. (2013). The money or the media? Lessons from contrasting developments in US and Australian whistleblowing laws. Seattle Journal for Social Science, 2013, 652-713.

Bruner, J. (2002). Making stories Law, Literature, Life. London: Harvard University Press.

Callahan, E. S., \& Dworkin, T. M. (1992). Do good and get rich: Financial incentives for whistleblowing and the False Claims Act. Vill. L. Rev. 37, 273. Retrieved from http://digitalcommons.law.villanova.edu/vlr/vol37/iss2/2.

Dahle-Olsen, H. (2015). Norsk arbeidsliv i turbulente tider. Oslo: Gyldendal Akademiske.

Dege, J. T. (2009). Den individuell arbeidsrett. Oslo: Minerva AS.

Devine, T. (2017). Whistleblowing in the United States of America: "Irrefragable proof" and the next generation of U.S. Government whistleblower rights. In C. R. Apaza \& Y. Chang (Eds.), Whistleblowing in the world (pp. 59-76). New York: Springer.

Dworkin, T. M. (2006). SOX and whistleblowing. Mich. L. Rev., 105, 1757.

Eckhoff, T., \& Smith, E. (2018). Forvaltningsrett. Oslo: Universitetsforlaget.

Eggen, K. (2004). Ansattes ytringsfrihet. Rettslige bånd eller gyldne lenker? Arbeidsrett, 2004(nr. 1), 2-24.

Eriksen, B. (2014). Varsling om korrupsjon. In B. Eriksen (Ed.), Å bekjempe et samfunnsonde Om korrupsjon, varsling, granskning og organisasjonskultur. Oslo: Gyldendal arbeidsliv.

Evju,S. (2010). Arbeidsrett Utvalgte artikler (2001-2010). Oslo: Universitetsforlaget.

Fasterling, B. (2014). Whistleblower protection: A comparative law perspective. In A. J. Brown, D. Lewis, R. Moberley, \& W. Vandekerckhove (Eds.), 
International handbook on whistleblowing research. Cheltenham, UK and Northampton, MA: Edward Elgar Publishing.

Faunce, T., Crowe, K., Nikolic, T., \& Morgan, F. M. M. Jr. (2014). Because they have evidence: Global financial incentives for corporate fraud whistleblowers. In A. J. Brown, D. Lewis, R. Moberley, \& W. Vandekerckhove (Eds.), International handbook on whistleblowing research. Cheltenham, UK and Northampton, MA: Edward Elgar Publishing.

Frank, J. (1931). Law and the modern mind. New Brunswick, NJ: Transaction Publishers.

Gimmingsrud, K. (2017). \14-2 Fortrinnsrett til ny ansettelse. In H. Aune, N. Kroken, \& C. Lenth (Eds.), Arbeidsrett.no-kommentarer til arbeidsmiliøloven. Oslo: Cappelen Damm.

Horn, K. (2010). Varsleren Viktig og Verdig 12 sterke varslerhistorier. Oslo: Kolofon. Jakhelln, H., \& Løne, Aa. C. (2017). \ 2-4 Varsling om kritikkverdige forhold i virksomheten. In H. Aune, N. Kroken, \& C. Lenth (Eds.), Arbeidsrett.nokommentarer til arbeidsmiljøloven. Oslo: Cappelen Damm.

Lewis, D., \& Trygstad, S. (2009). Protecting whistleblowers in Norway and UK: A case of mix and match? International Journal of Law and Management, 2009(51), 374-388. https://doi.org/10.1108/27542430911005918.

Lewis, D., \& Vandekerckhove, W. (2012). The content of whistleblowing procedures: A critical review of recent official guidelines. Journal of Business Ethics,108(2), 253-264. https://doi.org/10.1007/s10551-011-1089-1.

Lewis, D., Devine, T., \& Harpur, P. (2014). The key to protection: Civil and employment law remedies. In A. J. Brown, D. Lewis, R. Moberley, \& W. Vandekerckhove (Eds.), International handbook on whistleblowing research. Cheltenham, UK and Northampton, MA: Edward Elgar Publishing.

Mikkola, M. (2016). Collective labour rights as human rights. In B. H. Mulder, M. J. Hotvedt, M. Nesvik, \& L. Sundet (Eds.), T. Sui Generis Festskrift til Stein Evju. Oslo: Universitetsforlaget.

Moen, O. H. (2018). Forvaltningsskjønn og domstolskontroll. Oslo: Universitetet i Oslo.

Near, J. P., \& Miceli, M. P. (1985). Organizational dissidence: The case of whistleblowing. Journal of Business Ethics, 4(1), 1-16.

Near, J. P., \& Miceli, M. P. (2013). Implications of the voice literature for research. In R. J. Burke \& C. L. Cooper (Eds.), Voice and whistleblowing in organizations (p. 183). Cheltenham, UK and Northampton, MA: Edward Elgar Publishing.

Skivenes, M., \& Trygstad, S. (2010). When whistle-blowing works: The Norwegian case. Human Relations, 63(7), 1071-1097. https://doi.org/10.1177/00 1 872670353054.

Skivenes, M., \& Trygstad, S. (2014). Wrongdoing: Definitions, identification and categorizations. In A. J. Brown, D. Lewis, R. Moberley, \& W. Vandekerckhove (Eds.), International handbook on whistleblowing research. Cheltenham, UK and Northampton, MA: Edward Elgar Publishing.

Skivenes, M., \& Trygstad, S. (2017). Explaining whistle blowing processes in the Norwegian labour market: Between individual power resources and institutional arrangements. Economic and Industrial Democracy, 38(1), 119-143. https://doi.org/10.1177/0143831X14559783.

Sønsteli, J. A., \& Stueland, E. (2015). Arbeidsmiljøloven kommentarer og praksis. Oslo: Gyldendal Akademiske. 
Trygstad, S., \& Ødegård, A. M. (2016). Varsling og ytringsfribet i norsk arbeidsliv 2016:33. Oslo: Fafo.

Tsahuridu, E. E., \& Vandekerckhove, W. (2008). Organisational whistleblowing policies: Making employees responsible or liable? Journal of Business Ethics, 82, 107-118. https://doi.org/10.1007/s10551-007-9565-3.

Vaughn, R. G. (2014). The successes and failures of whistleblower laws. Cheltenham, UK and Northampton, MA: Edward Elgar Publishing.

Weltzien, K. V. (2017). En komparasjon mellom Sverige og Norge. Arbeidsrett, 14, 31-49. https://doi-org.ezproxy.inn.no/10.18261/issn.1504-3088-2017-01-02.

\section{International Conventions, Legislation, Preliminary Works, Court Decisions, and Collective Agreements}

\section{International Conventions}

The European Convention of Human Rights. Article 10. Retrieved from www. equalityhumanrights.com/en/human-rights-act/article-10-freedom-expression.

The United Nations International Covenant on Civil and Political Rights. Article 19. Retrieved from https://lovdata.no/dokument/NL/lov/1999-05-21-30/ KAPITTEL_spe\#KAPITTEL_spe.

\section{Legislation}

Ministry of Labour and Social Affairs. (2005). Act relating to working environment, working hours and employment protection, etc. (Working Environment Act, WEA). Oslo: Ministry of Labour and Social Affairs.

\section{Preliminary Works}

Arbeids- og inkluderingsdepartementet. (2005-2006). Ot.prp. nr. 84 Om lov om endringeriarbeidsmiljøloven(varsling).Oslo:Arbeids-oginkluderingsdepartementet.

Arbeids- og sosialdepartementet. (2004-2005). Ot.prp. nr. 49 Om lov om arbeidsmiljø, arbeidstid og stillingsvern (arbeidsmiljøloven). Oslo: Arbeids- og sosialdepartementet.

Arbeids- og sosialdepartementet. (2016-2017). Prop.72 L Om lov om endringer $i$ arbeidsmiljøloven (varsling og arbeidstid). Oslo: Arbeids- og sosialdepartementet. Justis- og politidepartementet. (1999). NOU nr. 27 "Ytringsfribet bør finde sted" Forslag til ny Grunnlov $\$ 100$. Oslo: Justis- og politidepartementet.

\section{Court Decisions}

EMD Langner v. Germany application no. 14464/11.

LB-2009-36995. Retrieved from https://lovdata.no/pro/\#document/LBSIV/avgjorelse/ lb-2009-36995 ? searchResultContext=2816\&rowNumber=1\&totalHits=10.

LB-2009-70215. Retrieved from https://lovdata.no/pro/\#result\&id=2868\&q $=$ LB-2009-70215,\%20LB-2009-70215 - *.

Rt-2003-1614. Retrieved from https://lovdata.no/pro/\#document/HRSIV/avgjorelse/ hr-2003-88-a? searchResultContext=2908\&rowNumber=1\&totalHits=44. 


\section{Anne Oline Haugen}

TOSLO-2004-99016. Retrieved from https://lovdata.no/pro/\#document/TRSIV/ avgjorelse/toslo-2004-99016 ? searchResultContext $=2657 \&$ rowNumber $=1 \& \mathrm{t}$ otalHits=10.

\section{Collective Agreements}

Collective agreement between the union of communities and the labor organizations. Retrieved from www.ks.no/globalassets/fagomrader/lonn-og-tariff/ hovedtariffavtalen-1.5.2018-30.4.2020.pdf. 


\title{
5 Whistleblowing, Identity \\ Construction, and Strategic Communication
}

\author{
Corey Bruno and Charles Conrad
}

In some ways, the story of Peer Jacob Svenkerud (PJS) is distinctive. Whistleblowers like him rarely come from the ranks of upper management, even less frequently maintain their anonymity for many months, and almost never are charged with managing their organization's image during the very crisis they initiated. Also, relatively few employees who find organizational practices to be unethical voice their concerns to supervisors or other overseers, such as ombudspersons or human resources specialists. Fewer still continue to dissent after management either rejects their appeals or accepts their concerns and makes changes. Only a tiny proportion "go public" with their concerns, and almost none continue their quests to the bitter end.

But in many other ways PJS's story is typical-in, for example, the motivations, effects, and outcomes of principled dissent in large, bureaucratic organizations, as well as the processes of image/identity management that usually are employed when charges of illegal or unethical organizational behavior reach the public policy or media agendas. What it provides us is a detailed case study of how a dissenter grapples with the often contradictory actions of the key players, including his own (see Weick Chapter 6).

In this chapter, we examine PJS's story through the perspective provided by "strategic communication," broadly defined as the purposeful use of symbols to achieve individual, organizational, and/or political goals. We suggest that social actors narratively construct, enact, and revise their individual identities (Gergen, 1994; Gergen \& Gergen, 1983), as they interpret and strategically manage organizational and communicative situations, which in turn influences their interpretations of those situations and their choice of communication strategies. Thus, self-knowledge and self-perception at a given point in time/space guides and constrains actors' symbolic action and their identity narratives (Giddens, 1991; Weick, Chapter 6).

\section{The Same Old Story}

Like many concepts in the human sciences, research on dissent/whistleblowing typically assumes actors are rational, at least boundedly so. An 


\section{2}

employee, usually someone highly committed to their organization, detects organizational practices that appear either illegal, unethical, or illegitimate (Hananel, 2002; Kassing, 2002, 2005; Miceli, Near, \& Dworkin, 2008). Although sometimes based on seemingly objective observations (e.g., questionable budget allocations), attaching the label/interpretation is a subjective and inter-subjective process. This explains why dissenters sometimes are the only ones upset about the practices and also stresses that communication between the potential dissenter and other employees is an important part of the initial decision to act.

Once dissenters decide that unethical actions are taking place, they search for signs that the organization is willing to take corrective action. If they conclude otherwise, they may become demoralized, experience declining morale and job satisfaction, emotionally (or even physically) withdraw from their jobs, and/or search for employment elsewhere. Alternatively, they may try to foster organizational change, usually by following the chain of command, although circumventing their immediate supervisor does occur (Kassing, 2007). Significantly, almost every observer of perceived wrongdoing who eventually reports it to an outside entity had reported it to at least one person inside their organization (Martin, 2008; Miceli, Near, \& Dworkin, 2008; Near, Rheg, van Scotter, \& Miceli, 2004). They balance concerns about both their risks (to their position, careers, and image) and the likelihood of success mixed with retaliation (Dozier \& Miceli, 1985; Miceli, Near, \& Dworkin, 2008) against their ethical codes, particularly regarding harm to innocent third parties, broad issues of human rights, and/or the defined purpose of the institution. It is the third concern that PJS most often reported as his primary motivation. Of course, dissenters sometimes are simply naïve-they believed by dissenting that they were just doing their jobs, pointing out that rules had not been followed, or filing a grievance using standard procedures. And sometimes they are motivated by narrow selfinterest or malice or envy (Martin, 2008). But the decision to dissent is complex-multiple "additional variables affect the cost-benefit analysis of blowing the whistle, including the whistleblower's attributions about why the wrongdoer acted and the wrongdoer's attempt to influence the whistleblower through impression management" (Miceli, Near, \& Dworkin, 2008, p. 91). In addition, the existence of co-workers who legitimize the potential dissenter's allegations and support their intention to dissent increase the likelihood of their acting, continuing in the face of resistance, and escalating the strategies used. If the employee does decide to act, he or she will likely opt for factual appeals combined with proposed concrete solutions. In many cases, perhaps half, dissenters actually can influence organizational practices, especially if they have supervisory rank/responsibilities, are perceived as being generally happy in their job, and have amicable relationships with their supervisors and upper management (Near et al., 2004). 
There are, however, many reasons for leaders to refuse to change their practices. Some are concrete or material. For example, the desired change may be seen as threatening a key income generator for the organization or one of its core functions. Or it may threaten the rewards and power of the administrative elite. Or it may put at risk key relationships with people in the organization's environment (Perry, 1992; Miceli \& Near, 2002). Similarly, leaders, and especially boards of directors, often have close network ties to one another, and a threat to one is viewed as a threat to all, as well as to the organization itself (Kuhrana, 2002).

Other reasons may be cultural. If the local culture would define an unethical behavior as "serious," either in itself or in its effects, dissent is more likely, both because dissenters find allies among other employees and because dissent is viewed as normal. Ironically, seriousness of wrongdoing also increases the likelihood and intensity of resistance to the dissenter because it threatens the identities, status, and livelihood of both managers and the dissenters' co-workers (Staw, Sundelands, \& Dutton, 1981). If the behavior is frequent (but not enough to be "normal"), the link between the behavior and undesirable effects is clear; and if the victims of the activity are obvious and viewed as innocent or powerless, dissent is more likely (Misangyi, Weaver, \& Elms, 2008). Conversely, dissent is less likely when the victims are a large and amorphous group, such as taxpayers or "society." That's often the case in instances of theft, waste, inadequate safety, or anti-discrimination practices, or where victims have been dehumanized through existing rhetoric, as with some civilians during wartime (Kelman \& Hamilton, 1989).

At the level of organizational cultures, even in the 21st century, it's now normal for organizations to be undemocratic or even anti-democratic enterprises (Cheney \& Lair, 2008; Jackall, 2010). As Charles Redding observed long ago, the attitude of leaders often is that "we don't particularly need boat-rockers" (1985, p. 245; see also Sprague \& Rudd, 1988). When the questioned policies or actions are deeply embedded in an organization's history, or "loyalty" is a core organizational value, dissent is particularly upsetting. As a result, firms that engage in illegal behavior are likely to repeat it (Baucus \& Baucus, 1997), especially if they are in industries or sectors of the economy, like defense procurement, where such behavior has been normalized. Wrongdoing becomes entrenched in patterns of acting, embedded in organizational memory, normalized through socialization of newcomers, and hidden in organizational structures (including reward systems) and routine operations so that members engage in it "mindlessly" or rationalize it through rhetoric that has been legitimized within their organizations (Ashforth \& Anand, 2003; Anand, Ashforth, \& Joshi, 2004; Gino \& Bazerman, 2007). In so-called strong culture organizations, members who are highly satisfied with their jobs and rewards may view the dissenter as a threat to both of those things, and members who strongly identify with the organization 
may view dissent as a threat to their very identity (Fairhurst $\&$ Zoller, 2008). For example, Enron's excesses-massive spending on perks for upper management and bacchanalia for the less entitled—enacted much of the identity of the firm, and the rituals differentiated it from its previous, staid identity (Bryce, 2002).

Once dissenters conclude that internal appeals won't bring desired changes, they must decide if and how to take the issue public. Faced with a vague or ambivalent response, or outright rejection, the mix of self-oriented, ethical concerns and a desire to protect or defend her or his organization begins to shift. Individual ethical concerns become more salient (Kassing \& Armstrong, 2002; Kassing, 2011), and they focus more on getting desired changes made and less on possible retaliation (Miceli, Near, \& Dworkin, 2008). If those concerns are openly supported by their peers, informal retaliation is less likely. But formal retaliation is still likely unless they are supported by upper management (Conrad \& Poole, 2010). If dissenters become whistleblowers who take their concerns outside the organization, the likelihood and intensity of both formal and informal retaliation increases, and co-worker support is either silenced or replaced with stigmatization (Hewlin \& Rosette, 2005; Lipman-Blumen, 2008).

Escalating cycles of dissent/intransigence and retaliation take over. Formal retaliation begins with verbal strategies of discursive closure (nullification and/or issue containment/minimization); escalates to verbal harassment, denial of resources necessary for the whistleblower to do his or her job (often combined with being subjected to repeated psychological evaluations or arbitrary/negative performance reviews); to job redefinition, demotion, pressure to resign and dismissal (when legal barriers to do so are minimal). Informal retaliation includes ostracizing, threatening, or intimidating. In sum, "external reporting leads to more retaliation and more retaliation leads to external reporting" (Miceli, Near, \& Dworkin, 2008, p. 114; see also Ashforth \& Mael, 1998). Even in industries covered by presumably strong "whistleblower protection" laws-nuclear power plant safety, defense procurement, hospital careretaliation seems to be almost inevitable and "protection" is meaningless (Conrad \& Poole, 2010; see, e.g., Marsh, Aug 14, 2017). Because these costs are widely known, only some $10 \%$ of dissenters go public, and of those who do, many withdraw their complaints before corrective action is taken (McMillan, 1990).

Finally, the small proportion of whistleblowers who persist in pressing their claims often find that external review fails to effect change. The problem then is something called "regulatory capture." Regulatory bodies often are "captured" by the industries they regulate, more often through the actions of policy-makers who limit their power than through regulator failures (Baker, Conrad, Cudahy, \& Willyard, 2009; Graham, 1986). If a whistleblower manages to elevate a case of malfeasance to the public-policy agenda, friendly legislators have a wide range of strategies 
available to placate public pressure while making minimal and/or ineffectual changes (Cobb \& Ross, 1997). The usual whistleblowing story ends when management either refuses to make desired changes, makes only trivial changes, or silences dissent. The dissenter's often long story of sensemaking, cost/benefit analysis, strategy selection, and exhaustion ends with a whimper or a purge. PJS's experience uniquely works itself into the typical dissenter story, though his construction of his identity makes it distinct and thus theoretically interesting.

\section{PJS's Story as More of the Same}

In 2010, PJS entered what contemporary advocates of "corporate culture" strategies of organizing would have called a "strong culture organization," but it was a culture enjoying the distinctive advantages of a monopoly. Through its managerial elite and board of directors, NT was tightly connected, both internally and externally. Personal and financial ties linked its elite to suppliers and recipients of its legally mandated financing of nonprofit organizations. Similarly, it was linked closely to the political elite-during PJS's tenure, two new chairmen of the board were appointed, both former government officials, with ties to the two major political parties. The organization itself occupied a unique position at the boundaries among multiple political organizations. As the summary report of the parliamentary investigating committee clearly indicates, this structure provided the organization with exceptional autonomy because agencies that oversee its operations, including government auditors, have little or no enforcement powers, and those with power must rely on other agencies, or independent contractors, for information on the organization's operations. Compounding the situation is the dual mandate of the Gaming Commission, to support the gaming industry and regulate it. Like the U.S. Atomic Energy Commission before the Three Mile Island incident, and the now-defunct Minerals Management Service regulating offshore drilling during the Deepwater Horizon accident, this dual mandate inhibits oversight and facilitates regulatory capture. As a result, while potential whistleblowers can appeal to public opinion, legal and political appeals are unlikely to change organizational practices or culture.

Indeed, in many ways the report of the Standing Committee on Scrutiny on Constitutional Affairs was laughable. The committee repeatedly commented that NT's "particular situation" relies almost completely on the integrity and ethical commitments of its management, but just as frequently demonstrated that there was little or no direct oversight of its actions, and that there was a serious lack of transparency in the operations of the agencies involved in that oversight. For example, the Auditor General's Report of June 2009, which took place only because of the actions of a whistleblower, included "especially severe criticism" of the company's operations, but those results were not communicated to 
any of the agencies that might have provided oversight, or to Parliament (Auditor General Report p. 2). In addition, it notes that the Ministry of Cultural Affairs has "several instruments available for government of NT" but offers multiple comments that suggest "regulatory capture"-an extensive pattern of "informal" interactions "between the administration and civil servants at the ministry," and between the company and its subsidiaries, patterns that were condemned by the auditor general, and that the committee concluded undermined the transparency that it repeatedly notes is essential for a government organization, particularly one with a lucrative monopoly position. Yet, the committee accepted the Ministry of Culture's promises to "do better" in the future and provided the ministry with excuses for past failures, stating that it "is not natural for the Ministry to take charge of any details of ongoing business operations (Auditor General Report p. 3). In the end, it recommended-but did not mandate- that the ministry enhance its oversight of the organization's "relations with its contractors"; provide guidelines for doing so; actually begin to keep formal, written records of interactions between the organization's management and the ministry, contractors, and the auditor general; and consider use of an independent (external) auditor (Auditor General Report p. 4), all of which are standard operating procedures in developed democracies. Moreover, "the Committee is satisfied that the board of directors at NT has initiated an independent investigation of the two matters that were not discussed in Auditor General Report, p. 14 (2008-2009) [those not involving landscaping]." No enhancement of the enforcement powers of various regulatory groups, or of their level of transparency, either with one another or with Parliament, were proposed. In short, the committee failed to take any steps that might prevent a recurrence of the problems identified in their hearings.

Like many new hires, PJS excitedly swallowed NT's rhetoric. The firm boasted a charismatic CEO; an avowed commitment to corporate social responsibility, both directly in its mission to stop gambling addiction and indirectly in its largess to sports-related non-profit organizations; a strong brand identity; and widespread popular support. Added to all these appeals was the promise of "a joyous time with problems that easily could be solved."

But as PJS encountered outsiders questioning the organization's operations and ethics, and heard murmurs of disenchantment among workers, the bloom quickly left the rose. He faced the dissenter's dilemmasacrifice one's personal moral code or speak out, ever more pointedly, which would threaten his position and, in a tightly interconnected industry, risk ending his career and reputation. All of this was complicated by his professional responsibility to publicly defend an organization that in some ways was indefensible:

What were my choices? My own moral and ethical questions were staring me in the face. Was this right? Did I pass the ethical tests 
that all companies and their employees should abide by and that had become my mantra in business? If all other options were exhausted, what choice was left but to blow the whistle? Alternatively, was I simply negotiating my personal ethics with those found in the dominant organizational culture over issues that would not commonly be recognized as corruption?

NT also seems to have developed a typical set of responses to internal dissent. As employees learned more and more unsettling information about budgets and contracts, informal discussions of ethical issues became increasingly common. Questioning by external sources increased as well. Management then stepped in to silence dissent, both externally and internally, just as PJS's friend, the corruption expert, had predicted. Some dissenters left the company, while others were threatened with demotion and/or transfer to less desirable positions and assignments. All of these examples were well known throughout the organization. Some, like PJS's primary confidante, found that the threats would be implemented. In PJS's case, and his communication through his lawyer to NT, he claims the evaluation systems were manipulated to legitimize predetermined negative conclusions. These response strategies-from labeling dissenters "traitors" (or "unfaithful servants," adding a religious overtone), to McCarthyite grilling of innocent workers so as to persuade them to turn on their colleagues, to giving PJS multiple ultimata once his identity was known, some cast in the form of "helpful career advice"-intensified after multiple resignations of upper-level executives and members of the board of directors. Thus, it seems clear that intolerance of dissent was deeply embedded in the organization's culture. It may be, as PJS points out, that "the CEO was very much an institution in the company," but it's also clear that his values and attitudes toward dissent had become institutionalized there.

Given such a closed, autocratic culture, it's not surprising that co-workers who had agreed with PJS's assessments of wrongdoing and potential damage to the organization's reputation and mission, and who had encouraged him to pursue remediation, largely disappeared once his identity was widely known. Once a whistle has been blown, colleagues are relieved of the dissonance that they feel from observing activities that violate their own ethical/moral codes (Burke \& Cooper, 2013), and once retribution begins, their own cost-benefit analyses shift markedly. For PJS, and for the organization, these shifts meant that important sources of hard evidence no longer were available to him. It proved a crucial change, because upper management and Deloitte's internal investigation dismissed all but one charge as lacking sufficient evidence (Deloitte report).

In sum, multiple elements of PJS's story come as no surprise; they provide yet another example of principled dissenters detecting organizational wrongdoing and taking exceptional personal, financial, career, and emotional risks in an effort to effect change. Most employees, in the 
same situation, would remain silent. Given the risks they face, doing so is the rational course of action. A very few do speak out, usually following the chain of command. Some, perhaps half of those very few, succeed in achieving a degree of organizational change, although it's often more symbolic than substantive. Those who fail must make a fateful decision about whether to take their message outside the organization. Most do not. But once someone else tells their stories, they're celebrated, or reviled, as "whistleblowers."

Ironically, the most celebrated dissenters in recent U.S. history-Sherron Watkins of Enron, Coleen Rowley of the F.B.I., and Cynthia Cooper of WorldCom-provide examples of all three outcomes. Cooper took her case over the head of her supervisors to the board of directors and made a case so compelling that the board took corrective action, including dismissing the upper management. Meanwhile, she experienced extensive harassment from her superiors and co-workers-and serious financial losses when her employer went bankrupt. Through it all, though, she took her case to no one outside of WorldCom. Rowley, on the other hand, took her concerns to F.B.I. Director Robert Mueller and eventually told her story to various congressional committees. She, too, faced extensive internal harassment and reprisals but retired from the F.B.I. some years later. As for Watkins, she sent a letter to Enron C.E.O. Kenneth Lay, but, like Rowley, did not "go public" until congressional hearings investigated what was, by then, old news. Of course, all three should be celebrated for their integrity, bravery, and tenacity. Still, they did not do what PJS did.

PJS's case forces us to examine a very different question: Why do a handful of dissenters continue their efforts to the "end of the line"? Sometimes the answer involves the malfeasance itself. Take Vera English, pioneer whistleblower in the 1980s, fired by General Electric for exposing the company's widespread radiation contamination, and whose response to her dismissal reached the U.S. Supreme Court (English $v$. General Electric). For her trouble, she lost her career, underwent years of excruciating emotional pain as government oversight agencies and federal courts delayed acting, discredited her, and dismissed her wellsupported complaints, and in the end found that it cost her more than ten times as much money as GE was fined for a pattern of practices that created what Charles Perrow has labeled high "net catastrophic potential" (1984). (For a summary of the case, see Conrad \& Poole, 2010, pp. 270-271.) At first her whistleblowing may have been influenced by the widespread presumption that the Three Mile Island accident had elevated safety to the top of the industry's concerns, and that it had among the strongest whistleblower protection laws in the country. But even after these presumptions were punctured, she persisted.

But PJS persisted because of ideals, not potential catastrophes. He believed that public organizations have a special responsibility to citizens 
to be open, honest, and efficient (maybe even frugal), that all organizations touting themselves as "socially responsible" should actually act that way, and that regulatory agencies have a responsibility to, well, regulate. The actions taken at NT did not threaten a Chernobyl-like disaster; indeed, not a single person would lose life or limb if the practices continued. Yet, he refused to back down. Why?

We think that PJS's story provides an excellent opportunity to explore that question, as it relates to most other whistleblowers as well. Yes, rational considerations are always relevant, but all of us are guided and constrained by complex processes of sensemaking, and that emotionality sometimes drives decision-making. The key process involves the construction of our individual identity in conjunction with our construction of the ethical situation.

\section{Narrativizing Identity and Whistleblower Storytelling}

Traditional research on individual identity, Kenneth and Mary Gergen argue, tends to be both "mechanistic" (treating its subject as a relatively stable internal attribute that is determined by external pressures) and "synchronic" (an individual's self-characterization at a given point in time; Gergen \& Gergen, 1983) See also Gergen, 1997). As a result, the processes through which a social actor's identity is formed and transformed and the impact that personal history has on those processes is lost. Humans' efforts to understand fragments of experience separated by time, or to develop coherent connections among life events, require a perspective that is reflexive and diachronic. Identities are created through symbolic interaction and, ironically, interaction encourages (or requires) one to articulate an account of oneself that is both stable and capable of change and adaptation; "one must be changing but maintain a stable character" (Gergen \& Gergen, 1983, p. 266). A given self-narrative can be maintained only if an individual is able to negotiate "successfully with others concerning the meaning of events in relationship with each other" (Gergen \& Gergen, 1983, p. 268, citing De Waele \& Harré, 1976). Conversely, sustaining an identity narrative is enabled by the active contribution of a supporting cast; self-construction is dialogic. Thus, selfnarrative is a strategic resource, "a linguistic implement constructed and reconstructed by people in relationships, and employed . . . to sustain, enhance, or impede various actions" (Gergen \& Gergen, 1983, p. 256; see also Gergen, 1994). Its use is guided and constrained by the structural configurations (Frye, 1957) and dominant myths (Campbell, 1991; Browning, Sørnes, \& Svenkeurd, Chapter 2) surrounding an interaction. In this sense, interactants appropriate "from a cultural repertoire of stories certain forms that become synthesized as personal stories" (Gergen, 1994, p. 20), particularly those that posit a positive outcome (enlightenment) for negative events (trials and tribulations). 
Ethicality is central to self-narratives because autobiographical accounts are moral tales. Indeed, "narrative requires an evaluative framework in which good or bad character helps to produce unfortunate or happy outcomes" (MacIntyre, 1981, p. 456). The details of personal narratives are selected based on the degree to which they "fit" the plot and characterization that are being constructed. They also are reflexive-the details that are included and the stories that are chosen as components of the narrative lead to revisions in the overall creation. Plot is the connective tissue (Frye, 1957) that links events and actions together via systems of meaning. It provides more than a chronicle of events; it establishes causal connections among them and deliberatively arranges them in ways that reveal their dramatic, thematic, and emotional significance. To answer questions such as "Am I improving," "Am I maintaining the high standards I once committed myself to," or "Am I growing as a person," the individual selects discrete events and/or images that occur over time, evaluates them, and links them together through an ethical self, and in turn revises his or her ethical self through the interpretive process.

The self-construction process-the ongoing interaction among situational guidelines and constraints, a hero's emerging identity, strategic choices, communication with others, and perceived impact on an organizationcan expand the resources available to a dissenter/whistleblower, reduce them, or transform them in ways that call for different strategic choices and relationships. For example, choosing to engage in open dissent within one's organization may activate supportive relationships or collaborative action with like-minded co-workers (see Fairhurst \& Zoller, 2008). At the same time, it may encourage others to initiate counter-discourse that functions to limit the dissenters' voices, exploit fissures or contradictions within their identities (e.g., labeling principled dissent as treachery or disloyalty), or push dissenters toward the exits (Ashforth \& Mael, 1998). On the other hand, successful dissent may encourage dissenters/ collaborators to define themselves as "radicals," reducing their credibility with other members of their organization and limiting their strategic options by defining compromise as a denial of their selves, or leading them to re-define their initial goals as too accommodating. Their new identities require "radical" action and deny them the option of accepting their success as adequate.

\section{PJS's Story as Self-Construction}

We and our fellow authors in this volume stepped into PJS's ongoing process of integrating his identity story with his experience at NT. By the time these chapters become available to other readers, he will presumably have revised his narrative many times and in many ways, large and small-through his communication with the editors both inside and outside of the interviews, with the authors both during and after their 
drafts became available to him, and with himself as he grapples with their disparate readings of his story. The process will even continue after the book is published, and beyond. Consequently, the analysis that we present in the remainder of this chapter focuses on only one moment in that ongoing process, on the narrative being constructed during his communication with us authors during the preparation and refining of the book proposal, both the interviews and his "introduction." We believe it is a story about whistleblowing, but it is more fundamental, more personal, more human than that. It is finally about his sense of belonging, of connection, and the paradoxical nature of solitude.

When PJS arrived at NT, he brought with him a version of the monomyth described by Svenkerud, Browning, and Sørnes (and borrowed from Joseph Campbell)- the notion that societies depend on their heroes for their stability, their excellence, and their ability to sustain their integrity from external and internal threats.

PJS's version of the monomyth included three subordinate myths. One has come to be called the "business case" for organizational ethics-the assumption that "doing good" in the long run helps organizations "do well," that businesses and their heroes can be both economic and social/ cultural heroes.

The second assumption is that both not-for-profit and governmental organizations have a nobler purpose than maximizing profits, namely, being good stewards of the resources that are made available to them, and serving the broader society, protecting its weaker members from exploitation, and so on. The resources they use and distribute are public goods, and the donors and taxpayers who provide them must rely on regulators and on the organization's management to protect their investments because they are too removed from the organization's operations to do so themselves. PJS, the parliamentary investigating committee, Deloitte, and virtually everyone else involved in the saga articulated this myth and did so repeatedly. In it, leaders become "heroes" through subordinating their own gains to those of other stakeholders.

A third, and related, subordinate myth is that the compensation afforded the leadership of those organizations should (and will) at least in part involve "donated labor" motivated by the leaders' commitment to the mission of the organization. As a result, their compensation will tend to be more limited than in comparably sized firms in the private sector (Frumkin \& Keating, 2001; Hallock, 2002).

Unfortunately, the available empirical evidence suggests that all three subordinate myths are unrealistic. First of all, there are many critiques of the business case for CSR (as well as the "business case" for other issues), all of which explain why the perspective rarely leads corporations to actually behave in social responsible ways, in part because they naively assume that market processes will enforce ethical standards (see, e.g., the chapters in May, Cheney, \& Roper, 2007). Second, research on 


\section{2}

"regulatory capture," mentioned earlier, suggests that external oversight often fails to generate, or even define, ethical organizational behavior. Even more so than in the for-profit sector, financial regulation of nonprofits is weak, and oversight is diffused across multiple levels of government and government agencies, which means that it is sometimes haphazard and often minimally constraining. Finally, while it is true that executive salaries in government agencies and non-profit organizations, especially religious organizations, are lower than in comparable for-profit firms, the gap in total compensation is much smaller, especially if psychological rewards are taken into account. For example, many government and nonprofit organizations somewhat compensate for lower incomes by providing extensive executive benefits, both financial (compensation and extensive expense accounts) and social (amenities such as flexible hours, more stable job prospects, and a slower pace of work), even if there is little or no link between these elements of executive compensation and organizational performance. The greater ambiguity of non-profit and government organizations' goals, combined with the greater difficulty in measuring concepts such as "progress to mission," limit boards' abilities to link executive performance and compensation. Instead, quantitative measures such as organizational size and cash flow are used to legitimize executive compensation, which in turn creates incentives for managers to focus more on these outcomes than on adhering to the organization's mission. Similarly, lower levels of direct competition in the government/ non-profit sectors reduce pressure to rein in compensation packages. In this subordinate myth, leaders are "heroic" if they sacrifice financial gain and associated trappings of wealth and status, and do so despite the absence of effective external controls. But, the available empirical evidence suggests that many of the practices that PJS found offensive are rather standard aspects of organizational functioning.

At first, NT seemed to offer PJS the capstone of his personal history. He would finally be living the ethical life that Mohammad Yunus has persuaded him was possible by becoming a driving force for the kind of organizational transformation(s) that Ev Rogers had studied. Earlier, "living the [CSR] dream" had proved insufficient for him, much as Yunus's Fulbright, Ph.D., and assistant professor position had not been for him. To enact his identity, the hero of PJS's own narrative required a leadership position through which he could have a sustained, significant impact. True, consulting and professoring both could be noble activities, but they were insufficient. NT, which had a recent history of ethical lapses and transformation, a strong organizational identity, and a popular image, offered him a position that would crown his narrative- "it promised to be a joyous time with problems that could be easily solved. I had found my place."

More precisely, PJS seems to have idealized NT as a special place that he could help move along even further toward his core values, 
despite its ambiguous history. Research on organizational socialization suggests that both before and immediately after entering a new organization, all of us try to construct a congruence between ourselves and our surrounding; this seems a common aspect of sensemaking (Louis, 1980; see also Weick). But PJS found no such congruence. By the end of his fifth year, his initial surprise at the contradiction between NT's purported commitments and its internal operations had morphed into a disappointed understanding of how the organization handled dissent. For example, a manager who had refused to cover up the CEO's private use of employees had been "educated" by the vice CEO and subsequently left the company; another "told me, 'I was told to shut up and cool down-and I would be put in another position if I continued.' A former executive told me [PJS] directly that he lost his leading position because he had asked too many questions." But, for PJS, neither exit nor compromise was consistent with the identity he was constructing. $\mathrm{He}$ eventually realized that he faced precisely the kind of constraining situation faced by dissenters in general: abandon his own values and opt for job security, or blow the whistle and experience retribution both by his firm and by his industry. His anguish was exacerbated by his realization that dissenting would destroy his ability to be an "internal change agent." It was further exacerbated by his being assigned to defend the organization against allegations, like his own, of wrongdoing. He found himself acting in ways that utterly contradicted his beliefs, values, and identity narrative. The pain that most potential dissenters/whistleblowers face-of impotently remaining silent when wrongs are being committed-was replaced by the even greater dissonance of actively articulating untruths and thereby helping perpetuate those wrongs (Chapter 1, Svenkerud, p. 9-10).

Secrecy had similar effects. Commonly used by leaders to silence dissent (Lipman-Blumen, 2008), secrecy took a different form in PJS's case by uniquely limiting his options and violating his identity as a change agent. It also accelerated the usual processes through which dissenters become progressively more isolated from their co-workers and potential supporters. In his idealism, PJS was doubtless naïve about the willingness of his sources and supporters to stand behind him if he went public with his claims, a faith that he maintained, at least for a while, even after they failed to act and/or abandoned him. Watching people who supported him and encouraged him to fight the battle sit silently by when he needed their help only exacerbated his feelings of abandonment. Retreating to the Norwegian War College provided temporary relief by inserting him into a pattern of interactions that reaffirmed his identity narrative. And retreating to the farm provided further solace. But neither provided him an opportunity to continue the process of constructing an integrated self. Because identities are developed and legitimized through interaction with others, both processes are destabilized by silence and solitude. 


\section{Conclusion}

Even two years after leaving NT, PJS observed that he still "felt unhappiness about where his life had taken him." But by the time he finished his introduction to this volume,

Something within me had changed. Not only had the constant tormented feeling of unrest gone away, but a different kind of balance had set in. With more certainty, it started to become clear to me that my self-confidence and ability to walk with my head held high in all kinds of situations had become easier. It almost felt that the question of finding out who I wanted to be had been answered. Slowly and surely, a new feeling of self-contentment started to emerge.

It may be that PJS's retreat to the farm severed his connections with the situation and people who had created his divided self. It may also be that his interactions with people who weren't part of NT allowed him to continue developing an integrated self-narrative. Or it may be even simpler: for a man whose identity was fundamentally tied to his professional life, his new position provided the space within which self-construction could continue. John Shotter has observed (1989, p. 146):

People not only have to have a life history, they are expected to be knowledgeable about it in some way, and that knowledge is expected to be influential in their actions. They have had (and are still susceptible to) traumas and triumphs, joys and regrets, delights and disasters, and what has happened to them in the past makes a difference to how they act now. They cannot just exist as ahistorical, atemporal beings.

But narrative theory suggests a more fundamental social explanation. Tragic heroes, Northrup Frye argued, are removed from society at the end of their stories-Oedipus is blinded; Lear, Hamlet, Othello, and Willy Loman die. In the "high mimetic" form of tragedy, the hero is superior to other characters and to the audience- "but what he or she does is subject both to social criticism and to the order of nature" (Frye, 1957). High mimetic plots involve disillusionment-a deep change of world view from positive to negative, powerful to impotent, and/or certain (morally and/or pragmatically) to lost and/or confused. The sagas of high mimetic heroes ask the audience to engage psychologically and emotionally, to identify with the hero's struggle, and to want her or him to succeed. In self-narratives, the narrator is himself part of that audience. As the chaos around him increased (see Browning, Sørnes, \& Svenkerud, Chapter 2), and PJS's identity was increasingly threatened, the intensity of his efforts to construct a new identity intensified. As his narrative construction continued, his need to tell his story increased and was increasingly frustrated. 
For example, his early-morning meeting with the new CEO initiated a series of interactions in which he expected to tell his story but was not allowed to do so. The interlude between jobs allowed him to resume the process, as did his interviews with the editors of this volume, plus his opportunity to write, revise, tell, and retell his story, together with the opportunities he will have to interact with the chapter authors, and eventually readers of the published volume. PJS's experience provides a rather straightforward answer to why some whistleblowers continue their battle long after it seems reasonable to do so-they must do so to confidently answer the question of "Who am I?"- and to be, finally, proud of the answer. Telling and retelling their story is the key process through which that revised identity is constructed.

\section{References}

Anand, V., Ashforth, B., \& Joshi, M. (2004). Business as usual. Academy of Management Executive, 18(2), 39-53.

Ashforth, B., \& Anand, V. (2003). The normalization of corruption in organizations. In R. Kramer \& B. Staw (Eds.), Research in organizational behavior (Vol. 25, pp. 1-52). Amsterdam: Elsevier.

Ashforth, B., \& Mael, E. (1998). The power of resistance. In R. Kramer \& M. Neale (Eds.), Power and influence in organizations (pp. 89-119). Thousand Oaks, CA: Sage.

Baker, J., Conrad, C., Cudahy, C., \& Willyard, J. (2009). The devil in disguise: Merck, the FDA, and the VIOXX recall. In R. Heath \& E. Toth (Eds.), Rhetorical and critical perspectives on public relations (2nd ed., pp. 172-194). Mahwah, NJ: Lawrence Erlbaum.

Baucus, M., \& Baucus, D. (1997). Paying the piper. Academy of Management Journal, 40, 129-151.

Bryce, R. (2002). Pipe dreams. New York: Public Affairs.

Burke, R., \& Cooper, C. (2013). Voice and whistleblowing in organizations. Cheltenham, UK and Northampton, MA: Edward Elgar Publishing.

Campbell, J. (1991). The power of myth. New York: Anchor.

Cheney, G., \& Lair, D. (2008). Elevating dissent and transcending fear-based cultures at war and work. In S. Banks (Ed.), Dissent and the failure of leadership (pp. 182-207). Cheltenham, UK and Northampton, MA: Edward Elgar Publishing.

Cobb, R., \& Ross, M. (1997). Cultural strategies of agenda denial. Lawrence, KS: KU Press.

Conrad, C., \& Poole, M. S. (2010). Strategic organizational communication in a global economy (7th ed.). New York: Wiley-Blackwell.

De Waele, J. P., \& Harré, R. (1976). The personality of individuals. In R. Harré (Ed.), Personality (pp. 187-206). Oxford: Blackwell.

Dozier, J. B., \& Miceli, M. P. (1985). Potential predictors of whistle-blowing: A prosocial behavior perspective. Academy of Management Review, 10, 823-836.

Fairhurst, G., \& Zoller, H. (2008). Resistance, dissent, and leadership. In S. Banks (Ed.), Dissent and the failure of leadership (pp. 135-148). Cheltenham, UK and Northampton, MA: Edward Elgar Publishing. 


\section{Corey Bruno and Charles Conrad}

Frumkin, P., \& Keating, E. (2001). The prices of doing good. Working Paper, Harvard (JFK School of Government).

Frye, N. (1957). Anatomy of criticism. Princeton, NJ: Princeton University Press. Gergen, K., \& Gergen, M. (1983). Narratives of the self. In T. Sarbin \& K. Scheibe (Eds.), Studies in social identity (pp. 254-273).

Gergen, M. (1994). The social construction of personal histories. In T. Sarbin \& J. Kitsuse (Eds.), Constructing the social (pp. 19-44). Thousand Oaks, CA: Sage.

Gergen, M. (1997). The place of the psyche in a constructed world. Theory and Psychology, 7, 723-746.

Giddens, A. (1991). Modernity and self-identity. Palo Alto, CA: Stanford University Press.

Gino, F., \& Bazerman, M. (2007). Slippery slopes and misconduct. Pittsburgh, PA: Carnegie Mellon Tepper School of Business, Harvard Business School.

Graham, J. (1986). Principled organizational dissent. In B. S. Taw \& L. Cummings (Eds.), Research in organizational behavior (Vol. 8, pp. 1-52). Greenwich, CT: JAI Press.

Hallock, K. F. (2002). Managerial pay and governance in American nonprofits. Retrieved July 15, 2018, from Cornell University, ILR School site: http://digital commons.ilr.cornell.edu/articles/200

Hananel, S. (2002). Whistle-blower report cites abuses. Washington Post, September 1. Retrieved from www.whistleblosers.org/html/Whistle-Blower\%20 Report\%20Cites\%20Abuses.htm.

Hewlin, P., \& Rosette, A. (2005, August). Stigma avoidance. Paper presented at the annual national meeting of the Academy of Management, Honolulu, Hawaii.

Jackall, R. (2010). Moral mazes. New York: Oxford University Press.

Kassing, J. (2002). Speaking up. Management Communication Quarterly, 16, 187-209.

Kassing, J. (2005). Speaking up competently. Communication Research Reports, 22, 227-234.

Kassing, J. (2007). Going around the boss. Management Communication Quarterly, 21, 55-74.

Kassing, J. (2011). Dissent in organizations. Cambridge: Polity Press.

Kassing, J., \& Armstrong, T. (2002). Someone's going to hear about this. Management Communication Quarterly, 16, 39-65.

Kelman, H., \& Hamilton, V. (1989). Crimes of obedience. New Haven, CT: Yale University Press.

Kuhrana, R. (2002). Searching for a corporate saviour. Princeton, NJ: Princeton University Press.

Lipman-Blumen, J. (2008). Dissent in the time of crisis. In S. Banks (Ed.). Dissent and the failure of leadership (pp. 37-52). Cheltenham, UK and Northampton, MA: Edward Elgar Publishing.

Louis, M. R. (1980). Surprise and sense-making in organizations. Administrative Science Quarterly, 25, 226-251.

MacIntyre, A. (1981). After virtue. Notre Dame, IN: Notre Dame University Press.

Marsh, A. (2017). Unprotected: How the feds failed two Wells Fargo whistleblowers. American Banker, August 14. Retrieved from www.americanbanker. com/news/unprotected-how-the-feds-failed-two-wells-fargo-whistleblowers 
Martin, B. (2008). Varieties of dissent. In S. Banks (Ed.), Dissent and the failure of leadership (pp. 22-36). Cheltenham, UK and Northampton, MA: Edward Elgar Publishing.

May, S., Cheney, G., \& Roper, J. (2007). The debate over corporate social responsibility. New York: Oxford University Press.

McMillan, J. (1990). Legal protection of whistleblowers. In S. Prosser, R. Wear, \& J. Nethercote (Eds.), Corruption and reform (pp. 28-48). St. Lucia, Australia: University of Queensland Press.

Miceli, M., \& Near, J. (2002). What makes whistle-blowers effective? Human Relations, 55, 455-479.

Miceli, M., Near, J., \& Dworkin, T. (2008). Whistle-blowing in organizations. New York: Taylor \& Francis.

Misangyi, V., Weaver, G., \& Elms, H. (2008). Ending Corruption. Academy of Management Review, 33, 750-770.

Near, J., Rheg, M., van Scotter, J., \& Miceli, J. P. (2004). Does type of wrongdoing affect the whistle-blowing process. Business Ethics Quarterly, 14, 219-242.

Perrow, C. (1984). Normal accidents. New York: Basic Books.

Perry, J. (1992). The consequences of speaking out. Paper presented at the Academy of Management, Las Vegas, August.

Redding, W. C. (1985). Rocking boars, blowing whistles, and teaching speech communication. Communication Education, 34, 245-258.

Shotter, J. (1989). Social accountability and the social construction of "you". In J. Shotter \& K. Gergen (Eds.), Texts of identity (pp. 133-151). London: Sage.

Sprague, J., \& Rudd, G. (1988). Boat-rocking in the high technology culture. American Behavioral Scientist, 32, 169-193.

Staw, B. M., Sundelands, L. E., \& Dutton, J. E. (1981). Threat-rigidity effects in organizational behavior. Administrative Science Quarterly, 26, 501-524. 


\section{Part III}

\section{How Does It Happen?}




\title{
6 Sensemaking and Whistleblowing
}

\author{
Karl E. Weick
}

We're all put to the test ... but it never comes in the form or at the point we would prefer, does it?

(David Mamet, source unknown)

The test of a first-rate intelligence is the ability to hold two opposed ideas in the mind at the same time, and still retain the ability to function. I've always disliked the unnecessary comma in the middle of this famous Fitzgerald dictum, suggestive as it is of an inability to hold two opposed ideas in the mind at the same time while still retaining etc.

(Shields, 2011, entry \#401)

These two insights, applied to this case of whistleblowing, foreshadow a story about sensemaking in the face of multiple unexpected tests. These tests are composed of opposed ideas that become increasingly difficult to manage. As these incompatible ideas evolve, they form "surfaces of apprehension" (Taylor \& Van Every, 2000, pp. 40-41), meaning that they add to understanding but also to wariness. Peer Jacob Svenkerud (PJS) apprehends more of what the organization is really like and grows more wary of future trouble and what to do about it. This disquieting apprehension steadily becomes more dominant in his sensemaking.

To flesh out a sensemaking interpretation of the Norsk Tipping (NT) case, I describe the concept of sensemaking, sensemaking in the service of whistleblowing, and the management of sensemaking in the context of whistleblowing.

\section{On Sensemaking}

Sensemaking is an explanatory process, built out of the cyclical entanglement of actions and interpretations, which tends to be accentuated by incompatible psychological implications, interruptions, and confusion. "Sensemaking privileges epistemological anxiety and it is for this reason that adherents endeavor to be plausible rather than accurate" 


\section{Karl E. Weick}

(Keenoy, 2008, pp. 467-468). Maitlis and Christianson (2014) describe sensemaking as "a process, prompted by violated expectations, that involves attending to and bracketing cues in the environment, creating intersubjective meaning through cycles of interpretation and action, and thereby enacting a more ordered environment from which further cues can be drawn" (p. 67).

The term sensemaking is not hyphenated because sense is literally made, created, and enacted when actions of bracketing and the extraction of cues shape what is sensed as a story, and what happens next. "Significance and valence do not pre-exist 'out there,' but are enacted, brought forth, and constituted by living beings" (Thompson, 2007, p. 158).

When expectations are disconfirmed and significance and valence are enacted, phenomena are carved out of raw experience and "conceptually fixed and labeled so that they can become the common currency for communicational exchanges" (Chia, 2000, p. 517). In more general terms, sensemaking occurs when an imbalance or incompatibility between the organism and the environment is triggered, and efforts are made to restore a balance and reduce tension. In John Dewey's words (2008), "Life is interruptions and recoveries.... At these moments of a shifting of activity, conscious feeling and thought arise and are accentuated" (p. 125). During these moments of accentuation, four important things happen. First, our experience gets sifted, and much of it gets lost. Second, we name the parts that remain. Third, we act in order to discover what the names mean. And fourth, we step back and inquire about our process and its products.

When thoughts and feelings are accentuated, data given to sense are sifted. We

transform the order in which experience comes into an entirely different order, that of the conceived world. ... The conceptual scheme is a sort of sieve in which we try to gather up the world's contents. Most facts and relations fall through its meshes, being either too subtle or insignificant to be fixed in any conception. But whenever a physical reality is caught and identified as the same with something already conceived, it remains on the sieve, and all the predicates and relations of the conception with which it is identified becomes its predicates and relations too; it is subjected to the sieve's network, in other words.

$$
\text { (James, 1981, p. 455) }
$$

But what if the reality that is caught is not the same as something already conceived? What if the conceptions that exclude the insignificant and the overly subtle, themselves turn out to be limited by norms, experience, and expectations? What if that which falls through the sieve as seemingly subtle and insignificant, now coheres into a pattern 
of significance and prominence that disconfirms the "sieve's network"? Now two questions dominate: "what's the story here?" and "what should we do?" (Weick et al., 2005, p. 410).

Sensemaking involves turning circumstances into a situation that is comprehended explicitly in words and that serves as a springboard for action (Taylor \& Van Every, 2000, p. 40). Circumstances are the flowing stream. A situation is what is caught on the mesh of a sieve. And the predicates and relations are the words, categories, and descriptions that serve as a springboard to action. We are able to make sense when we seem to capture continuous experience in discontinuous concepts, when actions and comments fit into a finite number of types, and when experiences are edited in the interest of collaboration.

Sensemaking can be seen as both episodic and continuous. It appears to be episodic in the sense that it increases when there is a breach and recedes once a breach is restored. "[S]ensemaking is confined to specific episodes (in which some organizational activities are interrupted until they are satisfactorily restored)" (Sandberg \& Tsoukas, 2015 , p. S26). However, sensemaking also appears to be continuous in the sense that it is an ongoing process that produces and sustains a sense of shared meaning (Gephart, Topal, \& Zhang, 2010, p. 284). Gephart et al. assert that there is "no timeout from sensemaking" (p. 281) and ground that assertion in their definition of sensemaking: "An ongoing process that creates an Intersubjective sense of shared meanings through conversation and non-verbal behavior in face to face settings where people seek to produce, negotiate, and maintain a shared sense of meaning."

Both positions can be reconciled if we argue that episodic sensemaking does not stop once a breach is restored. Instead, the reconstituted sense is built into the evolving present by means of altered activity, redrafted expectations, and lessons learned. While a breach does accentuate sensemaking, restoration doesn't terminate the sensemaking. It terminates the accentuation ... until the next breach.

\section{On Sensemaking in the Service of Whistleblowing}

Several of the properties of sensemaking just mentioned are visible in the NT case. For example, we see instances of interconnected actions and interpretations, disconfirmed expectations, selective attention to cues in the environment, imbalance or incompatibility, accentuation of conscious feeling and thought, and the creation of images that rationalize what people are doing. These conceptual labels suggest a story. But more importantly, they focus that story on reasons why, for PJS, "every day is a struggle," and why those discomforting struggles grow harder and harder to reduce.

One way to focus the story is to center it on seven factors (Weick, 1995, pp. 17-63) that are proximal influences on the specific sense that 
is made. These seven factors include social context, $\underline{i}$ dentity formulation, $\underline{r}$ etrospective interpretation, meaningful $\underline{c}$ ues, ongoing events, plausible stories, and effortful enactment (SIR-COPE).

All seven figure prominently in PJS's account. His social context is made up of associates such as an applauding board, subdued employees, a majority, and mentors. PJS continues to ponder the questions, "Who am I?" and "When am I?"-questions regarding identity. He describes a long-standing "feeling of general unhappiness about where my life has taken me, that has resulted in a sense of not belonging and a feeling that I have failed to accomplish anything meaningful." PJS often relies on retrospect for meaning, looking back at his CSR roots, success at Telenor, early recruiting promises at NT, earlier counsel from mentors, and early misgivings. Normal occurrences become cues of something that is not right:

The company was flying high on the expense side. This I knew for a fact. The repeatedly extravagant meetings and events were noticed by outsiders, including the media. Phone-calls from the media asking about spending and apparent lack of transparency became harder and harder to answer.

(see Chapter 1)

These cues, when combined with those of invoices for gardening payments, apparent board indifference to his cautions, and questionable buyer-seller interactions, are hard to ignore. Over several years the inconsistencies are ongoing, as are complaints, deadlines for positive annual reports, executive meetings, and external reporting. Nothing stops or goes away, and disorder increases (e.g., "We have an 'unfaithful servant' in our midst"). Plausible meanings are seemingly everywhere, but seldom align with one another. A plausible good company co-exists with a plausible "dirty culture." The board's efforts to provide "satisfactory answers" to PJS about the first CEO's conduct are incompatible with PJS's plausible hunches that the board is trying to minimize its own culpability. In the role of whistleblower, PJS says, "There is something wrong with this organization," but as the Senior Vice President Information and External Relations he "says that NT is excellent" (see Chapter 1). Finally, efforts to enact order into this growing chaos seem to heighten disorder (e.g., PJS lists a collection of problems at NT for the board chair, who listens silently, and then advises PJS not to leave the firm but to pretend like nothing happened and create a strategy to answer the questions that he has secretly raised).

To consolidate these observations even further we can take a closer look at PJS's comment that, "Certainly, I think I experienced some dissonance. In some aspects, I tried to reduce the dissonance by saying, 'Okay, well, I can do something about this if I do it the right way'.” However, 
as the months pass, the "right way" becomes more and more elusive and more of a source of contradictions in which PJS has a stake.

Consider this description in interview 18 :

The way in which the company was using its resources [to mow the CEO's lawn, travel for fishing trips, pay for the CEO's driver, award expensive contracts to buddies] became a very disturbing element in my job. I keep telling the public that this company is using its resources in a socially responsible manner while privately, I am seeing more and more instances where they are not.

PJS affirms a CSR agenda publicly while observing privately that it is being violated.

Conceptually this is a story of a deepening struggle to make sense under conditions in which a growing set of implications become increasingly incompatible. This unfolding can be crudely represented by a cognitivedissonance ratio of elements tied to a generative cognition (Beauvois \& Joule, 1996). By generative cognition we mean "the representation of the subject's behavior" (p. 6), which is treated as the focal element. Such a generative cognition could be PJS's efforts to convince the public that NT is a virtuous, socially responsible, well-run firm, while attempting "to do this the right way." Given this anchor, relevant elements that rationalize the behavior are either dissonant or consonant. Given a generative cognition, the ratio consists of elements that are dissonant with the generative cognition (e.g., "I am hiding the truth which is not the right way"), relative to the total number of the relevant elements that are dissonant and consonant (e.g., "I am fostering a balancing act"). An increase in dissonant elements (e.g., "the company is suffering from your presence") without any corresponding increase in consonant elements, leads to increased tension (e.g., sleep and digestion problems) as well as increased efforts to reduce the ratio (e.g., PJS adds a "social report" section to the 2005 and 2006 annual reports). As the ratio increases or fails to decrease, sensemaking becomes more and more filled with thoughts, feelings, and actions whose sense is shaped by their relevance to the ratio (e.g., my days seem to be filled with a CEO who won't listen to me, employees who keep complaining about leadership, people who urge me to "do something”). PJS apprehends more about NT while he simultaneously grows more apprehensive about his future and that of NT. Both forms of apprehension are conveyed in at least four forms: “(1) as a question ('Did you know that ...?' (2) as an exclamation, 'That ... is terrible!' (3) as an injunction, 'Do something about ...!' (4) or as a mere statement of fact, 'It is the case that'" (Elliston, 1982, p. 168). All of these forms are incorporated into the dissonance ratio and into sensemaking itself. As Eliot Aronson (1999) puts it, "cognitive dissonance theory is essentially a theory about sense making: how people try to make sense out of their environment and their behavior and, 
thus, to lead lives that are (at least in their own mind) sensible and meaningful" (p. 105).

Thus, one interpretation of this case is that PJS is troubled by the belief that this is a corrupt firm, which contradicts his public communications that this firm is virtuous, socially responsible, well run. Common methods of dissonance reduction appear to be blocked. Because interfacing with the media is his job, PJS can't treat the dissonance as unimportant. There are few consonant elements to add, since he knows too much to do this. It is also hard to remove dissonant elements since he keeps seeing and hearing more complaints about the CEO's use of resources and his flawed leadership. He can't plead that he was forced to do this job since he chose to join the firm. Over time, PJS experiences growing rather than diminishing importance of the focal element, more dissonant elements, fewer consonant elements, and growing feelings of responsibility to do something.

He carries this imbalance through time by means of ongoing sensemaking. The imbalance infuses sensemaking by means of what John Dewey called the "continuity of experience." "Every experience enacted and undergone modifies the one who acts and undergoes. . . [T]his modification affects, whether we wish it or not, the quality of subsequent experiences. For it is a somewhat different person who enters into them. ... (T)he principle of continuity of experience means that every experience both takes up something from those which have gone before and modifies in some way the quality of those which come after" (Dewey, 1997, p. 35). PJS "becomes" a different person as he faces unresolved contradictions, sees more of the subsequent world as cues that become relevant to the contradiction, all while carrying around a "backpack" labeled, "We all have to be truthful to ourselves."

\section{On Managing Sensemaking in the Context of Whistleblowing}

Whistleblowing can be treated as a deepening struggle to make sense under conditions in which a growing set of implications, tied to a generative cognition, become increasingly incompatible. In the case of NT, the evolving implications of opposed ideas consume more and more attention. This growing attention heightens both provisional understandings and fear, the two faces of apprehension. While this sensemaking interpretation may be, in William James's words, a "monstrous abridgement," it also serves as a "sketch map for showing us our bearings [although it] can never supersede perception" (1996, p. 100).

Sketch map or not, it remains true that "There is no theory-neutral observation, description, interpretation, theorization, explanation, or whatever. There is, in other words, no unmediated access to the world: access is always mediated. Whenever we reflect upon an entity, our sense data is always mediated by a pre-existing stock of conceptual resources, 
which we use to interpret, make sense of and understand what is, and take appropriate action" (Fleetwood, 2004, p. 30).

The conceptual resources of sensemaking suggest several possibilities for "handling" and managing whistleblowing. We sample some of these in terms of the dissonance ratio, the properties of sensemaking, and organizational culture.

\section{Dissonance}

The dissonance ratio itself can be managed toward less tension if more than one generative cognition is salient (e.g., self-concept and a public irrevocable action and an explicit expectation and a confidential conversation); if fewer cognitions are treated as relevant; and if interpretations of action include more frameworks than those of morals and ethics. These modifications, along with the more traditional methods of dissonance reduction such as adding consonant elements, decreasing dissonant elements, reducing the importance of the issue, and emphasizing being forced to confront the issue, all affect the ratio. With less dissonance to reduce there is less felt pressure to interpret the world largely in terms of its potential effects on the ratio.

An especially troublesome generative cognition is the label "whistleblower.' PJS observes that he was "advised, don't let them label you a whistleblower because it has negative connotations." Different consequences would likely flow from labels such as guardian, issue seller, lookout, futurist, advisor, representative, or communication hub. Literally, the label of whistleblower is inaccurate anyway since a corporate whistleblower can't stop the action the way a referee's whistle can.

\section{Sensemaking}

The process of sensemaking itself can be modified to manage whistleblowing. For example, suggestibility is heightened when one's self-concept is unstable rather than more secure. The heightening should be intensified in the midst of upheaval. If feelings of doubt and uncertainty change into feelings of assurance, then those changes can be mistaken for knowledge. That is likely if active needs override a less-biased look at the particulars of the situation (Bacon, 2012, p. 54). Thus, a secure self-concept that is built around resilience and adaptability can reduce a dissonance ratio and enact a broader range of responses. PJS has a tough time building clearer knowledge of clear-cut harm since his evolving identity of integrity and autonomy is made more unstable when he is treated as a traitor, liar, and hunted man.

A related mechanism of sensemaking involves expectations. Expectations that are less realistic produce more discomfort when disconfirmed because they raise bigger questions about one's grasp, which distorts subsequent 
sensemaking. Thus, from my own authorial position of hindsight, I hear PJS's expectations firm up with positive images when he says, "The new job entailed responsibility for all internal and external communications, national TV drawings, and external sponsorships. I reported directly to the CEO and was part of the top leadership group. The job provided opportunities I had never imagined so close to home. The world seemed to be more in balance." That is a formidable positive scenario that seems vulnerable to consequences such as disconfirmation, an intense interruption, and recovery that are likely to remain salient in subsequent sensemaking.

A different format that could guide how people handle whistleblowing involves a focus on options and volatility. Roe and Schulman (2008) suggest that operators in high-reliability firms (e.g., electric grid-control rooms) adopt just such a focus. To answer the question "Now what?" one can ask, "Would the proposal, if implemented, reduce (or at least not increase) the volatility faced by operators who are really frontline defenders? Would it increase (or at least preserve) those options to respond to volatility" (p. 213, i.a.). A similar set of questions can help people try to make sense when there is silence in the presence of questionable practices. If one anticipates that volatility will increase and options decrease, this provides a clearer understanding of how one might handle whistleblowing. That clarity may take several forms. Options and volatility, which are more salient, can be modified directly. For example, installation of a hotline increases options while declaring a stand-down decreases volatility. Perceptions can be managed if, again, an increase in options is proposed (e.g., we can solve this in small steps) and if apparent volatility is decreased (e.g., this is an outlier). A balance between options and volatility can be highlighted if balance itself is treated as a generative cognition (see the discussion of balance later in the chapter).

Sensemaking can be directly managed if the 7 properties summarized in the acronym SIR-COPE are used as a checklist. Pressures associated with whistleblowing can seem overwhelming when social interactions are restricted and redundant, identity is in flux, retrospect is focused on a specific time period rather than being more free-ranging, cues are misjudged because they are gathered to confirm a developing bias, ongoing events get ahead of efforts to cope, everything or nothing seems plausible, and enactment violates important norms that, if violated, diminish one's influence.

\section{Culture}

Organizational culture has become a hasty label for any residual pattern of orderliness that can't be explained by concepts such as power, authority, centralization, or routine. Mindful of that caveat, there do seem to be some macro-level influences, subsumed under the concept of culture, that can handle whistleblowing. 
Formally, we treat culture as "the system of meanings which are shared by members of a human grouping and which define what is good and bad, right and wrong, and what are the appropriate ways for members of that group to think and behave" (Watson, 2001). Less formally culture is "how we see and do things around here" or, with less latitude, "We do things in a particular way around here, don't try doing things differently." For our purposes, we modify these summaries slightly and argue that culture is also "what we expect around here." Cultures affect both what people expect from one another internally (these expectations are often called "norms") and what people expect from their dealings with the external environment of customers, suppliers, and other stakeholders.

Consider this description of NT's culture found in PJS's third interview:

it was a very subdued culture, where-to summarize it-subdued culture, where no one-not very many asked questions. And, if you asked questions, there was an internal understanding that if you asked too many questions, that will have a consequence. You should really be glad that you're getting an opportunity to work here.

More broadly it would seem that a culture whose reputation is built on fun, joy, and positiveness, as was true at NT, makes it more difficult to give voice to concerns that are more negative. The spectacle of a Viking ship emerging from the fog with the CEO at the bow in Viking gear, staged for a select few, may be fun, but when it's paid for with resources destined for charities, blowing the whistle can carry a considerable cost.

The grounds for whistleblowing can be reduced if the enactment of culture is sensitive to two findings from research on high-reliability organizations (Schulman, 2004). Schulman describes these two this way. First, it has been found that the major determinant of reliability in an organization "is not how greatly it values reliability over other organizational values, but rather how strongly it disapproves of mis-specification, misestimation, and misunderstanding of things." Second, it has been found that the more people in an organization "who are concerned about the misidentification, mis-specification, and misunderstanding of things, the higher the reliability that organization can hope to achieve" (p. 39). These three errors of mis-specification, misestimation, and misunderstanding are all errors of sensemaking. When made part of the culture, this frame of reference can forestall the development of larger problems that are more difficult to solve and more obvious candidates for whistleblowing.

A striking image in the NT case is PJS's effort to introduce greater social responsibility at NT by using a picture of a balancing act on a balance beam as the cover of the 2004 annual report. This image points to a larger issue of the emphasis that firms place on balancing. Notice that this is not the static image, balance, but the dynamic image of balancing. 
"The image of tightrope walkers depicts such dynamic balancing; their stability on the thin rope depends on consistent, ongoing microshifts. Smith and Lewis (2011, p. 386) propose a dynamic equilibrium model, which invokes such "constant motion across opposing forces" (Schad, Lewis, Raisch, \& Smith, 2016, p. 38).

It could be argued that balancing was precisely what PJS was doing as he shifted his attention back and forth between communicating what is good and bad, right and wrong. Aside from his heroics, however, the more general point is that balancing as a norm is a buffer against excess, an ongoing acceptance of alternatives, and support for moving between contradictory poles. All of these cultural conventions can lead to adaptation with modest dissonance rather than to fixation with stronger dissonance that edits sensemaking more severely.

SIR-COPE again suggests a form of organizing that manages occasions so that they trigger whistleblowing less often and deal with it more wisely when it does occur. Other things being equal, an organization that encourages more diverse and questioning conversations, clearer and more stable identities, more use of elapsed action as a guide to interpretation, unobstructed access to a wider range of cues, more focused attention on interruptions whenever projects are disrupted, wider dissemination of stories, and deeper acceptance of the reality that people face situations that are of their own making, should be less susceptible to sustained whistleblowing. The NT "culture" falls short on most of these. It is possible that these shortcomings made this a more visible and disruptive set of events.

\section{Conclusion}

Whistleblowing can be portrayed as a surface of apprehension that persists because of an unresolved dissonance ratio and continuities of experience. Both of these mold sensemaking. Such a portrayal highlights different qualities of the PJS story than do Hirschman's exit, voice, and loyalty or Campbell's hero's journey. A sensemaking portrayal does not privilege moral or ethical issues, but neither does it dismiss them. What a sensemaking interpretation does suggest is a pathway by which an incompatibility or paradox can become an ethical issue.

A sensemaking interpretation also suggests that whistleblowing is something other than a rare, vivid exposé of wrongdoing. Everyday life often generates small-scale focal cognitions that connect with relevant elements whose implications are consonant and dissonant with the focus. These are what Dewey referred to as "interruptions and recoveries." Since interruptions can accentuate thoughts and feelings, these accentuations can alter subsequent sensemaking. Subsequent sensemaking can strengthen, weaken, or remove issues that foster whistleblowing. Taken to the extreme, this argument suggests that whistleblowing is as much in the eye of the whistleblower as it is in the actions of the wrongdoer. That suggestion is simply an application of the earlier statement that 
"Significance and valence do not pre-exist 'out there,' but are enacted, brought forth, and constituted by living beings."

In the final analysis, sensemaking boils down to living forward with flawed foresight and understanding backward with flawed hindsight (Kierkegaard, 1997, p. 306). As William James put it: "The present sheds a backward light on the world's previous processes. They may have been truth-processes for the actors in them. They are not so for one who knows the later revelations of the story" (James, 1975, p. 107). Marianne Paget (1988) made a similar point when she argued that medical mistakes are "complex cognitions of the experience of now and then. ... The now of mistakes collides with the then of acting with uncertain knowledge. Now represents the more exact science of hindsight, then the unknown future coming into being" (p. 48). People believe ahead of the evidence. And this is why sensemaking is infused with faith, presumptions, and expectations.

The fundamentals of sensemaking are still summarized well by an early (1983) description:

The basic idea of sensemaking is that reality is an ongoing accomplishment that emerges from efforts to create order and make retrospective sense of what occurs. .. . [I]ndividuals are not seen as living in, and acting out their lives in relation to, a wider reality, so much as creating and sustaining images of a wider reality, in part to rationalize what they are doing. They realize their reality by 'reading into' their situation patterns of significant meaning.

(Morgan, Frost, \& Pondy, 1983, p. 24)

The tone of a sensemaking perspective leans toward the existential. Life is nothing until it is lived. But that living tends to be understood after the fact, based on rolling hindsight. Usually that understanding occurs just in time. Sometimes, however, it occurs too late.

\section{References}

Aronson, E. (1999). Dissonance, hypocrisy, and the self-concept. In E. HarmonJones \& J. Mills (Eds.), Cognitive dissonance: Progress on a pivotal theory in social psychology (pp. 102-126). Washington, DC: American Psychological Association.

Bacon, M. (2012). Pragmatism. Malden, MA: Polity

Beauvois, J. L., \& Joule, R. V. (1996). A radical dissonance theory. London: Taylor and Francis.

Chia, R. (2000). Discourse analysis as organizational analysis. Organization, 7(3), 513-518.

Dewey, J. (1997). Experience and education. New York: Free Press.

Dewey, J. (2008). Human nature and conduct: Volume 14: The middle works. Carbondale, IL: Southern Illinois University.

Elliston, F. A. (1982). Anonymity and whistleblowing. Journal of Business Ethics, $1(3), 167-177$. 


\section{Karl E. Weick}

Fleetwood, S. (2005). An ontology for organization and management studies: Critical realist applications in organisation and management studies. Organization, 12(2), 197-222.

Gephart, R. P., Topal, C., \& Zhang, Z. (2010). Future-oriented sensemaking: Temporalities and institutional legitimation. In T. Hernes \& S. Maitlis (Eds.), Process, sensemaking, and organizing (pp. 275-312). New York: Oxford.

James, W. (1975). Pragmatism. Cambridge, MA: Harvard University Press.

James, W. (1981). The principles of psychology (Vol. 1). Cambridge, MA: Harvard University Press.

James, W. (1996). Some problems of philosophy: A beginning of an introduction to philosophy. Lincoln, NE: University of Nebraska Press.

Keenoy, T. (2008). 700 sage words. In D. Barry \& H. Hansen (Eds.), The SAGE handbook of new approaches in management and organization (pp. 467-468). Thousand Oaks, CA: Sage.

Kierkegaard, S. (1997). Søren Kierkegaards Skrifter (Vol. 18, p. 306). Copenhagen: Søren Kierkegaard Research Center.

Maitlis, S., \& Christianson, M. (2014). Sensemaking in organizations: Taking stock and moving forward. Academy of Management Annals, 8(1), 57-125.

Morgan, G., Frost, P. J., \& Pondy, L. R. (1983). Organizational symbolism. In Monographs in organizational behavior \& industrial relations. Greenwich, CT: JAI Press.

Paget, M. A. (1988). The unity of mistakes. Philadelphia, PA: Temple University Press.

Roe, E., \& Schulman, P. S. (2008). High reliability management: Operating on the edge. Stanford, CA: Stanford Business Books.

Sandberg, J., \& Tsoukas, H. (2015). Making sense of the sensemaking perspective: Its constituents, limitations, and opportunities for further development. Journal of Organizational Behavior, 36(S1), S6-S32.

Schad, J., Lewis, W., Raisch, S., \& Smith, W. K. (2016). Paradox research in management science: Looking back to move forward. The Academy of Management Annals, 10(1), 5-64.

Schulman, P. R. (2004). General attributes of safe organizations. Quality and Safety in Health Care, 13(suppl. II), ii39-ii44.0.

Shields, D. (2011). Reality hunger: A manifesto. New York: Vintage.

Smith, W. K., \& Lewis, M. W. (2011). Toward a theory of paradox: A dynamic equilibrium model of organizing. Academy of Management Review, 36(2), 381-403.

Taylor, J. R., \& Van Every, E. J. (2000). The emergent organization: Communication as its site and surface. Mahwah, NJ: Erlbaum.

Thompson, E. (2007). Mind in life: Biology. Phenomenology and the sciences of mind. Cambridge, MA: Belknap.

Watson, T. J. (2001). In search of management: Culture, chaos and control in managerial work. London: South-Western/Cengage.

Weick, K. E. (1995). Sensemaking in organizations. Thousand Oaks, CA: Sage Publications.

Weick, K. E., Sutcliffe, K. M., \& Obstfeld, D. (2005). Organizing and the process of sensemaking. Organization Science, 16(4), 409-421. 


\title{
7 Ethical Blindness as an Explanation for Non-Reporting of Organizational Wrongdoing
}

\author{
Einar Øverenget and Åse Storhang Hole
}

\section{Introduction}

"If you know what is right, you will do what is right," Socrates says in one of Plato's dialogues.

It's easy to dismiss that statement as false. Everyday experience shows us that a person can know what is right, or at least what is consistent with common ethics, and still act against it. A person is also able to watch others behave unethically and still not protest, even when he or she knows better. But we don't have to conclude that only a bad individual would be guilty of such ethical inconsistency. Probably all of us have done wrong, even if unintentionally. We can also retrospectively admit to an ethical misstep — and admit that we knew it all along. We can also sometimes behave unethically without being aware of it and may even be convinced we're doing the right thing.

The phenomenon known as "ethical blindness" helps explain why, how, and under what conditions we all fail to make ethical decisions. This chapter builds on ethical blindness research as it relates to whistleblowing (Rhodes \& Strain, 2004; Rendtorff, 2014; Near \& Miceli, 1995; Near \& Miceli, 2016).

For the past decades, research on whistleblowing has tried to explain why some people righteously report wrongdoing, and why others stand by, doing nothing (Olsen, 2014; Near \& Miceli, 2016; Vandekerckhove, Brown, \& Tsahuridu, 2014). Whistleblowing has been comprehensively defined as "the disclosure by organization members, including former members and job applicants, of illegal, immoral or illegitimate practices, including omissions, under the control of their employers, to persons or organizations who may be able to effect action" (Near \& Miceli, 1985, p. 4). The decision to blow the whistle-or not-turns out to be a surprisingly complex process, and raises several intriguing questions (Near \& Miceli, 1995; Miceli, Near, \& Schwenk, 1991; Chen \& Lai, 2014). Both individual and situational factors can affect one's decision to blow the whistle. Is the issue at stake part of the employee's responsibility? Is the wrongdoing a common practice at this particular workplace? Will 


\section{Einar Øverenget and Åse Storhang Hole}

anybody listen? Is the wrongdoing serious enough? Answering these questions may create problems and conflicts for oneself, one's organization, and society.

Most employees who observe wrongdoing won't report it, but they tend to do so if the wrongdoing is serious, the evidence is clear, the organization has implemented whistleblowing routines, and management provides a culture receptive to hearing and acknowledging bad news (Near \& Miceli, 2016). If, on the other hand, they fear retaliation, or believe that nothing can or will be done about the problem, or feel uncertainty about the seriousness of the wrongdoing, or lack trust in the recipients of their concerns, then they're likely to just stand by (Near, Rehg, Van Scotter, \& Miceli, 2004).

Most ethical decision-making models are based on rational assumptions. The process usually consists of four stages (Jones, 1991; Chen \& Lai, 2014): recognition, attitude, intention, and action. Ethical decisionmaking begins when a person recognizes that some issue poses an ethical concern. Next, the person makes a judgment about the issue at hand, and this influences intention, which is the subjective probability or willingness to act. Intention is influenced by attitudes, subjective norms, and perceived behavioral controls. Finally, intention is a good predictor of subsequent behavior (Chen \& Lai, 2014).

But not all ethical decision-making processes are expressly rational. Sometimes the decision not to blow the whistle stems from mere habit or unconscious perceptions and processes. Ethical fading and ethical blindness are theoretical constructs that might help explain these unconscious processes in ethical decision-making (Palazzo, Krings, \& Hoffrage, 2012).

Our own way to explain non-reporting behavior is to focus on more unconscious processes and the temporary state of ethical blindness. We start by considering how different perceptions of the seriousness of particular wrongdoing can influence whistleblowing intent and actual whistleblowing.

\section{Wrongdoing}

How one rates the seriousness of the wrongdoing significantly affects whether one reports it (Olsen, 2014). The now classic definition of wrongdoing in empirical research on whistleblowing describes it as "illegitimate, illegal or immoral actions or practices" (Near \& Miceli, 1985; Miceli, Near, Rehg, \& Van Scotter, 2012; Skivenes \& Trygstad, 2014). The very broadness of this definition helps explain why it may be difficult for employees to rate the seriousness of the issue at stake. Employees' decisions about whether to blow the whistle appear to be influenced by their organizational context, their perceptions of the seriousness of the wrongdoing, their beliefs about whether reporting the wrongdoing will serve any good purpose, and whether superiors are involved in the 
wrongdoing (Trygstad, 2017; (Miceli, Near, \& Dworkin, 2009, 2013; Near et al., 2004).

The likelihood of reporting increases when employees assess wrongdoing to be more serious and frequent, when they have solid proof of the wrongdoing (as opposed to passively observing it), and when it affects them personally. The likelihood of reporting decreases, meanwhile, when these features are not present, when employees determine that the wrongdoing involves multiple participants, or when the participants are at a higher organizational level than the observer. According to Skivenes and Trygstad (2014), six dimensions can influence how one assesses the wrongdoing: (1) The perception of its seriousness can be highly subjective, and others don't necessarily share the whistleblower's private perceptions and reactions to the wrongdoing. This is a well-known problem in whistleblowing research (Miceli et al., 2009; Skivenes \& Trygstad, 2014). (2) The wrongdoing may be related to facts or to values and norms, any of which may be subject to different evaluations. (3) Frequency may be a criterion for assessing the seriousness of the wrongdoing. Did it happen once, or often? (4) Is the wrongdoing intentional or unintentional? (5) Is it of public interest? (6) Does the wrongdoing imply vulnerable persons? Is a powerless person affected by the wrongdoing?

Many explanations have been proposed to account for the myriad perceptions of wrongdoing. One implication of the foregoing discussion is that perceptions and considerations of wrongdoing are rational processes. In some cases, they doubtless are. But we aim to extend the understanding of non-reporting behavior by applying the theory of ethical blindness. Why do some employees simply not see the problem?

\section{Ethics and Practical Rationality}

Socrates' statement in our opening sentence expresses a now conventional understanding of ethics: there is an intrinsic relation among virtues, principles, and actions. By knowing what is right, we act accordingly. By extension, bad behavior springs from bad people. This assumption has had a profound influence upon moral philosophy from Plato and Aristotle to Kant and beyond. Modern ethical theories, such as deontology and utilitarianism, still have in common that they are epistemologically driven. Actions are a result of self-aware humans making explicit decisions based on their knowledge of virtues and ethical principles, whether these be utilitarian calculations, the categorical imperative, or the Aristotelian notion of the golden mean.

But we're coming to recognize the shortcomings of this view, especially in relation to ethical failure. We will not fully understand ethical failure if we assume an intrinsic relation between virtues and actions. Moreover, if we keep trying to describe what goes on mentally when decisions are being made, we will most likely not recognize the fundamental tenet, 
very optimistic, of what is referred to as the prescriptive approachnamely, that "People are rational human beings, who make conscious decisions about how to act" (De Cremer \& Vandekerckhove, 2017). Rejecting that view, these two scholars recommend an alternative one, a descriptive approach, that focuses on what is going on, contextually, when decisions actually are being made. By doing so, they place themselves in a tradition of the phenomenology of Husserl and Heidegger. The phenomenological slogan "Zu den Sachen selbst" ("to the things themselves") advocates the necessity of describing specifically what is going on in our everyday dealings with the world rather than assuming what ought to take place (Øverenget, 1998). Heidegger points out that we are always already involved in a web of meanings and assignments he calls, simply, the world. That implies that our reasoning is always situated. It does not imply that we are not rational but rather that our rationality is embedded. Accordingly, it does not even imply that we are unconscious. In the phenomenological tradition going back to Husserl, who was influenced by Brentano, consciousness does not imply reflective awareness. To be conscious of something is to be somehow directed toward it, involved with it; and the most original way of dealing with the world is by pre-reflexive practical coping. That means that any dealings with the world, including those of an ethical nature, are rational, yes, but this very rationality is embedded in a practical and instrumental context. Accordingly, actions typically are not preceded by reflective deliberation but by a practical everyday orientation and familiarity toward the situation (Øverenget, 1998).

De Cremer, Van Dick, Tenbrunsel, Pillutla, and Murnighan (2011) employ a descriptive approach to account for ethical decision-making in general, and ethical failure in particular, but such an approach does not necessarily imply the lack of rationality or consciousness. On the contrary, this is a result of the workings of instrumental rationality and consciousness in its most original form. If we take description to its full measure, we must avoid implicitly understanding it within the framework of scientific rationality-and hence, by that token, realize that the lack of scientific rationality implies something irrational. The concept of theoretical or scientific rationality does not exhaust the concept of rationality. Heidegger suggests that it is a subset of a more original form of practical rationality (Sandberg \& Tsoukas, 2011).

In all likelihood, it was Arendt's deep understanding of phenomenology and the philosophy of Heidegger that led to her analysis of Eichmann and the concept of the "banality of evil." Zimbardo's Stanford prison experiment and Milgram's experiments on obedience to authority suggest similar ways of understanding ethical failure. It is not a product of nonrationality or the unconscious, but a pre-reflexive, context-familiaritydriven state, nurtured by forces such as instrumentality, conformity, and authority (Zimbardo, 2007; Milgram, 1963; Arendt, 1963). These forces 
enable us to see what is right within a given context, but they will also blind us to whether the right thing is a good thing. We are, temporarily at least, ethically blind.

\section{Ethical Blindness}

Ethical blindness speaks to one of the great human puzzles, namely, why "good people behave in pathological ways that are alien to their nature" (Zimbardo, 2007, p. 195). Put another way, what is it that makes people unable to access ethical values or prototypes that, in principle, are available to them (De Maria, 2006; Reynolds, 2006)?

Tenbrunsel and Messick (2004) argue that under specific circumstances the ethical aspect of a decision fades away so that the decisionmaker gradually becomes unaware of it. There are several triggers of this so-called ethical fading. One is the use of euphemistic language. For example, euphemisms like "We didn't bribe anyone, we just did our job" help people disguise or overlook their own wrongdoing. Another trigger is noted by Chugh and Bazerman (2007), who, in their work on bounded ethicality, analyze how the computational limits of the human mind lead to the use of simple heuristics, which might, in turn, give rise to unethical decisions beyond the decision-maker's awareness. Ethical fading is similar to moral disengagement. Bandura (2002) argues that unethical decisions are promoted by disengaging from the decision's moral dimension, and he shows how moral disengagement is driven by individual, situational, and institutional forces. A consequence of ethical fading might be that employees and leaders in organizations are unable to see the wrongdoing and thus also are unable to report it.

Palazzo et al. (2012) define ethical blindness as the temporary inability of a decision-maker to see the ethical dimension of some decision. They understand the phenomenon as identity, temporary state, and unconscious. The first aspect is that although people have values and principles that are part of their very identity, and though they have tried to live by this identity in the past, they are still able to act against their principles. As already mentioned, the main reason for that is that everyday decisionmaking in general, and ethical decision-making in particular, cannot be fully understood in terms of deliberately applying theories or engaging in self-aware reflection. Even if we actually have virtues, we would be naive to assume that everyday ethical decision-making necessarily is based on these virtues. Constant practical rationality entails a different orientation and does not take its point of departure in theoretical deliberation. The second aspect is that the blindness is a temporary state, being contextbound. It describes a psychological state of people with normal (or even high) levels of integrity and the ability for moral reasoning. For some reason(s), however, often related to the situation, they are not able to engage these capacities when making the decision. When the situation 


\section{Einar Øverenget and Åse Storhang Hole}

changes, however, they are likely to return to practicing their original values and principles-and might be surprised or even shocked by their own prior behavior (Chugh \& Bazerman, 2007). The third aspect of ethical blindness is that it is unconscious. We argue that a better way of describing this aspect is to say that it is pre-reflexive. Ethical blindness can be conscious in the sense that it is a result of engaging with the world: the person is directed to something and can be absorbed to an extent that she is not thematically aware of. This state of being deeply absorbed, or "conscious of," creates the unawareness that partly constitutes ethical blindness.

In the following, we relate these three aspects of ethical blindness to the concept of framing, particularly focusing upon how rigid framing can cause ethical blindness. Further, we show how the theory of ethical blindness helps us understand the internal dealings in Norsk Tipping (NT) as presented by Peer Jacob Svenkerud's (PJS) story of whistleblowing, the audit reports, the annual reports of the company, and discussions of it in the national press.

\section{Frames and Rigid Framing}

A general observation in the hermeneutic tradition is that every time we understand something, our understanding rests on some prior understanding (Porter \& Robinson, 2011), which eventually establishes a certain frame for understanding. Likewise, every time we perceive something, it occurs within a framework of prior experience. We are therefore able to see more than what actually meets the eye. Frames filter what we see and how we see it and structure how we apprehend reality. Typically we aren't conscious of this structuring. Frames describe how we always view, understand, and approach the world from a certain perspective (Palazzo et al., 2012). They are both indispensable and unavoidable. They are also exclusive in the sense that we only use one frame at a time. According to the constructionist view (Weick, 1995, 1996), individuals act upon frames that they develop while interacting with their environment. Frames are "mental structures that simplify and guide our understanding of a complex reality" (Russo \& Schoemaker, 2004, p. 21). They constrict our view of the world to one particular, and thus necessarily limited, way and guide how information is processed and controlled, selected and obscured. Without these mental structures, we would not be able to perceive, let alone understand, a complex situation.

But sometimes a frame can be so rigid that we get ourselves locked into it, unable to switch to another frame (Schoemaker \& Russo, 2001). A defining feature of rigid framing is that we are less able to view the world from a different perspective, as when a mother suggests to her inconsiderate child, "What if someone did this to you?" The change of perspective is a central tenet of ethics simply because what we are doing 
often looks perfectly fine from our point of view. Thus, frames have blind spots because they impose "mental boundaries on options" (Russo \& Schoemaker, 2004, p. 137). Blind spots in attention and perception affect our ability to understand a complex situation (Moberg, 2006). In sum, rigid framing makes it hard to transcend a specific view on the world and adopt a different frame. Thus, it prevents us from compensating for a frame's blind spots and from developing a deeper understanding of a situation.

Further, the more homogenous a group is, and the more conformity within it that is allowed to flourish, the less probable is the urge to change perspective. Rigid framing will typically develop within a context of conformity where situational forces make it practically impossible to adopt a different frame, to view the situation from a different perspective. The group will consolidate its perspective and likely ignore information that does not endorse the normative paradigm (Lakoff, 2004; Vuori \& Huy, 2016). Hence, what appears unethical from the outside may be considered perfectly acceptable on the inside. The danger is that the culture will be unable to recognize unacceptable practices (Brief, Buttram, \& Dukerich, 2001).

A consequence of rigid framing is thus that it limits our ability to acknowledge other possible frames. The more rigidly people apply specific frames when making decisions, the lower their ability to switch to another perspective (Palazzo et al., 2012). So, for example, a homogenous group of trained economists applying a strictly economic frame may find it hard to identify ethical, cultural, and reputational aspects of their dealings. Likewise, lawyers operating within a rigid legal frame may find it difficult to identify essential moral aspects of their decisions.

Ethical blindness may thus result from framing a decision-making situation too rigidly. Using these frames unbendingly increases the probability that people won't see the ethical dimension of their decision (Tenbrunsel \& Messick, 2004).

\section{Examples of Rigid Framing in the PJS Narrative}

So one possible explanation of the ethical failures as described by PJS is in terms of rigid framing. Based on his story, and also on the data from the interviews, newspaper articles, annual reports of NT, and reports from the auditor general, we suggest that the following three frames might have sufficient rigidity to cause ethical blindness:

\section{We have a good company}

The company's reputation was excellent, both in the region and on national-level assessments, rating reputation, and customer satisfaction. People wanted to work for NT, one of the most attractive 
and prestigious workplaces in its region. The company culture was proud, and through its munificent sponsoring of many outside organizations with millions every year, it did good for many people. The company had also won international prizes for excellent "knowledge management" - a buzz term in the early 21 st century.

\section{We do as we please}

It is popularly believed that a state-owned Norwegian company will be thoroughly supervised by both the Ministry of Culture and NT's board appointed by the ministry. But with NT, the Audit General Report concluded that there were insufficient controls with respect to policies, procedures, budgets, and regulations. Indeed, it received serious criticism for its lack of control, including the way it had spent money on extravagances, such as providing company cars, gifts, and business travel perks.

\section{We do not ask questions here}

Reading the interview data, one infers a somewhat suppressed, subdued company culture, where few people raised critical questions. Several reasons might explain this. When you ask critical questions, and then sense that asking them will jeopardize you, you will stop asking. There seemed to be an unwritten agreement among both employees and leaders to uphold a corporate identity of happiness. Raising critical questions might undercut that positive picture.

\section{Analysis}

Our analysis follows the aforementioned framing structure. We give examples and discuss how these three rigid frames may have caused a temporary state of ethical blindness, and thus made central actors unwilling or unable to report on the wrongdoing.

\section{Frame 1: We Have a Good Company}

NT was by far the most prestigious organization in its hometown of Hamar, Norway, and the careers it offered were unmatched there. Its annual reports from 2003-2010 give an impression of a hugely successful company, not just locally but internationally, too. For example, in 2004 , an international committee consisting of managers and experts in knowledge management ranked NT among the ten "Most Admired Knowledge Enterprises" of the world (the MAKE reward). Other companies on the list were Nokia, Shell, and Siemens. Criteria for the knowledge-management ranking include achievements concerned with building a learning- and knowledge-sharing culture within a company, 
and creating value through knowledge management. NT was the best company among this group with respect to maximizing the values of its intellectual capital (Annual Report, 2004, p. 2). Further, NT had also been successful with innovations, and had endured, without missing a beat, major technological and organizational changes. For example, the company went through a major transition from an analog gaming industry to an electronic industry offering services online. This period of service innovation received international attention, and the CEO's leadership through these organizational changes gained him a lot of praise, both internally and externally.

Immense success for many years created a tradition of organizational pride among employees, as well as a reputation, among external stakeholders in the local community, that was beyond reproach. The company's impressive copper-dome exterior and plush interior seemed to confirm this proud identity. The company culture, though, had traits that could lead to rigid framing. The rigidity of a frame depends on both proximal (internal) and distal (external) contextual factors (Palazzo et al., 2012). We argue that both these factors may have caused a rigid frame: We have a good company, so we needn't change anything here. Hence, the CEO's comment, as recalled by PJS, when a new strategy of corporate social responsibility (CSR) was discussed: "Why are we drawing so much attention to this? Let's continue as we have always done." Instead of listening to occasional corrective advice from consultants and advisors, it seemed more important to maintain the positive image, by reinforcing NT's reputation as a happy and exceptionally enlighened workplace.

Indeed, it's not hard to see how the view that "we are a good company" can develop in an organization that donates millions of dollars to very good causes, like athletics. After all, in a country that esteems physical fitness, what can be better than to finance sports and, by doing so, help create good role models for young people at the same time? Not only was the company doing good, but also eventually it felt itself beyond criticism because whatever it did was inherently good. This view was probably so deeply rooted in the organization that it was nearly impossible for anyone working there to see it differently. It was the very model of a rigid frame.

\section{Frame 2: We Do as We Please}

There are many descriptions of NT's virtual autonomy, and PJS describes it in terms of a lack of control by the Norwegian government: "We had company cars, newspapers, telephones-everything paid for. Which is not abnormal. But what I think, in the aftermath, became the greatest criticism of NT, is that lack of control that the government had on this endeavor." 


\section{2}

Einar Øverenget and Åse Storhang Hole

The Ministry of Culture appointed the board members. Even so, control was weak, and it received critical notices from the auditor general. Just a few government executives were working directly with NT, and they seemed to have an indulgent relationship with the top executives in the company. As PJS put it, "The Board members appointed by the Ministry of Culture are not really controlling us." When Norway's Office of the Auditor General made an extended audit of NT in 2008 and 2009, it concluded that there had been a general lack of control (Document 3:14 [2008-2009]). For instance, it questioned whether the board had sufficiently been monitoring the CEO's execution of role and responsibility (p. 15), and it found it critical that the board as well as the ministry had not sufficiently managed these problems. It stated that "the Ministry's follow-up of the Board has been inadequate in a period where high-risk decisions have been made" (p. 15). The lack of control had trickled down to the organization. The General Audit report also pointed out that "due to the inadequate follow-up by the Board, the CEO has been given a larger room of maneuver than the Board formally should have accepted" (p. 27).

This trickle-down of inadequate control in the end might have created such a view as this: "In this company, we do as we please. The Ministry is not really controlling the Board, and the Board is not really controlling the CEO." Over time, this view seems to have been embedded in the organization to an extent that it developed the kind of rigidity-in the name of autonomy-that can cause ethical blindness.

\section{Frame 3: We Do Not Ask Questions Here}

In its report, the Standing Committee on Scrutiny and Constitutional Affairs stated that it was pleased that an individual had the courage to notify the public about censurable conditions at NT but was concerned that these same conditions weren't detected by the company's internal control routines (Committee hearing, 2010, p. 2). The committee also noted the Office of the Auditor General's especially severe criticism of the company in Document No. 3:14 (2008-2009) and wondered why the facts in such a serious matter were not revealed earlier. The committee stated that some of the conditions were so serious that they should have already been discovered and dealt with. Throughout his narrative, PJS points out that the organizational culture of the company didn't welcome critical questions. There was a common belief, it seems, among both leaders and employees that asking too many questions might jeopardize one's career. PJS describes how a former executive had been replaced because he was too inquisitive, "that he had been asked to step aside because he asked too many questions. Because he was too critical."

According to PJS's observations, the board members and the top management group didn't ask many questions either. While the board's chair 
had raised some critical questions, he got no visible support from the board itself. He was a chair for ten years. "It all happened on his watch," PJS said, "and he had been there for such a long time, not seeing it or understanding it or grasping it."

Given the rigid frames described earlier-we are a good company (and are not to be criticized) and we do as we please (since we do not need to be controlled)—it's hardly surprising that a third rigid frame evolves: We do not ask questions here. When examining the first two frames, that third frame follows almost inevitably. In many ways, it would have been more surprising if the first two rigid frames did not produce the third one. This evidently became a top-down strategy. One way to exercise control is by asking critical questions. When the Office of the Auditor General pointed out that the control had been inadequate, the reason for this might have been that critical questions simply were not asked. The strategy of not really answering to anybody can also be described in terms of not really listening to anyone, which in turn can cause what is known as the "deaf effect," which occurs when the decision-maker does not hear, ignores, or overrules bad news (Cuellar, Keil, \& Johnson, 2006). Several factors can sustain a kind of organizational deafness, and entrenched hierarchical status is a central tenet (Mannion \& Davies, 2015). The internal control system did not manage to reveal censurable conditions criticized by the auditor general. Hence, not surprisingly, nobody challenged any actions and decisions. Organizational deafness might have created a culture of silence at NT that not only had consequences top-down (not listening and not answering) but also caused silence bottom-up as well (not asking).

\section{Discussion}

We contend that descriptions of the organizational culture and attitudes in the company delineate frames, and that these frames had enough rigidity to cause ethical blindness (Russo \& Schoemaker, 2004). A temporary ethical blindness can in turn cause non-reporting of organizational wrongdoing. As mentioned previously, rigid framing will typically develop within a context of conformity where situational forces make it practically impossible to adopt a different frame or to view a situation from a different perspective. The first rigid frame, we have a good company, was made up through a shared impression of great organizational pride and long-term success (Deal \& Key, 1998; Schein, 1985; Bittner, 1965).

The working conditions were positive, and the salaries were high. In addition, NT had a splendid reputation, in part because it contributed generously-and very publicly-to society through sponsoring voluntary organizations. The consensus was that NT was doing good for both the local community and Norwegian society at large. NT is located in a relatively small town where everyone knows everyone. PJS 


\section{Einar Øverenget and Åse Storhang Hole}

also describes the powerful position of the CEO in the local community, where hierarchies were starkly visible. If people recruited into higher positions in the company usually were part of the same network, the ground was prepared for conformity. Within the context of this conformity, a certain organizational pride might have developed to a level of blindness: we are a good company, we do good things, we are proud of our achievements. Under such circumstances, who would be inclined to question NT's good intentions? Thus, the blindness is not just a matter of not seeing because of fearing what you might see, but also it is a matter of not seeing at all. Although some may argue that there were people seeing and addressing problems, the prevalent attitude was not to recognize information that would challenge the view that this is a very good company.

This practice is closely linked to the second frame: We do as we please. If whatever we do is good, why should we not do as we please? The general attitude of the culture described in PJS's narrative draws a picture of an autonomous organization, with inadequate measures of external control. The attitude of "doing as we please" was dominating, even though its employees might have been willing to accept, on a more reflective level, the view that NT cannot do as it pleases. The rigidity is connected to practice, not argument. Although people might behave in accordance with this frame, they would most likely be hesitant to accept it as a valid argument. The rigidity of the frame ensures that people never really find it necessary to question established practice (Tenbrunsel \& Messick, 2004; Russo \& Schoemaker, 2004).

Given the two rigid frames described earlier, the third, we do not ask questions here, follows almost inevitably. If working at NT in fact discloses a practical, everyday coping that does not entail the possibility of there being something questionable with established practice, nobody asks questions. Wanting to ask questions, but refraining from doing so, is one thing. More interestingly, there is reason to believe that the reason for not asking questions is more than having questions but fearing to ask them. It may simply mean that you have no questions to ask, period (Brief et al., 2001). In a subdued culture, there is perhaps no room for having questions-without exception. After all, what is the use of having questions if there is nowhere to air them? People soon learn that questioning is futile. It's like babbling on the street corner. There might also be a national twist to this frame. The general view in Norway is that we live in an open, transparent society, and that is, of course, mostly true. If we compare Norway to other countries, we will certainly find it ranking somewhere near the top of the list of open and transparent societies. But this view can also establish a narrative that in turn can become a rigid frame: We are so open and transparent that there is no need for questions. We have nothing to hide, so why even ask?

The three frames have enough rigidity to cause ethical blindness. This is not simply a matter of holding a certain view; it is a matter of engaging 
in a practice that promotes certain ways of dealing with the world that ignore other perspectives. Thus, one of the possible explanations of the non-reporting of wrongdoing at NT was the ethical blindness that had its origin in rigid framing.

If so, one may ask, how could the whistleblower not be blind himself? One explanation might be that he wasn't recruited from the same network as some of the other people who were hired into managerial positions in the company. The rigid frames had existed in the company for a long time, and the whistleblower was perhaps not locked into one specific frame and was therefore able to switch into a different frame. This may have helped him escape the ethical blindness caused by rigid framing. Recent research into whistleblowing has found that whistleblowers tend to have altruistic motives as well as more power, status, tenure, and education than their colleagues (Near \& Miceli, 2016).

Flexible framing may be a partial solution to avoiding rigid framing. Flexible framing reduces the risk of ethical blindness, because it challenges mindless routines and promotes moral imagination (Johnson, 1993). In other words, flexible framing is somehow the opposite of rigid framing. By hiring a person with a different background, experience, and x, NT unwittingly brought in a voice capable of challenging the routines, traditions, and practices that constitute blindness. By this, it also promoted moral imagination in the company (Johnson, 1993). A person who is able to view a situation from a different perspective, and apply a different frame, such as "we cannot do as we please," "not all that we do is good," or "we should encourage people to ask questions," will be able to identify organizational wrongdoings and perhaps report on them.

\section{Managerial Implications}

We argue that flexible framing can help avoid rigid framing. Leadership qualities play an equally important role. Leaders who openly invite dissent are more likely to challenge rigid framing and foster flexible framing. Russo and Schoemaker (2004) argue that a dissent-promoting leadership style-one that allows disagreement and discussions-will foster more flexible framing. Brief et al. (2001) have criticized the fact that management scholars have focused on how to ensure compliance rather than on how to promote dissent. Managers should instead encourage fruitful disagreement, in order to avoid rigid framing, both among employees and employers.

One way to introduce fruitful disagreement would be to disperse authority through decentralization of decisions and power in the organization, and thus encourage responsibility and multiple perspectives, and weakening conformity and rigid frames. As Near and Miceli (2016) argue, managerial responses and reactions are important throughout the whistleblowing process. They underline the 
importance of listening to whistleblowers, investigating the cases, and protecting the whistleblowers. Vandekerckhove et al. (2014) state that there is an increasing recognition of whistleblowing as a crucial source of management information. Managers should be licensed to foster both "hearer courage" and "protector courage" in their cultures and management styles-in other words, be able to both listen to whistleblowers and protect them. Further, Hole, Haugen, and Risberg (2019) argue that whistleblowing can be a management tool for organizational learning and change. By questioning practices, values, and the origins of the wrongdoing, managers might develop an organizational climate that promotes flexible framing. Last, by addressing ethical dilemmas and different perceptions of the seriousness of unethical practices at the workplace, managers can help avoid rigid framing and also help employees develop their consciousness about ethical decision-making processes (Øverenget \& Hole, 2014). Developing "moral courage" among employees, which is courage to stand up and act according to principles, requires authentic leadership (Hannah, Avolio, \& Walumbwa, 2011). Authentic leadership is acting in line with principles and values-in short, promoting openness, trust, and accountability. A suggestion for future research is to explore in more depth the reactions and decisions of managers in whistleblowing processes, including the relationship among authentic leadership, moral courage, and whistleblowing.

\section{References}

Arendt, H. (1963). Eichman in Jerusalem: A report on the banality of evil. New York: The Viking Press.

Bandura, A. (2002). Selective moral disengagement in the exercise of moral agency. Journal of Moral Education, 31(2), 101-119.

Bittner, E. (1965). The concept of organization. Social Research, 239-255.

Brief, A. P., Buttram, R. T., \& Dukerich, J. M. (2001). Collective corruption in the corporate world: Toward a process model. Groups at Work: Theory and Research, 471, 499.

Chen, C. P., \& Lai, C. T. (2014). To blow or not to blow the whistle: The effects of potential harm, social pressure and organisational commitment on whistleblowing intention and behaviour. Business Ethics: A European Review, 23(3), 327-342.

Chugh, D., \& Bazerman, M. H. (2007). Bounded awareness: What you fail to see can hurt you. Mind \& Society, 6(1), 1-18.

Cuellar, M. J., Keil, M., \& Johnson, R. D. (2006). The deaf effect response to bad news reporting in information systems projects. e-Service Journal, 5(1), 75-97.

De Cremer, D., \& Vandekerckhove, W. (2017). Managing unethical behavior in organizations: The need for a behavioral business ethics approach. Journal of Management \& Organization, 23(3), 437-455.

De Cremer, D., Van Dick, R., Tenbrunsel, A., Pillutla, M., \& Murnighan, J. K. (2011). Understanding ethical behavior and decision making in management: 
A behavioural business ethics approach. British Journal of Management, 22(s1).

De Maria, W. (2006). Brother secret, sister silence: Sibling conspiracies against managerial integrity. Journal of Business Ethics, 65(3), 219.

Deal, T. E., \& Key, M. K. (1998). Corporate celebration: Play, purpose, and profit at work. Berrett-Koehler Publishers.

Hannah, S. T., Avolio, B. J., \& Walumbwa, F. O. (2011). Relationships between authentic leadership, moral courage, and ethical and pro-social behaviors. Business Ethics Quarterly, 21(4), 555-578.

Hole, A. S., Haugen, A. O., \& Risberg, A. (2019). The aftermath of whistleblowing. In Whistleblowing as a management tool for organizational learning. In press.

Johnson, M. (1993). Moral imagination. Chicago, IL: University of Chicago Press. Jones, T. M. (1991). Ethical decision making by individuals in organizations: An issue-contingent model. Academy of Management Review, 16(2), 366-395.

Lakoff, G. (2004). Don't think of an elephant! White River Junction, VT: Chelsea Green Publishing.

Mannion, R., \& Davies, H. T. (2015). Cultures of silence and cultures of voice: The role of whistleblowing in healthcare organisations. International Journal of Health Policy and Management, 4(8), 503.

Miceli, M. P., Near, J. P., \& Dworkin, T. M. (2009). A word to the wise: How managers and policy-makers can encourage employees to report wrongdoing. Journal of Business Ethics, 86(3), 379-396.

Miceli, M. P., Near, J. P., \& Dworkin, T. M. (2013). Whistle-blowing in organizations. Hove East Sussex: Taylor \& Frances.

Miceli, M. P., Near, J. P., Rehg, M. T., \& Van Scotter, J. R. (2012). Predicting employee reactions to perceived organizational wrongdoing: Demoralization, justice, proactive personality, and whistle-blowing. Human Relations, 65(8), 923-954.

Miceli, M. P., Near, J. P., \& Schwenk, C. R. (1991). Who blows the whistle and why? ILR Review, 45(1), 113-130.

Milgram, S. (1963). Behavioral study of obedience. The Journal of Abnormal and Social Psychology, 67(4), 371.

Moberg, D. J. (2006). Ethics blind spots in organizations: How systematic errors in person perception undermine moral agency. Organization Studies, 27(3), 413-428.

Near, J. P., \& Miceli, M. P. (1985). Organizational dissidence: The case of whistleblowing. Journal of Business Ethics, 4(1), 1-16.

Near, J. P., \& Miceli, M. P. (1995). Effective-whistle blowing. Academy of Management Review, 20(3), 679-708.

Near, J. P., \& Miceli, M. P. (2016). After the wrongdoing: What managers should know about whistleblowing. Business Horizons, 59(1), 105-114.

Near, J. P., Rehg, M. T., Van Scotter, J. R., \& Miceli, M. P. (2004). Does type of wrongdoing affect the whistle-blowing process?. Business Ethics Quarterly, 14(2), 219-242.

Olsen, J. (2014). Reporting versus inaction: How much is there, what explains the differences and what to measure. In International handbook on whistleblowing research. Cheltenham, UK and Northampton, MA: Edward Elgar Publishing. 
Øverenget, E. (1998). Seeing the self, Heidegger on subjectivity. Dordrecht/Boston/London: Kluwer Academic Publisher.

Øverenget, E., \& Hole, Å. S. (2014). Moralsk nøytralisering. Når handlinger ikke følger holdninger. In A. O. Haugen \& Å. S. Hole (Eds.), Personalledelse $i$ et kunnskapsbasert arbeidsliv. Hamar: Oplandske Bokforlag.

Palazzo, G., Krings, F., \& Hoffrage, U. (2012). Ethical blindness. Journal of Business Ethics, 109(3), 323-338.

Porter, E. S., \& Robinson, J. C. (2011). Hermeneutics: An introduction to interpretive theory. Cambridge: Eerdmans Publishing Company.

Rendtorff, J. D. (2014). Risk management, banality of evil and moral blindness in organizations and corporations. In Business ethics and risk management (pp. 45-70). Dordrecht: Springer.

Reynolds, S. J. (2006). A neurocognitive model of the ethical decision-making process: Implications for study and practice. Journal of Applied Psychology, 91, 737-748.

Rhodes, R., \& Strain, J. J. (2004). Whistleblowing in academic medicine. Journal of Medical Ethics, 30(1), 35-39.

Russo, J. E., \& Schoemaker, P. J. H. (2004). Winning decisions: Getting it right the first time. New York: Doubleday.

Sandberg, J., \& Tsoukas, H. (2011). Grasping the logic of practice: Theorizing through practical rationality. Academy of Management Review, 36(2), 338-360.

Schein, E. H. (1985). Organizational culture and leadership: A dynamic view. San Francisco, CA: Jossey Bass.

Schein, E. H. (2010). Organizational culture and leadership (Vol. 2). San Francisco, CA: John Wiley \& Sons.

Schoemaker, P. J. H., \& Russo, J. E. (2001). Managing frames to make better decisions. In S. Hoch \& H. Kunreuther (Eds.), Wharton on making decisions (pp. 131-155). Ort: Wiley.

Skivenes, M., \& Trygstad, S. (2014). Wrongdoing: Definitions, identification and categorizations. In International handbook on whistleblowing research. Cheltenham, UK and Northampton, MA: Edward Elgar Publishing.

Tenbrunsel, A. E., \& Messick, D. M. (2004). Ethical fading: The role of selfdeception in unethical behavior. Social Justice Research, 17(2), 223-236.

Trygstad, S. (2017). Kunnskapsstatus om varsling og varslingsprosesser [Whistleblowing and whistleblowing processes]. FAFO-rapport 2017:03. Oslo. ISSN 0804-5135.

Vandekerckhove, W., Brown, A. J., \& Tsahuridu, E. (2014). Managerial responsiveness to whistleblowing: Expanding the research horizon. In International handbook on whistleblowing research. Cheltenham, UK and Northampton, MA: Edward Elgar Publishing.

Vuori, T. O., \& Huy, Q. N. (2016). Distributed attention and shared emotions in the innovation process: How Nokia lost the smartphone battle. Administrative Science Quarterly, 61(1), 9-51.

Weick, K. E. (1995). Sensemaking in organizations. Thousand Oaks, CA: Sage.

Weick, K. E. (1996). Drop your tools: An allegory for organizational studies. Administrative Science Quarterly, 301-313.

Zimbardo, P. (2007). The Lucifer effect: Understanding how good people turn evil. New York: Random House. 


\section{Annual Report 2004}

The Annual Report Norsk Tipping (2004)

https://nsd.no/polsys/data/filer/aarsmeldinger/AE_2004_7624.pdf

The report from Auditor General 2008/2009 (Document 3:14 (2008-2009)).

The report from the Standing Committee on Scrutiny and Constitutional Affairs (2010).

www.nsd.uib.no/polsys/data/filer/aarsmeldinger/AN_2004_7624.pdfwww.nsd. uib.no/polsys/data/filer/aarsmeldinger/AN_2004_7624.pdf 


\section{Chronotopic Distinctions in Whistleblowing Events

\author{
$\mathrm{X}$-Rays of Power and \\ Sustaining Values
}

\section{Sarah Amira de la Garza}

It was a morning of high drama. Less than an hour before one of my grad students was to sit for his dissertation defense, we committee members got word that someone had anonymously called the university's ethics hotline, claiming that this very dissertation had violated Internal Review Board (IRB) requirements for use of human subjects. That claim, I knew, was utter nonsense and within two days would be formally debunked, but now my challenge was to somehow inform the student without wrecking his ability to defend his dissertation and also to allay the fears of another committee member who was especially rattled. Like me, this person had been encouraged to cancel the defense. But because of deadlines and university policies, this could have killed the young man's chances for his degree, so we proceeded as scheduled. Ironically, the young man's dissertation (Clow, 2015) - a beauty-was itself about whistleblowing. It had evolved from his exposing some ethical problems with heavily funded government-sponsored research. Written in the style of creative nonfiction (Gutkind, 1997), it recounted that whole messy experience and related it to existing whistleblowing literature. Now he himself was the target-the classic case of a whistleblower victimized for speaking truth to power.

Everyday statements, along with other forms of taken-for-granted communication, are indexical signs of the informal and routine ways that we indicate our awareness of power in the time and space of our relations. Whistleblowing experiences are vivid displays of conflict between forces of power and largely unspoken values. In this chapter, I want to unpack distinctions in power as reflected in some accounts of whistleblowing in an American university and introduce a method of inquiry I'll call chronotopic distinctions. These distinctions help identify the locus of power and influence in the patterns of values that are upheld and concealed in whistleblowing events, and I illustrate this through some examples from the Norsk Tipping (NT) whistleblowing story.

I began my considerations for this chapter initially believing I would emphasize a theoretical analysis of organizational communication in my experience as the advocate for a student who risked his graduate career 
by blowing the whistle on a federal research program plagued with serious ethical concerns. I had a rather tidy and predictable application of theories planned-critiquing groupthink (Janis, 1973), sensemaking (Weick, 1995), and reflecting on the ethical tension points in whistleblowing (Jensen,1987). My reflection led me to realize I was relying on my own experience with whistleblowing in my analysis, and this reflection hinted at ways the juxtaposition of the two experiences might actually reveal deeper insights into how power and control were operating in the events that transpired. I turned to social theorists of literary criticism and social relations, to locate an epistemological basis for my analysis. I take liberty in my application of the notion of distinction as raised by Bourdieu (1986) to interrogate and reveal the presence of power and class in the everyday. In the end, I focused on a few key texts from which to examine the subjective, situated, and affective experience of two distinct whistleblowing events occurring in the same institution at two positions of time and space. My project was to juxtapose narration of the two whistleblowing events (one in 1995 and the other from 2012-2015) to allow for accounts of experience to reveal the organizational and cultural topoi operating to influence and generate responses or actions. Epistemologically, it is the methodology of juxtaposing events to highlight distinction that helps us to know.

In his 1996 lecture entitled, "Physical Space, Social Space, and Habitus," Pierre Bourdieu discusses how the real is relational and that social agents are located in social spaces; he critiques the creation and use of what he calls "grand theory," created without reference to any empirical reality (p. 7). His call is at the same time epistemological and methodological, insisting that "the deepest logic of the social world can be grasped provided only that one plunges into the particularity of an empirical reality, historically located and dated" (p. 8). My reading of Bourdieu's critique suggests that when such grand theories are applied in analysis, the analysis tends to emphasize substantial or mechanical aspects of phenomena, arriving at essentialist analyses that effectively tie any insights obtained to an abstraction. This does help us understand certain features of phenomena, such as Jensen's ethical tension points (1987), which can be "universally" applied; however, in large part, we miss unique aspects of the experience because of our epistemological locus in assumed theoretical frameworks for organizations and events. I attempt to depart from what Bourdieu (1996) considered a largely American tendency in sociological research, which can amount to what he called "scholasticism" (Weininger, 2005), with knowledge that is deduced from existing theoretical/conceptual frameworks rather than more organically or rhizomatically (Deleuze \& Guattari, 1987) from empirical material-in this case, descriptions of experience. To do so, I couple a methodology of foregrounding empirical distinctions through narration with a methodological device derived by employing Bakhtin's notion of the chronotope 


\section{Sarah Amira de la Garza}

(Bakhtin,1981a) (the term borrowed from the work of Albert Einstein in his theory of relativity). Bakhtin offers the chronotope (Bemong \& Borghart, 2010) as a unit of analysis that emphasizes the consideration of time/space, where topoi emerge because chronotopes function effectively as " $\mathrm{x}$-rays of the forces at work in the culture system from which they spring" (Bakhtin,1981b). In this following brief illustration of a methodology for the study of whistleblowing (and other organizational/cultural experience), the distinctions visible when highlighting chronotopes guide us through the emergent dynamics of implicit power in the narrative experiences set into motion through acts of whistleblowing. Each chronotope offers parallel segments of time and narrative substance in the accounts set in distinction.

\section{Chronotope I}

In 1994, after ten years working as an assistant professor at three universities, I moved into an administrative position, directing a presidential initiative for my university. Meanwhile, I continued to teach at the graduate level.

In 2012, my student had experience as a successful master's candidate, graduate instructor, research associate, and his own impressive record of work as a research consultant and project manager for a leading East Coast survey-sampling organization.

\section{Chronotope II}

In 1995, while administering the budget and programming for my position as director of a multi-program project, I would meet regularly with deans, provosts, faculty, and university executives in student affairs. I'd held the job for almost a year, and throughout that year I would frequently get suggestions from upper-level administration that I should expand the breadth of the programs I was directing. I'd reply with a familiar university mantra, "If I had the budget ....", usually to knowing chuckles and sighs and cynical humor that bonded us in the struggle of working in a state university. But then one executive responded by telling me that there was no reason I should be stymied-that he'd seen my budget and I had "more than enough money." I thought that I, too, had seen it. But his comment led me to reinvestigate my budget. I discovered that almost $50 \%$ of the money intended for use by the initiative had been appropriated for the hiring of staff for another program not affiliated with the project I directed.

In 2012, my student was employed as a research associate with a project that made use of his quick mind and ability to synthesize large amounts of information. He was driven by the desire to solve puzzles and contribute to research that led to interesting, new knowledge. He was on a fast track to success in his disciplinary niche, able to claim affiliation with a type and size of sponsored research that few students could claim. As he 
describes it, "idle time" distracted him from focusing on the documents from the research project in order to do the work. Instead, because of his free time, he applied his curiosity and skill at quick reviewing of literature to more fully read the original research proposal. This led to the discovery of plans in the research project to engage in activities he believed to violate ethics at a high level, potentially leading to questionable use of human subjects, questionable informed consent, and highly disturbing plans for use of the research (Clow, 2015).

\section{Chronotope III}

I realized there was no way that my program could properly expand without access to the funds I now knew belonged to it, but that had been concealed from me. Within my branch of the university, there was no one higher than my supervisor to whom I could turn. So I decided to take my case directly to the university president. I wrote him a confidential letter requesting an opportunity to meet with him to discuss concerns I had that threatened the success of his initiative.

My student began to panic as he realized he could not ethically continue with this work. But he couldn't ethically "sit on it" either, since subjects in the research might be ignorant of its questionable goals. Complicating matters still further, his funding for graduate study depended on his work as a research associate, and his dissertation director led the sponsored project. He had no idea how to reach the federal agency that funded the research and less confidence that they would share his concerns, since the research as planned served national defense interests. Additionally, their federal-level affiliation intimidated him, as did the capacity of his mentors to blackball him. He'd emphasized organizational studies in his graduate work; he was aware of the conditions he was facing. He requested a follow-up meeting with me, for more advising.

\section{Chronotope IV}

I met with the president and told him what I had discovered, framing the disclosure of the misappropriated funds within my concern for the success of his pet program, being careful to state that I was not meeting with him with any vengeful intent to destroy the career of my supervisor, a successful scholar. Our conversation was calm. He asked me to wait, told me that he would talk to the provost, and they would determine what to do.

My student told me about the fears he had if he blew the whistle, and I advised him on ways that he could proceed to protect his status in the graduate program. He had decided that the only effective way to raise awareness of the scandal was to "go public." But how? He decided to pursue media contacts. I offered to meet with him again if he needed to discuss his plans, saying I was especially willing to advise him if he had 


\section{Sarah Amira de la Garza}

problems navigating a strategy for completing his degree, although I was not on his committee.

\section{Chronotope V}

I was called to a meeting with the provost and an executive vice president of the university. They invited me to move my program, along with support staff and the complete budget, to another major unit of the university. I accepted, making clear I didn't want to be in a position where I would be expected to lie to others. In many ways, it felt as if I had been rewarded.

My student approached his dissertation director and expressed a desire to change his research focus. Since the director already carried a full load because of his position as research P.I., losing the student as an advisee was no big deal. But when my student asked another faculty member to be his dissertation director, alluding to the issues he was facing, he ran into a wall. Although the professor praised his potential and said he liked working with him, he declined the request, saying that he didn't want to upset his relationship with the professor currently directing the research study, especially if the student pursued the whistleblowing.

\section{Chronotope VI}

During my move to the new unit in the university, my supervisor came to my office and demanded that I tell him what I had said to the president. Apparently, he had been notified. I said that I had told the president that it wasn't possible for me to direct my program if I wasn't allowed access to its full budget. I didn't explicitly mention the misappropriation of funds. I also assured him, rather pointedly, that I had specifically told the president I was not "out to get" him. I held my gaze. He then muttered something I do not recall and left in a huff.

Meanwhile, my student was desperate, aware that if he didn't get a new dissertation director, he wouldn't be able to complete his degree. He was also actively seeking avenues to publicize his research at a level that would gain the attention necessary to have an impact. In addition, he had begun to look for work, aware that he might have to leave and give up his funding. I expressed my heartfelt concern. He said he was willing to accept this, because he couldn't keep quiet. I then offered to direct him if he were willing to write a different type of dissertation-a creative nonfiction account and analysis of his experience with whistleblowing, applying organizational theory. The offer intrigued him. This consoled him, too, as no other professor would work with him, he was apprehensive about whom he told, and most fellow graduate students now kept him at arm's length. I then used my networks to find two professors who agreed to sit on his committee after I had described the project as something relevant to their own areas of study. 


\section{Chronotope VII}

I continued my work with the program, expanding it and its staff by creating several new programs, and boosting its budget and my salary. Meanwhile, my previous supervisor found fresh funds to support the staff he'd paid with the project budget. We evolved a workable, civil relationship, and I was even called to assist with several programs within his unit. The budget thing was "our secret." A scandal had been avoided. My career continued on its own trajectory. For all intents and purposes, the events were "over," the problem resolved.

My student struggled working full time, and he decided to relocate more than a thousand miles away to work in a job using skills he'd previously used before doctoral studies. In periodic conversations with me, he expressed frustration and fatigue. He eventually succeeded in finding a nationally known freelance journalist who created an online video that accurately presented the sordid details of the grant. It rapidly swept the Internet, capturing the attention of people interested in such controversial research, while the university, embarrassed, intervened to control access to information about the project. His health suffered, and he lost weight, but I encouraged him to keep writing, and he did. He wrote a beautiful, evocative account, using his own experience and notes as the basis for the creative nonfiction story he told. Then, finally, came his formal defense of the dissertation. A new member of the research team for the project sat in on it after the unsuccessful attempts to prevent the scheduled defense with the anonymous hotline call. This individual posed a series of intimidating questions about the whistleblowing (and not the dissertation), moving the committee to call the public part of the defense to an end. As a committee, we advised the student to revise the formal document to remove any specific identifying features of the narrative to avoid future backlash. In time, the research study lost its funding, and it was publicly attributed to other bureaucratic reasons, but the timing of the response coincided with the online controversy about the project. Other, similar research continues to receive funding in other units of the university, with more carefully neutral and socially positive framing.

\section{Chronotopic Distinctions: The "X-Rays"}

Employing what Bourdieu called the " $\mathrm{x}$-ray" capability of the chronotope as a unit of analysis, what immediately became apparent to me were the clear distinctions in power and voice that were a function not only of the chronotope of the whistleblowing scenes, but also of the implicit life experience of the primary agents as aspects of their habitus. Importantly, there emerges an awareness of the abstract glossing that occurs by referring to the distinction simply as experience, for in fact, what is implicit and embedded within that which is called "experience" is 


\section{Sarah Amira de la Garza}

evidence of acquisition of institutional and political grammars of power that operate in the choices that each of us made. Bourdieu stresses that the most adequate readings we can obtain are through an examination of the choices that reflect one's social positioning, disposition, and stances (which he calls relational, habitus, and position taking) (1996, p. 10).

From the outset, we are dealing with the phenomenon of an agent choosing to voice that which within the organization is otherwise hidden. At this level of analysis, it would be easy to focus on what happens when, or what is required to, disrupt the assumed loyalty to actions held in place through adherence to organizational or group norms or structured functions. But it goes beyond the simple exposé of information or facts that is expected to remain unrevealed. Through the comparison of these two instances of whistleblowing by two individuals in the same university, but at a variety of different chronotopes, what stood out to me was the evidence of more than simple organizational socialization and experience or knowledge, but the subjugation of affect and the capacity to create texts that work while simultaneously disrupting. This could be seen as evidenced by my communicative approach in the 1995 incidents, which I find similar to Bakhtin's idea of heteroglossia, or phenomenon of being "double-voiced," where a character expresses both his intentions and the "refracted" voice of the author (1981b, p. 324). We can recognize this in my capacity to express my intentions to the university president, while making clear that I was also speaking with the voice of the academy. When we consider the parallel chronotopes of my student, his lack of institutional power is evident by the emphasis on affect and personal vulnerability.

Guattari (2009a) expresses that power is evident when one's expression is written-metaphorically as well as literally; words become "texts." This creating of texts is the ability to express things in such a way that their syntactic value is recognized as memetic-that which is expressed will be recognized as a desirable semantic whole. This requires a rather powerful disciplining of affect that could make the expression particularistic, and even risky (especially when affect would imply a view threatening a subjugated experience of the organization). In other words, we are asking, can the whistleblower put things into words that those who receive the information/news are not only willing, but desiring to employ or repeat? Put still another way, will those who receive my whistleblowing message use my language and its framing to assist in the resolution of the transgression motivating the whistleblowing? By comparing the various chronotopic moments of these two events side by side, and considering that the whistleblower in the 1995 situation was the advisor to the whistleblower in the 2012-2015 situation, we can see a distinction between the relatively raw nature of the whistleblowing disclosures in 2012 and the highly double-voiced textual nature of the disclosure in 1995. Similarly, in the 2003-2007 whistleblowing events at Norsk Tipping, we are 
able to see the capacity of Peer Jacob Svenkerud (PJS) to elegantly navigate events largely in part because of the power that accompanied his experience and position, as well as the power of having governmental agencies collaborating to investigate. My student's low status and lack of reliable social networks of power, as well as the looming power of federal government agencies benefitting from the ethically questionable research, made such cooperation unfeasible.

Second, we come to see how once articulated, the whistleblowing text (spoken or written) takes on a materiality that is simultaneously rhetorical, value-laden, and indicative of the agent's subjective value. This subjective value can be argued to be partially informed by one's formal structural power within a social or institutional hierarchy, but what is lost in such facile reasoning is the power located in an individual's subjugation of any affect that would compete with the normative and appropriate, privileged, affective expression within the culture. At every point of space and time, the interactions accompanying organizational whistleblowing simultaneously demonstrate and reinforce existing taken-forgranted sources of power and capacities to influence/control events. This is incredibly significant, since the whistleblowing ostensibly is a blatant challenge to ways in which power and influence have been used in corrupt or illegal, unethical ways.

A chronotopic view of whistleblowing trajectories, especially when juxtaposed with other disclosures within an organization or culture, can be used as a spotlight revealing the value of an individual with respect to the ways of not only the disclosure, but also how the syntactic text of such disclosure is congruent with the hierarchy of values within the culture. These hierarchies include values of varying levels of importance that sustain the organization or culture. In these hierarchies exist those values that are driving forces to keep the culture going-what I might call primary root values. These hold a high expressive value matched by actions that reinforce them. These are often unquestioned and the basis for influence.

We can see this in the ultimate 2011 departure from NT of PJS, as well as in the institutional cover-up of my whistleblowing of misappropriation of funds despite changing formal organizational structure. Similarly, in my student's situation, despite the termination of funding for the research and his ultimate success completing his degree, the federal funding found units better able to narrate the work. And, my student's dissertation was forced to omit significant details in the creative nonfiction account, rendering it rather impotent for posterity. What we often fail to acknowledge are those values accepted as important to espouse, as part of the culture's image or brand, but that are not as powerful and do not always find themselves employed or enacted-what I call image values. These are the values that would have PJS proclaiming to reporters in 2010, "I had no choice; I could not live with this knowledge on my conscience" (Østlendingen, 2010). This mirrors powerfully the motivation behind all 


\section{Sarah Amira de la Garza}

whistleblowing, I would argue. These values are understood as politically, morally, or ethically significant, but ultimately, they are not as significant as the primary root values, although rarely (or even never) acknowledged as such. PJS somewhat acknowledges an awareness of this in the same statement, saying, "A whistle-blower can also be an asset" (Østlendingen, 2010), implying the underlying prevailing belief that they are liabilities. Image values are informally understood as not taking precedence when pursuing a course of action-for instance, as in many cases, the value of "diversity," or commitment to gender equality in work practices. With the ability to see distinctions in chronotopic x-rays, the whistleblowing events described show us how the internalization of the values of the institution stand out as ultimately powerful. The value of the symbolic power of the tenured professor was implicitly acknowledged in the phrasing and framing in the 1995 case shared, as well as the 2015 muting of the dissertation content in order to attain the sacred Ph.D.

An additional level of values can also be identified: the unquestioned value of preserving an image of "all's well" or "above board," in what could be argued are persistent efforts to obfuscate or downplay enduring values or practices that are powerful and determining of action, but that are considered unacceptable to articulate explicitly. These hidden root values are in a sense a sort of shadow values. In certain instances, these might very well function to contradict image values. For this reason, actions taken in support of hidden root values can be duplicitous, evasive, or misleading.

In the 1995 whistleblowing scenario, the hidden root value of preserving the honor of significant tenured faculty who have transgressed is implied through the syntactic structure of the whistleblowing messages. In the 2012 whistleblowing scenario, because the blame for a violation of ethics in the conduct of research has a paper trail that leads directly to named (and tenured) individuals, this hidden root value was threatened. This lessened the security of the as yet academically unlettered whistleblower. Bourdieu's critique of grand theory analyses can push us to consider how the logical coherence of elements of organizational experience, rank, and formal power would fail to help us see that which is hidden or implicit. Through the simultaneous use of a methodology employing distinction and chronotopes, a less constrained awareness is possible. It is in many ways affective knowing that arises from the raw narratives of experience. This does not mean that we can simply throw out the use of grand theories; rather, we might wish to see what is not seen, as the over-reliance on grand theories may function to support the continued obfuscation of the hidden, unexpressed, and subjugated aspects of organizational and cultural experience. Organizations may adhere to business-as-usual despite any changes that whistleblowing might bring about. Ultimately, the attempt to keep the organizational values intact can overshadow the potential for increased power given to renewed ethical practices and open disclosures of violations. 
What is at stake in whistleblowing events are often hidden hierarchies of significance to power relations and agency within an organization or culture. The trajectories explored through an inquiry into chronotopes would lead us to ask how one has come to learn how to express difficult disclosures in ways that do not unconsciously threaten image or hidden root values. These are the ways that hegemonic patterns of power and influence are maintained. In both my whistleblowing as an administrator and PJS's accounts of whistleblowing, we see the evidence of the discursive locus of power necessary to navigate a whistleblowing challenge to organizational practices. The student's evident affective reactions betrayed him as not properly subjugated, not necessarily trustworthy to upholding the sustaining values of the culture; he needed an advocate to legitimate his actions when facing the institution he challenged.

It is not readily visible in public statements the way that one's affect must be subjugated in order to navigate topics that threaten the institution's values and simultaneously arouse intense affective responses in the individual. When gathering accounts for an analysis that would employ this methodology of distinction and chronotopes, it would be important to gather accounts of experience that capture aspects of the affect present during events, much as the lengthy interviews of PJS by the research team (for details, see Chapter 2), and the years of conversations with my student, as well as my own awareness of my own experience in the events shared. The whistleblower treads on fragile surfaces, often revealing through the responses and backlash to one's disclosures those values that are powerful enough to demand subjugation or distortion of one's subjectivity, expression, or affect. The permissibility of one's affective, subjective, and expressed presence is in a sense converted to material and physical realities, through the active face of culture, and vice versa. From this perspective, the 1995 events described demonstrate intense subjugation of affect. Any emotions of anger, threat, fear, or insecurity were not expressed in the interactions. Interactions were calculated. I would argue that the successful outcome of the whistleblowing was a sort of reward for appropriate affect in communication, while simultaneously holding intact the importance of image and both primary and hidden root values. In my student's experience, it was this same awareness of the importance of subjugation of affect that operated in advising the student in the mildly dishonest framing of the dropping of the chair of his committee. It was not only the subjugation of the student's affect, but also the prevention of the arousal of affect in the interaction with his professor that was advised. His "request" could not risk honest expression of a rationale that would threaten the important values implicit in the professor's multiple roles. And in PJS's newspaper reflections, he hints at that which was subjugated in his statement: "The process has obviously had an influence on my life" (Østlendingen, 2010). The details of our 


\section{Sarah Amira de la Garza}

subjective reality and influence on our work and lives are largely behind closed doors; in my student's experience, they were literally deleted from the formal thesis.

Similarly, although not expressed in the chronotopic accounts, it is important to consider how whistleblowing and the public knowledge of one's whistleblowing will affect the social and operational networks within a culture for the individual who is known to have disclosed something threatening to the sustaining values of the culture. As a whistleblowing event can lead to an awareness of how the sustaining values of the culture have been threatened, affiliation with the whistleblower can become symbolic of one's affinity with these threats. As such, whistleblowing can increase the intensity of hegemonic responses to sanction the whistleblower and his allies (i.e., the use of the ritual of questioning in a defense to intimidate, using a hotline to sabotage, or a defensive confrontation in a private conversation). The implicit threats in the whistleblowing can strengthen allegiance to cultural or organizational goals and values because of the awareness of threatening narrations in the communicative environment, and ultimately affecting the sense of institutionally supported individual security for many. It is important to stress here that hegemony and allegiance to cultural/organizational goals and values are often silent, the epitome of subjugation. It is through communication (including silencing) that conditions are created for the "production of subjectivity"(Guattari, 2009b). Ultimately the entire experience of a whistleblowing event, whether successful or not in repairing the ethical, legal, or operational ruptures in an organization or culture, can reveal for us the subtle codes and literacies necessary to have power. Success in whistleblowing where the sustaining values are themselves oppressive may simply be a long-term delay in bringing to light those things that cannot even be voiced. On the other hand, as in the case of Norway, where whistleblowing is increasingly found to "work" (Skivenes \& Trygstad, 2010), perhaps we are seeing that an open embrace and defense of shared values at a macro-cultural level can function to make whistleblowing an ally to these values, rather than a threat to sustaining values within a culture that are themselves evidence of deceptive norms of representation and actions. Even so, serious scholars of organizational discourse ought to embrace the opportunities that these accounts provide to study the subtle ways organizations persist and resist change, even when seemingly forced to make dramatic adjustments.

\section{References}

Bakhtin, M. M. (1981a). Forms of time and of the chronotope in the novel: Notes toward a historical poetics. In M. Holquist (Ed.), C. Emerson \& M. Holquist (Trans.), Mikhail M. Bakhtin. The dialogic imagination: Four essays (pp. 84-258). Austin, TX: University of Texas Press. 
Bakhtin, M. M. (1981b). Discourse in the novel. In M. Holquist (Ed.), C. Emerson \& M. Holquist (Trans.), Mikhail M. Bakhtin. The dialogic imagination: Four essays (pp. 259-422). Austin, TX: University of Texas Press.

Bemong, N., \& Borghart, P. (2010). Bakhtin's theory of the literary chronotope: Reflections, applications, and perspectives. In N. Bemong, P. Borghart, M. De Dobbeleer, K. Demoen, K. De Temmerman, \& B. Keunen (Eds.), Bakbtin's theory of the literary chronotope: Reflections, applications and perspectives (pp. 3-16). Gent, Belgium: Academia Press.

Bourdieu, P. (1986). Distinction: A social critique of the judgment of taste. London: Routledge.

Bourdieu, P. (1996). Physical space, social space, and habitus. Rapport 10. Oslo: Institutt for sosiologi og samfunnsgeografi Universitetet i Oslo.

Clow, C. L. (2015). Living the experience of whistleblowing: An analysis of organizational whistleblowing through creative nonfiction. Unpublished doctoral dissertation. Tempe, AZ: Arizona State University.

DeLeuze, G., \& Guattari, F. (1987). A thousand plateaus: Capitalism and schizophrenia (2nd ed.). Minneapolis, MN: University of Minnesota Press.

Guattari, F. (2009a). Molecular revolutions. In S. Lotringer (Ed.), Chaosophy: Texts and interviews 1972-1977 (pp. 275-290). South Pasadena, CA: Semiotext(e).

Guattari, F. (2009b). La Borde: A clinic unlike any other. In S. Lotringer (Ed.), Chaosophy: Texts and interviews 1972-1977 (pp. 176-194). South Pasadena, CA: Semiotext(e).

Gutkind, L. (1997). The art of creative nonfiction. Hoboken, NJ: Wiley. Janis, I. (1973). Victims of groupthink. Boston, MA: Houghton Mifflin.

Jensen, J. V. (1987). Ethical tension points in whistleblowing. Journal of Business Ethics, 6(4), 321-328.

Skivenes, M., \& Trygstad, S. (2010). When whistle-blowing works: The Norwegian case. Human Relations, 2(7), 1071-1097. https://doi.org/10.1177/001872670 9353954.

Utgitt av AS Østlendingen. (2010). Man from Elverum blew the whistle on questionable ethics. Østlendingen Newspaper, January 16. Elverum, Norway.

Weick, K. E. (1995). Sensemaking in organizations. Thousand Oaks, CA: Sage.

Weininger, E. B., 2005. Pierre Bourdieu on social class and symbolic violence. In: Wright, E. O. (Ed.), Approaches to class analysis (chapter 4, pp. 116-165). Cambridge: Cambridge University Press. 


\title{
9 Whistleblowing
}

\section{Making a Weak Signal Stronger}

\author{
Bjørn T. Bakken and Thorvald Horem
}

\section{Introduction}

Whistleblowing cases are high on the public agenda in Norway, as evidenced by the many news reports and articles in Norwegian national and regional news channels. In a commentary, Helle Stensbak, chief economist in a major Norwegian labor union (Stensbak, in Aftenposten, 10.9.2018, p. 2), notes that the societal costs are lower when further misconduct is prevented by internal whistleblowing, compared with when it's exposed by external control mechanisms. But, in either case, whistleblowing is problematic. It's estimated that only half of all instances of misconduct are reported, and in $65 \%$ of reported instances, no improvements result. It's also estimated that whistleblowing, if acted upon, might save Norway as a society more than one billion USD a year (Stensbak, in Aftenposten, 10.9.2018).

But one recurring problem is that blowing the whistle can be risky. Typically, the person accused of misconduct (often a manager) will try to divert the blame away from himself and instead pin it on the accuser. He'll do this by concealing or delaying posting the true information, and also by spreading lies or half-truths about the whistleblower throughout the organization. These tactics can be particularly effective if the credibility of the whistleblower may somehow be questioned (see Chapter 2).

The manager's defensive action may be successful, given that fellow employees, and even the public swayed by sensationalistic media, accept the diversion and direct their indignation at the whistleblower. This may prove fruitful if, as just mentioned, the personal background of the whistleblower can be manipulated into a more catchy story-for example, by portraying him as a sore-headed troublemaker rather than a conscientious and self-sacrificing employee with the greater good in mind. Even if the case goes to court, the accused is seldom found guilty, often because of a lack of incontrovertible evidence. The failure to make the case can happen when, for example, witnesses and experts offer conflicting interpretations of the facts (see, e.g., the Siemens case in Monsen, 2008; the Norfund case in Rafat, 2013; and the Monika case in Schaefer, 2019). An acquittal of the accused can lead to an even bigger tragedy 
for the whistleblower. A whistleblower may stand no better chance if his accusations are investigated internally by an ombudsman. In a recent case in which employees reported nine instances of harassment at a large Norwegian hospital, only three instances were accounted credible enough to justify dismissing the accused manager (Skogstrøm, Dommerud, \& Olsen, in Aftenposten, 3.2.2019, pp. 6-7).

Large-scale, cross-sectional surveys conducted among employees in Norway (e.g., Trygstad \& Ødegård, 2016: the FAFO survey) point to worsened conditions for freedom of speech, including blowing the whistle, in the corporate world. Today, a significantly smaller number than five years ago believe that blowing the whistle may improve conditions. Sadly, the conditions for whistleblowing may be even worse in public organizations, according to commentary by Knut Olav Åmås (Åmås, in Aftenposten, 16.10.2016, p. 2-3). He cites an informant from the FAFO survey who works in the Norwegian health service and who recounts how management is determined to track down and punish employees it sees as "troublesome." Consequently, fewer employees consider reporting workplace misconduct, and those who do rightly fear retaliation (see also commentary by Professor Petter Gottschalk in Agderposten, 22.8.2018, p. 21).

The whistleblower in this book, Peer Jacob Svenkerud (PJS) in 2007 blew the whistle on Norsk Tipping, the government-owned company operating Norway's national lottery. Our chapter reviews a theory that provides valuable insights into how a problematic issue can be detected at an early stage while a weak signal and while it's still possible to correct it using relatively limited company resources. We discuss PJS's whistleblowing case in light of several streams of research: the literature on weak signals and strategic surprises (e.g., Ansoff, 1975); sensemaking and divergent thinking (e.g., Weick, 1995); organizational and safety culture (e.g., Reason, 1997); and mindful organizing (e.g., Weick \& Sutcliffe, 2015). These research streams all have one thing in common: they contend that being informed is the most important basis for highquality decision-making and action-taking in organizations. Perhaps more important than the objective information elements (i.e., the data) is the subjective apprehension of those elements by the management. We need to understand the psychological processes by which (objective) data are transformed into (subjective) perceptions and beliefs (mental models)and the aforementioned theories are enlightening in that respect. A core point is that the transition from data to perception and understanding is less than perfect, indeed usually a fault-ridden process (see, e.g., Kahneman, 2012). When it comes to PJS's case, we identify what went wrong when the organization's upper management failed to interpret correctly and take action on his whistleblowing, and what lessons can be learned to ensure proper handling of similar cases in the future.

During the course of PJS's story, we find several times when the upper management received information that, had it been properly acknowledged and promptly acted upon, could have prevented an escalation from 


\section{Bjørn T. Bakken and Thorvald Horem}

signal to crisis. It starts when PJS approaches the chairman of the board and exposes the gross misuse of funds by his charismatic boss, the CEO of NT (Riksrevisjonen, 2008-2009). Apparently, the chairman of the board takes PJS's disclosures seriously and decides to act on them. But when PJS offers to leave the organization for a position elsewhere, the chairman discourages that idea and instead asks him to stay on as NT's Senior Vice President Information and External Relations. The plan is for PJS to remain unidentified as the whistleblower and to assist in the firm's moral recovery. While this might seem a sensible move seen from the chairman's side, the situation worsens a few weeks later when the $\mathrm{CEO}$ has been informed that the whistleblower is actually an employee in his own organization. Instead of taking the opportunity to reform his own ways, the CEO starts a witch hunt for the "unfaithful servant" By now, PJS had gone from acting with integrity and autonomy to becoming a hunted man in his own organization-and being unhappily complicit in his own cover-up.

\section{Theory}

Whistleblowing can be understood as an employee's attempt to make a "weak signal" stronger-that is, an attempt, early on, to alert the management, the media, or a government agency to problems needing prompt correction (Gottschalk, 2018). It's a "weak signal" because its purpose is more preventive than punitive. It aims to give the organization a chance to correct the wrong before it escalates into a full-blown crisis (see Near \& Miceli, 1985, 1995, 2016; Jubb, 1999). Many organizations that have experienced ethical crises have concluded that an early reaction to weak signals might well have prevented a catastrophe.

Since Igor Ansoff coined the idea of "weak signals" with his groundbreaking article about strategic surprises (Ansoff, 1975), we have been able to understand reports from the numerous crises striking organizations everywhere in a different perspective. In a way reminiscent of Murphy's Law, no matter how ingenious the security, safety, and riskmanagement systems they devise, organizations continue to be surprised by unexpected events that eventually lead to crises (e.g., Schoemaker \& Day, 2009a, 2009b). Think, for example, of the petroleum-scarcity crisis in the 1970s, or the global financial crisis in the late ' 80 s, or the subprime lending crisis after the turn of the century. Such crises occur frequently (Ansoff, 1975), and it would be easy to ascribe our failure to foresee them to the world's growing complexity. Is the problem, we wonder, due to the increasing interconnectedness and globalization of commodity, information, financial, and labor markets? Or is it perhaps from our failure to distinguish small signals that spell trouble from other signals that are just unpleasant but harmless "noise" in the background (Gottschalk, 2018)? 
Here, we argue that we should look to psychological and cultural explanations for our own managerial blindness. Many systems that are designed to manage risks and avoid unwanted surprises focus on surveillance-the suppression and prevention of adverse "forces" that are external to the organization. Might the key to avoiding many such surprises actually lie within the organization rather than outside it? We believe that, more often than not, it is not a lack of comprehensive, detailed information from numerous external sources that is the problem. Rather, it is the lack of (correct) interpretation, prioritization, and action by management that contributes to an emerging, full-blown organizational crisis (Watkins \& Bazerman, 2003).

Ansoff (1975) prescribes that an organization, to protect itself from just such a crisis, should actively prepare for the consequences of crises (i.e., effective crisis management) as well as strive to minimize the probability of being stricken by crisis (i.e., effective preparedness and surveillance measures). The latter includes barriers (safety and security systems; Reason, 1997) to prevent minor events (e.g., accidents, failures, and "disturbances") from escalating into full-blown crises, as well as systematically gathering information to be acted upon early enough to avoid the most severe consequences of them.

A core point in Ansoff's (1975) theory is that an organization's response to a potential threat should not be dictated by the information needs of the "strategic planning technology." Doing so would stifle the formal planning process; it is risky to act on information that is vague and unclear. The solution? The organization should look for feasible courses of action as strategic information becomes gradually available during the emerging phase of a crisis. "Early in the life of a threat, when the information is vague and its future course unclear, the responses will be correspondingly unfocused, aimed at increasing the strategic flexibility of the firm" (Ansoff, 1975, p. 23). For example, if an early, vague signal hints that some kind of misconduct is going on (but without being specific or conclusive), the management could promptly investigate the matter, that is, seek more knowledge. Another possible response could be to review current practices to determine whether they actually comply with generally accepted standards for doing business. In either case, the response to a weak signal would be to gather more information, in order to have a better basis for further decision-making and action. Such strategies are examples of what Ansoff (1975) would call "internal readiness and awareness" strategies.

Researchers (e.g., Nesse, 2016) and practitioners (e.g., Eriksen, 2011; Lunde, 2014) often promote this proactive approach to crisis management. An over-arching dimension of James Reason's (1997) concept of a safety culture is for an organization to stay informed. It's essential to have a system for safety management. Within such a system, members of an organization are encouraged-and sometimes even instructed or 


\section{6}

obliged by law-to report any incident, large or small, that may indicate deviations from normal practice, and thereby constitute a potential threat to safety. The logic is that most, if not all, critical threatening situations start out as minuscule events, hardly noticeable except to the personnel directly involved. Timely, accurate reporting of local events is therefore necessary for management to take quick, appropriate action. Even "near-accidents" should be reported, because such cases may constitute a vital source of learning, to avoid actual accidents in the future (Dekker, 2012).

Within Weick and Sutcliffe's (2015) “mindful organizing” theory for managing the unexpected, we find that information gathering, analysis, and action are important for preventing smaller disturbances from escalating into full-blown crises. This perspective is also shared by Beck and Plowman (2009), who propose, and explain, their two-step analysis: "Divergent thinking early in the recognition of a rare and unusual event encourages multiple ways of interpreting and viewing the event. Convergence, in contrast, enables action and adaptation" (p. 909). The discovery and interpretation of rare events should not be reserved exclusively for the top management; middle managers have an important role, too, as they're more likely to provide a richer interpretation of events and are less likely to make mistakes (Beck \& Plowman, 2009). Middle management's involvement requires that they take an active part in "sensemaking," an important skill when one is exposed to rare and unexpected events. "The cues that get noticed and extracted are the ones that get enhanced with meaning and interpretations," says Weick (1995, cited in Beck \& Plowman, 2009, p. 910). Noticing is particularly relevant with rare and unusual events, for which existing narratives typically fail to provide meaningful or satisfactory interpretations (Beck \& Plowman, 2009).

According to Watkins and Bazerman (2003; see also Bazerman \& Watkins, 2005), "predictable surprises" arise out of failures by management to recognize, prioritize, or mobilize against unwanted events. To discern in retrospect whether a disaster could have been avoided, they contend, one has to ask the following three questions: (1) Did the leader recognize the threat? (2) Did the leader make the proper prioritizations? (3) Did the leader mobilize effectively? (p. 74). These questions are akin to performing a risk assessment and then developing a plan for contingency management. For the first question, this is usually a matter of having enough resources to scan the environment for emerging threats. In addition, data need to be properly analyzed and interpreted by the management. As for the second question, this is a matter of singling out potential surprises (disasters) from other events that follow a more normal pattern. The key here is to acknowledge that any (unwanted) event has an associated risk, which is a product of probability and potential cost. An analytical leader should prioritize 
those unwanted events posing the highest risk. And as for the third question, it requires taking precautionary measures that are appropriate to handle the risks identified. A key point in Bazerman and Watkins' (2005) argument is that a manager who does a reasonable job at risk management-that is, has taken the necessary precautions against unwanted and uncertain events-shouldn't be blamed if such an event occurs despite relevant measures taken.

While Watkins and Bazerman (2003) prescribe a systematic approach to risk management, with preparedness as a main focus, Cunha, Clegg, and Kamoche (2006) offer a typology for how to handle unexpected and potentially harmful events once they've occurred. As such, their approach to handling surprises is closer to crisis management than preparedness. They describe four types of surprising events, ranked by degree of surprise, that organizations may encounter, and then prescribe the different managerial approaches that each requires.

Sometimes a surprise will occur when routines are in place but not followed by employees, so management must simply regain control. Such cases (type 1) are usually predictable, and although they may occur regularly, they don't occur with certainty. For sudden events (type 2), where the issue is unexpected but the process is well known, the event can be a source of learning. Management's task is then to facilitate it. In situations in which a process changes unexpectedly, but the issue is known (type 3, "creeping developments")—for example, when complex and interactive processes lead to unexpected situations ("normal accidents," Perrow, 1999)—-the recommendation is to manage by distributing responsibilities and empowering the employees (see Reason, 1997, 2000). In the most profound kind of surprise-situations in which both processes as well as issues are unexpected (type 4, "loss of meaning"), leading to completely unexpected and incomprehensible situations-the recommendation is to engage in sensemaking (see Weick, 1995; Barton, Sutcliffe, Vogus, \& DeWitt, 2015) to create a radical and fresh understanding of what is going on.

\section{The Relevance to Whistleblowing}

In light of the theory presented so far, whistleblowing contains aspects, or stages, relevant to both preparedness and risk management (Bazerman \& Watkins, 2005), as well as crisis management, including sensemaking (Cunha et al., 2006).

Preparedness concerns measures taken to prevent a crisis from happening in the first place and includes surveillance of the environment, detection, and interpretation of anomalies (Barton et al., 2015), as well as acting on weak signals with appropriate actions (Ansoff, 1975). Because employees are a key source of information, it's essential to foster a "generative" organizational culture (Westrum, 2004), which includes high 


\section{8}

cooperation among employees (the sources of information), training of messengers, sharing of risks, and encouragement to step forward with critical information. That culture will include the understanding that the organization will reward informants, even when the information is negative or critical, and will also implement changes that prevent similar surprises in the future (Westrum, 2004; see also Dekker, 2012; Mannion \& Davies, 2015). In fact, Schein (2016) goes so far as to argue that trust, openness, and personalization make whistleblowing obsolete. But Hussain, Shu, Tangirala, and Ekkirala (2018) contend that too much trust and openness can lead to the opposite effect. They call this "positive organizational climate paradox": when redundant information reduces the likelihood of voice ("the voice bystander effect"). In social psychology, the so-called bystander effect holds that when some emergency, such as a crime or accident, is witnessed by a number of bystanders, the likelihood of anybody intervening to help the victim(s) decreases as the number of bystanders increases (Darley \& Latané, 1968). Many theories purport to explain this phenomenon, but they mainly contend that in the presence of several potential helpers, one's own felt responsibility to help diminishes.

Crisis management, meanwhile, concerns handling the event in order to minimize damages, once the event has occurred, and success requires that a sufficient understanding of the situation has been developed. Such an understanding could be reached, for example, through processes of sensemaking (Weick, 1995) and situation assessment (Endsley, 1997), and should result in revised mental models of high quality (Brehmer, 2009).

\section{Twice a Surprise-The "Double Trouble" of Whistleblowing}

A whistleblowing case may contain two surprises that occur in sequence. The first one is the embarrassing discovery that wrongdoing has occurred in the organization, and that somebody in (upper) management is to blame. This will likely be a surprise of type 1 or 2 in the Cunha et al. (2006) typology, because once the upper management is alerted to the wrongdoing, they will realize that it is in fact a breach of routine or directive, even though they might not react as if they immediately understand the severity of the case.

The second, more intricate surprise involves the reactions of the upper management to the whistleblower's blowing the whistle. In the PJS case, the surprise here will be that the actions taken by upper management don't resolve the crisis. If there is a lack of resolution, it's likely that the surprise will be of a type 3 or 4 in the typology of Cunha et al. (2006). If true, it's likely that a new understanding is needed, and that employees may indeed be a vital source of information, even though the information they provide may be critical of current practices. 
To avoid being surprised by whistleblowing events, we now turn to theory that promotes an organizational culture recognizing the importance of the correct interpretation and handling of weak signals. Weick and Sutcliffe (2015) offer five principles of "mindful management" that provide a foundation for prudent, robust management by placing the discovery and interpretation of small signals at the forefront of managers' minds. These signals can address potential major disasters while they are still minor incidents-hardly noticeable, but presumably easy and straightforward to handle.

Mindful management is about paying attention to small signals indicating that something is not as it should be and calling for prompt fixing. Weick and Sutcliffe (2015) put it well: "As a problem begins to unfold, weak signals are hard to detect but easy to remedy. As time passes, this state of affairs tends to reverse. Signals become easy to detect but hard to remedy" (p. 3).

In the following section, we discuss aspects of the PJS case, focusing on "what went wrong" and how the organization's upper management might have successfully corrected it. Our discussion will apply the five principles of mindful management and link each principle to a problematic practice that either caused the initial surprise or contributed to worsening the situation once the whistle was blown.

\section{The PJS Case}

\section{Preoccupation With Failure: Placing the Burden on the Whistleblower}

The principle of "preoccupation with failure" is about management's being alert to small signs indicating that undesirable events are occurring (or about to) in the company. Such signs, if overlooked, would then lead to conditions that almost inevitably metastasize.

After PJS blew the whistle on his CEO, the logical response would have been for the chairman of the board to take immediate and decisive action toward the CEO, the target of the whistleblowing. Instead, the chairman of the board placed the burden on PJS by insisting that he keep quiet and develop a Program for defending the organization.

At NT, the outcome might have been far different if internal auditing procedures had been able to catch the illegal use of corporate funds to pay for the CEO's personal gardening expenses (Riksrevisjonen, 20082009), making PJS's intervention unnecessary. Of course, if taken to the extreme, being "preoccupied with failure" could lead to a ruinously distrustful organizational climate, where everybody is suspicious, skeptical, and critical, alert to even the most trivial breach of commonly accepted (or legally permitted) business practice (see Reason, 1997; 
Dekker, 2012). On the other hand, in some industries, even the slightest rule or procedural violation could indeed lead to disaster, such as in the nuclear power industry, aviation, or in space (e.g., Perrow, 2011).

\section{Reluctance to Simplify: Ambiguous Legal Agreements}

In the case of PJS's whistleblowing, the CEO had an agreement with the NT board to have some of his gardening needs shouldered by the company caretaker (Riksrevisjonen, 2008-2009). This arrangement sought to compensate him for some of the burdens of having a heavy schedule that also included a lot of traveling. But the agreement was later interpreted (allegedly) to imply that the CEO had the right to hire a gardening company of his own choosing - and have NT pay the hefty bill. Aside from that questionable practice, which borders on corruption, there is also the issue of tax evasion. The expenses paid by the company weren't reported to the Norwegian tax authorities (Riksrevisjonen, 2008-2009).

The principle of "reluctance to simplify" is supposed to prevent unpleasant surprises caused by someone's failure to distinguish a questionable practice from normal, accepted business practice. It would appear that to run their business efficiently, managers should focus on "key issues and indicators" (Weick \& Sutcliffe, 2015, p. 8) and avoid getting too bogged down in details. But such simplification can instead lead to overlooking some nuances of doing business-nuances that may prove vital if signs of misconduct are to be discovered early and then promptly corrected.

\section{Sensitivity to Operations: Operating Costs Unjustified With Regard to Core Business}

It appears that NT permitted some activities whose costs couldn't be justified in light of its primary mission (Riksrevisjonen, 2008-2009). One example was the yearly report, which had a budget for design and printing far greater than what was needed to communicate the operational and financial status of the organization. Furthermore, high-profile events and parties, like the Viking Party at the Høsbjør Hotel outside the city of Hamar, enjoyed budgets grossly excessive for a governmentowned nonprofit.

The principle of "sensitivity to operations" concerns knowing the core activities of an organization and placing them at the forefront in the dayto-day schedule. For a commercial organization, the effort should be directed toward those activities directly related to generating profit. To that end, managerial control philosophies such as "Balanced Scorecard" (Kaplan \& Norton, 1996) and "Activity Based Costing (ABC)" (Kaplan $\&$ Bruns, 1987) are applied to ensure that daily activities don't drift off 
the organization's primary mission. At least, their costs should be justifiable in relation to their purpose and ability to generate income beyond their costs.

When a company appears to be using time and money on activities that can't be justified by their profit-generating potential, managers need to notice such activities and take action, either changing them or abandoning them altogether. Some typical examples: expensive advertising campaigns, lobbying activities that have unmeasurable results, and expensive traveling that doesn't take advantage of low fares and discounts.

\section{Commitment to Resilience: Avoid Taking Charge to Resolve the Situation}

One may ask, to what degree did NT exhibit resilience after PJS blew the whistle? It appears that the chairman of the board initially doubted PJS when he first outlined the questionable practices he had discovered. Had the chairman behaved in a resilient manner, he would have taken PJS's story and all the supporting evidence at face value instead of questioning it. Just after PJS's meeting with him, the chairman tried to mitigate the consequences by having PJS promise secrecy instead of actively addressing the problems, thus probably making things worse for both PJS and his fellow employees. Consider, for example, the "witch hunt" that the CEO launched to root out the "prince of darkness." Apparently, PJS's colleagues weren't ready to accept that their CEO exhibited questionable—and even unlawful—practices when managing their organization. Instead of posing probing questions to establish the truth, they remained loyal to the CEO.

The principle of "commitment to resilience" concerns the fact that no matter how mindful an organization may be, it occasionally will find itself tested by embarrassing incidents. An organization that's able to withstand such tests, and regain normal operational status within a reasonable time, can be said to be resilient.

The essence of resilience is . . the intrinsic ability of an organization (system) to maintain or regain a dynamically stable state, which allows it to continue operations after a major mishap and/or in the presence of a continuous stress.

(Hollnagel, 2006, cited in Weick \& Sutcliffe, 2015, p. 12)

The hallmark of a resilient organization is not that it is free from errors but that errors don't disable it (Weick \& Sutcliffe, 2015).

In many ways, resilience is the opposite of the "reluctance to simplify" principle, since an organization's resilience is often derived from its effort to maintain a control system that mirrors the complexity of the issues to be handled (see Perrow, 1999). Such an organization refrains from 


\section{Bjørn T. Bakken and Thorvald Horem}

streamlining its structure (e.g., by firing or retiring older employees, while only hiring young, newly graduated candidates) and acknowledges that a broad range of skills and competencies will be needed to solve future issues, both simple and complex.

\section{Deference to Expertise: Avoid External (and Internal) Attention, Keeping Silent}

In the case of PJS, he tells us that he sought legal counsel to mitigate some of the burdens he experienced as a whistleblower. He needed to confide in someone he could trust, an expert who had experience with such problems. NT, meanwhile, failed significantly when the board initially elected to keep silent about the allegations. In doing so, it missed an opportunity to put legal and HR expertise on the issues early and thus possibly contain the crisis. Furthermore, by not acknowledging the value of expertise in such complex matters, it also failed to learn and change its ways.

The principle of "deference to expertise" involves acknowledging that decisions in dynamic organizations should be "made on the front line, and authority migrates to the people with most expertise, regardless of their rank" (Weick \& Sutcliffe, 2015, p. 14). This principle suggests that rigid, hierarchically structured organizations face particular challenges when it comes to detecting and interpreting worrisome signals. When an issue or error isn't addressed early on, it tends to become worse (Brehmer, 2002), and a hierarchically structured managerial system is normally incapable of making the necessary quick response or adjustment called for. This is particularly true when the problem is non-routine (Pentland, Hærem, \& Hillison, 2010) or not previously experienced (Klein, 1998, 2003). The principle also applies to those cases when warnings, or "signals," originate from particularly experienced personnel. Such warnings must be taken seriously. For example, it would be a big mistake for a bank to dismiss a financial expert's opinion on the negative effects of mixing defaulted, high-risk loans with more moderate and low-risk loans when computing the bank's total risk exposure.

\section{Discussion}

Weick and Sutcliffe (2015) have studied a wide range of organizations that must maintain structure and function under uncertainty, where the potential for error and disaster can lead to catastrophe. Their main tenet is that mindful organizing helps organizations maintain resilience during critical events through anticipation and containment. Anticipation is all about preparedness (see Watkins \& Bazerman, 2003). It involves sensing events early and taking action to ward off their developing into undesirable events. Because not all unwanted events can be anticipated, the containment principles can help in handling those unanticipated or 
unexpected events that in fact occur (crisis management; see Cunha et al., 2006). Anticipation is associated with these three principles: preoccupation with failure, reluctance to simplify, and sensitivity to operations. Containment has two principles: commitment to resilience and deference to expertise.

We have discussed several aspects of PJS's whistleblowing story where the story could have been different had NT, and in particular its board of directors, been more mindful when they were presented with the issues that constituted PJS's whistleblowing reports. The preoccupation with failure principle helps us see that the board of directors could have acknowledged PJS's reports of misconduct upfront; also, that the firm's auditing procedures should have been capable of detecting irregular and questionable transactions in the first place. As for reluctance to simplify, the company should have taken more care, and been more specific and rule-oriented, when entering into agreements of fringe benefits with the CEO. The principle of sensitivity to operations was violated given the excessive resources allocated to activities that clearly were outside the company's core activities. Examples include the CEO's gardening expenses and the company's extensive sponsoring of activities outside its approved strategy. Significantly, the sponsoring strategy was later revised by the board, with a number of limitations and restrictions implemented (Riksrevisjonen, 2008-2009, p. 44).

When it became more or less apparent that PJS's story was citing past events that should have been promptly handled, the principle of commitment to resilience becomes relevant. Here we learned that the company failed on several accounts-both in questioning compelling evidence and in delaying action. Even more severe, instead of solving the real problem, a "witch hunt" was initiated by the CEO, effectively diverting attention from the real problem at hand. Finally, and contrary to the deference to expertise principle, the company's board of directors initially didn't take the necessary steps to consult experts on the problems they had been alerted to by PJS.

When looking at mechanisms to prevent serious issues from escalating, Reason (1997) takes a more distinct step toward managers being proactive when it comes to detecting and taking action on signals of wrongdoing. He suggests designing a formal information system for the reporting and proper processing of signals that warn of critical incidents in organizations. Furthermore, he suggests that the organization needs to be able to adapt to, and learn from, current problems. Finally, for this to work, good managerial leadership is essential. Managers should act as role models for their employees in all matters that relate to safety and security. For a long time, we have understood that there is a difference between how the routine is written and how it is enacted (Pentland \& Feldman, 2008). Still, the intention behind the formal system, and 


\section{Bjørn T. Bakken and Thorvald Horem}

its corresponding influence on behavior, should not be underestimated (Pentland \& Feldman, 2008; D’Adderio, 2008).

\section{Concluding Remarks}

Throughout this chapter we have reviewed relevant theory regarding the detection, interpretation, and handling of weak signals and strategic surprises, and applied that theory to a case of whistleblowing. We have seen that a formal risk-management system (e.g., Reason, 1997) may prove especially useful in that respect; so, too, a safety-minded organizational culture (e.g., Westrum, 2004), specifically, mindful organizing (Weick \& Sutcliffe, 2015)

Recommendations include taking precautions and preventive measures (e.g., Watkins \& Bazerman, 2003) as well as having a capacity to perform crisis management (Cunha et al., 2006; see also Klein, 1998, 2003, 2013), which may include sensemaking (Weick, 1995), situation awareness (Endsley, 1997), and modification and even (re-)creating of mental models (Brehmer, 2009). Without a culture or even a formal system to aid in interpreting and handling weak signals, whistleblowing cases will continue to pose a threat to management rather than an opportunity to curb mismanagement and create a new future for the organization.

\section{References}

Åmås, K. O. (2016). Et kaldere klima for kritikk. Aftenposten, October 16, pp. 2-3. Ansoff, I. (1975). Managing strategic surprise by response to weak signals. California Management Review, 18(2), 21-33.

Barton, M. A., Sutcliffe, K. M., Vogus, T. J., \& DeWitt, T. (2015). Performing under uncertainty: Contextualized engagement in wildland firefighting. Journal of Contingencies and Crisis Management, 23(2), 74-83.

Bazerman, M. H., \& Watkins, M. (2005). Airline security, the failure of 9/11, and predictable surprises. International Public Management Journal, 8(3), 365-377, https://doi.org/10.1080/10967490500439677.

Beck, T. E., \& Plowman, D. A. (2009). Experiencing rare and unusual events richly: The role of middle managers in animating and guiding organizational interpretation. Organization Science, 20(5), 909-924.

Brehmer, B. (2002). Learning to control a dynamic system. Unpublished manuscript. Stockholm: Swedish National Defence College.

Brehmer, B. (2009). Command without commanders. Paper presented at the 14th International Command and Control Research and Technology Symposium, Washington, DC.

Cunha, M. P., Clegg, S. R., \& Kamoche, K. (2006). Surprises in management and organization: Concept, sources and a typology. British Journal of Management, 17, 317-329.

D'Adderio, L. (2008). The performativity of routines: Theorising the influence of artefacts and distributed agencies on routines dynamics. Research Policy, 37(5), 769-789. https://doi.org/10.1016/j.respol.2007.12.012. 
Darley, J. M., \& Latané, B. (1968). Bystander intervention in emergencies: Diffusion of responsibility. Journal of Personality and Social Psychology, 8(4, Pt.1), 377-383.

Dekker, S. W. A. (2012). Just culture: Balancing safety and accountability (2nd ed.) Farnham, UK: Ashgate Publishing Co.

Endsley, M. R. (1997). The role of situation awareness in naturalistic decision making. In: C. E. Zsambok \& G. Klein (Eds.), Naturalistic decision making (pp. 269-283). Mahwah, NJ: LEA.

Eriksen, J. (2011). Krise- og beredskapsledelse. Teamtrening. Oslo: Cappelen Damm.

Gottschalk, P. (2018). Maktmisbruk kan være et stikkord for KS-advokaters strategi. Agderposten, August 22, p. 21.

Gottschalk, P. (2018). Varsling: Teori om signalgjenkjenning. MAGMA, 3/2018, 12-13.

Hussain, I., Shu, R., Tangirala, S., \& Ekkirala, S. (2018). The voice bystander effect: How information redundancy inhibits employee voice. Academy of Management Journal, 62(3), 828-849 https://doi.org/10.5465/amj.2017.0245.

Jubb, P. B. (1999). Whistleblowing: A restrictive definition and interpretation. Journal of Business Ethics, 21, 77-94.

Kahneman, D. (2012). Thinking, fast and slow. New York: Farrar, Straus \& Giroux.

Kaplan, R. S., \& Bruns, W. (1987). Accounting and management: A field study perspective. Boston, MA: Harvard Business School Press.

Kaplan, R. S., \& Norton, D. P. (1996). The balanced scorecard: Translating strategy into action. Boston, MA. Harvard Business School Press.

Klein, G. (1998). Sources of power: How people make decisions. Cambridge, MA: MIT Press.

Klein, G. (2003). Intuition at work. New York: Doubleday.

Klein, G. (2013). Seeing what others don't: The remarkable ways we gain insights. New York: Public Affairs.

Lunde,I.K. (2014).Praktisk krise-og beredskapsledelse. Oslo: Universitetsforlaget.

Mannion, R., \& Davies, H. T. (2015). Cultures of silence and cultures of voice: The role of whistleblowing in healthcare organisations. International Journal of Health Policy and Management, 4(8), 503-505.

Monsen, P. Y. (2008). Muldvarp i Siemens. En dokumentar. Oslo: Spartacus Forlag.

Near, J. P., \& Miceli, M. P. (1985). Organizational dissidence: The case of whistleblowing. Journal of Business Ethics, 4(1), 1-16.

Near, J. P., \& Miceli, M. P. (1995). Effective-whistle blowing. Academy of Management Review, 20(3), 679-708.

Near, J. P., \& Miceli, M. P. (2016). After the wrongdoing: What managers should know about whistleblowing. Business Horizons, 59(1), 105-114.

Nesse, S. (2016). Et helhetlig perspektiv på rekruttering, seleksjon og utvikling av kriseledelseskompetanse. MAGMA, 04/2016, 50-68.

Pentland, B. T., \& Feldman, M. S. (2008). Designing routines: On the folly of designing artifacts, while hoping for patterns of action. Information and Organization, 18(4), 235-250. https://doi.org/10.1016/j.infoandorg.2008.08.001.

Pentland, B. T., Hærem, T., \& Hillison, D. (2010). Comparing Organizational Routines as Recurrent Patterns of Action. Organization Studies, 31(7), 917-940. 


\section{Bjørn T. Bakken and Thorvald Horem}

Perrow, C. (1999). Normal accidents: Living with high-risk technologies. Princeton, NJ: Princeton University Press.

Perrow, C. (2011). Fukushima and the inevitability of accidents. Bulletin of the Atomic Scientists, 67(6), 44-52.

Rafat, M. (2013). Ingen må få vite. En varsler forteller. Oslo: Z-forlag.

Reason, J. (1997). Managing the risks of organizational accidents. Farnham, Surrey: Ashgate.

Reason, J. (2000). Safety paradoxes and safety culture. Injury Control and Safety Promotion, 7(1), 3-14.

Riksrevisjonen (2008-2009). Riksrevisjonens utvidede revisjon av Norsk Tipping AS. Dokument nr 3:14. Retrieved from www.riksrevisjonen.no

Schaefer, R. (2019). Monika-saken. Norges største politiskandale. Bergen: Vigmostad \& Bjørke.

Schein, E. H. (2016). Whistle blowing: A message to leaders and managers; Comment on "cultures of silence and cultures of voice: The role of whistleblowing in healthcare organizations". International Journal of Health Policy and Management, 5(4), 265-266.

Schoemaker, P. J. H., \& Day, G. S. (2009a). How to make sense of weak signals. MIT Sloan Management Review, 50(3), 81-89.

Schoemaker, P. J. H., \& Day. G. S. (2009b). Why we miss the signs. MIT Sloan Management Review, 50(2), 43-44.

Skogstrøm, L., Dommerud, T., \& Olsen, O. (2019). Tre mistet jobben ved OUS etter trakassering i fjor. Aftenposten, February 3, pp. 6-7.

Stensbak, H. (2018). Verdiene i varsling. Aftenposten, September 10, p. 2.

Trygstad, S. C., \& Ødegård, A. M. (2016). Varsling og ytringsfribet i norsk arbeidsliv. Fafo-rapport 2016:33. Retrieved from www.fafo.no/index.php/zoopublikasjoner/item/varsling-og-ytringsfrihet-i-norsk-arbeidsliv-2016

Watkins, M. D., \& Bazerman, M. H. (2003). Predictable surprises: The disasters you should have seen coming. Harvard Business Review, 81(3), 72-80.

Weick, K. E. (1995). Sensemaking in organizations. Thousand Oaks, CA: Sage Publications.

Weick, K. E., \& Sutcliffe, K. M. (2015). Managing the unexpected: Sustained performance in a complex world. New York: John Wiley \& sons, Inc.

Westrum, R. (2004). A typology of organizational cultures. Quality \& Safety in Healthcare, 13(suppl. II), ii22-ii27. 


\section{Part IV}

\section{What Makes Whistleblowing a Risky Business?}




\title{
10 Blowing the Whistle Is Laden With Risk
}

\author{
Joseph McGlynn
}

Blowing the whistle is fraught with risks. They can be known or unknown, visible or invisible, certain or uncertain. When Peer Jacob Svenkerud (PJS) exposed the financial misdeeds of the CEO at Norsk Tipping (NT), he faced potential slander, shaming, and intimidation. And indeed he experienced all three. They took their toll on him physically and emotionallyeven financially. But, as with any whistleblower, his story illustrates how risk judgments reflect his values and priorities, and how his perceptions of risk likelihood and magnitude influenced his response to organizational wrongdoing. Prospect theory (Kahneman \& Tversky, 1979) posits that losses loom larger than gains when people make judgments of risk with uncertain outcomes. For PJS, the risk of being untrue to himself, as well as to others, finally outweighed his fears of retaliation.

PJS took on the risk of exposing organizational wrongdoing while working for an organization whose very existence, ironically, is grounded in risk. NT is a government-owned company, started in 1948, that offers lotteries, sports, and games of chance that prove enticing to Norwegians, with all profits supposedly channeled back to the country's sports and culture sectors. So NT seeks to encourage people to take on reasonable risks, both for themselves and for the greater good. PJS's own risk calculation concerned whether to alert the world to unethical behavior by NT's CEO. Once he acted on that decision, he encountered retaliation at both the personal and professional level. In subsequent interviews, PJS describes feeling isolated and unsupported by colleagues at NT. He even faced losing his job as well as suffering other financial and social repercussions.

Why would anyone hazard such risk? In PJS's case, it was perhaps to avoid an even greater risk: the risk of inaction. If he chose to ignore the wrongdoing, he risked losing an opportunity to discover, maybe even to define his true character-his deepest values and priorities-both to himself and to others. It was truly a watershed for him, a coming-of-age moment.

In the pages ahead, I describe some key concepts and dimensions of risk theories, highlight those elements of risk most relevant to whistleblowing, and use risk theory to illuminate the process of PJS's decision 
to blow the whistle, identifying the practical, logistical, and emotional factors that influenced his risk judgments and experience.

\section{Risk Perceptions and Judgments}

We humans, through our choices and actions, have a unique ability both to create and minimize risk in our lives (Slovic, 1987). Two questions guide our decisions about risk-taking: What is the likelihood of a bad result happening, and how bad a result might it be (Fischoff, Slovic, Lichtenstein, Read, \& Combs, 1978)? These two considerations reflect decision processes of risk as analysis and risk as feelings (Slovic, Finucane, Peters, \& MacGregor, 2004). The former approaches risk decisions very analytically, with logic, deliberation, and reasoning (Slovic \& Peters, 2006). The latter approaches them suprarationally, relying on experience, intuition, and instinct. We are always estimating both the probability and the magnitude of any risk (Sztompka, 1999).

All risk decisions involve three things: options, outcomes, and uncertainty (Fischoff et al., 1978). The quality and characteristics of these inputs are influenced by social norms, context, and the language used to describe them. For whistleblowers, risk inputs include their options (blow the whistle vs. remain silent), outcomes (e.g., retaliation, successful cessation of wrongdoing), and uncertainty (how likely, and how great, is the retaliation they may face). Although risk can be quantified, the perception of it is influenced by emotions. To conceptualize risk, it's necessary to identify the emotions that motivate risk-taking. Affective responses have a substantial influence on risk decisions. Higher positive affect increases perceptions of benefits and decreases perceptions of risk (Finucane, Alhakami, Slovic, \& Johnson, 2000).

Language choices and the message frames used to describe a threat also influence risk judgments and perceptions (Tversky \& Kahneman, 1981). The framing of events prompts different affective and cognitive reactions to risks (Cho, 2012). Language choices reflect the beliefs of the speaker, as a speaker's choice of message frames communicates a particular vantage point and shape the meaning of an event (Fairhurst, 2005). Language choices can influence perceptions of risk severity (McGlone, Bell, Zaitchik, \& McGlynn, 2013) and attributions of risk responsibility (McGlynn \& McGlone, 2018).

\section{Prospect Theory}

Most risk judgments involve our factoring in both our potential losses and our potential gains (Kahneman, 2012) - that is, our costs and benefits (Fischoff et al., 1978). According to prospect theory (Kahneman \& Tversky, 1979), when we evaluate our risks, any potential losses tend to outweigh any potential gains. Fearing loss, we tend to become increasingly 
risk-tolerant, or even risk-seeking. But when assessing the risks associated with our potential gains, we tend to be risk-averse because we want to avoid losing those gains. To avoid a possible perceived loss, people are more willing to take risks, and they show a higher tolerance for supporting risky behavior. Perceptions of gains and losses influence whistleblowers' risk judgments and decision to blow the whistle.

Emotions influence risk perceptions (Slovic, Finucane, Peters, \& MacGregor, 2002). Emotions of anger and fear play key roles in whether to blow the whistle (Gundlach, Douglas, \& Martinko, 2003). Fear increases risk aversion, while anger increases risk-seeking (Lerner, Gonzalez, Small, \& Fischoff, 2003; Lerner \& Keltner, 2000). Control and uncertainty are key drivers of emotional reactions to risk (Lerner et al., 2003, Lerner \& Keltner, 2000). As whistleblowers debate the risks of blowing the whistle, they must acknowledge the hazard of uncertainty as they navigate the unknown risks, costs, and benefits of their possible actions.

For risks with known probabilities of outcomes, such as casinos, the weather (well, sometimes), or even the games sponsored by NT, logic and statistical thinking suffice for reasonable risk decisions (Gigerenzer \& Gaissmaier, 2011). But for risk judgments with unknown outcomes, like whistleblowing, intuition and emotional responses are needed for effective risk judgments. Although emotional responses to risk influence judgments (Finucane et al., 2000), so does the whistleblowers' perception of the ability of their actions to create change and successfully stop the wrongdoing.

\section{The Extended Parallel Process Model}

The Extended Parallel Process Model (EPPM) of risk perception (Witte, 1994, Witte \& Allen, 2000) proposes that whether we engage in risk depends on our perceptions of both the threat itself (How severe is it? How personally susceptible are we?) and also our perception of our ability to change the situation (self-efficacy, response efficacy). If we perceive risk to be low, we're unlikely to try to enact changes. However, when we perceive threats to be high, we then consider our ability to create change through our actions. Specifically, we consider our own self-efficacy, our ability to successfully create change, and response efficacy, our perception of how effective our available responses will be.

Many whistleblowers feel powerless to affect change in their situation (Miceli, Near, \& Dworkin, 2008). In such cases, self-efficacy and response efficacy remain low. So instead of acting, these whistleblowers would choose simply to try to minimize their concern about the threat. For PJS, his decision to blow the whistle reflects his perception of both high threat severity and high confidence in his ability to create change through his actions. Without that confidence, he would have felt powerless. The risks that whistleblowers tolerate reflect how they perceive and prioritize potential gains, losses, and self-efficacy. 


\section{Whistleblowing and Risk}

Whistleblowing increases professional, personal, and reputation risks for whistleblowers. Whistleblowers report high levels of stress, anxiety, depression, and feelings of isolation (Miceli \& Near, 1992; Rothschild \& Miethe, 1999). Exposing organizational wrongdoing frequently presents "dire consequences to whistleblowers, to their careers, and to their personal lives as a result of their actions" (Johnson, 2003, p. 74). At its core, whistleblowing is an act of resistance (Rothschild \& Miethe, 1999). Because whistleblowers seek to create change (Near \& Miceli, 1995), it can make them threatening to organizations.

Context and personality differences also influence whether a potential whistleblower chooses to speak out. For example, people with a strong sense of public service are more apt to risk blowing the whistle (Brewer \& Selden, 1998; Perry \& Wise, 1990). Whistleblowers are also more likely to act when they feel affected personally (Near \& Miceli, 1985). Perceptions of the overall goodness or badness of an event strongly influence risk behaviors (Slovic et al., 2002). Whistleblowers are also much more likely to act when the wrongdoing is both consistent and recurring (Miceli et. al, 2008).

People who choose to blow the whistle put themselves in dangerous positions, frequently suffering organizational and individual repercussions (Rehg, Miceli, Near, \& Van Scotter, 2008). Perceptions of retaliation influence whistleblower behavior (Miceli et al., 2008). Whistleblowers feel isolation and often endure hardship from people both within and outside the organization (McGlynn \& Richardson, 2014). Previous research on whistleblowing and risk focuses largely on the risks of exposing organizational wrongdoing. However, each whistleblowing case is unique, since context and industry factors individualize them (Richardson \& McGlynn, 2011).

In the case of PJS, we learn that the risks facing prospective whistleblowers extend beyond possible retaliation. They can also come with choosing not to speak up.

\section{Risk in the Case of PJS}

Whistleblowers, such as PJS, must weigh the risks of blowing the whistle against the risks of remaining silent and possibly being complicit in the organizational wrongdoing. Some people remain silent out of selfdefense, thinking it lets them separate themselves from the wrongdoing. They basically attempt to shut down their thinking and feeling processes. PJS, more honest with himself, couldn't do that. In his narrative (Chapter 1 ), he asks himself five questions, weighing the practical and emotional consequences of speaking out:

Would blowing the whistle mean giving up a comfortable and prestigious life? Would I be able to get another job? Did I even have a 
choice now, given that I was working for a governmentally owned operation that had a monopoly on a tremendously profitable market? Was the only option to finally face myself and live with the consequences? Moreover, was a failure to face myself the real reason for the internal disorder that had shadowed me for years?

Here, he specifies with remarkable clarity the risks he confronts. These questions describe multiple types of risk, including personal risks ("giving up a comfortable and prestigious life"), professional risks ("Would I be able to get another job?"), and emotional risks ("Was a failure to face myself the real reason for internal disorder that had shadowed me for years?"). He also describes the double-edged nature of the risk ("Did I even have a choice now?") and the mounting urgency to make his choice ("Was the only option to finally face myself and live with the consequences?").

PJS's story illustrates various types of risk encountered by whistleblowers. His experience describes professional, financial, and social risks. PJS also describes risks to his own sense of self. His story portrays two risks, battling each other head-on. If he blows the whistle, he makes himself vulnerable from a professional and financial situation. But if he chooses to accept the wrongdoing and allow NT to continue flouting its national trust, he risks loss of all self-respect. These emotional, affective decision inputs frequently motivate actions (Slovic et al., 2006). Emotional responses to risk stimuli reflect the overall feeling of goodness or badness in choosing one's course of action (Finucane et al., 2000). PJS poignantly confesses:

You come to a point internally where you really have to take some tough decisions for yourself. And this was one of the decisive points of my professional life, in terms that-I had thought of the whole summer. What I did really defined me as a person-can I continue like this or can I do what I know, as a certainty, is the right thing to do? And that's-shall I practice what I preach? ... I concluded this is all about my character and what I do now.

For PJS, the threat of losing his self-approval, his dignity, finally outweighed professional and financial risks-to his job, to his farm, to his family.

PJS's decision to blow the whistle was motivated in part by his desire to make the invisible visible, to reveal to himself his potential or ideal self. He wishes, also, to avoid the negative feeling of unfulfillment, of potential wasted. He felt "as if a shadow were following me-a feeling of general unhappiness about where my life had taken me." This emotional context is critical to understanding the process of PJS's risk decision. He states the multi-dimensional nature of his risk decision when he says, eloquently, "You are your own value platform ... something you not only 
carry, but must face." The emotional discontent, or negative affect (Slovic \& Peters, 2006), that PJS felt for his current place in life, created a desire to avoid that outcome and to take a risk on creating a better outcome for himself. As he describes it, "But my unsettledness pressed on me, urging me to make some sort of radical life-change." This beautifully illustrates prospect theory's tenet that potential negative outcomes motivate riskseeking behavior (Kahneman \& Tversky, 1979).

PJS further describes the role of risk magnitude when evaluating the consequence of risk decisions: "What happens to the decision-making process in a company when critical voices are suppressed, when there is a feudal company culture that people quietly follow because the risk of speaking out seems too complicated and too consequential." Similarly, he later asks, "Was I a part of something that was unhealthy, and that, if it became public, would be a disaster?" Here, PJS acknowledges the risk of becoming complicit in the wrongdoing, not to mention its potential magnitude, expressing the duality of risk that whistleblowers face when they feel personally dirtied by the wrongdoing if they choose not to speak out.

Uncertainty motivates risk decisions (Kahneman \& Tversky, 1984). A key factor to PJS's decision to blow the whistle was a sense of the speed and velocity to the magnitude and existence of the organizational wrongdoing. He says: "I felt out of place, in the wrong place. My efforts seemed to lead nowhere. Pressure mounted as the outside media and other stakeholders kept on digging into possible 'company secrets.' I was there, defending them with rapidly increasing discomfort." In that last comment, he's acknowledging that perceptions of risk increase as the threat moves closer. These comments indicate his need, and readiness, to reduce the uncertainty and to make his decision, as does this one: "With more certainty, it started to become clear to me that my self-confidence and ability to walk with my head held high in all kinds of situations had become easier." He was "beyond the point of pretending. I was a man who knew too much, and I had reached a point where non-action was no longer an ethical option."

\section{Isolation and Duality of Support}

Even when successful at stopping the wrongdoing, whistleblowers often face risks of criticism and long-term social isolation from co-workers. And it can be disquietly inconsistent-a combination of private support but public alienation (McGlynn \& Richardson, 2014). PJS illustrates the mixed signals here: "The new chair of the board and the interim CEO knew about my role and both of them expressed support, assuring me 'You did the right thing' and 'We will protect you.' But those assurances failed to blot out my acute sense of isolation, nor did my guilt go away." During researcher interviews, PJS says he felt vindicated by an independent report from auditors, but that "What was more disturbing to me 
was that internally, the new permanent CEO never said that the whistleblower did the right thing." Whistleblowers are in positions where they need more support than they ever needed before, but more often than not they are ignored in public by the same people who support them privately.

PJS describes the difficulty of seeking and receiving support from colleagues, saying: "I had hoped that the new permanent CEO would say something in the nature of giving me support when I came to work. Well, I got a call from his secretary at quarter to 8 in the morning, saying that you need to come to NT now because the CEO wants to have a meeting. . . ." PJS talks specifically about the sense of isolation that whistleblowers risk: "I saw it as a big problem because I didn't get any local support. And, I think that I knew at that point in time that my time was over in NT." Here, PJS illustrates how the sense of isolation felt by whistleblowers ostracizes them from colleagues and threatens their former sense of self that was inseparable from their profession or their organization.

Whistleblowers may receive praise in private but may also be shunned in public by the same people (McGlynn \& Richardson, 2014). PJS offers a poignant description of the types and quality of support he received for exposing the wrongdoing at NT:

I had telephone calls nonstop and a lot of supportive telephone calls. And letters and other things as well which made me feel good. But, very few from the company itself, very few if any. Well, from my close allies there, I had supportive comments, but it was very silent from the HR and the CEO. They never called. They didn't call me in the afternoon to see how I was doing. I had a feeling that they really didn't care, and that they cared more about the people who were angry. I think they probably did.

In his account, PJS describes feeling that the people upset by his exposing of the issues at hand received greater attention and support from the CEO, even though he was the one who assumed the risk to call it out. PJS further articulates the duality of support received:

A month and a half earlier, he [the CEO] had said I was his greatest supporter, I did a good job, etc. Now, I felt I was a liability for him and for the company. This followed a pattern that I had read about. If you do blow the whistle, you have truly become a liability, no matter what you do.

He recalls a friend-a corruption expert-predicting just this isolation and lack of support. Here was that frightening prediction: "Imagine the feeling of being alone in a small boat, downstream on a small river, 
meeting a supertanker. That is how you will feel from now on. It will be you against everyone else!" Admitting that the isolation and lack of support had deleterious and engulfing effects on his morale, PJS says that "that feeling of being completely by yourself is sometimes-very overwhelming. And it just swamps you and overwhelms you."

\section{Social Stigma}

Whistleblowers often describe the lasting stigma left by their decision to blow the whistle (Richardson \& McGlynn, 2011). PJS acknowledges fearing just that fate: "My story would undoubtedly follow me for the rest of my life. Who would dare to trust a whistleblower?" And again: "I felt that my situation in NT became increasingly vulnerable, in that if I suddenly one day was without a job, who would hire a person that had been-that could be connected to such a scandal?" Even friends and coworkers tend to distance themselves from people who report unethical behavior. PJS says:

It follows you throughout your life, I am convinced of. And I am convinced of, in listening to other people's stories, that it does not bring very much good to your professional career because there will always be skeptics out there that will look at your history and pertaining that you will bring your past into the present and perhaps do the same thing again and that you constitute a risk.

Ironically, in choosing to engage in risk to expose the wrongdoing, PJS actually became a risk to the organization. He acknowledges the common negative fate of whistleblowers, saying "you're also influenced by all the stories that you hear about the fate of whistleblowers, that they variously become squeezed out of the organization eventually. It follows them throughout their lives."

He describes himself as a sort of pariah, unwanted by either side, and fearing that the effects will linger forward. Talking about the difficulty of finding suitable employment, he states: "But that is something that other whistleblowers communicate as being one of the major problems in getting rehired, for example. Would you want the person like this on board your company, that is perhaps your hidden enemy?" PJS worries that people see him as someone looking to hurt co-workers at every opportunity, saying that others may think of him as "a person where you never know where you stand and that will always be behind you with a hidden weapon, ready to stab you when you least expect it."

PJS later expounds on the unfortunate reaction from his co-workers in a situation in which he felt that they were working for the same side: "For me, it was a very sad ending to something I honestly thought we could have solved. But I probably was too naïve in terms of thinking that that would be the case." 


\section{Outcomes}

PJS's experience exposing wrongdoing by the CEO at NT echoes many of the negative outcomes reported in the whistleblowing literature (Near \& Miceli, 1995; Rothschild \& Miethe, 1999). "Everything I had heard about blowing the whistle seemed to come true," he says.

But, thankfully, the effects were not exclusively negative. As he embarked on a process of self-discovery throughout his ordeal, PJS also experienced significant personal growth, and with it, a gratifying sense of rebirth:

On the other side though, in terms of personal development, something radical happened during that whole period of time. I had become very clear about who I was and what I wanted to do. I had been very conscientious about my own value platform and that was not a platform that you could exercise whenever you chose. I had to exercise it every day, both at home and at work. So, I think I've become a much better human being and a much better leader just having gone through that process.

In this account, PJS describes the clarity he received from choosing to engage in the risk to blow the whistle. He discusses the personal development and radical change he experienced as the results of risk decision, citing his growth as a person, a leader, and a citizen. Reminding us of the driving motivation behind his actions, PJS sums it up this way: "I decided to do this because I thought if I did not, I would not be true to myself."

\section{Conclusion}

This analysis sought to apply risk theory and research to reveal key influences experienced by PJS in the whistleblowing process, to lend insight into the psychological mechanisms that motivated PJS's whistleblowing disclosure, and to describe risk factors that complicated his actions. He ultimately decided it was too big of a risk not to blow the whistle. For not to act was to acquiesce to the gnawing feeling of regret: it had been "as if a shadow were following me," "of failing to accomplish anything meaningful" (Chapter 1). Blowing the whistle reflected his openness to risk in the face of potential lost opportunity (Kahneman \& Tversky, 1979). For PJS, the lost opportunity associated with inaction in the face of wrongdoing posed a greater risk than any retribution or shaming.

Blowing the whistle is inherently risky, with unpredictable outcomes. On the one hand, exposing organizational wrongdoing is bound to incur retaliation, including threats, slander, and reputation costs (Bhal \& Dadhich, 2011). It's an all-too-common experience for whistleblowers (Miceli, Near, \& Dworkin, 2008). But as PJS's story illustrates, there are 
also risks to not blowing the whistle. By keeping quiet about suspected or acknowledged wrongdoing is to feel complicit in it and to feel the guilt that comes with discovering one's cowardice and compromised values.

PJS's example describes social, organizational, and identity dynamics that influence whistleblower risk judgments and behaviors. When assessing whistleblowing risk, people consider the likelihood of negative outcomes and the magnitude of costs of those outcomes occurring. Whistleblowers often acknowledge the possibility of retaliation and negative outcomes but sometimes decide they must act. In the case of PJS and NT, sometimes the safest course is to take a risk.

\section{References}

Bhal, K. T., \& Dadhich, A. (2011). Impact of ethical leadership and leaderMember exchange on whistle blowing: The moderating impact of the moral intensity of the issue. Journal of Business Ethics, 103(3), 485-496.

Brewer, G. A., \& Selden, S. C. (1998). Whistle blowers in the federal civil service: New evidence of the public service ethic. Journal of Public Administration Research and Theory, 8(3), 413-440.

Cho, H. (Ed.). (2012). Health communication message design: Theory and practice. Thousand Oaks, CA: Sage.

Fairhurst, G. T. (2005). Reframing The Art of Framing: Problems and prospects for leadership. Leadership, 1, 165-185.

Finucane, M. L., Alhakami, A., Slovic, P., \& Johnson, S. M. (2000). The affect heuristic in judgments of risks and benefits. Journal of Behavioral Decision Making, 13, 1-17.

Fischoff, B., Slovic, P., Lichtenstein, S., Read, S., \& Combs, B. (1978). How safe is safe enough? A psychometric study of attitudes towards technological risks and benefits. Policy Sciences, 9, 127-152.

Gigerenzer, G., \& Gaissmaier, W. (2011). Heuristic decision making. Annual Review of Pscybology, 62, 451-482.

Gundlach, M. J., Douglas, S. C., \& Martinko, M. J. (2003). The decision to blow the whistle: A social information processing framework. Academy of Management Review, 28, 107-123.

Johnson, R. A. (2003). Whistleblowing: When it works and why. Boulder, CO: Lynne Rienner Publishers, Inc.

Kahneman, D. (2012). Thinking, fast and slow. New York: Farrar, Straus \& Giroux.

Kahneman, D., \& Tversky, A. (1979). Prospect theory: Analysis of decision under risk. Econometrica, 47, 263-291. https://doi.org/10.2307/1914185.

Kahneman, D., \& Tversky, A. (1984). Choices, values, and frames. American Psychologist, 39, 341-350.

Lerner, J. S., Gonzalez, R. M., Small, D. A., \& Fischoff, B. (2003). Effects of fear and anger on perceived risks of terrorism: A national field experiment. Psychological Science, 14(2), 144-150.

Lerner, J. S., \& Keltner, D. (2000). Beyond valence: Toward a model of emotionspecific influences on judgement and choice. Cognition and Emotion, 14(4), 473-493. 
McGlone, M. S., Bell, R. A., Zaitchik, S. T., \& McGlynn III, J. (2013). Don't let the flu catch you: Agency assignment in printed educational materials about the H1N1 influenza virus. Journal of Health Communication, 18, 740-756. https://doi.org/10.1080/10810730.2012.727950.

McGlynn, J., \& McGlone, M. S. (2018). Desire or disease? Framing obesity to influence attributions of responsibility and policy support. Health Communication. https://doi.org/10.1080/10410236.2018.1431025.

McGlynn III, J., \& Richardson, B. K. (2014). Private support, public alienation: Whistle-blowers and the paradox of social support. Western Journal of Communication, 78, 213-237. https://doi.org/10.1080/10570314.2013. 807436.

Miceli, M. P., \& Near, J. P. (1992). Blowing the whistle: The organizational and legal implications for companies and employees. New York: Lexington Books.

Miceli, M. P., \& Near, J. P. (1994). Relationships among value congruence, perceived victimization, and retaliation against whistle-blowers. Journal of Management, 20, 773-794.

Miceli, M. P., Near, J. P., \& Dworkin, T. M. (2008). Whistle-blowing in organizations. New York: Routledge.

Near, J. P., \& Miceli, M. P. (1985). Organizational dissidence: The case of whistleblowing. Journal of Business Ethics, 4, 1-16.

Near, J. P., \& Miceli, M. P. (1995). Effective whistle-blowing. Academy of Management Review, 20, 679-708.

Perry, J. L., \& Wise, L. R. (1990). The motivational bases of public service. Public Administration Review, 50, 367-373.

Rehg, M. T., Miceli, M. P., Near, J. P., \& Van Scotter, J. R. (2008). Antecedents and outcomes of retaliation against whistle-blowers: Gender differences and power relationships. Organization Science, 19, 221-240.

Richardson, B. K., \& McGlynn, J. (2011). Rabid fans, death threats, and dysfunctional stakeholders: The influence of organizational and industry contexts on whistle-blowing cases. Management Communication Quarterly, 25, 121-150. https://doi.org/10.1177/0893318910380344.

Rothschild, J., \& Miethe, T. D. (1999). Whistle-blower disclosures and management retaliation: The battle to control information about organization corruption. Work and Occupations, 26, 107-128.

Slovic, P. (1987). Perceptions of risk. Science, 236, 280-285.

Slovic, P., \& Peters, E. (2006). Risk perception and affect. Current Directions in Psychological Science, 15(6), 322-325.

Slovic, P., Finucane, M. L., Peters, E., \& MacGregor, D. G. (2002). The affect heuristic. In T. Gilovich, D. Griffin, \& D. Kahneman (Eds.), Heuristics and biases: The psychology of intuitive judgment (pp. 397-420). New York: Cambridge University Press.

Slovic, P., Finucane, M. L., Peters, E., \& MacGregor, D. G. (2004). Risk as analysis and risk as feelings: Some thoughts about affect, reason, risk, and rationality. Risk Analysis, 24(2), 311-322.

Sztompka, P. (1999). Trust: A sociological theory. Cambridge: Cambridge University Press.

Tversky, A., \& Kahneman, D. (1981). The framing of decisions and the psychology of choice. Science, 211, 453-458. 


\section{Joseph McGlynn}

Witte, K. (1994). Fear control and danger control: A test of the Extended Parallel Process Model. Communication Monographs, 61, 113-134. https://doi. org/10.1080/03637759409376328.

Witte, K., \& Allen, M. (2000). A meta-analysis of fear appeals: Implications for effective public health campaigns. Health Education and Behavior, 27, 608632. https://doi.org/10.1177/109019810002700506. 


\title{
11 Hero or "Prince of Darkness"? Locating Peer Jacob Svenkerud in an Attributions-Based Typology of Whistleblowers
}

\author{
Brian K. Richardson
}

Did stakeholders consider whistleblower Peer Jacob Svenkerud (PJS) a "hero" or a "prince of darkness"? The answer depends on which stakeholder you ask. Stakeholders include "any group or individual who can affect or is affected by the achievement of the organization's objectives" (Freeman, 1984, p. 46). One of their primary functions, then, is to grant (or withdraw) social legitimacy to the focal organization. Because whistleblowers' accusations threaten organizations' legitimacy, they're often met with management retaliation. But if whistleblowers can garner stakeholder support, their chances of ending wrongdoing and preserving their positions are enhanced (Sawyer, Johnson, \& Holub, 2010). The PJS account offers us an opportunity to examine, in detail, stakeholder involvement in a high-profile whistleblowing case. The academic literature proves reductionistic in addressing how stakeholders view whistleblowers. Rather than differentiating between them, most scholarship and media accounts cast them as heroes, the proverbial "David" taking on the corrupt "Goliath." This ignores the reality that stakeholders might have very different perceptions of whistleblowers based on the attributions they make about them.

This chapter develops a more sophisticated approach to understanding how stakeholders, particularly those outside the organization, might categorize whistleblowers. After a brief literature review addressing motives and attribution theory, I propose a whistleblower typology followed by several theoretical propositions about how select stakeholders might perceive a whistleblower. I then propose PJS's location in the typology before using case details to assess the typology and associated propositions.

\section{Whistleblower: Definitions and Typology}

Whistleblowers are commonly hailed as "heroes" and "saints" by some groups, namely the media, the general public, and victims of corporate malfeasance, while derided as "snitches," "rats," or "traitors" by the accused and those stakeholders who are dependent upon the focal organization (Grant, 2002; Khan, 2018; Trevino \& Victor, 1992). This was 


\section{Brian K. Richardson}

certainly true of PJS, who found himself labeled the "prince of darkness," "man in black," "weak," and a "backstabber" by members of Norsk Tipping's (NT) leadership team but praised for his forthrightness by external auditors. Still, we actually know little about why stakeholders apply such labels to whistleblowers (Heumann, Friedes, Redlawsk, Cassak, \& Kesari, 2015).

In developing a model describing types of whistleblowers, I rely on literature examining (1) the relationship between whistleblower definitions and motives, (2) how stakeholders make sense of whistleblowers, (3) whistleblower attributes of credibility and legitimacy, and (4) attribution theory.

\section{Whistleblowers' Motives}

Some scholars contend that an individual who reports wrongdoing must have pure or altruistic motives to properly qualify as a "whistleblower." For example, Grant (2002) argues that those who personally gain from their reports-for example, through promotions or revenge against othersaren't genuine whistleblowers. Conversely, many scholars acknowledge that, though some individuals who blow the whistle do so for selfish reasons, they are still whistleblowers (Jubb, 1999; Miceli \& Near, 1997). They contend that whistleblowers may be motivated by personal interests such as seeking a promotion or settling personal scores (Loyens, 2013), but as long as wrongdoing is being revealed, their motivations are immaterial (O'Sullivan \& Ngau, 2014). As Bouville succinctly put it, a whistleblower "making the right decision for the wrong reasons is still making the right decision" (2008, p. 583). I myself agree. Anyone who reports wrongdoing to those who may be able to effect action (Near \& Miceli, 1985) merits the title "whistleblower." This is not to suggest, though, that motives are unimportant; indeed, they can influence stakeholders' perceptions of whistleblowers, which can in turn influence whistleblowers' eventual fate.

\section{Stakeholders and Whistleblowing Cases}

Scholars are increasingly noting the potential influence stakeholders can bear on whistleblowing cases. In fact, Sawyer et al. (2010) contend that "whistleblowers usually lose" (p. 93) when stakeholders don't get involved in their cases. Existing research, while limited, suggests stakeholders make judgments about whistleblowers that could influence whether they support or retaliate against them. Teo and Caspersz (2011), for example, found that employees of a small financial services organization said they'd have a hard time trusting a whistleblower because they likened the activity to betrayal and backstabbing; further, they themselves wouldn't want to be labeled a "whistleblower" for fear of ostracism. Heumann et al. (2015) found that the general public holds widely disparate views about whistleblowers. Specifically, $47 \%$ of respondents viewed 
whistleblowers as protectors of the public, $20 \%$ thought whistleblowers "held a grudge," and $15 \%$ believed they are "out to "gain personally" (p. 11). Stakeholders presumably make similar inferences about whistleblowers' motivations. Other research indicates stakeholders get involved in whistleblowing cases by actually becoming whistleblowers themselves (Johnson, Sellnow, Seeger, Barrett, \& Hasbargen, 2004), or can retaliate against or ally with whistleblowers (Richardson \& McGlynn, 2011; Sawyer et al., 2010).

Different kinds of stakeholders might become involved in whistleblowing cases. These include the mass media, regulatory agencies, the general public, and bystanders. All these stakeholders possess power and resources to aid or inhibit whistleblowers (Mitchell, Agle, \& Wood, 1997). The mass media, including local and national news outlets with online and traditional platforms, can add legitimacy to whistleblowers' reports or raise questions about their credibility (Johnson et al., 2004). Regulatory agencies are able to offer support to a whistleblower so that real change can be brought to a context in which wrongdoing is occurring. Sawyer et al. (2010) identified auditors, ombudsmen, and securities commissions as important regulatory targets for whistleblowers' allegations. The general public, too, now has a platform for offering support or detracting from a whistleblower's claims (Park \& Jan, 2017). Finally, bystanders include innocent employees of the organization where wrongdoing is occurring and management of other organizations in the same industry. While these groups aren't directly involved in the whistleblowing case and possess no mandate to address the allegations, whistleblowers could seek their support, thereby enhancing their credibility and legitimacy. Next, I review attribution theory which suggests stakeholders' judgments of whistleblowers will be affected by their perceptions of whistleblowers' motives.

\section{Attribution Theory}

Jones, Spraakman, and Sànchez-Rodríguez (2014) believe that whistleblowing always involves some self-interest. I agree but would add that as the nature of that interest becomes known by stakeholders, they will judge the whistleblower accordingly. Attribution theory contends that people make interpretations about the causes of events that in turn affect their perceptions and responses (Weiner, 1980). Initial judgments are affected by three dimensions: controllability, stability, and, related to this study, locus. "Locus" refers to locus of control-that is, whether a behavior was under an individual's volition or induced by external forces. Some whistleblowers were involved in the unethical behavior they report, suggesting internal control. Meanwhile, other whistleblowers were witnesses to wrongdoing caused by other individuals or groups. Kelsey, Kearney, Plax, Allen, and Ritter (2004) found people ascribe internal attribution to negative behaviors, which suggests they might label complicit wrongdoers 


\section{Brian K. Richardson}

as "dishonest" or "unethical" people even if they later blew the whistle on this activity. Thus, it's reasonable to expect most stakeholders to be critical of whistleblowers who were engaged in the very wrongdoing they are now exposing.

Another factor related to attribution is motivation, or the perceived reason why someone engaged in a particular behavior. The decision to blow the whistle can be motivated by either selfish or altruistic reasons. Altruistic motivations are characterized as purely voluntary and are also not inspired by the potential of rewards or to avoiding punishment, or being beneficial to others (Leeds, 1963). Conversely, selfish motives stem from individuals personally benefitting from their actions (Quigley, Gaes, \& Tedeschi, 1989). Weinstein, DeHaan, and Ryan (2010) found that when people make altruistic attributions about others' helping behaviors, they are more thankful and perceive the helper "as more generous, admirable, and as exhibiting a larger number of positive and a smaller number of negative personality characteristics" (p. 428). Conversely, we would expect that when stakeholders attribute others' behaviors to selfish reasons, they view them negatively. Research indicates the public is less supportive of whistleblowers motivated by self-interest than by altruism (Heumann et al., 2015).

My proposed typology is developed along two dimensions that I believe are critical in stakeholders' attributions of whistleblowers' reports. First, stakeholders take note of whether the whistleblower participated in or merely observed the alleged wrongdoing. The typology's second dimension involves whether the whistleblower's motives are altruistic or selfish. Selfish reasons for blowing the whistle include seeking fame, revenge, and financial reward (Miceli \& Near, 1997). Miceli and Near believe that stakeholders may disapprove when someone materially benefits from reporting wrongdoing.

\section{The Typology}

In this section, I present the four types of whistleblowers. I call them the confessor, the jilted lover, the saint, and the opportunist. For each, I offer theoretical propositions related to stakeholders' perceptions of their credibility and legitimacy.

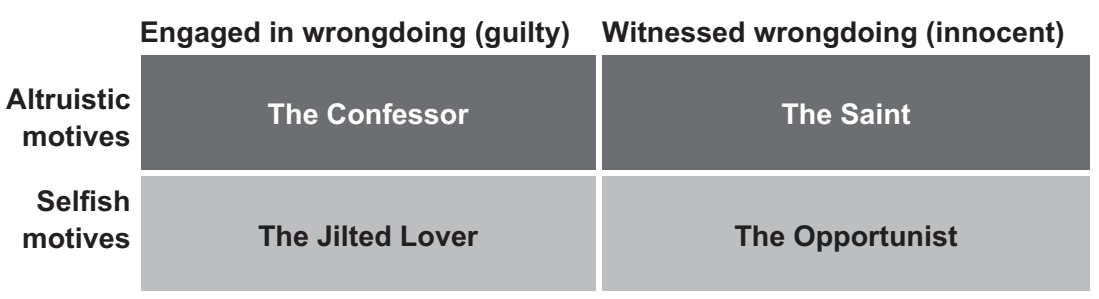

Figure 11.1 Typology of Whistleblowers 
The Confessor (guilty + altruistic). The "Confessor" is the whistleblower who participated in wrongdoing and is now reporting it for altruistic, soulcleansing reasons, in effect confessing their prior transgressions. Miceli and Near (1997) acknowledge wrongdoers may be motivated to blow the whistle on their own actions if their conscience is bothering them. This latter reason, as well as the person using the wrongdoing to promote a larger cause, represents altruistic reasons for a wrongdoer to turn whistleblower.

The Jilted Lover (guilty + selfish). This whistleblower type, like the Confessor, engaged in wrongdoing but is motivated to report it for selfish reasons, such as revenge, chest-beating, or material gain.

The Opportunist (innocent + selfish). "Opportunists" are whistleblowers who observed wrongdoing and reported it for selfish, or opportunistic, reasons. Heumann, Friedes, Cassak, Wright, and Joshi (2013) use the term "avenger" to refer to whistleblowers whose motives are largely revenge or retributive. While this is certainly true of whistleblowers in the opportunist type, not all of them aim to hurt other individuals. Some will use their whistleblowing for material benefit.

The Saint (innocent observer + altruistic). "Saints" are whistleblowers who have observed wrongdoing and are reporting it for altruistic reasons. The Saint resembles Heumann et al.s (2013) "altruist"-the whistleblower who "sees an evil, objects fearlessly, and fights valiantly within, and even beyond, the organization for the sake of justice and remedy" (p. 40). He or she "is the conscience of the organization, standing, personally and directly to gain nothing from the proven truth of the claims made" (p. 40).

\section{Propositions}

I now discuss two resources critical to whistleblowers' effectiveness that will be presented as part of theoretical propositions.

Credibility. Credibility is one of the most regularly cited factors for explaining whistleblowing effectiveness (Guthrie, Norman, \& Rose, 2012), as it enhances the possibility that it will influence top management to correct wrongdoing (Near \& Miceli, 1985, 1995). The scholars contend that stakeholders' perceptions of credibility are tied to whistleblowers' motives, whether they are focused on helping others or serving their own interests; whistleblowers possessing altruistic motives are more likely to achieve desired changes, whereas those perceived as possessing selfish motives may have their claims disregarded altogether. Johnson et al. (2004) suggest whistleblowers often use the mass media to bring attention to their claims; whistleblowers perceived as high in credibility are more likely to have the media treat their reports as serious and worthwhile. Sawyer et al. (2010) suggest management retaliation against whistleblowers is employed to undercut their credibility, which in turn makes them susceptible to more retaliation. 


\section{Brian K. Richardson}

Legitimacy. Legitimacy is "a generalized perception or assumption that the actions of an entity are desirable, proper or appropriate within some socially constructed system of norms, values, beliefs, and definitions" (Suchman, 1995, p. 77). Stakeholders can confer legitimacy upon organizations and individuals; however, they can also take away this resource which is associated with organizational survival and personal influence (Sawyer et al., 2010). Sawyer et al. suggest whistleblowers are stakeholders of their organizations. But without legitimacy conferred by more powerful stakeholders, they often lack power to end wrongdoing. Whistleblowers who acquire the support of powerful stakeholders, such as the Department of Justice, increase their chances of success. Further, the whistleblower's legitimacy possesses a negative correlation with the organization's legitimacy - that is, as the whistleblower's legitimacy increases, the organization's decreases. Thus, accused organizations often use retaliation to reduce a whistleblower's perceived legitimacy (Sawyer et al., 2010). I contend legitimacy is a critical resource for whistleblowers, at least partly determining their ability to get key audiences to listen to their claims.

Since research finds that individuals, including whistleblowers, who are motivated by altruism will be held in higher regard than their selfish counterparts (Heumann et al., 2013; Weinstein et al., 2010), we expect altruistic and innocent whistleblowers to generate more positive perceptions about their actions than their selfish, guilty counterparts. It follows that the Saint and the Confessor will have the most altruistic attributions bestowed upon them, as they are acting to help the situation. Since Saints aren't tainted by participation in the unethical behavior, they will be perceived as more legitimate than Confessors. Conversely, we would expect when stakeholders attribute others' behaviors to selfish reasons, they see them negatively, suggesting the Opportunist and Jilted Lover are found low in legitimacy. Since the Jilted Lover is tainted by participation in wrongdoing, he or she would be viewed as less legitimate than the Opportunist. Thus:

Proposition 1: Stakeholder groups will perceive the Saint as the most legitimate whistleblower, followed by the Confessor, the Opportunist, and the Jilted Lover.

Credibility. Stewart (1980) recognized the importance of credibility when she argued that whistleblowers "are more likely to be heard and believed if they appear to lose from their act" (p. 95). With regard to the news media, Liebes and Blum-Kulka (2004) contend that those whistleblowers most eager to tell their stories are less trustworthy and the information they report is tainted, suggesting that whistleblowers who report for selfish reasons are viewed as less credible. Johnson et al. (2004) contend that "if a whistle-blower is labeled as a self-serving, disloyal squealer or stool 
pigeon, then credibility is questioned and the message has less impact" (p. 356). In light of this literature, I offer the following proposition:

Proposition 2: Stakeholder groups will perceive the Saint as the most credible whistleblower, followed by the Confessor, the Opportunist, and the Jilted Lover.

Retaliation. Alleged wrongdoers and others in an organization often employ retaliatory measures against whistleblowers (Richardson \& McGlynn, 2011; Rothschild \& Miethe, 1999). Retaliation is used to lower the whistleblower's perceived credibility and legitimacy (Sawyer et al., 2010). For example, Richardson and McGlynn (2011) found that organizations use tactics such as isolation, labeling, and interpersonal conflict to discredit whistleblowers. I anticipate that the more credible and legitimate a whistleblower is perceived to be, the more retaliation they will encounter. Thus, I propose the following:

Proposition 3: The Saint, followed by the Confessor, the Opportunist, and the Jilted Lover, will receive the maximum retaliation.

Properly testing these theoretical propositions will require comparative cases beyond that of PJS's. Still, the rich data related to his case, provided by interviews, internal documents, and media stories, offer an opportunity for preliminary assessment of the typology. In other words, the PJS case is useful for an initial assessment of the typology and its associated propositions. I now locate PJS within the typology.

\section{Locating PJS Within the Typology}

PJS appears to represent the "Saint" type of whistleblower. According to the interview data, he reported wrongdoing for altruistic reasons. For example, when discussing his growing confidence that blowing the whistle was necessary, he said:

If Norsk Tipping said that we were responsible, we had to show it. It's time for it. I think basically I thought, 'if I leave now and do not stick up what I have preached, or what I have communicated to the company and to the surroundings, that would be unfair to whom I wanted to be."

Identity statements, such as “... whom I wanted to be," are cues for altruistic motives as they reflect the whistleblower speaking out as a result of his internal values. It further appears that PJS was largely an innocent bystander to unethical behavior, though he does confess to benefitting from some of the organization's lavish spending. For example, he 


\section{8}

mentions having attended a gaming conference in South Africa at which a client of NT "paid all the bills. All the alcohol, all the dinners, rounding up tens of thousands of crowns in costs and we never questioned it. I was in on it." Involvement in wrongdoing would shift PJS's categorization to a Confessor, one who was involved in wrongdoing but is not reporting it for altruistic reasons. Despite this admission to at least some participation in various excessive spending, I would still categorize PJS as a Saint whistleblower. There is no evidence that stakeholders knew of his participation in this particular event nor was it an egregious violation of ethical protocol. Even as his identity as whistleblower became public, he was never accused of benefitting from wrongdoing by his fellow administrators. PJS's case reveals an important aspect of the proposed typology: stakeholders perceived PJS as an innocent bystander and thus he was treated as one. Perception was reality.

PJS's anonymity, particularly early in the case, reveals a possible limitation of the typology. For much of the case, stakeholders didn't know who had blown the whistle at NT, so they were unable to make judgments about the whistleblower's motives. The present model does not account for anonymity. Based upon existing literature, stakeholders will question the motives of anonymous whistleblowers or assign motives that are inaccurate (Elliston, 1982). Indeed, PJS recognized that his anonymity allowed the CEO to develop an unflattering narrative about "the whistleblower." PJS said:

And that was a big handicap of being anonymous and being in the role that I was. The CEO and others were able to establish a picture of a person that just wanted him out, that was a hidden enemy that ran behind him with a knife, ready to stab him in the back. It took several years before I could say anything. I was completely helpless in that aspect.

While it appears the proposed typology might be limited to open whistleblowers, stakeholders can and do make attributions of anonymous ones. But these attributions may be inaccurate. Further, if sympathetic stakeholders don't know the identity of a whistleblower, the most support they can provide is indirect. Thus, whether a whistleblower is known or anonymous should be added as a dimension to the model.

While the data don't allow a direct comparison between PJS and other whistleblowers, he appeared to possess high credibility and legitimacy with those stakeholders who knew his identity. As a Saint whistleblower, this is expected; he isn't tarnished by either participation in wrongdoing or blowing the whistle for selfish reasons. When PJS revealed his identity as the whistleblower to the auditors, they followed his lead as they investigated the company. They even praised him as "the whistleblower" in their final report. There is no evidence that the auditors ever doubted 
PJS's veracity. The media also treated PJS with reverence in their account that publicly outed him as the whistleblower. His perception of the story was that "everything was correct." In addition, he viewed other external stakeholders, such as members of the Norwegian Athletic Association (NAA) and communications consultants, as supporting his efforts:

A senior executive of the Norwegian Athletic Association was very supportive, and very vocal about what he thought was wrong. . . . I also had some consultants that I used that were experts on communications. And they were, of course, very supportive because they said, 'You're doing the right thing. There is absolutely no question about it. You just need to stick to it.'

External stakeholders treated PJS as a credible, legitimate source. While we lack direct evidence confirming their support for him, I believe his lack of involvement in unethical behavior and his altruistic motivations facilitated it. Based upon the propositions described earlier, he received more support than he would have had he been one of the other types of whistleblowers because of lowered perceptions of his credibility and legitimacy.

Finally, the model proposes that a Saint whistleblower typically faces greater retaliation than the other types in an attempt to reduce their credibility and legitimacy. Recall what happened when PJS was called to a meeting with other NT executives shortly after the news media outed him. There, he was put on the carpet, questioned about his authority, and criticized by several of his colleagues. For roughly a year and a half, from January 2010 to July 2011, NT's new permanent CEO consistently sent him unsolicited and mixed messages about his role within the firm. PJS exited it when he determined that his prior status in the company would never be regained. I am left wondering if this is the fate of many Saint whistleblowers. Saints are pure; they didn't participate in wrongdoing, and they blew the whistle for honorable reasons. An incoming CEO will assemble a new executive team, and while they may not have engaged in unethical behavior themselves, they may not trust the Saint whistleblower when they attempt to navigate the gray spaces of the organizational bureaucracy. After all, "it is normally assumed that the whistleblower will re-offend, that is, once a whistleblower, always a whistleblower" (Sawyer et al., 2010, p. 98).

\section{Conclusion}

Whistleblowing doesn't occur in a vacuum (Gundlach, Douglas, \& Martinko, 2003; Vadera, Aguilera, \& Caza, 2009). Individuals contemplating whether to blow the whistle may be influenced by various things-impression-management tactics of the wrongdoer (Gundlach 
et al., 2003), support from top management (Vadera et al., 2009), or peer-group pressure (Ash, 2016). Once they blow the whistle, if they're lucky they'll enjoy social support offered by co-workers or peers (McGlynn \& Richardson, 2014). Thus, scholars have identified how elements internal to the organization influence whistleblowing. My purpose here was to contribute to the emerging research investigating how external groups impact whistleblowing decisions and outcomes (Heumann et al., 2015; Sawyer et al., 2010). The PJS-NT case offers, in rich detail, the opportunity to explore relationships among elements of whistleblowing often overlooked in research, including whistleblower motives, (external) stakeholder involvement, and anonymity.

It's reasonable to wonder whether PJS would have become a whistleblower without the influence of key stakeholders. Indeed, stakeholder involvement was present throughout his whistleblowing process. Early on, representatives of the NAA raised concerns with him about how NT utilized its financial resources. Similarly, a prominent journalist questioned the relationship between the CEOs of NT and one of the company's primary vendors. It's possible these stakeholders reinforced PJS's concerns about NT's business practices, emboldening him to speak out. As the case progressed, he received critical social support for his cause from several stakeholders, including a senior executive of the NAA. However, because of his anonymity, it's unclear whether he could have garnered more stakeholder support, which might have altered the trajectory of the case. Another stakeholder, the news media, eventually outed PJS as the whistleblower but did so evenhandedly. It was apparent journalists perceived PJS as a credible whistleblower arguably because of his lack of involvement in wrongdoing and his altruistic reasons for blowing the whistle. Unfortunately, this outing likely led to PJS's pressured exit from the organization.

The PJS case raises questions about why external stakeholders become involved in whistleblowing cases. At present, much of the whistleblowing literature either ignores the presence and influence of external stakeholders or fails to explain why and how these stakeholders may become involved in these cases. To address this gap in our understanding of whistleblowing, I used the PJS case as an impetus to develop a typology of whistleblowers based on their culpability (or innocence) in the wrongdoing and their motives (altruistic or selfish) for blowing the whistle (altruistic or selfish). I then located PJS within the typology to assess it and relevant propositions, which revealed that stakeholder perceptions about whistleblower motives and culpability are key; stakeholders either were unaware of PJS's minimal involvement in the lavish vendor celebration or didn't think it rose to the level of unethical behavior. The case further reveals the importance of whether a whistleblower is anonymous or known. PJS received minimal direct support from key stakeholders during the early phases of the case because of his anonymity. Thus, anonymity 
should be added to the model as an important dimension. While comparative data were not available, PJS seemed to fit the profile of the Saint whistleblower. He appeared to be viewed as credible and legitimate by external stakeholders. Unfortunately, though, he appeared too "pure" for NT's new CEO, who may have questioned PJS's loyalty had he remained with the firm. This suspicion likely led to PJS's exit from the company. As it relates to the model, the Saint whistleblower (PJS) experienced severe retaliation for his reports of wrongdoing.

The exploration of the PJS case within the proposed typology offers promise for research into whistleblowing processes; still, further inquiries are required to determine support for the model and the propositions I've advanced. For example, researchers could conduct experiments assessing how stakeholders perceive whistleblowers based upon their innocence/ culpability and whether they possessed altruistic/selfish motives for blowing the whistle. Interpretive scholars could closely examine case studies to determine if additional dimensions, such as communication channels, are relevant to how stakeholders perceive whistleblowers. Until such research is executed, we are relying on a "one size fits all" approach for understanding how stakeholders perceive whistleblowers that may have limited usefulness and functionality. After all, without the involvement and support of key stakeholders, PJS may never have become a whistleblower.

\section{References}

Ash, A. (2016). Whistleblowing and ethics in health and social care. London: Jessica Kingsley Publishers.

Bouville, M. (2008). Whistle-blowing and morality. Journal of Business Ethics, 81, 579-585.

Elliston, F. A. (1982). Anonymity and whistleblowing. Journal of Business Ethics, 1, 167-177.

Freeman, R. E. (1984). Strategic management. Marshfield, MA: Pitman.

Grant, C. (2002). Whistle blowers: Saints of secular culture. Journal of Business Ethics, 39, 391399.

Gundlach, M. J., Douglas, S. C., \& Martinko, M. J. (2003). The decision to blow the whistle: A social information processing framework. Academy of Management Review, 28, 107-123.

Guthrie, C. P., Norman, C. S., \& Rose, J. M. (2012). Chief audit executives' evaluation of whistle-blowing allegations. Behavioral Research in Accounting, 24, 87-99.

Heumann, M., Friedes, A., Cassak, L., Wright, W., \& Joshi, E. (2013). The world of whistleblowing. Public Integrity, 16, 25-52.

Heumann, M., Friedes, A., Redlawsk, D., Cassak, L., \& Kesari, A. (2015). Public perceptions of whistleblowing. Public Integrity, 18, 6-24. https://doi.org/10.1 080/10999922.2015.1093997.

Johnson, C. E., Sellnow, T. L., Seeger, M. W., Barrett, M. S., \& Hasbargen, K. C. (2004). Blowing the whistle on Fen-Phen. Journal of Business Communication, 41,350-369. 


\section{Brian K. Richardson}

Jones, J. C., Spraakman, G., \& Sànchez-Rodríguez, C. (2014). What's in it for me? An examination of accounting students' likelihood to report faculty misconduct. Journal of Business Ethics, 123, 645-667.

Jubb, P. B. (1999). Whistleblowing: A restrictive definition and interpretation. Journal of Business Ethics, 21, 77-94.

Kelsey, D. M., Kearney, P., Plax, T. G., Allen, T. H., \& Ritter, K. J. (2004). College students' attributions of teacher misbehaviors. Communication Education, 53, $40-55$.

Khan, R. (2018). Whistleblower: Warrior, saboteur or snitch? Forbes. Retrieved from www.forbes.com/sites/roomykhan/2018/07/05/whistleblower-warriorsaboteur-or-snitch/\#53bb06736362.

Leeds, R. (1963). Altruism and the norm of giving. Merrill-Palmer Quarterly, 9, 229-240.

Liebes, T., \& Blum-Kulka, S. (2004). It takes two to blow the whistle: Do journalists control the outbreak of scandal? American Behavioral Science, 47, 1153-1170.

Loyens, K. (2013). Towards a custom-made whistleblowing policy. Using gridgroup cultural theory to match policy measures to different styles of peer reporting. Journal of Business Ethics, 114, 239-249.

McGlynn, J., \& Richardson, B. K. (2014). Public support, private alienation: Whistle-blowers and the paradox of social support. Western Journal of Communication, 78(2), 213-237.

Miceli, M., \& Near, J. (1997). Whistleblowing as antisocial behavior. In R. A. Giacalone \& D. B. Greenberg (Eds.), Antisocial behavior in organizations

Mitchell, R. K., Agle, B. R., \& Wood, D. J. (1997). Toward a theory of stakeholder identification: Defining the principle of who and what really counts. Academy of Management Review, 22, 853-886.

Near, J. P., \& Miceli, M. P. (1985). Organizational dissidence: The case of whistle-blowing. Journal of Business Ethics, 4, 1-16. https://doi.org/10.1007/ BF00382668.

Near, J. P., \& Miceli, M. P. (1995). Effective whistle-blowing. Academy of Management Review, 20, 679-708.

O'Sullivan, P., \& Ngau, O. (2014). Whistleblowing: A critical philosophical analysis of the component moral decisions of the act and some new perspectives on its moral significance. Business Ethics: A European Review, 23, 401-415.

Park, Y. J., \& Jang, S. M. (2017). Public attention, social media, and the Edward Snowden saga. First Monday, 11. Retrieved from http://firstmonday.org/ojs/ index.php/fm/article/view/7818/6517

Quigley, B., Gaes, G. G., \& Tedeschi, J. T. (1989). Does asking make a difference? Effects of initiator, possible gain, and risk on attributed altruism. The Journal of Social Psychology, 129, 259-267.

Richardson, B. K., \& McGlynn, J. (2011). Rabid fans, death threats, and dysfunctional stakeholders: The influence of organizational and industry contexts on whistle-blowing cases. Management Communication Quarterly, 25, 121-150.

Rothschild, J., \& Miethe, T. D. (1999). Whistle-blower disclosures and management retaliation. Work and Occupations, 26(1), 107-128.

Sawyer, K. R., Johnson, J., \& Holub, M. (2010). The necessary illegitimacy of the whistleblower. Business \& Professional Ethics Journal, 29, 85-107. 
Stewart, L. P. (1980). "Whistle blowing”: Implications for organizational communication. Journal of Communication, 30, 90-101.

Suchman, M. C. (1995). Managing legitimacy: Strategic and institutional approaches. Academy of Management Review, 20, 571-610.

Teo, H., \& Caspersz, D. (2011). Dissenting discourse: Exploring alternatives to the whistleblowing/silence dichotomy. Journal of Business Ethics, 104, 237-249.

Trevino, L. K., \& Victor, B. (1992). Peer reporting of unethical behavior: A social context perspective. Academy of Management Journal, 35, 38-64.

Vadera, A. K., Aguilera, R. V., \& Caza, B. (2009). Making sense of whistleblowing's antecedents: Learning from research on identity and ethics programs. Business Ethics Quarterly, 19, 553-586.

Weiner, B. (1980). A cognitive (attribution)-emotion-action model of motivated behavior: An analysis of judgments of help-giving. Journal of Personality and Social Psychology, 39, 186-200.

Weinstein, N., DeHaan, C., \& Ryan, R. (2010). Attributing autonomous versus introjected motivation to helpers and the recipient experience. Effects on gratitude, attitudes, and well-being. Motivation \& Emotion, 34, 418-431. 


\title{
12 Norsk Tipping's Loneliest Stakeholder
}

\author{
Crisis, Issues, and the Stakeholder Voice
}

\author{
Audra Diers-Lawson
}

The company was suffering from my presence, given what had happened. 'You have done a very good job,' he [the new permanent $C E O$ ] said, 'but it's time to go. Your mission is accomplished.' . . . I was puzzled. I was in shock. A month and a half earlier, he had said I was his greatest supporter. . . Now, I was a liability for the company-not just for him, but for the company. This followed a pattern that I had read about. If you do blow the whistle, you have truly become a liability, no matter what you do.

—Peer Jacob Svenkerud

Throughout this book, we have dipped in and out of the riveting experience of Peer Jacob Svenkerud (PJS) as a whistleblower at NT. Yet, for me the foregoing passage is perhaps the most moving of all, as it encapsulates the profound sadness and utter loneliness of his protracted ordeal. In exposing NTs transgression, he triggered a major crisis. He also fomented much-needed reforms there. But, ironically, he also became, in the eyes of many, the very personification of the NT scandal, even though he was not at fault. His experience bears our close attention. In crisis communication, we typically hear narratives of recovery and renewal, or we hear from internal and external stakeholders about their surprise and dismay at some scandal, or we hear about what the organization did well and could have done better, or we hear about the external stakeholders affected by the crisis. Yet, we seldom are afforded a glimpse into the employee's momentous decision whether to stay silent or blow the whistle, and what happens to them in the aftermath of speaking out (Chen \& Lai, 2014; Edwards, Lawrence, \& Ashkanasy, 2016; Heide \& Simonsson, 2015).

This underscores a point that Frandsen and Johansen (2016) made: crises are especially challenging to analyze because they represent the intersection of many stakeholder voices and perspectives on an organization and situation. My purpose here is to explore whistleblowing from a crisis perspective and the whistleblower himself as a vital stakeholder whose 
duality of experience-as both initiator and casualty of the crisis—reveals new insights into our understanding of crises and crisis communication. PJS's experience broadens our understanding of the complexity of crises in general, as well as the unique components of those crises triggered by whistleblowing. It helps us to better understand that the relationships among crisis issues, stakeholders, and the organization are indeed multilayered and fluid.

For example, in a case like this, the question of blame attribution is both easy and hard to answer. It's easy because we have a well-substantiated transgression-a situation in which the organization has clearly done something wrong (Diers-Lawson, 2017a). Yet, because it has also been triggered by a whistleblower, other stakeholders-both within and outside the company-may view him not as a hero but as a villain or at least a problem. This makes blame attribution less a question of the facts of a situation than a question of perception and competing interests. Thus, PJS's account of his experience as a whistleblower provides a telling example of competing stakeholder interests in the crisis context.

To better understand the NT case and the challenges of sorting out competing stakeholder interests in crises, I frame whistleblowing within the crisis context, discuss a stakeholder relationship-management approach to understanding whistleblowing, and discuss PJS's experience throughout to help unpack the difficulties in managing whistleblowing from a crisis perspective.

\section{Whistleblowing in the Crisis Context}

From the first formal study of crises and crisis communication in the mid-20th century to the turn of the 21st century, a crisis was generally thought of as a "low probability, high-impact event that threatens the viability of the organization and is characterized by ambiguity of cause, effect, and means of resolution, as well as by a belief that decisions must be made quickly" (Pearson \& Clair, 1998, p. 60). This definition of crisis was subsequently supported by the body of research that emerged throughout the past 40 years. Over time, both practitioners and academics further recognized that crises are also increasingly ill-structured and complex (Mitroff, Alpaslan, \& Green, 2004), particularly in an increasingly global and connected world.

But, thanks to the greater volume of research, diversity of theoretical perspectives, and internationalization in crisis communication over the past 15 years or so, how we define a crisis has also evolved (Diers-Lawson, 2017a). Instead of thinking of crises as low-probability and high-impact events with ambiguous causes and outcomes, we now typically think of them as "untimely but predictable events that have actual or potential consequences for stakeholders' interests as well as the reputation of the 


\section{6}

organization" (Heath \& Millar, 2004, p. 2). This means that while Pearson and Clair's (1998) definition of "crisis" describes some types of crisis, what we generally understand to be a crisis requires a more sophisticated understanding of the connection among risk, triggers, and stakeholder impact. As such, the precipitating events for crises can actually range considerably-from circumstances entirely beyond an organization's control, to the careless mistakes of individuals within an organization, to systematic breakdowns or inefficiencies, and to many circumstances in between (Argenti, 2002; King, 2002; Pearson \& Clair, 1998; Reilly, 1987). A modern understanding of "crisis" provides a strong conceptual underpinning for understanding the NT case, helping us to understand that while many crises are predictable and avoidable, the evolution of those crises and their impact on different stakeholders remain damaging for both the organization and the stakeholders.

The NT case also helps to demonstrate three characteristics of crises that are consistent no matter what events precipitate them.

First, crises are inherently public in nature (Moore, 2004). The NT scandal proved impossible to contain. As some facts of financial mismanagement began to emerge and then as information about the whistleblowing also emerged, it was played out incessantly-in the local press, the local community, and even in the broader national community. Additionally, given the company's prestigious standing in its hometown and the potential implications of it, there was little respite for the companyor for PJS himself.

Second, while crises happen to or because of an organization, its members do not exist in isolation. Crises affect lots of people-not just those within the organization but also those in the community, country, and region(s) in which it operates. This means that crisis management and crisis communication should always be focused on the people and groups with an interest in the organization and its activities, namely, its stakeholders (Freeman, 1999). The NT crisis was clearly divisive for PJS, NT, and the local community, not to mention a network of organizations affected by the situation. In PJS's narrative, this is why we see the oftentimes contradictory praise, condemnation, and questioning of his actions: each stakeholder involved was viewing the crisis and his or her actions from the perspective of their own interests.

Third, the core stake at risk in a crisis is the relationship between an organization and its stakeholder(s). If these relationships fail, the outcomes of that failure can range from reputational damage to the wholesale failure of the organization and/or its mission. By the same token, if these relationships are ultimately strengthened, then an organization can prosper despite the crisis-or perhaps even because of it. Herein lies one of the inherent contradictions of a whistleblowing crisis. Where PJS's integrity and self-sacrifice as a whistleblower were celebrated by many stakeholders, mostly externally, internally he became the troublemaking 
"dark knight" and represented a liability for NT, both because many colleagues now feared him and because he was a constant reminder of the company's misdeeds. One could assume NT believed it would be more difficult for the company to reconstruct its reputation so long as he remained an employee.

Yet, despite his often tumultuous journey, Peer is also able to step outside of himself as a whistleblower to analyze his situation with its various organizational challenges, and to reflect on the decision-making process that brought him to finally speak up. In their analysis of processes like his, Chen and Lai (2014) found that the choice to blow the whistle represented a relatively rational ethical decision-making framework where the whistleblower balanced the moral exigencies of the situation against the potential harms and social pressures he might face after exposing the wrongdoing. These findings are consistent with numerous studies examining the employee perspective on whistleblowing. They have found that organizational and contextual factors shape employee perceptions and emotions and will ultimately predict either whistleblowing or silence in the face of transgressions (Edwards et al., 2016; Grimm, Choo, Horvath, \& Nitta, 2016; Liu, Liao, \& Wei, 2015; Mesmer-Magnus \& Viswesvaran, 2005). In PJS's case, we see the internal conflict play out between the categorical imperative he felt-to be a socially responsible citizen and employee- and the unspoken expectations that went with being a good team member, or loyalist. His ultimate advocacy meant that his own understanding of "loyal" was not the same as how others at NT defined it. These conflicting value systems inevitably took their toll on his ability to manage his professional and interpersonal relationships within the organization. He felt trapped-and indeed was.

This case also provides an important and often ignored narrative about transgressions in organizations-the emotional journey that employees take through the crisis, no matter whether they are whistleblowers or simply onlookers trying to make sense of the unfolding events. In crisis communication, we often focus exclusively on external stakeholders, ignoring the employee voices and perspectives that are vital to managing issues and crises alike (Heide \& Simonsson, 2015; Mazzei, Kim, \& Dell'Oro, 2012; Mazzei \& Ravazzani, 2014). As such, the question of how an organization might best manage a crisis may be better understood in the context of whistleblowing, as it lets us evaluate the quality of relationships between organizations and their many different kinds of stakeholders during and after a crisis goes public.

\section{Whistleblowing and Stakeholder Relationship Management}

If we are to talk about whistleblowing within a stakeholder framework, then it's important to better understand the nature of the voices and perspectives that stakeholders can represent. At the simplest level, "stakeholders" 


\section{Audra Diers-Lawson}

are those groups or individuals who can affect or be affected by an organization (Freeman, 1994). But as straightforward as this definition seems, the degree to which stakeholder voices and perspectives are actually integrated with organizational objectives and behaviors will depend on the nature of the relationship among them. Much of the foundational work in stakeholder theory in organizational communication (Connolly, Conlon, \& Deutsch, 1980; Frooman, 1999; Henriques \& Sadorsky, 1999; Mitchell, Agle, \& Wood, 1997; Rowley, 1997) identifies the dimensions of interorganizational relationships as characterized by five factors.

First, relational valence describes the relative affect-positive to negative-that's felt between an organization and a stakeholder (Atkins \& Lowe, 1994). Not surprisingly, for whistleblowers, that relationship can be highly adversarial. For example, PJS's experience of finding himself characterized as a "dark knight," plus the replacement CEO's apparent campaign not only to root out the anonymous whistleblower but also the ongoing efforts to push him out of NT once the organization was in a post-crisis recovery mode, all prove the negativity-the negative valence-that whistleblowers can face as stakeholders.

The second factor is the history of interaction between organizations and particular stakeholders that allows for structures and rituals of interaction to emerge (Harris, 1994; Jennings, Artz, Gillin, \& Christodouloy, 2000; Scott \& Lane, 2000; Trice \& Beyer, 1993). To illustrate the employee history at NT, PJS characterized the organizational culture as being subdued: any employees who asked too many questions "could face consequences." His predecessor was removed, Peer says, because he had questioned the company's approach too much.

The third factor focuses on an organization's assessment of a stakeholder group's legitimacy — that is, its recognizability, reputation, and/or expertise relevant to the organization's core work (Haley, 1996; Suchman, 1995). For example, NT's go-along, get-along culture seemed to be supported by other stakeholders such as unions. PJS described the union members as "loyal soldiers" who never challenged management. This suggests that dissenting views, voices, and interests at NT had been effectively delegitimized.

Fourth, the power that a stakeholder has, or doesn't have, to influence the organization or its success will affect their relationship with the organization (Heath, 1994; Mitchell et al., 1997). Recall PJS describing his early days of acculturation in the organization. It became clear to him that even though he and a number of external stakeholders would have welcomed changes both to the sponsorship programs and to NT's approach to gaming, their perspectives weren't valued by the company, so their influence was limited, and early opportunities to avoid the larger crises to follow weren't taken.

Fifth is the urgency of a stakeholder's interest in the organization. "Urgency" refers to the extent to which a stakeholder's interest or influence is time-sensitive or critical to the organization's well-being at 
a particular time (Connolly et al., 1980; Mitchell et al., 1997; Scott \& Lane, 2000). In PJS's case, once he was outed by a Norwegian financial newspaper, NT's new CEO had to engage the employees directly about that news. Unfortunately, where the CEO had previously supported PJS's role as a whistleblower, PJS interpreted his actions in that they were now framed to the employees in terms of the "complications" they would cause NT instead of as a prime opportunity for them all to learn and improve. This important departure in the CEO's narrative and sensemaking about the crisis from PJS's point of view marked a change in the nature of their relationship based on the urgency of addressing PJS's role as both an employee and as the whistleblower.

\section{Complexity Within Organizational Environments}

One of the best lessons we can learn from PJS's experience is just how complex, challenging, and changeable crises will seem once we consider the environments in which organizations operate. Both organizations and organizational actors are subject to many pressures because they serve multiple stakeholders (Connolly et al., 1980; Frooman, 1999). These stakeholders range widely. They can include groups such as employees, customers or clients, regulators, and competitors (Figure 12.1).

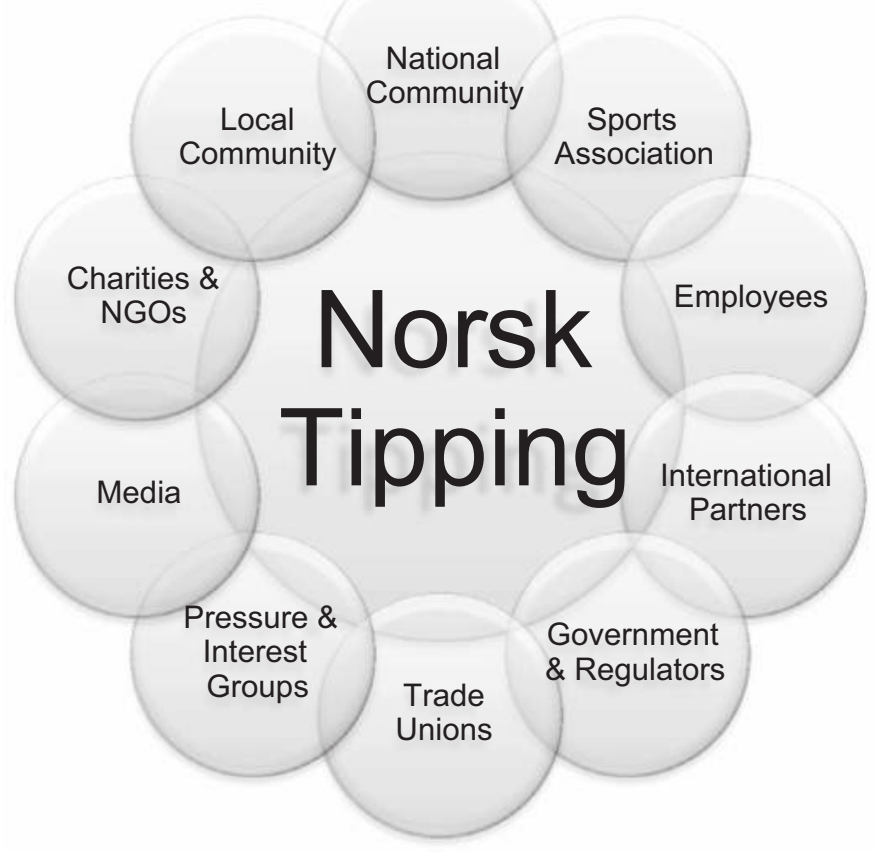

Figure 12.1 Examples of Some of Norsk Tipping's Stakeholders 
But, complicating matters still further, even these interactions between organizations and stakeholders happen not in isolation but rather in a web of relationships (Rowley, 1997). In fact, Fombrun (1982) suggests that we should think of an organization's environment as a series of overlapping networks that help to explain why organizations act, or do not act, and even how they perform. Furthermore, Heath (1994) argues that what an organization is and does is really just an outcome of managing all of the interests of all the stakeholders it values. Thus, a prime purpose of communication is to help an organization and its stakeholders enact and manage their relationships (Heath, 1994).

But as PJS's experience demonstrates, stakeholders not only demand different forms of engagement but also have vastly different expectations as well. So where Frandsen and Johansen (2016) describe crises as the intersection of different voices and perspectives, we should probably be thinking of crises as cases in which organizations have failed to meet at least one important stakeholder expectation. Sometimes crises will arise because of competitive stakeholder interests. In the case of NT, one of its core purposes was to serve the public interest by funding charities, sports, and public works across Norway. The company made much of its vaunted "social responsibility." Yet, this could be at odds with some of the very activities it conducted. For example, gaming funded a lot of the good work that NT sought to do. However, PJS flagged the challenge of managing gaming against the risks of encouraging gambling addictiona perfect example of potentially contradictory stakeholder interests. It wasn't enough to use the proceeds from gaming to support socially responsible ends; NT also needed to be socially responsible when earning those proceeds. Earning some of it from gambling addicts whose addiction the company itself helped create raised all kinds of moral questions sure to bother at least some stakeholders.

\section{Stakeholder Relationship Management Model}

If we think about the nature of organizational crises, with all their competing voices and interests, plus the sometimes contradictory environment in which organizations operate, then the importance of managing stakeholder relationships is a key part of what it means for organizations to be stewards of stakeholder interests. We might think about the interplay among organizations, their stakeholders, and the many issues relevant to them as a tricky "love triangle" where the continuing challenge is to build, maintain, or repair relationships with different stakeholders. Yet, unlike interpersonal relationships, stakeholder relationships are necessarily based on perceived vested interests between the organization and its stakeholder(s). Moreover, as Heath (2002) argues, to be ethical, the relationship should be mutually beneficial. This criterion provides a concrete basis for evaluating an organization's actions relative to its 


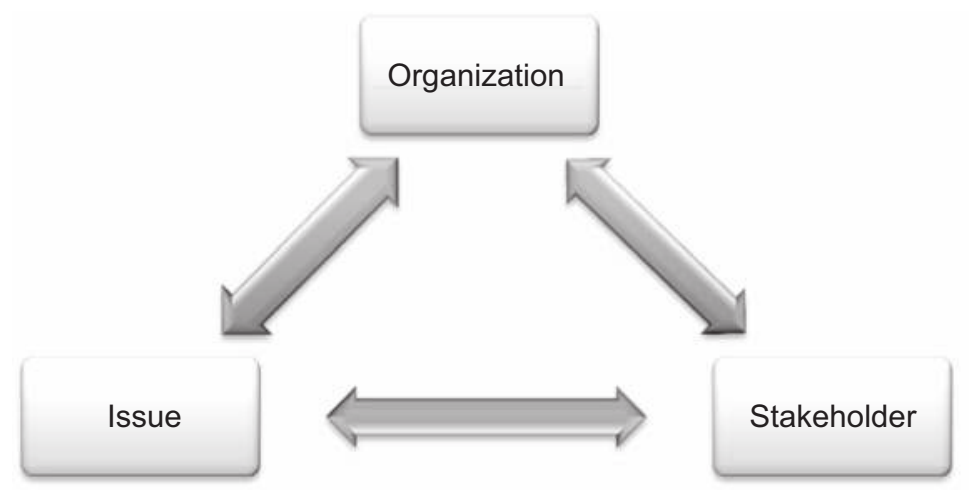

Figure 12.2 The Stakeholder Relationship Management Model

social obligations, especially for any organization whose value proposition centers on social value. Thus, the stakeholder relationship management model (Figure 12.2) provides a heuristic for better understanding the intersection of voices connected to the emergence, management, and recovery from crises (Diers-Lawson, 2017b; Diers, 2012).

The Stakeholder Relationship Management (SRM) Model gives us a way to organize previous research uncovering the various things that are apt to influence how organizations are evaluated (Diers, 2012) such things as attitudes (Claes, Rust, \& Dekimpe, 2010), public pressure from interested stakeholders in the face of crises (Piotrowski \& Guyette, 2010; Uccello, 2009), and engagement with stakeholders (Hong, Yang, \& Rim, 2010). For stakeholders, issues can involve anything from the quality of the organization's products or services to related topics that the stakeholders care about, such as health care or the environment. Issues are a lot like the baggage that comes with any relationship. They represent both risks and opportunities. Stakeholder judgments about an organization can concern not only whether they like its products, services, policies, customer service, and so on, but also how they evaluate its performance with respect to other issues that also matter to them. In the PJS case, no matter whether he was discussing the first CEO's seemingly extravagant expenditures on fishing junkets, its disproportionate financial support of the local community compared with the rest of Norway, or the ethics of responsible gaming, the question about what the company stood for was directly connected to his understanding of social responsibility. Likewise, once he blew the whistle and involved external stakeholders in the case, many of them came to similar conclusions. This meant that there was a disconnect between NT's behaviors and its stakeholders' expectations. 
We can more directly unpack the violations of expectations and relationship problems by examining the three core relationships threatened by the crisis.

\section{Relationship Between the Organization and Key Issues}

Stakeholders will make judgments about any connection between the organization and any issue(s) connected to the crisis. For example, one of the primary judgments is blame or responsibility attribution, which has emerged from the research on attribution theory (Weiner, 1985, 2006). Blame attribution evaluates how much control stakeholders believe an organization has over some issue. The more responsibility that stakeholders attribute to the organization, the more they'll expect of it with regard to that issue. Blame attribution is one of the most important predictors of stakeholder attitudes about an organization after a crisis, and it's become a core concept in situational crisis communication theory (Coombs, 2007; Coombs \& Holladay, 2004; Jeong, 2008; Schwarz, 2008). But it's also applied in other related crisis communication research, connecting to such factors as corporate social responsibility, crisis history, and ethics (Kim, 2013; Ping, Ishaq, \& Li, 2015).

Yet, core as it is, in the context of whistleblowing, blame attribution is complex. In NT's case, of course, there was a blatant material crisis-the cronyism and financial problems emerging from PJS's whistleblowing. But throughout the interviews with him, despite those organizational transgressions, we find considerable blame directed away from NT itself. For example, some of it was directed at PJS himself throughout the crisis, both internally and externally. Early on, a major concern, internally, was that the whistleblower would make NT look "foolish" if the situation weren't handled summarily, in "very brute fashion." And then, as the crisis emerged, the first CEO described the whistleblower externally as a "hidden enemy running after me with a rusty knife." But even in the post-crisis recovery phase, it seemed PJS was viewed as having betrayed his leadership team, ultimately making himself a liability to the company. Beyond that, his alleged ineffectiveness as a communications director was also cited as a reason that the crisis emerged, not only internally but also by the media: "I was criticized by the media for not taking command in the communication of this [the situation]," PJS recalls.

Yet another challenge to our evaluation of the relationship between NT and the crisis involves potential missed opportunities to make changes that would have mitigated PJS's need to blow the whistle in the first place. NT had enjoyed a sterling reputation for years. But as the whistleblowing case emerged, external stakeholder judgments about the company's positive intention, concern, and commitment to social responsibility could begin to be questioned, which indicted the authenticity of its intention in serving the public interest (Huang, 2008). Positive intention is often 
connected with hygiene-motivation theory (Lacey, Kennett-Hensel, \& Manolis, 2014), which suggests that if stakeholders believe that an organization's intentions are positive with respect to social responsibility, then it benefits the organization's reputation. But if they believe the organization's interest in an issue is inauthentic, it doesn't matter how good the organization otherwise behaves, for it's unlikely to positively influence the organization's reputation. PJS discussed this concept throughout the interviews in terms of his own interest in social responsibility, the missed opportunities to change stakeholder perceptions after the commissioned brand survey in Norway, the evolution of his outing as the whistleblower, and the former CEO's criticism of him.

Finally, clear association also matters in influencing stakeholders' perceptions of the connection between the organization and any issue connected to the crisis. If they believe there is a logical connection between an issue and the organization's core business or mission, then the organization's interest in that issue is more compelling to them and can thus change their judgment about the organization, particularly after a crisis emerges (Claeys \& Cauberghe, 2015; Coombs \& Holladay, 2015; De Bruycker \& Walgrave, 2014; Kernisky, 1997; Knight \& Greenberg, 2002). And this is where PJS's position at NT became a liability after the crisis, at least in the eyes of his new CEO. So long as PJS was associated with the organization, it seemed the CEO believed he inhibited the company's overcoming the scandal and moving beyond it. Internally, if PJS remained, he would not only be the "dark knight," but also his loyalty would be constantly questioned. Externally, one could assume the CEO to believe that PJS would be a reminder of the problems that NT wanted to move past.

\section{The Relationship Between the Stakeholder and Issues}

From a risk- or crisis-management perspective, the more intensely stakeholders feel connected to issues, the more likely those issues will trigger stakeholders to act. Yet, in crisis communication research, this relationship is only beginning to emerge as an important predictor. This is why PJS's experience with whistleblowing provides a more sophisticated understanding of how stakeholders relate to the issues affecting them and the organization.

Stakeholders' emotional involvement with issues is crucial to understand. At their heart, crises are incredibly emotional for internal and external stakeholders alike, with a lot of emotionally charged communication, but regrettably there's scant research examining the emotional experiences, trauma, and labor connected to crises (van der Meer \& Verhoeven, 2014). Fortunately, we're beginning to see an increasing recognition of the impact that emotion plays in the outcomes of crises. In NT's case, we're afforded an insider's view of the company's culture and the 
emotional journey that PJS took over several years. Too often, we only consider the immediate public nature of crises without considering all that led up to them or the fallout from them for critical stakeholders.

Through PJS's story, we can understand the culture of "stability" at NT. "Turnover was virtually non-existing," he recalls. "People came and they stayed throughout their lives." In such a settled, complacent environment, PJS was almost instantly an outlier. As he started work and brought with him new ideas and well-meaning criticisms of the status quo, he was already set up for shunning-the precursor to his being labeled the "man in black or Prince of Darkness." Even then, though, he also found occasional support within the company and was encouraged to stay on. Also, he discusses the intersection of his own personal values, conflicts, and stress management. So his emotional involvement as a dutiful employee and then as a whistleblower made his personal connection to the misconduct issues even more important. For organizations, this is an important lesson: stakeholders, whether internal or external, who feel strong emotional connections with the issues are more likely to make sacrifices and less likely to be easily "managed" with either accommodative or defensive responses to the crisis (Diers-Lawson, 2017b; Diers-Lawson \& Pang, 2016). Yet, in the context of whistleblowing, the bullying, pressure, and loss of social support that PJS experienced suggest that the emotional connection between the whistleblower and the issues he's exposing require a unique strength in order for him to endure the extraordinary opprobrium he awakens as the company "Judas" and pariah.

His reactions to the situation influenced judgments related to their perceived susceptibility, severity of the issue, beliefs, demographics, and perceived efficacy regarding the issue (Rosenstock, Strecher, \& Becker, 1988). Such judgments influence stakeholder reactions not only to the situation but also to the organization. In his narrative, PJS recalls worrying about "becoming a very unpopular person right away" and describes a building sense of fear and lack of efficacy early on that temporarily silenced him. One fear was that his recommendations would be rejected out of hand because of NT's chummy, and almost incestuous, connection with the local community. Another fear arose from the first CEO's approach to using him to solve problems. PJS feared that he would lose his ability to be an advocate in the company if he lost favor with the CEO. But as NT's mismanagement issues began to emerge internally, PJS seemed to feel both an indirect pressure as well as some empowerment to act because of a growing sense of dissatisfaction from his colleagues. $\mathrm{He}$ recalls "an increasing number of people" who talked to him, suggesting that "something's got to happen."

These evolving feelings that he and some of his colleagues experienced reflect the changeable nature of the relationships among stakeholders, issues, and the organization. From the internal perspective, PJS's initial conflict between the moral imperative to act and his very practical 
concerns about his minimal support and social isolation began to give way as he received increasing confidential admissions from some colleagues regarding their concerns about the inefficacy and questionable ethics of particular programs. Increasingly, it seemed, he felt the need to take action to preserve NT's high-minded mission. This was exactly the kind of rational-ethical decision-making that, Chen and Lai (2014) say, prompts potential whistleblowers to take action. In this way, the value that PJS and his colleagues placed on the organization's survival changed the perceived susceptibility, severity, and inefficacy of problems they all had known about for some time. In part, this was also in anticipation of how the relationship among the financial issues, NT, and other stakeholders would change if or when external stakeholders learned what was happening inside the company.

To this point, I have discussed the relationship between the stakeholders and issues primarily from an internal point of view. But this concern about how other stakeholders would react to the "realities" NT was facing also reveals the importance of the many different voices' existing attitudes, social norms, and perceived situational control as a predictor for action (Ajzen, 2005). For any stakeholder, whether inside or outside an organization, the perceptions of uncertainty related to the issue and the organization's actions regarding the issue not only affect stakeholders' emotional reactions to crises but also their attitudes and actions toward the organization in crisis (Jin, Liu, Anagondahalli, \& Austin, 2014; McDonald \& Cokley, 2013; Mou \& Lin, 2014). PJS's narrative provides insight into a number of different stakeholder perceptions, concerns, and existing attitudes about NT and its social obligations. When PJS described the disproportionate resources accorded the company's local community compared with those communities farther away, and the disproportionate support for the local hockey team sponsorship compared with its agreement with the Norwegian Hockey Association, and the overall "loose operations everywhere ... that detract from the money and efficiency of the organization and ... its larger goals," it suggested that NT's reputation with other stakeholders was vulnerable.

In fact, despite the internal desire for stability and a dominant narrative emphasizing the company's strength, once different stakeholder perspectives were considered, those views would ultimately trigger the crisis for NT. Had the company been more open to different viewpoints, it might have averted its crisis. For example, the research PJS contracted on gaming as well as the annual report that directly discussed the challenge of balancing the social risks of gaming against the social benefit of the revenue it produced were early indicators that stakeholders had to have had mixed evaluations of NT's social performance. Yet, the sharp difference between the internal and external reception that PJS received for being the editor of the annual report revealed a lot about the company's vulnerabilities with different stakeholder attitudes toward the company 
and its approach to meeting its mission. From an issues-management perspective, each of these moments of reflection, research, or conversation revealed an opportunity for NT to change and thus avoid its meltdown. Yet, when we understand how the internal stakeholders such as the first $\mathrm{CEO}$, other employees, and unions were resistant to action or change, we can better understand how early warning signs and different stakeholder voices are often not recognized until crises are triggered. By examining the relationship between the stakeholder and the issue, we can also better appreciate how PJS's experiences provide a real-life example of the tensions that push a whistleblower to act, especially when he understands it will not be in his own personal interests and is likely to come at some costs, to do so.

\section{The Relationship Between Organizations and Stakeholders}

PJS's experience also shows us that after a crisis, stakeholders-especially whistleblowers-can find that the crisis has intensified changes in their attitudes about the organization and their own relationship to it. In the context of crisis communication, stakeholders' attitudes toward organizations, especially those in crisis, have been well studied in crisis communication research (Diers, 2012). Often treated as an outcome of a crisis, these judgments have been assessed across multiple fields of study, from communication and marketing to industry-specific studies in such different areas as health care and tourism. One of the critical concepts predicting the quality of the relationship between the organization and its stakeholders is the organization's reputation (Benoit, 1995; Carroll, 2009). Thus, there is considerable work in public relations, and crisis communication more directly, that explores topics such as the impact of a favorable pre-crisis reputation in protecting an organization's reputation during and after a crisis (Claeys \& Cauberghe, 2015), the role of the media and other external groups in influencing an organization's reputation during crises (Einwiller, Carroll, \& Korn, 2010), and the growing influence of social media on an organization's reputation in the context of crises (Brown \& Billings, 2013; Ott \& Theunissen, 2015; Utz, Schultz, \& Glocka, 2013), to name just a few ways that reputation is connected with stakeholder evaluations of organizations.

Yet, one of the reasons why the first CEO and other board members and employees within NT resisted PJS's recommendations was that the company had long enjoyed a sterling reputation for the work that it did and for the cosseted environment it offered its employees. This case can demonstrate that an extended positive reputation can, just by itself, create the vulnerability of complacency for organizations in which the decision-makers believe they can act with impunity. Certainly, as I have already discussed, such complacency paired with repeated transgressions by an organization can lead to whistleblowing, but the strongly positive 
reputation can itself also create a risk to an organization. Coombs and Holladay (2015) explain that stakeholder expectations of any organization consistently viewed as "socially responsible" tend to be high, so if it violates stakeholders' trust, the violation of the company's core identity can create even more risk to the company. As PJS explains, it's vital for a company to actually practice what it preaches.

The SRM model argues that one of the reasons for NT to pay better attention to the social responsibility of its practices to earn money, not just distribute it, was that the crisis itself can threaten the socially responsible value proposition for an organization by fundamentally changing stakeholders' perceived knowledge of the organization. In short, crises can call into question what stakeholders believe they know to be "true" about an organization (Diers, 2012). PJS discusses the importance of social responsibility and ethical behavior extensively when talking about multiple bottom lines for many organizations, saying that a good reputation increases an organization's value, and this is what helps to guide stakeholder perceptions of whether the company is fundamentally trustworthy (Freberg \& Palenchar, 2013).

In part, evaluations of the relationship between the organization and its stakeholders are made based on stakeholder judgments about whether or not the organization's and stakeholders' own values are congruent (Koerber, 2014). What became clear throughout PJS's experience was the disconnect between the values that most of NT's external stakeholders expected the company to embody and the internal value judgments guiding its actions. For example, when PJS's annual report came out candidly discussing NT's need to balance its different levels of obligations (e.g., with gaming promotion vs. gambling addiction), he recalls that "I got so much crap from the others in the CEO meeting ... and, of course, the external feedback on the annual report was good. I mean even the Minister (of cultural affairs within Norway) told me that ... but it was not very well-received internally." But even as knowledge of the crisis broadened and his work as a whistleblower became more public, this disconnect between the broader community reaction to his actions compared with that of the local community and NT revealed a stark difference between the values of the internal and local stakeholders compared with PJS's values and seemingly those of the broader Norwegian community. This lack of value alignment underscores the different self-interests of NT and many of its internal stakeholders, not to mention the local community that had benefitted from the company's largesse over the years, compared with PJS's social-responsibility focus, which he shared with the government and the larger national community.

At its heart, then, we can better understand what a crisis is for an organization: it is a discrepancy in the expectations of an organization's behaviors and those of its stakeholders who are most able to affect it. Moreover, it can be characterized as a change in the relationship between 


\section{Audra Diers-Lawson}

the organization and its stakeholders. This is what makes whistleblowers such challenging and lonely stakeholders-they have the power to fundamentally affect an organization and even its surrounding community so long as their actions are aligned with a larger community's values. But what PJS's case at NT also suggests is that whistleblowing would not be so necessary if an organization viewed itself in relation to its stakeholders and the issues that affect both of them.

This case demonstrates the tragedy of missed opportunities for organizations to manage their issues. The problems that NT faced were certainly precipitated by the first CEO's handling of financial issues, but they were reinforced by a broader culture that rejected questioning voices, innovation, and risk assessment while valuing abject obeisance to the CEO and board's decision-making. These conditions make any organization, but most especially those defining themselves as socially responsible, ripe for crisis because they forget that the organization's well-being is based on its ability to manage many voices and interests as well as its social obligations.

\section{References}

Ajzen, I. (2005). Explaining intentions and behavior: Attitudes, personality, and behavior (Vol. 2). Berkshire, UK: McGraw-Hill Education.

Argenti, P. (2002). Crisis communication: Lessons from 9/11. Harvard Business Review, 103-109.

Atkins, M., \& Lowe, J. (1994). Stakeholders and the strategy formation process in small and medium enterprises. International Small Business Journal, 12(3), 12-25.

Benoit, W. L. (1995). Sears' repair of its auto service image: Image restoration discourse in the corporate sector. Communication Studies, 46(1-2), 89-105.

Brown, N. A., \& Billings, A. C. (2013). Sports fans as crisis communicators on social media websites. Public Relations Review, 39(1), 74-81.

Carroll, C. (2009). Defying a reputational crisis-Cadbury's salmonella scare: Why are customers willing to forgive and forget? Corporate Reputation Review, 12(1), 64-82.

Chen, C. P., \& Lai, C. T. (2014). To blow or not to blow the whistle: The effects of potential harm, social pressure and organisational commitment on whistleblowing intention and behaviour. Business Ethics: A European Review, 23(3), 327-342.

Claes, F., Rust, R. T., \& Dekimpe, M. G. (2010). The effect of consumer satisfaction on consumer spending growth. Journal of Marketing Research, 47(1), 28-35. https://doi.org/10.1509/jmkr.47.1.28.

Claeys, A.-S., \& Cauberghe, V. (2015). The role of a favorable pre-crisis reputation in protecting organizations during crises. Public Relations Review, 41(1), 64-71. https://doi.org/10.1016/j.pubrev.2014.10.013.

Connolly, T., Conlon, E. J., \& Deutsch, S. J. (1980). Organizational effectiveness: A multiple-constituency approach. Academy of Management Journal, 5(2), 211-217. 
Coombs, W. T. (2007). Attribution theory as a guide for post-crisis communication research. Public Relations Review, 33(2), 135-139.

Coombs, W. T., \& Holladay, S. J. (2004). Reasoned action in crisis communication: An attribution theory-based approach to crisis management. In D. P. Millar \& R. L. Heath (Eds.), Responding to crisis: A rhetorical approach to crisis communication (pp. 95-115). Mahwah, NJ: Lawrence Erlbaum Associates.

Coombs, W. T., \& Holladay, S. J. (2015). CSR as crisis risk: Expanding how we conceptualize the relationship. Corporate Communications: An International Journal, 20(2), 144-162. https://doi.org/10.1108/CCIJ-10-2013-0078.

De Bruycker, I., \& Walgrave, S. (2014). How a new issue becomes an owned issue. Media coverage and the financial crisis in Belgium (2008-2009). International Journal of Public Opinion Research, 26(1), 86-97.

Diers-Lawson, A. (2017a). Crisis communication oxford research encyclopedia of communication. Oxford University Press. Retrieved from http://communi cation.oxfordre.com/view/10.1093/acrefore/9780190228613.001.0001/acre fore-9780190228613-e-397. doi:10.1093/acrefore/9780190228613.013.397

Diers-Lawson, A. (2017b). Will they like us when they're angry? Antecedents and indicators of strong emotional reactions to crises among stakeholders. In S. M. Croucher, B. Lewandowska-Tomaszczyk, \& P. Wilson (Eds.), Conflict, mediated message, and group dynamics (pp. 81-136). Lanham, MD: Lexington Books.

Diers-Lawson, A., \& Pang, A. (2016). Did BP atone for its transgressions? Expanding theory on 'ethical apology' in crisis communication. Journal of Contingencies and Crisis Management, 24(3), 148-161.

Diers, A. R. (2012). Reconstructing stakeholder relationships using 'corporate social responsibility' as a response strategy to cases of corporate irresponsibility: The case of the 2010 BP spill in the Gulf of Mexico. In R. Tench, W. Sun, \& B. Jones (Eds.), Corporate social irresponsibility: A challenging concept (Vol. 4, pp. 177-206). Bingley, UK: Emerald Group Publishing Limited.

Edwards, M. S., Lawrence, S. A., \& Ashkanasy, N. M. (2016). How perceptions and emotions shaped employee silence in the case of "Dr. Death" at Bundaberg Hospital. In Emotions and organizational governance (pp. 341-379). Bingley, UK: Emerald Group Publishing Limited.

Einwiller, S. A., Carroll, C. E., \& Korn, K. (2010). Under what conditions do the news influence corporate reputation? The roles of media dependency and need for orientation. Corporate Reputation Review, 12(4), 299-315.

Fombrun, C. J. (1982). Strategies for network research in organizations. Academy of Management Review, 7, 280-291.

Frandsen, F., \& Johansen, W. (2016). Organizational crisis communication: A multivocal approach. London: Sage.

Freberg, K., \& Palenchar, M. J. (2013). Convergence of digital negotiation and risk challenges: Strategic implications of social media for risk and crisis communications. In Social media and strategic communications (pp. 83-100). New York: Palgrave.

Freeman, R. E. (1994). Ethical theory and business. Englewood Cliffs, NJ: Prentice-Hall.

Freeman, R. E. (1999). Divergent stakeholder theory. Academy of Management Review, 24(2), 233-239. 
Frooman, J. (1999). Stakeholder influence strategies. Academy of Management Journal, 24(2), 191-205.

Grimm, V., Choo, L., Horvath, G., \& Nitta, K. (2016). Whistleblowing and diffusion of responsibility: An experimental investigation. Annual Conference 2016 (Augsburg): Demographic Change 145781, Verein für Socialpolitik/German Economic Association.

Haley, E. (1996). Exploring the construct of organization as source: Consumers' understandings of organizational sponsorship of advocacy advertising. Journal of Advertising, 25, 19-36.

Harris, S. G. (1994). Organizational cultures and individual sensemaking: A schema-based perspective. Organizational Science, 5, 309-321.

Heath, R. L. (1994). Management of corporate communication: From interpersonal contacts to external affairs. Hillsdale, NJ: Lawrence Erlbaum Associates.

Heath, R. L. (2002). Issues management: Its past, present, and future. Journal of Public Affairs, 2(2), 209-214.

Heath, R. L., \& Millar, D. P. (2004). A rhetorical approach to crisis communication: Management, communication processes, and strategic responses. In D. P. Millar \& R. L. Heath (Eds.), Responding to crisis: A rhetorical approach to crisis communication (pp. 1-18). Mahwah, NJ: Lawrence Erlbaum Associates.

Heide, M., \& Simonsson, C. (2015). Struggling with internal crisis communication: A balancing act between paradoxical tensions. Public Relations Inquiry, 4(2), 223-255. https://doi.org/10.1177/2046147X15570108.

Henriques, I., \& Sadorsky, P. (1999). The relationship between environmental commitment and managerial perceptions of stakeholder importance. Academy of Management Journal, 42(1), 87-99.

Hong, S., Yang, S., \& Rim, H. (2010). The influence of corporate social responsibility and customer-company identification on publics' dialogic communication intentions. Public Relations Review, 36(2), 196-198. https://doi.org/ 10.1016/j.pubrev.2009.10.005.

Huang, Y. (2008). Trust and relational commitment in corporate crises: The effects of crisis communicative strategy and form of crisis response. Journal of Public Relations Research, 20, 297-327.

Jennings, D. F., Artz, K., Gillin, L. M., \& Christodouloy, C. (2000). Determinants of trust in global strategic alliances: Amrad and the Australian biomedial industry. Competitiveness Review, 10(1), 25-44.

Jeong, S. (2008). Attributions in crisis communication: A test of attribution model and situational crisis communication theory. Paper presented at the National Communication Association, San Diego, CA.

Jin, Y., Liu, B. F., Anagondahalli, D., \& Austin, L. (2014). Scale development for measuring publics' emotions in organizational crises. Public Relations Review, 40(3), 509-518. https://doi.org/10.1016/j.pubrev.2014.04.007.

Kernisky, D. A. (1997). Proactive crisis management and ethical discourse: Dow Chemical's issues management bulletins 1979-1990. Journal of Business Ethics, 16(8), 843-853.

Kim, S. (2013). Corporate ability or virtue? Relative effectiveness of prior corporate associations in times of crisis. International Journal of Strategic Communication, 7(4), 241-256. https://doi.org/10.1080/1553118X.2013.824886.

King, G. I. (2002). Crisis management and team effectiveness: A closer examination. Journal of Business Ethics, 41, 235-249. 
Knight, G., \& Greenberg, J. (2002). Promotionalism and subpolitics: Nike and its labor critics. Management Communication Quarterly, 15(4), 541-570.

Koerber, D. (2014). Crisis communication response and political communities: The unusual case of Toronto mayor Rob Ford. Canadian Journal of Communication, 39(3).

Lacey, R., Kennett-Hensel, P. A., \& Manolis, C. (2014). Is corporate social responsibility a motivator or hygiene factor? Insights into its bivalent nature. Journal of the Academy of Marketing Science, 42(3). https://doi.org/10.1007/ s11747-014-0390-9.

Liu, S.-M., Liao, J.-Q., \& Wei, H. (2015). Authentic leadership and whistleblowing: Mediating roles of psychological safety and personal identification. Journal of Business Ethics, 131(1), 107-119.

Mazzei, A., \& Ravazzani, S. (2014). Internal crisis communication strategies to protect trust relationships: A study of Italian companies. International Journal of Business Communication, 1-19. https://doi.org/10.1177/2329488414525447.

Mazzei, A., Kim, J.-N., \& Dell'Oro, C. (2012). Strategic value of employee relationships and communicative actions: Overcoming corporate crisis with quality internal communication. International Journal of Strategic Communication, 6(1), 31-44.

McDonald, L. M., \& Cokley, J. (2013). Prepare for anger, look for love: A ready reckoner for crisis scenario planners. PRism, 10(1), 1-11.

Mesmer-Magnus, J. R., \& Viswesvaran, C. (2005). Whistleblowing in organizations: An examination of correlates of whistleblowing intentions, actions, and retaliation. Journal of Business Ethics, 62(3), 277-297.

Mitchell, R. K., Agle, B. R., \& Wood, D. J. (1997). Toward a theory of stakeholder identification and salience: Defining the principle of who and what really counts. Academy of Management Review, 22(4), 852-886.

Mitroff, I., Alpaslan, M. C., \& Green, S. E. (2004). Crises as ill-structured messes. International Studies Review, 6(1), 165-182.

Moore, S. (2004). Disaster's future: The prospects for corporate crisis management and communication. Business Horizons, 47(1), 29-36.

Mou, Y., \& Lin, C. A. (2014). Communicating food safety via the social media: The role of knowledge and emotions on risk perception and prevention. Science Communication, 36(5),593-616.https://doi.org/10.1177/1075547014549480.

Ott, L., \& Theunissen, P. (2015). Reputations at risk: Engagement during social media crises. Public Relations Review, 41(1), 97-102. https://doi.org/10.1016/j. pubrev.2014.10.015.

Pearson, C. M., \& Clair, J. A. (1998). Reframing crisis management. Academy of Management Review, 23(1), 58-76.

Ping, Q., Ishaq, M., \& Li, C. (2015). Product harm crisis, attribution of blame and decision making: An insight from the past. Journal of Applied Environmental and Biological Sciences, 5(5), 35-44.

Piotrowski, C., \& Guyette, R. W. (2010). Toyota recall crisis: Public attitudes on leadership and ethics. Organizational Development Journal, 28(2), 89-97.

Reilly, A. (1987). Are organisations ready for a crisis? Columbia Journal of World Business, 79-87.

Rosenstock, I. M., Strecher, V. J., \& Becker, M. H. (1988). Social learning theory and the health belief model. Health Education and Behavior, 15(2), 175-183. https://doi.org/10.1177/109019818801500203. 


\section{Audra Diers-Lawson}

Rowley, T. J. (1997). Moving beyond dyadic ties: A network theory of stakeholder influences. Academy of Management Review, 22(4), 887-910.

Schwarz, A. (2008). Covariation-based causal attributions during organizational crises: Suggestions for extending Situational Crisis Communication Theory (SCCT). International Journal of Strategic Communication, 2(1), 31-53.

Scott, S. G., \& Lane, V. R. (2000). A stakeholder approach to organizational identity. Academy of Management Review, 25(1), 43-65.

Suchman, M. C. (1995). Managing legitimacy: Strategic and institutional approach. Academy of Management Review, 20(3), 571-610.

Trice, H. M., \& Beyer, J. M. (1993). The cultures of work organizations. Upper Saddle River, NJ: Prentice Hall.

Uccello, C. (2009). Social interest and social responsibility in contemporary corporate environments. Journal of Individual Psychology, 65(4), 412-419.

Utz, S., Schultz, F., \& Glocka, S. (2013). Crisis communication online: How medium, crisis type and emotions affected public reactions in the Fukushima Daiichi nuclear disaster. Public Relations Review, 39(1), 40-46.

van der Meer, T. G., \& Verhoeven, J. W. (2014). Emotional crisis communication. Public Relations Review, 40(3), 526-536. https://doi.org/10.1016/j. pubrev.2014.03.004.

Weiner, B. (1985). An attributional theory of achievement motivation and emotion. Psychological Review, 92(4), 548.

Weiner, B. (2006). Social motivation, justice, and the moral emotions: An attributional approach. Mahwah, NJ: Laurence Erlbaum. 


\section{Part V \\ How to Encourage Employees to Report Wrongdoing}




\title{
13 The Influence of Psychological Contracts on Decision-Making in Whistleblowing Processes
}

\author{
Åse Storhang Hole and Therese E. Sverdrup
}

\section{Introduction}

Recent decades of research have considerably broadened our understanding of whistleblowing. To date, most of the focus has been on the whistleblowers themselves: what makes them report, what and how they report, and what happens to them after they've blown the whistle (Lewis, Brown, \& Moberly, 2014). But we think it no less important to focus on non-reporting behavior because most employees stand by in silence (Olsen, 2014). They may do so out of fear of retaliation, lack of trust in managers or other recipients of the concerns, a belief that nothing can or will be done about the problems, uncertainty about the seriousness and evidence of the wrongdoing, or a sense that others simply don't see the problem as they do (Near, Rehg, Van Scotter, \& Miceli, 2004). Another possible explanation for non-reporting, as we're about to demonstrate, may lie with close relationships between employee and employer, or between colleagues, reinforced by unwritten expectations about mutual loyalty. This chapter is about the effect of psychological contracts on whistleblowing.

The particular whistleblowing incident we are studying here occurred in a small Norwegian town, where close relationships are common, and colleagues are more tightly connected and dependent on one another than is usual in a larger society. As described by Peer Jacob Svenkerud (PJS), the whistleblower in this story, unwritten expectations permeated his company Norsk Tipping (NT). Employees enjoyed an interesting, well-paid job in one of the most prestigious firms in the region. Through the whistleblower's story, we learn about some of these unwritten expectations. For example, if media raised critical questions about NT, PJS was expected to defend its image and redirect the reporters' attention. Also, questionable practices were passed over at the weekly top-executive meetings. And employees seemed expected to promote NT's popular image of being a joyous workplace.

Expectations like these led to the following question in the introduction of the whistleblower's story in Chapter 1: "What happens to the decisionmaking processes in a company when critical voices are suppressed?" 


\section{Psychological Contracts}

The psychological contract is a concept that addresses unwritten expectations. It refers to the employees' perceptions about the reciprocal relationship with their employer (Rousseau, 1989). Mutual obligations are the essence of any employment contract, of course, as they define the relationship between employee and employer. Obligations, or beliefs, are what the employee expects to receive in return for loyalty, work effort, and commitment. The employer, meanwhile, has expectations of employees in return for wages and good working conditions. These expectations come from either implicit or explicit promises of future exchange or reciprocity, and constitute the psychological contracts between employer and employee- and between colleagues, too.

Research into psychological contracts, and especially their violation, shows that unwritten agreements and expectations between employers and employees greatly impact organizational behavior (Rousseau, 1989; Robinson \& Rousseau, 1994). Psychological contracts are individual and perceptual and can be transactional, relational, and ideological. Transactional contracts are short term and characterized by less involvement of the parties. Relational contracts are long term and characterized by mutual loyalty and trust (Rousseau, 1995). Ideological contracts are value based and involve working for a higher cause or ideology (Thompson \& Bunderson, 2003).

Fear of violating one or more of these contracts might well prohibit, or at least inhibit, whistleblowing. When unethical behavior occurs at the workplace, close relationships and strong mutual psychological contracts might hinder the reporting of wrongdoing, especially if the contracts are tight and mean a lot to the parties, as we find in the present case. Supervisors and colleagues alike react negatively toward the whistleblower because they consider whistleblowing a breach of a psychological contract, a violation of the unwritten expectations and beliefs about mutual agreements.

But here's a classic dilemma: What do you do if a close friend or colleague has engaged in issues that you consider unethical? And what if the wrongdoer is your own supervisor? By the same token, how does the wrongdoer react toward the whistleblower when he is a close colleague? Psychological contracts can cloud the judgments and reactions of all parties-the observers, the whistleblower, the wrongdoer, and the recipients of the concerns. Psychological contract theory may help our understanding of the outcomes of several stages of the whistleblowing process.

Our aim in this chapter is to show how psychological contract theory can explain the steps taken in the whistleblowing process-the fraught decision to blow the whistle, the receiver of the concern, and the reactions to the whistleblower. In the following section, we discuss the concept of whistleblowing, whistleblowing effectiveness, and the typical stages of a whistleblowing process. 


\section{The Concept of Whistleblowing}

A standard definition of whistleblowing is "the disclosure by organization members (former or current) of illegal, immoral, or illegitimate practices under the control of their employers, to persons or organizations that may be able to effect action" (Near \& Miceli, 1985, p. 4). Note that this definition excludes persons outside the organization. According to Miceli, Dreyfus, \& Near (2014), it's important to distinguish between whistleblowing behavior and other, external forms of disclosing of organizational wrongdoing. They call the latter "bell-ringing," which means the reporting of organizational wrongdoing by outsiders.

To distinguish normal reporting from whistleblowing, Skivenes and Trygstad (2014) introduced the classification of weak and strong whistleblowing, where weak whistleblowing involves reporting to your nearest manager, whereas strong whistleblowing refers to cases in which the employee then continues to report via other channels after seeing no improvement. Miethe (1999) argued that a broad definition of whistleblowing is important to encourage reporting of all kinds of concerns. Miceli and Near (2013) argued that although there are similarities between organizational voice behavior (i.e., constructive challenge to the status quo with the intent of improving the situation rather than merely criticizing) and whistleblowing, there are also differences. Matters that trigger voice and whistleblowing are not the same, because whistleblowing is a reaction to wrongdoing, while voice includes all kinds of concerns. Whereas voice often involves "friendly suggestions," whistleblowing questions managers' authority and ethical judgments.

Whistleblowing is generally viewed positively as a prosocial behavior (Miceli, Near, Rehg, \& Van Scotter, 2012; Miceli, Near, \& Dworkin, 2008; Dozier \& Miceli, 1985). People who blow the whistle are doing so in an attempt to correct wrongdoing. Prosocial behavior can include both selfish (egoistic) and unselfish (altruistic) motives on the part of the actor (Dozier \& Miceli, 1985). It is important to note, however, that while the motives of the whistleblower can be egoistic, he or she might help address important issues for the organization.

Our discussion in this chapter includes only whistleblowers who are former or present members of an organization. Another important distinction is that the recipient must be someone who's in a position to correct the wrongdoing. We consider all kinds of reporting of wrongdoing to be important and therefore prefer the broad definition of the concept.

\section{The Whistleblowing Process}

Whistleblowing is a complex process consisting of several stages, starting with observation of the wrongdoing and the decision of the observer 


\section{8 Åse Storhang Hole and Therese E. Sverdrup}

whether to blow the whistle, either through internal or external channels. Further stages of the process are the receiving of the concern, including the decisions and reactions of the recipient. Still later stages of the process account for if, and in what ways, the problems are resolved (Near \& Miceli, 1995). Finally, in an ideal situation, the process is evaluated and steps are taken to learn how to treat similar situations, problems, and concerns (NOU, 2018:6) (Figure 13.1).

The outcomes of each step in a whistleblowing process depend on both individual and situational factors concerning the issue at stake-for example, the power and position of the whistleblower, the wrongdoer, and the recipient of the concern (Near \& Miceli, 1995). Our focus here is to study the influence of the psychological contracts at several stages of the process through the lens of psychological contract theory. We propose that violation of psychological contracts, or fear of it, has influenced the development of this whistleblowing process at the six first stages in Figure 13.1.

Whistleblowing effectiveness may be defined as "the extent to which the questionable or wrongful practice (or omission) is terminated at least partly because of whistleblowing and within a reasonable time frame" (Near \& Miceli, 1995, p. 681). Outcomes of the different stages of a

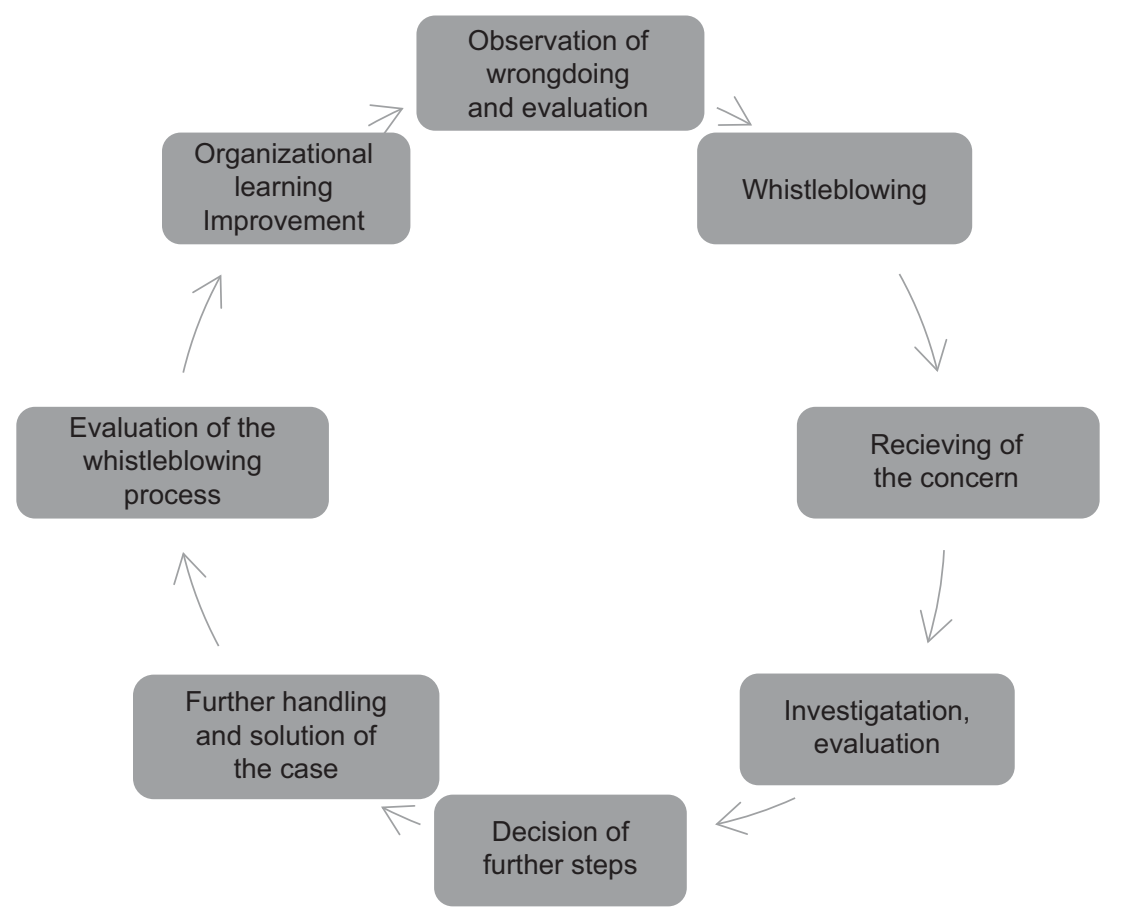

Figure 13.1 The Whistleblowing Process (based on Frøstrup et al. 2018, p. 137). 
whistleblowing process will influence the development of the total process and the whistleblowing effectiveness.

In the following section, we address the concept of the psychological contract and discuss different versions of it, which will lay the foundation for applying that perspective to the whistleblowing process in the present case.

\section{Psychological Contract Theory}

A psychological contract contains the individual's perceptions about the reciprocal relationship with their employer (Rousseau \& Tijoriwala, 1998). In a psychological contract, the employer and employee are engaged in a contractual relationship in which both parties feel they owe each other something. This "something" can refer to training, promotion, recognition, trust, fair pay, and a good working environment. An important part of the contract is that in exchange for good work the employee will expect something in return, such as further training or a promotion. Thus, a psychological contract implies that there is a reciprocal relationship between the parties. The premise is that without the promise of a future exchange, neither party has incentives to contribute much of anything to the other, which may result in a strain or termination of the relationship (Robinson \& Rousseau, 1994).

Most research on psychological contracts has focused on the consequences of contract breaches and has found connections to many work-related outcomes-for example, job satisfaction, organizational commitment, turnover intention, in-role performance, and organizational citizenship behavior (Zhao, Wayne, Glibkowski, \& Bravo, 2007). Also, a stream of research has been carried out on outcomes of psychological contract breach that can be labeled negative behavior (Turnley \& Feldman, 1999). Specifically, these studies suggest that when employees experience a psychological contract breach, they engage in counter-productive work behavior and strike back at the employer in various ways, such as via abuse, production deviance, sabotage, theft, and withdrawal (Bordia, Restubog, \& Tang, 2008; Restubog, Bordia, \& Tang, 2007; Jensen, Opland, \& Ryan, 2010). Thus, the consequences of breaching a psychological contract are substantial, meaning that handling breaches and knowing the content of the psychological contract (what exactly was breached) are important to prevent these negative consequences.

Research on the substance of the psychological contract shows that there are several different types that we enumerate here (Rousseau, 1990). A transactional contract is composed of specific, short-term obligations entailing limited involvement of the parties, as for a seasoned worker, who exchanges money for work (tit-for-tat). A relational contract entails broad, open-ended, long-term obligations and is based on mutual trust and loyalty (Morrison \& Robinson, 1997; 229)—for example, the permanent 
worker who exchanges lifetime work for loyalty to the company. According to Rousseau (2004), employees with a relational contract tend to put more effort into their job, help colleagues, and support changes in the organization. A value-based or ideological contract involves working for a higher cause or ideology and fulfilling expectations toward an overarching goal of the organization (Thompson \& Bunderson, 2003). Employees with such a contract have been shown to exert more extrarole behavior (Vantilborgh et al., 2014)—for example, a worker who is willing to work harder not only for money, but for a higher cause as well, such as working for a medical company that helps save lives, or a fertilizer company that helps feed the world. Normative contracts occur when several people agree on terms in their individual psychological contracts (Rousseau, 1995). When co-workers agree among themselves on the terms of their individual psychological contract with the employer, the agreement becomes a normative contract. Normative contracts are products of social integration, discussion, and interpretation, creating similarity in the way people see their organization and their relationship to it. A horizontal contract occurs among colleagues (Seeck \& Parzefall, 2008; Sverdrup, 2012; Sverdrup \& Schei, 2015). The exchanges and obligations are mostly concerned with the task that they work on-making an effort, delivering good quality - and with their mutual relationship, recognition, friendship, and generosity (Sverdrup, 2012). Contracts among colleagues can be evaluated not only through the content of the exchange, but also by the feature of constriction (tight vs. loose). That is, in some cases colleagues develop tight psychological contracts, meaning that you can trust that the other person will deliver to your expectations and be able to explicitly state those expectations (Sverdrup, 2014). Loose psychological contracts, by definition, have more breaches and more implicit expectations among colleagues. Thus, the content (task vs. relational) and type (tight vs. loose) of psychological contract have some implications for how colleagues act toward one another.

These different types of contracts hint at the relationships that are involved when whistleblowing occurs within the organization.

\section{Research Linking Whistleblowing and Psychological Contract Theory}

The relationship between psychological contracts and whistleblowing can be understood in two all-encompassing ways. On the one hand, violations of psychological contracts might lead an employee to blow the whistle because of a perception of harm and unfair treatment that amounts to a violation (Turnley \& Feldman, 1999). This is supported by Gundlach, Martinko, and Douglas (2008), who show that anger and disappointment after psychological contract breaches can result in whistleblowing. Furthermore, Vandekerckhove and Commers (2004) have 
argued that disrupting loyalty within psychological contracts can motivate one to blow the whistle.

On the other hand, a strong psychological contract, where both parties feel they owe each other loyalty, may inhibit whistleblowing. That is, close relationships can make it difficult both to recognize the wrongdoing and to report it (Miceli et al., 2008). For instance, the content of a psychological contract may be such that by blowing the whistle one violates the psychological contract of loyalty. This could also be the case with peers reporting. Yet, research on whistleblowing has focused primarily on reporting the wrongdoing of superiors rather than the wrongdoing of peers. Trevino and Victor (1992) studied peers reporting as a specific kind of whistleblowing behavior. Reporting a peer's wrongdoing to higher authorities may be more difficult than reporting a superior because of group norms against reporting peers' misconduct (Greenberger, Miceli, \& Cohen, 1987) and because of stronger identification and empathy with peers (Randall \& Gibson, 1991). Thus, a tight psychological contract among peers about not reporting one another's wrongdoing-we're all in this together-may lead to less whistleblowing.

Lewis (2011) suggested that whistleblowing should be regarded as an act of loyalty. Companies should develop psychological contracts that promote a culture of trust and openness. Such contracts might support and promote whistleblowing. Gundlach et al. (2008) stated that new understanding of the whistleblowing process could be gained by applying the psychological contract perspective and suggested that future research should examine the connection between the psychological contract and whistleblowing,

We hope that our analysis of this particular whistleblowing process can clarify the link between whistleblowing and the psychological contract. In the following section, we analyze some critical incidents of PJS's whistleblowing story, where we demonstrate how the psychological contract perspective sheds light on the decision-making of the central actors.

\section{Analyzing the Whistleblowing Process Through the Psychological Contract Perspective}

In the following discussion of PJS's narrative, we analyze the critical incidents following his observation of questionable practices. We trace his whistleblowing process in three steps: (1) blowing the whistle, (2) choosing to go public, and (3) choosing to resign. By applying the psychological contract perspective, we can better understand the dilemmas that a whistleblower faces when choosing to blow the whistle and dealing with the blowback. We use the narratives of PJS to show how psychological contracts with central actors such as the CEO, colleagues, and the chairman of the board (COB) influenced PJS's decisions along the way. We 


\section{2}

\section{Åse Storhang Hole and Therese E. Sverdrup}

also reference newspaper articles, the audit report, and NT's own annual reports to supplement the data from the narrative.

\section{Blowing the Whistle}

In the situation leading up to PJS's blowing the whistle to the COB, we find that the psychological contract played out both vertically and horizontally. PJS sensed what was expected through his hiring process and the first meetings. NT was one of the most attractive and prestigious companies in the region and had since 1948 been a vital source of funding for amateur Norwegian sports activities (Annual Report, 2017). The annual reports consistently state that the company's goals are to make people happy, give their dreams a chance every day, and support good social causes. Thus, by working at NT, employees enjoy a feeling of contributing to society. This is a value-based contract, where one works for a higher cause or ideology, and fulfills expectations toward an overarching goal of the organization (Thompson \& Bunderson, 2003). Hence, NT employees probably anticipate an ideological contract with the company. As PJS expressed it: "[NT] had a very good reputation. Everybody wanted to work here. I was flattered to have gotten the job. The turnover was virtually non-existent. People came and they stayed there throughout their lives."

One advantage of an ideological psychological contract is the feeling of loyalty it imparts toward the company's culture and its mission, making it difficult for people to think that anything can go wrong in a company with such a long and proud tradition. Hence, employees at NT had sound reasons for being in good faith when working in a company with idealistic values and visions. The fact that NT was state owned and a non-profit also strengthened the impression of it as value based.

When PJS started to work as the Senior Vice President Information and External Relations, he tells us that he soon began to worry about issues such as the huge budgets, the lack of a transparent budget process, and also the lack of corporate strategies concerning corporate social responsibility (CSR). These worries jolted him enough that he might have interpreted them as constituting an ideological contract breach, which may have initially triggered thoughts of reporting or whistleblowing (Gundlach et al., 2008). Countering that impulse, though, was his strong relational contract of being loyal to the company and the CEO, which also carried with it the condition that you don't question corporate policies and procedures. As PJS put it, "an internal understanding was that if you asked too many questions, it will have a consequence." Further, the company's employee benefits were excellent, thus leading to strong transactional contracts. Again, as PJS put it: "You should really be glad that you're getting an opportunity to work here and that you have a good salary. You should embrace the benefits you have, not challenge 
the benefits that people have." So here was his dilemma: Should he act on the violation of the ideological contract and report the irregularities, or should he honor his strong relational and transactional contract and stay silent?

A boat trip with a friend was a tipping point for his decision. That friend was also a respected colleague, so his friendship resembled a tight and relational horizontal contract. This seems to have reinforced PJS's choice to blow the whistle. When doing so, he presented a list of irregularities to the $\mathrm{COB}$, who both promised to protect him and encouraged him to remain in the company. In PJS's words, the COB said, "Work as you normally do, and trust me when I say that I will protect you." This promise shows how a psychological contract between the two men developed. But later, during the process of blowing the whistle to the board, PJS says he felt that his expectations of getting the COB's support were violated: "He kept his word about keeping it quiet, but he was never a visible supporter. He never called me to see how I was doing." PJS clearly expected visible support and care, and the $\mathrm{COB}$ violated that expectation. This shows how the psychological contract often is implicit, and if it is not mutual, it can have a strong influence on the feelings of the parties involved.

Although one of PJS's mentors had warned him that the COB and others on the board probably would try to downplay the case, they chose to violate their promises (the psychological contract) in a rank way. During the follow-up meeting, the $\mathrm{COB}$ asked if the whistleblower was satisfied with how management planned to handle the irregularities. They did not mention that they appreciated his openness and the fact that he had reported the wrongdoing. All they said was: "We'll come back to you. Is that good enough for you? Are you satisfied?"

Some colleagues of PJS had expressed concerns and raised critical questions themselves, but not openly. Instead, according to PJS, they had encouraged him to blow the whistle for them: "You have to do it!" Perhaps he had reason to believe that at least some of them would then give him visible support and stand by him, but no, he felt himself left standing alone, and nobody ever openly pledged to stand shoulder to shoulder with him. PJS might have viewed this as disloyalty, a breach of a psychological contract. But, to be fair to them, raising critical questions could mean violating a vertical contract of loyalty to the CEO and perhaps could cost them benefits, job safety, and well-being at the workplace (as outlined earlier).

PJS at last decided to blow the whistle, finally expecting that he would get at least some support. But, as already mentioned, he got none, at least not openly. Whistleblowing research shows that whistleblowers often experience collapsing support from managers and co-workers, and many of them feel lonely and isolated at the workplace. Many also suffer from retaliation (Trygstad, 2017; Bjørkelo, 2013; Near et al., 2004; Rehg, 


\section{4 Åse Storhaug Hole and Therese E. Sverdrup}

Miceli, Near, \& Van Scotter, 2008). Lack of support can be perceived as a breach of a relational contract among colleagues.

\section{Choosing to Go Public}

PJS remained in the company, still as an anonymous whistleblower, but felt lonely and guilty: "No one knew who had turned so many people's lives upside down." A new permanent CEO was hired in the fall of 2008, and, shortly after, a new COB replaced the one with whom PJS had negotiated the agreement. The audit general worked in the company for almost two years, which put a great strain on NT employees. The new leadership team had to focus on moving forward and getting business back to normal.

A dramatic turn of the whistleblowing process occurred in January 2010 when one of the biggest financial newspapers called PJS and informed him that they knew he was the whistleblower. PJS then insisted on coming forward, but the new permanent CEO hesitated and did not want him to do so. PJS probably saw this lack of support as a violation of a psychological contract and reacted with anger and frustration.

Similar reactions after a psychological contract violation are described in the literature (Sverdrup, 2012; Robinson \& Rousseau, 1994; Gundlach et al., 2008). In a meeting with all the company's managers, the top management's concern was how to repair NT's reputation and the future role of the whistleblower; little was said to support or praise PJS for courageously coming forward and reporting wrongdoing. Hence, because PJS at first was assured of support from the new CEO but then later was questioned about his future with the company, it looked to him like a strong contract breach. The rest of the managers chose to stand by the new CEO in silence, not supporting PJS. Nobody reassured him that he had done the right thing. As PJS says, "And that meeting was-as I see it- the start of my exit."

The tight psychological contract described by Sverdrup (2014) demonstrates how people might feel obligated to fulfill expectations to one another, as in "If I do something for you, you will do something for me." PJS states: "In a small city . . . everyone knows everyone. People that are recruited into higher positions are often part of the same network." Working with the same suppliers and companies in the business network for many years also created close ties: "We had some suppliers that we had had for years. It was a very personal relationship. They were friends." The narrative also describes close ties to the unions. We interpret this as strong horizontal contracts among the employees and possibly among the various external stakeholders, which explains why the whistleblowing was such a strain on so many people and relationships. Power distance matters in whistleblowing cases. Close relations make the process more difficult for the involved parties (Miceli et al., 2008). 
Summing up, the psychological contract breach between PJS and the new permanent CEO led to anger and frustration for PJS. The tight psychological contracts between the managers and external stakeholders prevented support for the actions taken by PJS and thus represented a breach of horizontal contracts.

\section{Choosing to Resign}

In the aftermath, when PJS's identity became known, many people shunned him. Although some colleagues had earlier supported him and encouraged him to voice concerns which they had themselves, they were silent in the aftermath. One colleague also expressed frustration. PJS's double role-blowing the whistle and remaining in the organization while keeping a secret-created frustration and anger among some colleagues in the top leadership group. As one of them said: "One thing might be that I do not agree with your assumptions and why you did what you did, but I certainly don't agree with you keeping this secret for this long." Colleagues had expected information, and by keeping the case a secret, PJS may have violated a psychological contract with them. PJS had also expected more support from external stakeholders, such as the Ministry of Culture, but they remained silent. The new permanent CEO and COB had promised their support, but gradually PJS realized that his time at the company was over: "They never called to ask how I was doing and seemed to care more about the people who were angry."

We have no data from the other parties in the process, but we have reason to believe that some of the leaders might have felt a breach of a psychological contract upon hearing that PJS had been hiding as a whistleblower. Tight psychological contracts had over time developed among the members of the top leadership group. This demonstrates how the psychological contract as a perspective allows for an understanding of both sides of the contract.

In the aftermath, the $\mathrm{COB}$ and others in top management were concerned with restoring NT's image and focused on normalizing the organization. The notes and objections in the audit reports had to be handled and corrected. Hence, the well-being of the whistleblower got less attention. For the whistleblower, this might be interpreted as a psychological contract breach.

\section{Discussion}

By applying the psychological contract perspective, we hope to have shed light on the complexity of a whistleblowing process with respect to the different parties involved, the dilemmas raised, and the reason the process unfolded as it did. Our analysis shows how psychological contracts both with respect to the contracts between the individual and the organization 


\section{6 Åse Storhaug Hole and Therese E. Sverdrup}

(ideological, relational, transactional), between the group and the organization (normative), and between individuals (horizontal—tight/loose) and whether or not these contracts were fulfilled or breached, can serve as one possible explanation of why the whistleblowing process proceeded as it did. We argue that all categories of contracts came into play throughout the whistleblowing process. Sverdrup $(2012,2014)$ found that horizontal contracts, and especially tight and relational contracts among colleagues in teams, influenced trust, collaborations, and friendship. These relations are important to people, and naturally one might fear violating the contracts. Examples from the narrative demonstrate that there probably existed both transactional and relational contracts among members of the top-executive team and among board members. Fear of losing friendships, together with close relationships in business networks, might have made colleagues hesitant to report; it might even have temporarily made them ethically blind, as discussed by Øverenget \& Storhaug Hole in Chapter 7. Unwritten agreements and expectations concerning mutual loyalty and trust among individuals on the board, in the leadership group, in the Ministry of Culture, and among colleagues within NT, seem to have influenced both the development of the whistleblowing process and its outcomes. Throughout the process, we get the impression of a subdued company culture where people did not voice concerns or express opinions openly.

Correcting the wrongdoing in a reasonable amount of time constitutes whistleblowing effectiveness (Near \& Miceli, 1995; Trygstad, 2017). In NT's case, the whistleblowing process lasted for many years. True, the wrongdoing was eventually corrected, but not within a reasonable time, and the seemingly interminable process put a heavy strain on everyone involved.

When blowing the whistle, PJS violated normative psychological contracts established in the company and the top leadership group: the unwritten expectations of supporting one another and keeping silent about company affairs. Though the Auditor General ultimately documented irregularities, PJS nonetheless seemed to get little support from co-workers (Auditor General, 2008/2009). Despite documented evidence of wrongdoing, it seems like they didn't dare support the whistleblower openly. They might have feared that by supporting the whistleblower, they too would violate normative psychological contracts and run the risk of reprisals themselves, such as social ostracism and loss of benefits and friendship. PJS's perception of lack of support is common in whistleblower cases (Rehg et al., 2008). Retaliation need not be open to be effective. There are other, more subtle ways of punishing the whistleblower-silence, freezing out, wage intimations, and holding back information (Mesmer-Magnus \& Viswesvaran, 2005; Bjørkelo, Einarsen, Nielsen, \& Matthiesen, 2011; Bjørkelo, 2013; Rehg et al., 2008). 


\section{Concluding Remarks}

Our analysis of this whistleblowing case shows that psychological contracts came into play, influencing several critical stages of the process. The way psychological contracts among people in business networks influence decision-making processes and outcomes needs further investigation. Based on our analysis of critical incidents in this narrative, and with support of earlier research into psychological contracts, we find that violation, or fear of violation, of both horizontal and vertical contracts influenced outcomes of this whistleblowing process. Psychological contracts might hinder employees and leaders from stepping forward and reporting, affecting both their willingness to report as well as their perception of the seriousness of the wrongdoing. Further, psychological contracts influence both decision-making processes and managerial responses to whistleblowing throughout the process, and we argue that this strongly affected the whistleblowing in this case.

The outcomes of a whistleblowing process depend significantly on managerial responses and the organizational climate (Trygstad \& Ødegaard, 2016; Trygstad, Ødegaard, \& Svarstad, 2018; Near \& Miceli, 2016). According to Lewis et al. (2014), research on managerial responses to whistleblowing is still in its infancy, but there is a growing interest in them. Vandekerckhove, Brown, and Tsahuridu (2014) argue that managers must both listen to and support the whistleblower. If managers are one of the parties in a whistleblowing case, as here, more conflicts tend to arise, the process lasts longer, and some cases remain unsolved (Trygstad, 2017). In our analysis, we find that managerial responses negatively influenced the development of the case. We suggest that psychological contract theory helps explain these research results and why the whistleblowing effectiveness was affected negatively.

\section{References}

Annual Report Norwegian Lottery 2017. Retrieved from http://2017.norsktipping.no/en/

Bjørkelo, B. (2013). Workplace bullying after whistleblowing: Future research and implications. Journal of Managerial Psychology, 28(3), 306-323.

Bjørkelo, B., Einarsen, S., Nielsen, M. B., \& Matthiesen, S. B. (2011). Silence is golden? Characteristics and experiences of self-reported whistleblowers. European Journal of Work and Organizational Psychology, 20(2), 206-238.

Bordia, P., Restubog, S. L. D., \& Tang, R. L. (2008). When employees strike back: Investigating mediating mechanisms between psychological contract breach and workplace deviance. Journal of Applied psychology, 93(5), 1104-1117.

Dozier, J. B., \& Miceli, M. P. (1985). Potential predictors of whistle-blowing: A prosocial behavior perspective. Academy of Management Review, 10(4), 823-836. 
Frøstrup, A. C. et al. (2018). Varslinger: verdier og vern. Varslingsutvalgets utredning om varsling $i$ arbeidslivet (NOU 2018:6). Oslo: The Department.

Greenberger, D. B., Miceli, M. P., \& Cohen, D. J. (1987). Oppositionists and group norms: The reciprocal influence of whistle-blowers and co-workers. Journal of Business Ethics, 6(7), 527-542.

Gundlach, M. J., Martinko, M. J., \& Douglas, S. C. (2008). A new approach to examining whistle-blowing: The influence of cognitions and anger. S.A.M. Advanced Management Journal, 73(4), 40-50.

Jensen, J., Opland, R., \& Ryan, A. (2010). Psychological contracts and counterproductive work behaviors: Employee responses to transactional and relational breach. Journal of Business \& Psychology, 25(4), 555-568.

Lewis, D. (2011). Whistleblowing in a changing legal climate: Is it time to revisit our approach to trust and loyalty at the workplace? Business Ethics: A European Review, 20(1), 71-87.

Lewis, D., Brown, A. J., \& Moberly, R. (2014). Whistleblowing, its importance and the state of the research. In Brown et al. (Eds.), International handbook on whistleblowing research. Cheltenham, UK and Northampton, MA: Edward Elgar Publishing.

Mesmer-Magnus, J. R., \& Viswesvaran, C. (2005). Whistleblowing in organizations: An examination of correlates of whistleblowing intentions, actions, and retaliation. Journal of Business Ethics, 62(3), 277-297.

Miceli, M. P., Dreyfus, S., \& Near, J. P. (2014). Outsider whistleblowers: Conceptualizing and distinguishing "bell-ringing” behavior. In Brown, A. J., Lewis, D., Moberly, R., \& Vandekerckhove, W. (Eds.), International handbook on whistleblowing research (pp. 71-94). Cheltenham, UK and Northampton, MA: Edward Elgar Publishing.

Miceli, M. P., \& Near, J. P. (2013). Some implications of the voice literature for research on whistle-blowing. In Voice and whistleblowing in organizations: Overcoming fear, fostering courage and unleashing candour (pp. 182-202). Cheltenham, UK and Northampton, MA: Edward Elgar Publishing.

Miceli, M. P., Near, J. P., \& Dworkin, T. M. (2008). Whistle-blowing in organizations. New York: Tylor Francis.

Miceli, M. P., Near, J. P., Rehg, M. T., \& Van Scotter, J. R. (2012). Predicting employee reactions to perceived organizational wrongdoing: Demoralization, justice, proactive personality, and whistle-blowing. Human Relations, 65(8), 923-954.

Miethe, T. D. (1999). Whistleblowing at work: Tough choices in exposing fraud, waste, and abuse on the job. Boulder, CO: Westview Press.

Morrison, E. W., \& Robinson, S. L. (1997). When employees feel betrayed: A model of how psychological contract violation develops. The Academy of Management Review, 22(1), 226-256.

Near, J. P., \& Miceli, M. P. (1985). Organizational dissidence: The case of whistleblowing. Journal of Business Ethics, 4(1), 1-16.

Near, J. P., \& Miceli, M. P. (1995). Effective-whistle blowing. Academy of management review, 20(3), 679-708.

Near, J. P., \& Miceli, M. P. (2016). After the wrongdoing: What managers should know about whistleblowing. Business Horizons, 59(1), 105-114.

Near, J. P., Rehg, M. T., Van Scotter, J. R., \& Miceli, M. P. (2004). Does type of wrongdoing affect the whistle-blowing process? Business Ethics Quarterly, 14(2), 219-242. 
NOU 2018:6. Varsling og vern. Official Norwegian Report on Whistleblowing. Retrieved from www.regjeringen.no/no/dokumenter/nou-2018-6/id2593665/

Olsen, J. (2014). Reporting versus inaction: How much is there, what explains the differences and what to measure. In International handbook on whistleblowing research. Cheltenham, UK and Northampton, MA: Edward Elgar Publishing.

Randall, D. M., \& Gibson, A. M. (1991). Ethical decision making in the medical profession: An application of the theory of planned behavior. Journal of Business Ethics, 10(2), 111-122.

Rehg, M. T., Miceli, M. P., Near, J. P., \& Van Scotter, J. R. (2008). Antecedents and outcomes of retaliation against whistleblowers: Gender differences and power relationships. Organization Science, 19(2), 221-240.

The report from Auditor General 2008/2009 (Document 3:14 (2008-2009)).

Restubog, S. L. D., Bordia, P., \& Tang, R. L. (2007). Behavioural outcomes of psychological contract breach in a non-western culture: The moderating role of equity sensitivity. British Journal of Management, 18(4), 376-386. https://doi. org/10.1111/j.1467-8551.2007.00531.x

Robinson, S. L., \& Rousseau, D. M. (1994). Violating the psychological contract: Not the exception but the norm. Journal of Organizational Behavior, 15(3), 245-259.

Rousseau, D. M. (1995). Psychological contracts in organizations: Understanding written and unwritten agreements. Thousand Oaks, CA: Sage Publications.

Rousseau, D. M. (1989). Psychological and implied contracts in organizations. Employee Responsibilities and Rights Journal, 2(2), 121-139.

Rousseau, D. M. (1990). New hire perceptions of their own and their employer's obligations: A study of psychological contracts. Journal of Organizational Behavior, 11(5), 389-400.

Rousseau, D. M. (2004). Psychological contracts in the workplace. Understanding the ties that motivate. Academy of Management Executive, 18(1), 120-127.

Rousseau, D. M., \& Tijoriwala, S. A. (1998). Assessing psychological contracts: Issues, alternatives and measures. Journal of Organizational Behavior, 19, 679-695.

Seeck, H., \& Parzefall, M. R. (2008). Employee agency: Challenges and opportunities for psychological contract theory. Personnel Review, 37(5), 473-489.

Skivenes, M., \& Trygstad, S. (2010). When whistle-blowing works: The Norwegian case. Human Relations, 63, 1071-1097.

Skivenes, M., \& Trygstad, S. (2014). Wrongdoing: Definitions, identification and categorizations. In Brown, A. J., Lewis, D., Moberly, R., \& Vandekerckhove, W. (Eds.), International handbook on whistleblowing research. Cheltenham, UK and Northampton, MA: Edward Elgar Publishing.

Sverdrup, T. E. (2012). The strength of reciprocity: Exploring horizontal psychological contracts in work groups. PhD-dissertation. Bergen: NHH Norwegian School of Economics.

Sverdrup, T. E. (2014). Psykologiske kontrakter i team. Beta, 28(2).

Sverdrup, T. E., \& Schei, V. (2015). "Cut me some slack”: The psychological contracts as a foundation for understanding team charters. Journal of Applied Behavioral Science, 51(4), 451-478.

Thompson, J. A., \& Bunderson, J. S. (2003). Violations of principle: Ideological currency in the psychological contract. Academy of Management Review, 28(4), 571-586. 
Trevino, L. K., \& Victor, B. (1992). PJS reporting of unethical behavior: A social context perspective. Academy of Management Journal, 35(1), 38-64.

Trygstad, S. C. (2017). Kunnskapsstatus og varsling og varslingsprosesser. Oslo: FAFO-notat.

Trygstad, S. C., \& Ødegaard, A. M. (2016). Whistleblowing and freedom of speech in Norwegian working life 2016. English summary of Varsling og ytringsfrihet i norsk arbeidsliv 2016. FAFO-rapport 2016:33.

Trygstad, S. C., Ødegaard, A. M., \& Svarstad, E. (2018). Varslingsrutiner på arbeidsplassen som redskap for åpenhet og trygghet. (Whistleblowing routines as management tools for openness and safety). Magma, 03-2018, 48-56.

Turnley, W. H., \& Feldman, D. C. (1999). The impact of psychological contract violations on exit, voice, loyalty, and neglect. Human Relations, 52(7), 895-922.

Vandekerckhove, W., Brown, A., \& Tsahuridu, E. (2014). Managerial responsiveness to whistleblowing. Expanding the research horizon. In Brown, A. J., Lewis, D., Moberly, R., \& Vandekerckhove, W. (Eds.), International handbook on whistleblowing research. Cheltenham, UK and Northampton, MA: Edward Elgar Publishing.

Vandekerckhove, W., \& Commers, M. R. (2004). Whistle blowing and rational loyalty. Journal of Business Ethics, 53(1-2), 225-233.

Vantilborgh, T., Bidee, J., Pepermans, R., Willems, J., Huybrechts, G., \& Jegers, M. (2014). Effects of ideological and relational psychological contract breach and fulfilment on volunteers' work effort. European Journal of Work \& Organizational Psychology, 23(2), 217-230.

Zhao, H. A. O., Wayne, S. J., Glibkowski, B. C., \& Bravo, J. (2007). The impact of psychological contract breach on work-related outcomes: A meta-analysis. Personnel Psychology, 60(3), 647-680. 


\title{
14 Culture Eats Control for Breakfast
}

\author{
The Difficulty of Designing \\ Management Systems for \\ Whistleblowing
}

June Borge Doornich

\section{Introduction}

In the aftermath of several large white-collar scandals in the late 1990s, such as at Enron, WorldCom, and Tyco, judicial frameworks worldwide have been strengthened to promote and protect employees exposing improprieties at their workplace. In many countries, the judicial framework forces companies to implement a management control system that both eases the threshold for blowing the whistle and protects the whistleblower afterward. Researchers like myself are now busy studying the actual effectiveness of just such systems.

A management control system (MCS) includes "those systems, rules, practices, values and other activities management put in place" to guide employees' behavior and actions (Malmi \& Brown, 2008, p. 290; Simons, 1995). Basically, an MCS is a package of five types of controladministrative controls, planning, cybernetic controls, reward and compensation, and cultural controls. With whistleblowing, researchers have focused on administrative and cultural controls and how they enhance the effectiveness of the MCS for promoting and protecting whistleblowing (Callahan, Dworkin, Fort, \& Schipani, 2002; Farooqi, Abid, \& Ahmed, 2017; Miceli, Near, \& Dworkin, 2009).

Whereas administrative controls attempt to specify and monitor employees' behavior and actions through formal organizational structures and systems, policies, and regulations, cultural controls endeavor to guide employees' behavior and actions through informal norms, values, and belief structures. But scholars investigating the MCS for whistleblowing have found conflicting results on the effectiveness of such controls. While some scholarship has shown that administrative control mechanisms really do improve employees' acceptance of whistleblowing-and also their sense of protection when reporting on workplace misconduct (Bowden \& Smythe, 2009; Lee \& Fargher, 2013; Miceli et al., 2009)— others have shown that the culture of the company may severely undermine administrative controls and actually limit the threshold for both blowing the whistle and punishing the whistleblower. So administrative 


\section{2}

June Borge Doornich

control mechanisms alone may not be enough to promote and protect whistleblowing. In fact, the culture of the company may, ironically, have a still stronger control function-one that undermines the judicial intention here.

Although previous studies report on how company culture influences whistleblowing, their methodological approaches are mainly descriptive (Matthiesen, Bjørkelo, \& Nielsen, 2008; Trygstad, 2017; Trygstad \& Ødegård, 2016). Other studies rely on quantitative analysis (Callahan et al., 2002; Near \& Miceli, 1986; Patel, 2003; Rehg, Miceli, Near, \& Van Scotter, 2008). While both qualitative and quantitative studies are useful, nonetheless they do not completely demonstrate how a company's culture can impact whistleblowing over time.

My purpose in this chapter is to explore the effects of culture on whistleblowing. This analysis is based partly on the interviews that relate what Peer Jacob Svenkerud (PJS) experienced as a whistleblower in Norsk Tipping (NT). But it's also based on my own professional observations of strong, embedded cultures' use of administrative controls, while focusing on PJS's case from a Norwegian cultural perspective.

In what follows, I offer an overview of the management control system as a package of both administrative and cultural controls, discuss current research literature on the effectiveness of those controls for whistleblowing, and then draw on both the NT case and my own observations of particularities of the Norwegian culture. I end with some remarks about the contributions of this chapter.

\section{Management Control Systems as a Package}

A management control system (MCS) is a set of mechanisms designed to guide employees' behavior toward certain organizational objectives (Abernethy \& Chua, 1996). Because it involves a panoply of both formal and informal systems that need to overlap to be effective, the MCS is best viewed as a package that is "structured around how control is exercised and, as such it broadly maps the tools, systems, and practices managers have available to formally and informally direct employee behavior" (Malmi \& Brown, 2008, p. 295). Accordingly, the MCS package consists of five main control categories as illustrated in Table 14.1.

In the mid-section of the framework, the three control types of planning - (1) cybernetic, (2) reward, and (3) compensation-are tightly linked in a temporal order from left to right. Planning focuses on both short-term tactical actions and long-term planning, with defined goals for employees to aim for daily. Cybernetic controls are both financial and non-financial measures that guide behavior by setting high standards for performance and targeted short-term and long-term goals. Reward and compensation seek to motivate goal congruence between the financial/ non-financial measures and employees' behavior. These three controls are 
Culture Eats Control for Breakfast 203

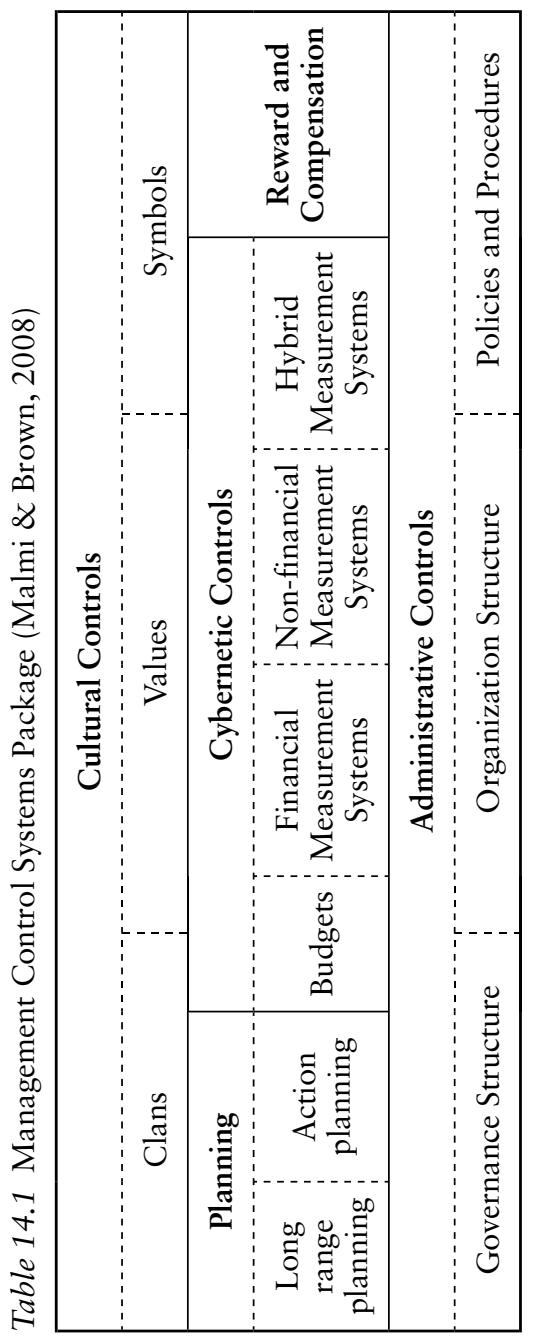




\section{June Borge Doornich}

less relevant here, as I believe they have minor influence on the MCS's effectiveness for promoting and protecting the whistleblower.

Administrative controls are at the bottom of the framework and set the structure for the middle section of controls. They seek to direct employees' behavior through the way individuals and groups are arranged in the organization (organization structure), through where the responsibility and accountability are placed (governance structure), and through specifying what behavior and actions are, or are not, to be performed (policies and procedures) (Macintosh \& Daft, 1987; Malmi \& Brown, 2008; Simons, 1987). Organization structure refers to how departments and individuals are arranged in the organization with certain connected relationships, the intention being to "reduce the variability of behavior and, in turn, increase its predictability" (Flamholtz, 1983, p. 158). Governance structure refers to the formal structures of authority and accountability as well as the communication and coordination between departments and individuals-both vertically and horizontally (Abernethy \& Chua, 1996). Policies and procedures are those techniques that specify and constrain behavior and processes, such as standard operating procedures, rules, guidelines, and best practices (Ouchi, 1979).

With respect to whistleblowing, the governance structure ideally clarifies the formal lines of responsibility for receiving and handling reports on misconduct. Ideally, they specify the authority on how to proceed with both individuals and groups who report on the whistleblower. Formal policies as ethical codes of conduct are formulated to eliminate the risk of wrongdoing in the first place and to promote and protect individuals should they decide to report. The procedures and policies should detail how a whistleblower proceeds to report on misconduct and clarify how he or she is protected. Those procedures and policies should be easily available and enable anonymous reporting.

Organization structure is the "taken-for-granted values, underlying assumptions, expectations, collective memories, and definitions present in an organization. It represents 'how things are done around here"' (Cameron \& Quinn, 2011, p. 9). The management-control literature presumes that an organization's culture can be controlled by guiding, and regulating, employees' behavior through shared norms, values, and belief structures (Flamholtz, Das, \& Tsui, 1985). Malmi and Brown (2008) include three forms of cultural control in their MCS framework: value-based, symbol-based, and clan control. Here is their formulation: Value-based controls embrace "the explicit set of organizational definitions that senior managers communicate formally and reinforce systematically to provide basic values, purpose, and direction of the organization" (Simons, 1995, p. 34). Organizational values are the moral, ethical, and professional attributes that form employees' character and become a guide for judging what is right or wrong in their behavior and actions-in effect, an ethical platform. Behaving ethically, then, means to 
behave consistently with both company and societal values. Values operate as a control mechanism by stating the ideal premises for employees' behavior and actions that have all employees singing from the same sheet of music. When the company's stated values and operating values are disconnected, and when the employees' and company's values are also separated, behavior and actions become dysfunctional and unpredictable. With respect to whistleblowing, values can be very effective as a control mechanism for promoting and protecting employees who report misconduct. Values such as loyalty, transparency, and trust that are strongly embedded in a company culture may eliminate wrongdoing in the first place - or at least encourage employees to report it when they find it.

Continuing with Malmi and Browns' (2008) model, symbol-based controls are conscious visual expressions by the company that are integrated at the workplace to influence certain forms of communication, collaboration, and relations among employees (Schein, 1991). Such symbolic control mechanisms involve, among other things, the way the workspace is designed (e.g., open office landscape vs. closed doors), the dress code expected of the employees or specific groups of them (formal vs. informal), and the language used by them (professional, serious, or unrestrained). I believe that such control mechanisms have minimal impact on promoting or protecting whistleblowing, although they may symbolize-and even enhance-the general openness and transparency of the company.

"Clans," as the final form of cultural control, refers to employee or management cultures fostered within the company through a socialization process that "instils in them a set of skills and values" that is controlled through "the ceremonies and rituals of the clan" (Ouchi, 1979; Malmi \& Brown, 2008, p. 295). Malmi and Brown (2008) associate clans with subgroups within the company that foster a tribal affiliation by a particular group of employees. The clan is rooted in a consensus of collaboration and reciprocity of trust among its participants. Expected behaviors and actions are based on commitments and traditions, fostered over the years, that create an atmosphere in which participants bond, caring for one another's welfare and resisting outside pressures.

But clan cultures can also have potential disadvantages (Cameron $\&$ Quinn, 1999). Employees can be hesitant to ever be thought wrong; also, clan cultures may lead to a bad corporate environment and poor performance. In relation to whistleblowing, clan cultures can foster a negative culture, with members of the clan engaging in unacceptable workplace behavior that goes under the radar because the reciprocity of the members ensures their hiding one another's wrongdoings. Clans can also make it difficult for non-members to report misconduct, knowing they'd be viewed as turncoats (Karaca, 2013). When wrongdoings occur within a clan, monitoring is often done, if done at all, through informal approaches in a modest way (Kowtha et al., 2001). With these views of 
control in mind, we turn now to the specific example of whistleblowing in Norway.

\section{Lack of Administrative Control Mechanisms for Whistleblowing}

In Norway, whistleblowing was enshrined in law in 2007 through the Working Environment Act (WEA), which required companies to create a management system that facilitates and protects whistleblowers by prohibiting retaliation. Specifically, it required a formal governance structure for handling whistleblowing within the company and for employees reporting misconduct. To complement the formal reporting system, the law also expected companies to create ethical codes of conduct, informal dialogues, and education on risks of misconduct, so as to increase employees' consciousness of what constitutes wrong and right behavior and actions (Eriksen, 2014).

Establishing these administrative control mechanisms helps ensure that wrongdoing is exposed promptly, letting management act quickly to minimize its costs and consequences (Chung et al., 2004; Lee \& Fargher, 2013). Companies with a strong corporate governance and good ethical codes of conduct are likelier to promote and protect whistleblowing and lower the threshold for blowing the whistle (Bowden \& Smythe, 2009; Lee \& Fargher, 2013; Miceli et al., 2009); they also experience fewer incidents of misconduct (Somers, 2001).

At NT, unfortunately, at the time, there were no administrative control systems in place for promoting and protecting whistleblowing. Bear in mind, though, that PJS's whistleblowing occurred before the WEA went into effect. When he first decided to speak up, he approached the chairman of the board, believing that the two of them shared a mutual obligation. But PJS had to follow his instincts on how to proceed by flying blind, as there was no defined governance structure that clarified the formal lines of responsibility for reports on company misconduct. Nor were there formal policies and procedures in place for promoting and protecting whistleblowing. The chairman who was approached by PJS was similarly disadvantaged. He lacked formal guidelines for how to handle the situation.

In this context of uncertainty, PJS had a second meeting with the chairman that included the vice chair. PJS shared the hard copy of gardening receipts, which were so incriminating-making it clear to both that something needed to be done. The chair instructed PJS to continue on with business as usual and remain in secret as the whistleblower, as the Senior Vice President Information and External Relations, while they investigated the matter. PJS recalls the chairman saying, "Just pretend that nothing happened. Work as you normally do and trust me when I say that I will protect you. No one will know whom this is. No one will know.” 


\section{Effect of Culture on Administrative Controls}

Although the WEA requires an effective MCS for whistleblowing that prohibits retaliation, whistleblowers in Norwegian companies often experience it. A 2008 study revealed that in $16 \%$ of all whistleblowing cases, the whistleblower met with retaliation (Matthiesen, Bjørkelo, \& Nielsen, 2008). A follow-up study in 2017 showed a worsening trend: in $25 \%$ of all cases the whistleblower met with retaliation (Trygstad, 2017). These studies document that blowing the whistle carries real risks. The degree of retaliation turns out to correlate with the severity of the conditions reported: the more severe the claims, the more punitive the retaliation (Matthiesen et al., 2008; Near \& Miceli, 1986). Whistleblowers often are stamped as disloyal and troublemakers-often even pressured to leave the company (Matthiesen et al., 2008; Near \& Miceli, 1986; Rehg et al., 2008; Trygstad, 2017; Trygstad \& Ødegård, 2016).

PJS experienced retaliation when he first reported the misconduct, and it only became stronger over time. When the misconduct was eventually exposed in the media, he was pressured to leave the company. In two distinct meetings, the new permanent CEO seemed to pressure him. In the first meeting, PJS recalls the CEO expressing: "You have done a very good job, he said-Your mission is accomplished. I said, what do you mean my mission is accomplished? He said well, you have done what you had to do. And now it's time to move on." In the second meeting, the CEO became even more aggressive: "I want you to come up with a specific date. If you do not do that, I will make sure that I will reorganize your department so that you will no longer be in charge of the communications department, I just want you to know that!"

After the law was strengthened in 2007, the number of reports on misconduct in Norwegian workplaces significantly increased, and the scope of criminal conviction also increased (Transparency International Norge, 2018). In 2014, that same law was revisited with the aim of providing even better insight into how it could be facilitated in companies and how whistleblowing could be protected by the employer, and what consequences whistleblowing should have for the person or organization that is reported on. The Ministry of Labor and Social Affairs appointed a committee to investigate these questions, and their findings were published in the report "ONR 2018:6-Whistleblowing-Values and Protection" (Official Norwegian Reports, 2018). Their report drew three main conclusions. First, many employees still experience formal and informal restriction in their right to blow the whistle. Second, there is a lack of both an internal system to protect the whistleblower and procedures for how to take prompt actions to investigate the alleged wrongdoing. Third, there is a need for greater awareness and changes in attitude toward reporting misconduct in Norway's workplaces. The committee concluded by affirming that whistleblowing is indeed a value, not a problem. 


\section{June Borge Doornich}

Taken together, the report from the ONR and the research literature agree that administrative control mechanisms are insufficient to promote and protect whistleblowing (Krawiec, 2003; Pascoe \& Welsh, 2011). Recommendations have included a need for greater awareness and changes in attitudes (ONR, 2018:6), good ethical codes of conduct (Bowden \& Smythe, 2009; Lee \& Fargher, 2013; Miceli et al., 2009), and informal dialogues and education on the risks of misconduct (Eriksen, 2014). Ideally, cultural controls will foster a common-clan environment rooted in a consensus about appropriate behavior and actions, with shared values serving as an ethical platform that is strengthened via communication, collaboration, and relations through certain organizational symbols to create a good working environment, goal achievement, and enhanced performance. With all this, however, corporate culture might still undermine administrative controls.

From my own observations, it seems that corporate culture in Norway, stuck in its old ways, can ensure that there is actually continuing resistance to change, despite administrative controls. New juridical frameworks get implemented within hardened governance and organizational structures, with policies and procedures often being changed only to meet the minimum requirements of the laws. In addition, any new policies and procedures are often met with resistance from the employees, who feel over controlled. Their resistance lessens over time, no doubt, as these feltintrusions become embedded as routines. But even then, the improved administrative controls might prove to be only a dormant control system, implemented primarily for the sake of appearances. It might roil the company should it need to make the system actually operative, were someone to blow the whistle.

So here's the point: governance and organizational structures, policies, and procedures can often become ineffective and superficial when they aren't embedded in the fundamental culture of the company. As the Chartered Institute of Internal Auditors put it: "effective internal whistleblowing arrangements are an important part of a healthy corporate culture. But it is also crucial to have the right organizational culture which encourages people to speak out without fear" $(2014$, p. 7).

\section{Clan Culture's Effect on Whistleblowing}

Studies that have investigated the effectiveness of cultural control show that various value-based control mechanisms are important to reinforce promoting and protecting whistleblowing. For both of those purposes, Callahan et al. (2002) found that cultural control should include accountability, reliance, and aspiration. Some years later, Farooqi, Abid, and Ahmed (2017) contended that clarity, consistency, and transparency should be integrated in cultural control. The same researchers further found that values should be tangible, comprehensive, all-inclusive, and 
communicated throughout the company (2017). Several other studies have shown that when values are unclear, it raises ambiguity as to expectations of appropriate behavior and actions. When employees are left to themselves to judge what is right or wrong, the risk for misconduct increases (Bird \& Waters, 1989; Kaptein, 1998; Balder \& Tyler, 2005). Value clarity creates a platform that guides employees in their attitudes and actions.

But clarity of values isn't enough. Those values need to be embedded, ensuring congruence between stated values and the daily practice of both employees and management (Farooqi et al., 2017). Management of the company must behave in congruence with expected values, since employees normally follow their leaders. Kaptein (1998) showed that unethical behavior by employees often occurred when management engaged in it themselves.

In the case of NT, the misconduct occurred at the management level, building a practice of continuous misconduct with values that reflected something completely different from promoting and protecting whistleblowing. A good ethical platform with values such as loyalty, transparency, and trust, in my opinion, wasn't present in the company; its culture seemed to be affected by self-interest and friend services with economic benefits.

Studies have shown that a transparent culture will make employees feel obliged to blow the whistle on misconduct (Farooqi et al., 2017; Kaptein, 1998). It will also help ensure that employees correct one another's behavior, thus lowering the risk of misconduct in the first place (Farooqi et al., 2017; Kaptein, 1998). Moral dilemmas and unethical behavior should be discussed among employees to clarify what is misbehavior in situations common to their workplace. At NT, the management seemed to ensure minimum transparency in order to hide their laxity. An example recalled by PJS is related to the budgeting process. A close ally of the CEO, one of the department heads, asked for 150 million Norwegian kroner in the budget and encountered no challenge as to where the money would be spent: "He didn't even need to press on the budget. I remember in budget meetings, he says-'Well, I need 150 million kroner for this.'” And when we asked-'How did you come up with that figure? He just put his figure to his mouth and-'well thats what it feels like." PJS also recalled that the budget of the CEO himself wasn't discussed either: "He (the first CEO) said-'Well, I have budget this and that's what I need."'

Misconduct often is perpetrated by whole groups of employees, both reflecting and further fostering a clan culture that has its own set of values and expectations as to what's acceptable (Farooqi et al., 2017; Punch, 2009). Wrongdoings by a clan are often shielded and thus never exposed, as values among the clan members are based on collaboration and reciprocity, where everyone is expected to support the other "family-members" (Farooqi et al., 2017; Punch, 2009). In the case of NT, a clan culture 


\section{June Borge Doornich}

developed at the management level. The clan was run by the company's strong threesome: the CEO, the vice CEO, and one of the department heads. According to PJS, "It was something that they had skillfully crafted for years and that was part of-an important element of the company culture." The situation at NT illustrates how a clan culture can distort a company's ethical values, creating an effect directly opposite from what is desired of the management control system framework with respect to using the clan as a control mechanism.

Over time, the NT clan strengthened as its members got ever more deeply involved with questionable actions and the members became more dependent on one another's loyalty not to report it, especially as the severity increased. The questionable behaviour could continue as a "normal" practice, with employees outside the clan unable to challenge it out of fear of the likely consequences: "Everyone knew what was going on and they were very critical to a variety of activities that were going on." "I was somewhat puzzled to learn that people knew but no one said anything." PJS describes this is as a very subdued culture in which questions were neither raised nor tolerated: "And, if you asked questions it was a common understanding that it could have a consequence." With the fear of retaliation, the clan could control the threshold for other employees contemplating blowing the whistle on them.

From my point of view, in Norway we speak about a phenomenon called "the boys club" (gutteklubben grei), where skilled men with a good sense for business always find a way to satisfy both themselves and fellow members of the club-by hiring obliging people in powerful positions, granting bidding rounds, and extending other significant business favors. They are found both internally in companies and also externally. At the national level, they include men from economically important sectors and companies; and at local levels, they can be found within smaller societies and local business sectors. The "boys club" at NT is a good example of this phenomenon, where a strong group of men inside the company governed all decisions and actions made, along with powerful men from external parties, ranging from local entrepreneurs to politicians with a central national position.

The questionable behavior by part of the management was occasionally challenged by the employees, but it seemed to be so strongly embedded in management practice that it had become the norm. Even when members of the management team occasionally tried to confront the CEO about some practices, they were ignored or disregarded. One instance, as recalled by PJS, was when a high-ranking manager talked to the CEO and vice CEO about the lawn mowing: "you know we cannot continue on doing this." He was basically told to shut up. "This is not something that you should concern yourself with. This is something that the Board has approved. Don't ask any more questions." This illustrates the power of the clan. Although challengers may suffer no direct punishment, they 
will be labeled as "difficult" and "bothersome." The clan thus exercises authority over other employees that goes well beyond their formal role and responsibility. It can be so embedded in the daily practice that people don't even think to challenge its members, since their behavior is taken for granted. What seems to be visible in the NT case is that no members of the clan feared that their misconduct would be exposed and reported. They assumed that new members of the company, through the socialization process, would accept the practices as "business as usual."

\section{Conclusion}

Pascoe and Welsh (2011) show the important relationship between national law and strong corporate governance structures containing explicit policies and procedures to both promote and protect whistleblowing, but that remains insufficient. Peter Drucker coined the phrase "culture eats strategy for breakfast." One could just as easily say "Culture eats control for breakfast." In the context of whistleblowing, while administrative control is important, I believe that culture is even more crucial. A company's culture must support administrative controls; otherwise they are likely to be undermined.

Companies need to implement value-based control mechanisms that foster clarity in expected ethical conduct, and consistency in expectations and practice. This will help ensure transparency, with an open dialog about what constitutes right and wrong actions. In effect, it's a broader "clanbased" control mechanism, espousing good ethical values and ensuring that employees have a "we-ness" feeling based on collaboration, loyalty, and reciprocity of trust.

While administrative control mechanisms are certainly important, they don't ensure that the corporate culture mirrors them. A good ethical culture will ensure that misconduct does not happen in the first place, or, if it does, it's promptly reported. To hold the moral compass steady, a highminded corporate culture for promoting and protecting whistleblowing is essential. Samuelson and Gentile (2005) put it well: “whistleblowing isn't a desirable end; it is a last resort. When we reach that stage, it means we have failed, both as organizations and as people" (Samuelson \& Gentile, 2005).

\section{References}

Abernethy, M. A., \& Chua, W. (1996). Field study of control system 'Redesign': The impact of institutional process on strategic choice. Contemporary Accounting Research, 13(2), 569-606.

Balder, S. L. \& Tyler, T. R. (2005). How can theories of organizational justice explain the effects of fairness? In Greenberg, J. \& J. A. Colquitt (Eds.), Handbook of organizational justice (pp. 329-354). Lawrence Erlbaum Associates Publishers. New York and London: Taylor \& Francis Group. 


\section{June Borge Doornich}

Bird, F. B., \& Waters, J. A. (1989). The moral muteness of managers. California Management Review, 32(1), 73-88.

Bowden, P., \& Smythe, V. (2009). Contemporary issues in international corporate governance. Victoria: Tilde University Press.

Callahan, E. S., Dworkin, T. M., Fort, T. L., \& Schipani, C. A. (2002). Integrating trends in whistleblowing and corporate governance: Promoting organizational effectiveness, societal responsibility, and employee empowerment. American Business Law Journal, 40(1), 177-236.

Cameron, K. S., \& Quinn, R. E. (1999). Diagnosing and changing organizational culture: Based on the competing values framework. Reading, MA: AddisonWesley Publishing.

Cameron, K. S., \& Quinn, R. E. (2011). Diagnosing and changing organizational culture: Based on the competing values framework (3rd ed.). San Francisco, CA: Jossey-Bass.

Charted Institute of Internal Audit. (2014). Culture and the role of internal audit: Looking below the surface. Retrieved from www.iia.org.uk/media/ 598939/0805-iia-culture-report-1-7-14-final.pdf

Chung, J., Monroe, G. S., \& Thorne, L. (2004). An examination of factors affecting external and internal whistle-blowing by auditors. Working Paper, York University, Toronto.

Eriksen, B. (2014). Å bekjempe et samfunnsonde. Om korrupsjon, varsling, granskning, og organisasjonskultur. Oslo: Gyldendal Norsk Forlag.

Farooqi, S., Abid, G., \& Ahmed, A. (2017). How bad it is to be good: Impact of organizational ethical culture on whistleblowing (the ethical partners). Arab Economic and Business Journal, 12, 69-80.

Flamholtz, E., (1983). Accounting, budgeting and control systems in their organizational context: Theoretical and empirical and empirical perspectives. Accounting, Organizations and Society, 8(2/3), 35-50.

Flamholtz, E. G., Das, T. K., \& Tsui, A. S. (1985). Toward an integrative framework of organizational control. Accounting, Organizations and Society, 10(1), 35-50.

Kaptein, M. (1998). Ethics management: Auditing and developing the ethical content of organizations. Dordrecht: Kluwer.

Karaca, H. (2013). An exploratory study on the impact of organizational silence in hierarchical organizations: Turkish national police case. European Scientific Journal, 9, 38-50.

Kowtha, R., Landau, J., \& Beng, C. H. (2001). The culture of voice: Exploring the relationship between employee voice and organizational culture. Research Paper Series (National University of Singapore. Faculty of Business Administration); 2001-005: 1-34.

Krawiec, K. (2003). Cosmetic compliance and the failure of negotiated governance. Washington University Law Quarterly, 81, 487-544.

Lee, G., \& Fargher, N. (2013). Companies' use of whistle-blowing to detect fraud: An examination of corporate whistle-blowing policies. Journal of Business Ethics, 114(2), 283-295.

Macintosh, N., \& Daft, R., (1987). Management control systems and departmental independencies: An empirical study. Accounting Organizations and Society, 12(1), 23-28.

Malmi, T., \& Brown, D. A. (2008). Management control systems as a packageOpportunities, challenges and research directions. Management Accounting Research, 19, 287-300. 
Matthiesen, S. B., Bjørkelo, B., \& Nielsen, M. B. (2008). Klanderverdig atferd og arsling I norsk arbeidsliv. Bergen: Universitetet i Bergen.

Miceli, M. P., Near, J. P., \& Dworkin, T. M. (2009). A word to the wise: How managers and policy-makers can encourage employees to report wrongdoing. Journal of Business Ethics, 86, 379-396.

Near, J., \& Miceli, M. (1986). Retaliation against whistle-blowers: Predictions and effects. Journal of Applied Psychology, 7(1), 137-145.

Official Norwegian Reports. (2018:6). Varsling-verdier og vern-varslingsutvalgets utredning om varsling $i$ arbeidslivet. Oslo: Ministry of labour and social affairs.

Ouchi, W. (1979). A conceptual framework for the design of organizational control mechanisms. Management Science, 25(9), 833-848.

Pascoe, J., \& Welsh, M. (2011). Whistleblowing, ethics and corporate culture: Theory and practice in Australia. Common Law World Review, 40, 144-173.

Patel, C. (2003). Some cross-cultural evidence on whistle-blowing as an internal control mechanism. Journal of International Accounting Research, 2, 69-96.

Punch, M. (2009). Police corruption: Deviance, accountability and reform in policing. London: Routledge.

Rehg, M. T., Miceli, M. P., Near, J. P., \& Van Scotter, J. R. (2008). Antecedents and outcomes of retaliation against whistle-blower: Gender differences and power relationships. Organization Science, 19(2), 221-240.

Samuelson, J., \& Gentile, M. C. (2005). Get aggressive about passivity. Harvard Business Review, November.

Schein, E. H. (1991). What is culture? In P. J. Frost, L. F. Moore, M. R. Louis, C. C. Lundberg, \& J. Martin (Eds.), Reframing organizational culture. Newbury Park: Sage.

Simons, R. (1987). Accounting control systems and business strategy: An empirical analysis. Accounting Organizations and Society, 12, 357-374.

Simons, R. (1995). Levers of control. Boston, MA: Harvard University Press.

Somers, M. J. (2001). Ethical codes of conduct and organizational context: A study of the relationship between codes of conduct, employee behavior and organizational values. Journal of Business Ethics, 30, 185-195.

Transparency International Norge. (2018). Korrupsjonsdommer i Norge 20032017. Oslo: Transparency International Norge.

Trygstad, S. C. (2017). Kunnskapsstatus om varsling og varslingsprosesser. Faforapport 2017:3. Oslo: Fafo.

Trygstad, S. C., \& Ødegård, A. M. (2016). Varsling og ytringsfribet i norsk arbeidsliv 2016. Fafo-rapport 2016:33. Oslo: Fafo.

Tyler, T. R., \& Blader, S. L. (2005). Can businesses effectively regulate employee conduct? The antecedents of rule following in work settings. Academy of Management Journal, 48(6), 1143-1158. 


\title{
15 Whistleblowing as a Means of $(\mathrm{Re})$ Constituting an Organization
}

\author{
William Rothel Smith III, Jeffrey W. Treem, \\ and Joshua B. Barbour
}

Scholarly studies of an organization often focus on one or more of its outcomes-such things as its survival, failure, performance, or production. The larger aim, nearly always, is to identify the specific resources, attributes, or conditions most likely to produce a successful outcome in any similar organization-or, for that matter, what it takes to avoid a bad outcome. So, for example, one might analyze the crisis at Norsk Tipping (NT) in terms of what had been lacking there, raising questions such as "What checks or oversight of financial expenditures might have limited the CEO's authority?" Such questions imply that, whatever the organizational context, crises-bad outcomes—can be prevented if only the right conditions are in place ahead of time. Whistleblowing, in this view, is a product of failed organizational structures that facilitated wrongdoing or stymied their correction. Whistleblowing, in short, is an action taken to address an organization gone wrong-a reaction to an already broken communication process.

Alternatively, one can view whistleblowing as a voiced protest against current norms of organizing in an environment organized over time to stifle self-criticism. Whistleblowing, in this larger view, signals the need to reconstitute the organization, and aims to marshal constitutive resources to do so. Hence, in this view, whistleblowing is not just an indictment of the organization, but also, ultimately, and more importantly, an appeal for a different way to organize it. As such, whistleblowing will be understood as situated between whatever interactions preceded it and what it now invites.

To our mind, viewing whistleblowing as constitutive, or reconstitutive, provides us two clear benefits. First, it recognizes what seems a selfevident truth, namely, a deep understanding of whistleblowing requires our examining interactions and discourses among a whole network of actors over time. And second, it promotes our investigating a different way for an organization to organize itself. In other words, it's not merely an objection to, or exposure of, the status quo. It's a call for a re-do.

The present whistleblowing case involving Peer Jacob Svenkerud (PJS) offers us an opportunity to demonstrate these benefits via a 
communication-constitutes-organizing (CCO) lens (Barbour \& Gill, 2017; Barbour, Gill, \& Barge, 2018; Cooren, 2010; Cooren \& Fairhurst, 2009; Fairhurst \& Putnam, 2004; Taylor, 1999; Taylor \& Van Every, 2000). $\mathrm{CCO}$ scholars contend that communication is central to the emergence, enactment, and evolution of organizations. It is not only the simple expression of ideas or messages, but also in fact it actively produces, generates, and transforms organizations. Put another way, organizations aren't merely contexts in which communication occurs, or entities that produce communicative products, but are themselves literally enacted through actions and interactions. $\mathrm{CCO}$ views organizations as always becoming. They are an ongoing accomplishment of a network of actors.

In this chapter, we show how a CCO lens interprets key aspects of PJS's story. In doing so, we show the value of construing whistleblowing as literally constructive, indeed as reconstitutive.

The scholarly movement of communicative constitution of organizations (CCO) proposes that communication is critical in constituting an organization-that is, very organization itself. CCO approaches can encompass both inductive (Taylor \& Van Every, 2000) and deductive (McPhee \& Zaug, 2009) explanations for collective activity. In either case, the focus is not on communication as a variable of study within an already formed organization. Instead, the seemingly mundane, dayto-day communicative actions of strategizing, branding, hiring, firing, promoting, requesting, ordering-all of these things ultimately serve to constitute the object of an organization. Taylor (2011) described the constitutive stance succinctly as "Not communication in organization, but rather organization in communication" (p. 4).

Generally, CCO helps us understand how the meaning of an organization emerges through communication: who gets to participate in creating that meaning, and ongoing communicative efforts to somehow reconstitute (i.e., improve) the organization.

We situate the present analysis primarily within the Montréal School of CCO scholarship (Cooren, 2006; Fairhurst \& Putnam, 2004; Taylor, 1999; Taylor \& Van Every, 2000). We like how it emphasizes the ways that legitimacy, authority, and voice are contested among actors through their ongoing interactions.

\section{$\mathrm{CCO}$}

A central concern of $\mathrm{CCO}$ is how the voices of myriad organization members come to constitute a single organizational chorus (Barbour et al., 2018; Kuhn, 2012). To bridge the gap between observing micro-level communicative events and explaining larger collective structures, Montréal School scholars suggest that a recursive interplay between what they call conversations and texts scale up to constitute a collective actor (the organization). The conversations comprise local and observable events, 
interactions, and practices. These conversations in turn generate a text, or shared interpretation of the conversation. This interplay between text and conversation forms a self-organizing loop, or "coorientation" system (Taylor, Cooren, Giroux, \& Robichaud, 1996; Taylor \& Van Every, 2000), wherein texts are "the inputs to, and outcomes of, conversation" (Kuhn, 2008, p. 1233).

In other words, voices eventually become a chorus as individuals draw upon this shared interpretation, this "text," to guide their conversations and collectively pursue goals. Texts are usually treated as an invisible resource, or an "understanding," that guides conversation rather than an explicit "thing" that individuals reference. But not always. "Texts" can also be periodically inscribed into concrete forms. Think, for example, of vision statements, policy documents, and procedural manuals, as well as organizational messaging to external audiences (Kuhn, 2008). During the conversation phase, which is ongoing, the resulting text is further altered. The organization itself emerges through communication in that it is described in text and enacted through conversation. Individuals collectively coorient by focusing on a shared object (the text, or organization). For example, three individuals starting a new environmental conservancy nonprofit may talk over the goals, purpose, activities, and practices of their emerging organization. Although not necessarily codified as a mission statement, this initial conversation creates a shared text that might be summarized as oceanic stewardship. As time passes and the nonprofit grows, the newly hired accountants, marketers, and fundraisers coorient. They draw upon and alter the shared idea of what oceanic stewardship actually means. As this text gains distance, the meaning and purpose of the organization, the text, might shift and expand to encompass sea life conservation, reducing reliance on plastic packaging, lobbying, educating, and social media activism. As individuals within the nonprofit carry out their daily work, the shared text of oceanic stewardship, whatever the text may have evolved to mean, guides their actions. That is, communication is both the site of emergence and the surface upon which the organization continues to exist (Taylor, 1999).

Instead of focusing, like other approaches, on organizational structures as influencing actions, which risks construing organizational life as largely static and predictable, $\mathrm{CCO}$ wisely views all organizational communication as the exercise of agency by a network of human and non-human actors, and human and non-human voices (Cooren, 2004; Cooren \& Fairhurst, 2009; Cooren, Kuhn, Cornelissen, \& Clark, 2011). In such a view, structure can be seen as whatever the actors do to materialize and "author" the organization to its own members, customers, or other stakeholders (Cooren, 2010). So, as an alternative to documenting the presence of organizational structures, we can examine what Kuhn (2008) terms authoritative texts that provide meaning and identity for firms. An authoritative text is the abstract representation of the entire organization 
reflected in the emerging and shared meaning around "oceanic stewardship" in the foregoing example. Authoritative texts provide a "trajectory" for organizational action and "portrays the relations of authority and criteria of appropriateness that become present in ongoing practice" (Kuhn, 2012 , p. 553). These texts are often revealed through networks of meaning that favor certain characteristics of organizing (Kuhn, 2008) rather than official codified policy. In other words, an authoritative text may be as simple as "how things are done around here" and not a solidified document. Despite their slippery character, authoritative texts help define organizations by providing members with a focus for coorientation that can guide actions.

Authoritative texts occur in the continuous flow of discourse that is found in everyday communication practices. Voices coalesce as fragments that can nonetheless be seen as a whole in the gestalt. Understanding the organizing of organizations requires examining talk and text not as isolated communication, but as the basis of action that provides meaning (Alvesson \& Karreman, 2000; Engestrom, 1999). Authoritative texts should be understood as "intertextually" influenced in the sense that they are shaped by, interact with, and encounter other texts and related discourses (Schoeneborn, Kuhn, \& Kärreman, 2019). Individuals make sense of the actions they take and establish and assert power through ongoing communication (Mumby,1987; Mumby \& Stohl, 1991; Weick,1979). As actors reproduce and disseminate texts in organizing, they create narratives around the meaning of work and the formation of ongoing practices (Clair, 1993; Deetz, 2003).

Authoritative texts emerge through the ongoing interplay of grand ideologies about how firms should be organized and operate (the Discourse), and everyday conversations that occur within the activity of work (the discourse) (Alvesson \& Karreman, 2000). The recognition of D/discourse at both the micro-level of interaction and the macro-level of institutions suggests that its role in organization should be understood as a recursive process in which each helps form the other. Organizations may emerge through conversation, but they don't emerge for the sake of conversation. No, they emerge and continue to exist in order to accomplish situated goals (Engestrom, 1999, p. 170). Recognizing the action-oriented nature of $\mathrm{D} /$ discourse in organizations prompts researchers to examine the production and implications of interactions.

\section{The Enactment of an Authoritative Text at Norsk Tipping}

PJS's fascinating retrospective account of his tenure at Norsk Tipping (NT) in Chapter 1 lets us access the constitution and reconstitution of the organization's authoritative text. That is, we can see a lone voice attempting to shift the whole that has coalesced. The interviews with PJS, the annual reports, the newspaper articles, the independent audit of NT, the 
record of his correspondence with his attorney-all indicate how events over time shifted the constitution of NT and the communication choices made by actors in conversation with others.

A helpful starting point for making sense of the communicative constitution of NT is to trace the D/discourses present. We can examine the constitution of NT at two levels: (1) the broader perception of what the organization was as a whole, and (2) the internal, situated discourses that signified to members what the organization was.

\section{Macro-Level Discourse of NT}

The fraud at NT was so startling in part because the organization was widely viewed as both upright and a desirable place to work. That, in short, was the prevailing external reading of the authoritative text of NT. Over decades, through its prominent public engagement and generous disbursement of winnings, NT acted in a manner consistent with what was expected from a reliable, state-owned company. Moreover, because of its monopolistic position and government support, the discourse regarding the organization became self-fulfilling. People came to trust that NT acted in the way a lottery organization should because it was the only organization of that type that they regularly experienced. Activities such as sponsoring athletic organizations and events allowed NT to have a prominent voice in the country and established the organization as a productive contributor to Norwegian life.

Indeed, at several points in PJS's interviews, his musings over the precise role of a state-owned organization are triggered by his awareness of the disjunction between the prevailing reading of NT's authoritative text and his own reading of it. For instance, in his first interview he reflects on his decision to join NT: "I thought this company, which was nationally based, $100 \%$ owned by the Norwegian government would be very conscientious about how they handled their financial matters." But after discovering NT allotted an exceptionally large budget for marketing, advertising, and research (several hundred million Norwegian crowns combined), he found himself wondering, "Is this right in terms of being a non-profit organization and in accordance with what non-profit means?"

A key element in the communicative constitution of NT is the way leadership came to shield decisions from the public, and even to members of the organization itself, to preserve the positive prevailing reading. PJS notes that given the funding and mission of the organization, he "had an understanding that we [NT] had to be visible." Yet over time, as the CEO altered patterns of spending, including making deals with friends, authorizing lavish business expenditures, and appropriating funds for his personal benefit, the company's activities and strategy were shared with ever fewer individuals. The CEO developed a small, close-knit group of advisors, and as for anyone he didn't trust, "he would remove you or he 
would freeze you out." Changing what he communicated about and with whom, the CEO effectively obscured NT's inner workings—and also preserved its image as a highly respected organization with a decades-old sterling reputation.

Meanwhile, PJS also encountered concrete texts from the Norwegian Ministry of Cultural Affairs that challenged his assumptions about NT's transparency. Although he had expected that the monopoly-in fact, a national monopoly-would practice perfect transparency both inside and outside its walls, he learned that "[NT] was, for some strange reason, under a law that did not require them to be as open as other state-owned companies." He later also learned that the Ministry of Culture had ruled that NT should receive cover under a law that obscured its operations in order to insulate it from increasing competition from online and international gaming companies. Establishing the appropriate level of transparency for NT involved a complex mixture of concrete and figurative texts. The very laws enacted to regulate addictive gambling behavior, ensure the financial viability of the state-owned monopoly, and safeguard the continued financial support for prosocial causes ultimately allowed NT greater leeway to perpetuate and cover up financial wrongdoing. NT's embracing of a mission to help curb destructive gambling gave the organization greater legitimacy and authority as an entity supporting the public good. In sum, the public Discourse indicated that NT existed and acted to support the betterment of Norway and the lives of Norwegians.

NT's annual reports also operated as a communicative device that supported this image of it as a well-managed, thoroughly responsible organization. PJS notes that he himself drew on these annual reports as texts with internal and external audiences to portray the organization as one forever challenged to balance the monopolistic regulation of a market with the need for sponsoring public benefits. Surely that alone deserved applause!

During the pre-whistleblowing time frame, multiple flows of seemingly inconsequential communication sustained NT. Much of the communicative "stuff" that constituted NT was procedural and mundane. For example, the day-to-day actions of NT's departments-filing invoices, researching new products, hiring, sending emails, updating websites, interacting with sponsors, etc.- - kept the assemblage of NT going. But these same seemingly mundane communicative actions helped perpetuate the wrongdoing. In one example, PJS experienced discomfort that the CEO had awarded a high-value contract to a close personal friend. When PJS asked the CEO about the outward appearance of this controversial practice, the man airily proclaimed, "I'm not worried about it. Just write a press release. We have everything covered. We have done our internal evaluations." Here the CEO references a separate flow of conversationproducing texts legitimizing his conduct. This story provides a noteworthy example of how mundane and micro-level communicative activities 
can actually have larger implications for the constitution of the organization. The texts-a press release and "internal evaluations"-conjured an image of an aboveboard organization. Through these practices, these texts reinforced NT's "business as usual" ethos.

It's not luck or happenstance that the wrongdoing at NT persisted for so long without more scrutiny or outcry. Rather, NT benefitted from a long-held, well-established, and carefully crafted Discourse establishing NT as above reproach. Indeed, the stellar reputation of NT and its stature in the community were principal reasons why PJS had excitedly joined the organization. Purposeful, strategic communicative actions taken by NT in the form of annual reports, sponsorships, press releases, public events, and management appearances reinforced this Discourse and made it material. As a result, a powerful authoritative text emerged that shielded the organization from criticism from employees and external stakeholders alike.

PJS notes that as the extravagant and irresponsible spending at NT increased, and its members' actions became further misaligned with popular expectations for public organizations, questions from the press and other government officials increased. A CCO perspective would read this dynamic as the authoritative text and associated communication of NT now diverging from the historical construction of expectations regarding how the organization ought to act. But despite the growing uneasiness over NT's management, these sentiments did not coalesce into a text that could have shifted the broader Discourse about NT, and it therefore didn't initiate substantive change. The broader external discourse wasn't powerful enough to influence change because a persistent positive discourse within NT always countered it.

\section{Micro-Level Discourse at NT}

The extent to which the actions of leadership, and the CEO's in particular, went unchallenged by workers within the organization is a consistent facet of PJS's story of his time at NT. Here, for example, he recalls the atmosphere at NT that surrounded and shielded the CEO: "it soon became clear to me that the CEO was very much an institution at the company" (int 18, p. 2). When the great man entered the building, employees "raced up and shook his hand ... you went into the restroom and made sure that your tie was straight." And "when he came into the reception, it almost seemed like people were standing up, saluting him," suggesting that the CEO, like a generalissimo, encouraged reverence, mixed with fear, in his lower-level employees. PJS explained that "all these things around him and his personality built up over time." Other stories emphasized the CEO's need for a larger-than-life personality. The stories gained distance and traveled from their original occurrence to represent the type of leadership that characterized NT and how they directed its organization. 
The self-serving actions of the $\mathrm{CEO}$ were widely known throughout the organization, and they came to constitute how the organization operated. The stories were among its givens, and workers just accepted them. It was the culture. But PJS, up closer to the executive suite, found it hard to adjust. As he noted about his own socialization, "I tried to learn the culture. But immediately, these [countervailing] stories came along"-stories of excess spending and extravagance. In one such tale, the company footed the bill to construct a replica Viking ship, rent Viking costumes, and have the CEO ride the ship into an event intended to welcome World Lottery Association delegates to Norway. The company spent, on average, in the neighborhood of 100,000 crowns per person (more than $\$ 11,000$ USD) for this 50-person event. Other stories of extravagant gifts from suppliers (such as a holiday trolley full of gifted liquor), expensive travel, private chauffeurs, and a Mercedes limousine with a well-stocked bar, were prevalent. The stories provided a model for NT employees and a basis of what was normal at NT. These stories could have been fodder for criticism or accusations of malfeasance, but against the backdrop of the charismatic reputation of the CEO and the positive reputation of NT, they were either ignored, excused, or explained away as how he chose to conduct business.

Two distinct communication strategies designed to show its ongoing success sustained the discourse that everything was just fine at NT. First, the CEO stifled dissent and criticism from associates. Here is PJS reflecting on the general understanding of the company's culture: "it was a very subdued culture . . . not very many asked questions. And if you asked questions, there was an internal understanding that if you asked too many questions, that will have a consequence." Leadership afforded workers few opportunities to question the decisions or the direction of the organization. Second, through his position leading external communication, PJS himself felt pressure to portray the organization as responsible and productive. The annual reports, press releases, and press interviews were texts constructed to reinforce a glowing view of NT. Those working within NT had little opportunity to alter the nature of communication around the direction of the company, and management and the communication professionals at NT obscured or obfuscated any reasons to question it.

\section{Authority in the Construction and Attempted Reconstruction of NT}

Modern organizations have formal hierarchies of institutional authority, with individuals near the top afforded greater authority (Weber, 1946; Fayol, 1949). Descriptions of his CEO as possessing magisterial authority, simply by virtue of his lofty position, dominate PJS's early stories. Whereas structural positions of authority within NT are certainly 
prevalent, a CCO lens argues for viewing authority as a distributed and negotiated phenomenon. The performative aspects of the CEO's role and his charisma matter. Rather than authority being equated with hierarchical position, CCO theory prompts us to consider how authority emerges through communicative interaction, distributed among actors.

Taking this view, an analysis of the present case can reveal how communication constituted and shifted authority over time. In particular, PJS's comments regarding the non-transparency of the actions and decision-making at NT, and how leadership resisted transparency, reveal the functioning of authority in communication, not just through the communication of those in positions of power. In this case, authority over who could have input into organizing offers a different view of transparency that centers on understanding the exercise of control over how NT was made more or less visible to actors by communication. Discourses are a product of what actors may see, know, and perceive. So when managements prevent individuals from seeing an organization, they are unlikely to communicate in ways that shift existing discourses.

From a coorientation perspective, the NT case shows how the conversations that lead to a shared authoritative text, one distanced from the local, were often restricted to a privileged few. As early as PJS's first interview, he references "off-record meetings" between the Ministry of Culture and top executives at NT. Worker protections through Norwegian unions might have given them the resources and cover needed to challenge the malfeasance at NT, but the CEO so tightly controlled access to the flow of conversation constituting the coorientation process at NT that union representatives on the board were ineffectual. PJS recalled that the CEO and vice president would hold pre-board meetings with the union representatives to ensure that those representatives didn't challenge anything later, during the actual meetings. He explained: "that was just to keep them in place, to show authority ... they called them into a meeting before the board meeting and then told them that, 'This is how we want it,' and that's how it went." Thus, leadership co-opted the representatives' authority to preserve its own legitimacy.

Their communication choices also limited the effectiveness of communication meant to challenge the malfeasance and shift the conversation at NT. When PJS confronted the board of directors with allegations of wrongdoing, he had to face a meeting at which the board anatomized each allegation point by point. Earlier, PJS had asked the advice of a highly respected lawyer, judge, and mediator with experience investigating corporate corruption for how to approach this meeting. The man cautioned, "Everything you say will —-they will attempt to downplay or dismiss ... everything you do, they will attempt to diminish or make less significant or dismiss." Indeed, the board attempted to explain away issues of wrongdoing. For example, expensive fishing trips with a supplier were brushed 
aside as "strategic meetings" for which they had no receipts. After minimizing each allegation, the board asked PJS if he was "satisfied" with the response rather than working to actually change the corrupt practices. Instead of addressing the underlying concerns, they shifted the purpose of the communication to satisfying PJS, at least nominally. This meeting represents another example of competing efforts to control the conversation and resulting textual outcomes. As this case illustrates, the exercise of authority relied less on formal hierarchical position, though bolstered by it, than on strategic communicative actions. Whereas board meetings appeared, superficially, as a site of acceptance and upholding questionable practices, PJS noted that certain conversations beyond the control of the CEO generated a different textual outcome. He explained: "There was a consensus among the top leadership group [that] to go against the $\mathrm{CEO}$ and to criticize the CEO openly, entailed a risk to them . . . still, though, the corridor talk communicated differently." He went on to say that individuals would privately chat with him after leadership meetings and voice concerns about particular questionable business practices but would not do so in visible ways. As the CEO attempted to control the coorientation process and create a shared interpretation that everything was normal and aboveboard through his strategic communication, other texts began to form and gain distance that countered the CEO's desired text.

\section{Voice as a Means of Legitimate Resistance to Authority}

To shift the discourse regarding the appropriateness of actions by NT's leadership, PJS needed to communicate an alternative discourse. $\mathrm{He}$ needed, that is, to voice a different way of being; he needed to intervene in the flow of conversation. The concept of "organizational member voice" owes much to the work of Hirschman (1970), who discussed three potential clusters of choices for action and communication that individuals have in confronting the sort of rupture that occurred at NT (see Chapter 2). First, they can decide to exit the organization and avoid, condemn, or distance themselves from the issue. Put another way, they can choose invisibility, silence, or speaking up from the outside. Second, they might conspicuously display loyalty and remain aboard but keep silent, at least for the time being, regarding any existing issues, probably just hoping that the organization would eventually turn things around. Third, they can actively use their voice: they can communicate concerns, undertake efforts to improve conditions, or call attention to problems. Some scholars have since presented a fourth path for members, termed "neglect." It involves individuals recognizing the problem yet taking no action-just waiting, resignedly, for the inevitable collapse (Farrell \& Rusbult, 1992). In PJS's case, he opted for a fifth response: voicing his concerns, while still aboard, felt like a moral obligation. 
Whistleblowing is a particular form of voice for dissent and resistance (Near \& Jensen, 1983; Stewart, 1980). Viewed through a CCO lens, whistleblowing attempts to constitute dissent as legitimate-and to undermine the legitimacy of existing authoritative texts. With the crisis at NT, this lens looks past individual acts of misconduct to acknowledge the virtual cascade of communication by actors over time that created the conditions that then supported wrongdoing and shielded perpetrators. The actions of PJS were his attempt to resist and redirect the dominant authoritative text, to constitute different organizing. As Gossett and Kilker (2006) noted, "By openly articulating their concerns, dissenting members provide an oppositional discourse that can challenge the dominant narrative and provide an alternative for making sense of the organization" (p. 66).

But the same organizational structures that empower wrongdoing to occur over time also make whistleblowing extremely risky, as those same structures are the matrix against which communicating dissent must often occur (Gabriel, 1999). In PJS's case, whistleblowing meant having to go outside the company leadership and communicate his concerns directly to the board of directors. His initial efforts to do so were either ignored or actively discouraged with name-calling and ridicule. This aspect of the case accords with some research documenting that whistleblowing occurs after active efforts to voice concerns within an organization fall short (Stewart, 1980). It was only when PJS found that his communication efforts weren't spurring an alternative path of action within NT that he communicated with other actors who might have greater authority to alter the dominant NT discourse.

\section{What a CCO Lens Can Tell Us About Whistleblowing and Organizations}

\section{Whistleblowing Shaped by Time and Place}

As a communicative act, whistleblowing typically does not occur at the time of the wrongdoing. Instead, it emerges based on contextual factors that eventually lead a person to deem it as necessary, appropriate, or feasible. Also typically, before the whistleblower (or, more often, their complaint) becomes public, that person remains an active organization member. The eventual meaning and effectiveness of the whistleblowing are influenced by the timing of the complaint and the series of activities that have preceded it, as well as by the distinct roles occupied by the whistleblower and others implicated. When the whistleblowing occurs, the organizational role of the whistleblower will affect his or her authority by shaping others' perceptions of their motivations. Yet, member voice can also lose authority when whistleblowers leave their organization (Gossett \& Kilker, 2006), for then they forfeit their status as an 
insider. They are now outliers, whether they remain or exit altogether. They may be labeled as disgruntled, vindictive, or opportunistic. Moreover, the shift from in-group member to out-group member makes them more susceptible to attacks from remaining co-workers who can portray them as actually never fitting in or as ineffectual.

In the wake of major fraud, outsiders may wonder how it could have been sustained for so long, and seemingly involved so many different people, without anyone protesting. What's overlooked is that the fraud rarely operates as a broad, coordinated conspiracy within the entire organization. More often, it functions exactly as it did at NT, where people in authority make decisions that they then shield from others or that few have the insight or the ability to change.

The whistleblowing authority of PJS derived in part from the sheer length and breadth of his insider knowledge. He could speak to a series of misdeeds committed over years and could even present them yet more concretely in list form to the board. Given the inertia of organizational discourse over time, and the authority generated by texts produced over years and across contexts, isolated claims, unlike PJS's, aren't nearly so likely to be seen as authoritative or powerful in shifting communication about ways of working. Therefore, we must view whistleblowing efforts as situated within, and a product of, a specific history of macro- and micro-level discourses regarding appropriate ways of organizing specific organizations. The case of PJS at NT exhibits the contingent nature of authority and associated discourses.

\section{Whistleblowing as Precarious Authority}

Scholarship consistently recognizes the huge risk assumed by a whistleblower. It includes not only the potential for retribution, but also the possibility that the complaint itself will be distrusted or ignored. The whistleblower's claim to authority is inherently paradoxical. In demonstrating that others have transgressed, the whistleblower may reveal their own complicity in transgressions. This paradox is reflected in the persistent moral dilemma faced by PJS regarding his appropriate course of action. He sounded the alarm only when he was ready to acknowledge, painfully, his own role in perpetuating the misconduct and genuinely believed the organization would not change without his intervention. He knew that his role as a leading communicator for NT provided him with inside information that could be critical in exposing wrongdoing-but that also made him complicit in perpetuating the charade.

His eventual success in convincing others of wrongdoing demonstrates how texts, as non-human actors, can exercise authority and undermine extant discourses. Though stories of extravagance regarding the CEO were widely known, the man's behavior could often be rationalized as supporting necessary business practices-essential travel, relationship-building, 
entertaining, and the like. It wasn't until PJS produced receipts exhibiting the CEO's personal lawn-care expenditures that the board got concrete, unimpeachable evidence of impropriety. Its specificity and concreteness provided him with authority, but the fact that the text was decoupled from PJS himself explains its effects in organizing.

\section{Conclusion}

PJS's case reveals how the entirety of the events were, in the final analysis, communicative attempts to reconstitute the organization. They underscore in CCO the need to conceptualize not just the flow of conversation and emergence of text, but also the strategic communication that actors employ to intervene in construction processes. NT had been constituted as having an organization dominated by a culture of deference to leadership, plus an acceptance of employee subordination and submission to established ways of working. As details of the whistleblowing became more widely known, both internally and externally, the elements demonstrated the communication involved in responding to the whistleblowing. Attempts to reframe the organization-to put a new face on it-were strategic communicative actions aimed to reconstitute it. NT's essence was, and will always be, instantiated through communicative acts codified and reflected in, but not reducible to, organizational structures. Like every big organization, NT finds itself continually made and remade, and those processes will shape how well it handles any future cases of wrongdoing.

\section{References}

Alvesson, M., \& Karreman, D. (2000). Varieties of discourse: On the study of organizations through discourse analysis. Human Relations, 53, 1125-1149. https://doi.org/10.1177/0018726700539002.

Barbour, J. B., \& Gill, R. (2017). Questioning as regulatory work practice: The communicative accomplishment of reliability for the safety oversight of nuclear power plants. Communication Monographs, 84, 466-487. https://doi.org/10.1 080/03637751.2017.1322212.

Barbour, J. B., Gill, R., \& Barge, J. K. (2018). Organizational communication design logics: A theory of communicative intervention and collective communication design. Communication Theory, 28, 332-353. https://doi.org/10.1093/ ct/qtx005.

Clair, R. P. (1993). The use of framing devices to sequester organizational narratives: Hegemony and harassment. Communication Monographs, 60, 113-136. https://doi.org/10.1080/03637759309376304.

Cooren, F. (2004). Textual agency: How texts do things in organizational settings. Organization, 11, 373-393. https://doi.org/10.1177/1350508404041998.

Cooren, F. (2006). The organizational world as a plenum of agencies. In F. Cooren, J. R. Taylor, \& E. J. Van Every (Eds.), Communication as organizing: Empirical 
and theoretical explorations in the dynamic of text and conversation. Mahwah, NJ: L. Erlbaum Associates.

Cooren, F. (2010). Action and agency in dialogue: Passion, incarnation and ventriloquism. Amsterdam, The Netherlands: John Benjamins.

Cooren, F., \& Fairhurst, G. (2009). Dislocation and stabilization: How to scale up from interactions to organization. In L. L. Putnam \& A. M. Nicotera (Eds.). Building theories of organization: The constitutive role of communication (pp. 117-152). Oxford: Taylor \& Francis.

Cooren, F., Kuhn, T., Cornelissen, J. P., \& Clark, T. (2011). Communication, organizing and organization: An overview and introduction to the special issue. Organization Studies, 32, 1149-1170. https://doi.org/10.1177/0170840611410836.

Deetz, S. (2003). Reclaiming the legacy of the linguistic turn. Organization, 10, 421-429. https://doi.org/10.1177/13505084030103002.

Engestrom, Y. (1999). Communication, discourse and activity. The Communication Review, 3, 165-185.

Fairhurst, G. T., \& Putnam, L. L. (2004). Organizations as discursive constructions. Communication Theory, 14, 5-26. https://doi.org/10.1093/ct/14.1.5.

Farrell, D., \& Rusbult, C. E. (1992). Exploring the exit, voice, loyalty, and neglect typology: The influence of job satisfaction, quality of alternatives, and investment size. Employee Responsibilities and Rights Journal, 5, 201-218.

Fayol, H. (1949). General and industrial management. New York, NY: Pitman.

Gabriel, Y. (1999). Beyond happy families: A critical re-evaluation of the controlresistance- identity triangle. Human Relations, 52, 179-203.

Gossett, L. M., \& Kilker, J. (2006). My job sucks: Examining counterinstitutional web sites as locations for organizational member voice, dissent, and resistance. Management Communication Quarterly, 20, 63-90.

Hirschman, A. O. (1970). Exit, voice, and loyalty: Responses to decline in firms, organizations, and states. Cambridge, MA: Harvard University Press.

Kuhn, T. (2008). A communicative theory of the firm: Developing an alternative perspective on intra-organizational power and stakeholder relationships. Organization Studies, 29, 1227-1254. https://doi.org/10.1177/0170840608094778.

Kuhn, T. (2012). Negotiating the micro-macro divide thought leadership from organizational communication for theorizing organization. Management Communication Quarterly, 26, 543-584.

McPhee, R. D., \& Zaug, P. (2009). The communicative constitution of organizations: A framework for explanation. In L. L. Putnam \& A. M. Nicotera (Eds.), Building theories of organization: The constitutive role of communication (pp. 21-47). New York: Routledge.

Mumby, D. K. (1987). The political function of narrative in organizations. Communication Monographs, 54, 113-127.

Mumby, D. K., \& Stohl, C. (1991). Power and discourse in organization studies: Absence and the dialectic of control. Discourse Society, 2, 313-332. https://doi. org/10.1177/0957926591002003004.

Near, J. P., \& Jensen, T. C. (1983). The whistleblowing process: Retaliation and perceived effectiveness. Work and Occupations, 10, 3-28.

Schoeneborn, D., Kuhn, T. R., \& Kärreman, D. (2019). The communicative constitution of organization, organizing, and organizationality. Organization Studies, 40, 475-496. https://doi.org/10.1177/0170840618782284. 


\section{William Rothel Smith III et al.}

Stewart, L. P. (1980). "Whistle blowing”: Implications for organizational communication. Journal of Communication, 30, 90-101.

Taylor, J. R. (1999). What is "organizational communication"? Communication as a dialogic of text and conversation. The Communication Review, 3, 21-63.

Taylor, J. R. (2011). Organization as an (imbricated) configuring of transactions. Organization Studies, 32(9), 1273-1294. https://doi.org/10.1177/0170840611 411396.

Taylor, J. R., \& Van Every, E. (2000). The emergent organization: Communication at its site and surface. Mahwah, NJ: Lawrence Erlbaum.

Taylor, J. R., Cooren, F., Giroux, N., \& Robichaud, D. (1996). The communicational basis of organization: Between the conversation and the text. Communication Theory, 6, 1-39.

Weber, M. (1946). From Max Weber: Essays in sociology. In H. H. Gerth \& C. Wright Mill (Trans. and Eds.). New York: Oxford University Press.

Weick, K. E. (1979). Social psychology of organizing. Reading, MA: AddisonWesley. 


\section{Part VI \\ Epilogue}




\title{
16 Epilogue \\ God and Devil, Hero and Villain, and the Long Journey Ahead
}

\author{
Rita L. Rahoi-Gilchrest
}

This collection of essays, showcasing the expertise of nearly two dozen organizational communication scholars, is a daring anomaly. All of its richly varied chapters explore just a single case study. More unusual still, they all focus on one man's intensely personal story of corporate whistleblowing in a country, Norway, otherwise renowned for its ethics and transparency.

How do our three co-editors defend such an approach? In Chapter 2, it is argued that the full complexity of any major socio-organizational event is best captured by triangulation-that is, by using multiple frames for analysis. So, at the outset, they offered each potential contributor two theoretical viewing lenses to consider: Hirschman's social-economic perspective on exiting organizations (a dialectic of self vs. organizational preservation) and Campbell's social-psychological model of the heroic monomyth (in a twist on that myth, the case study possibly reflects not heroic valuation but the dialectic tension of "saving" the self vs. a greater other).

In addition, they wisely made available to these contributors a rich array of primary and secondary source materials, any of which might prove especially pertinent to a scholar's preferred theoretical perspective. Given the variety of perspectives here, and given that all of them focus on a single story, we can expect that the book will prove fascinating, not to mention unusually accessible, to a wide range of readers.

Because this project was several years in gestation, the editors will seem prescient in their anticipation of the debates on whistleblowing that began dominating American politics in the fall of 2019. These latter events, far more public in scope and impact than the Norsk Tipping (NT) scandal, can prove difficult for many of us to interpret amid the cacophony of opinions being expressed. We might find this nuanced guide helpful, then, when revisiting our own sensemaking in interpreting the meaning of any single whistleblowing event, especially one of such national scope and impact. Here, we are able to explore whistleblowing more broadly-as a public, organizational, mediated, corporate, even "paracorporate" act of communication-thanks to the book's multiple views on the history, 


\section{Rita L. Raboi-Gilchrest}

practice, and perceptions of calling public attention to wrongdoing. These analyses also take our understanding of what whistleblowing is, and can be, far beyond typical "classifications" that merely identify top types of reported corporate wrongdoing (e.g., health care, defense contractor, tax/ IRS, securities, or procurement fraud; see Hagens Berman Sobol Shapiro, 2016).

Instead, these chapters bring to life the kind of deep understanding of whistleblowing that Sarah Amira de la Garza describes: "Whistleblowing experiences are vivid displays of conflict between forces of power and largely unspoken values." Reading this collection will be valuable to anyone seeking a more well-rounded appreciation of this very particular and dramatic form of organizational/rhetorical narrative. But the interdisciplinary and intercultural nature of this collection deserves to be noted as well. We hear from not only corporate and legal practitioners but also scholars from across the United States, England, and Norway, writing from departments of communication, economics, and business. This makes for an impressive wealth (or array) of interdisciplinary expertise.

Of the many intriguing questions and themes arising from the 15 chapters in this collection, I want to explore these four:

- How, rhetorically, do publics define and manage the concept of whistleblowing?

- How does this process shift over time as cultural norms and expectations change?

- How can the whistleblowing process be understood as a multidimensional, shifting matrix of dialectic tensions?

- How does whistleblowing hold potential for engaged research and practice in organizational and "paracorporate communication" (a term I'll define at the end of this epilogue)?

\section{How Whistleblowing Is Rhetorically Defined and Managed}

Let's begin with a classical rhetorical perspective on these contemporary events. Ronald Walter Greene, Daniel Horvath, and Larry Browning walk us through the applicability of the ancient Greek concept of parrhesia, denoting frank free speech that, like whistleblowing, involves both criticizing and truth-telling in the face of considerable personal risk. Their discussion establishes a foundation for our thinking about whistleblowing as a rhetorical act, not just a moral one. From the perspective of organizational communication scholarship, these authors also show how whistleblowing can lead to improving an organization's infrastructure and enhancing its democracy.

This discussion can be extended further, however, if we consider whistleblowing as not only a rhetorical/organizational act but also as a broader social process. The word "whistleblower" itself has been viewed 
by various publics as a "god term"—rhetorician Kenneth Burke's evocative name for what he called "the ultimates of motivation." Scholar Richard Weaver extended that idea by proposing a dichotomy between "god" and "devil" terms. "God" terms-words such as "liberty," "justice," "freedom," and "allies"—are sanctified by rhetorical communities or cultures and become guiding terms for collective inspiration and positive action, whereas "devil" terms-words such as "Nazi," "abortion," and "rapist" - are used because "there seems to be indeed some obscure psychic law which compels every nation to have in its national imagination an enemy ... for something which will personify 'the adversary"” (Weaver, 2009/1953, p. 222, see also Kperogi, 2016). These latter words, while negatively nuanced, can have the same rhetorical force as their dialectic opposites. What makes this dialectic-and therefore a challenging target when it comes to the rhetoric surrounding whistleblowing-is that both "god" and "devil" terms can, and do, shift over time.

\section{How Cultural Meaning-Making of Whistleblowing Shifts Over Time}

Given the history of whistleblowing legislation in America dating all the way back to 1778 (Stanger, cited in Naylor, 2019), we might expect whistleblowing to enjoy the cultural gravitas of a "god term." But can we truly say that whistleblowing is always so considered? Or is it instead an example of a principle caught in the dialectic of "god" vs. "devil" terms?

While the whistleblower's legal rights and protections have usually been defended during the past few decades, and while whistleblowers certainly have been romanticized if not glamorized in movies such as $\mathrm{On}$ the Waterfront, All the President's Men, and Erin Brockovich, consider its definition as it appears online and in the public domain in the second edition of Black's Law Dictionary. There, "whistleblower" is defined as "an employee who turns against their superiors to bring a problem out in the open" (italics mine). This is very different from Miceli and Near's (1985) summary quoted in several of these essays. And while Greene, Horvath, and Browning are justified in presenting a definition grounded in organizational scholarship, its wording- "disclosure ... to persons or organizations able to effect action"- does not quite convey the potential for backlash against whistleblowers in the way that Black's early legal definition can (and, I suggest, does). In the court of public opinion, this legal definition as it appears in the public domain might well carry more weight in shaping reactions to whistleblowing than definitions from a more limited field of study.

No less influential are the power and presence of those "superiors" in the Black's Law definition. When those superiors include the actual government or leadership of a country, our task of deciding whether "whistleblower" is a "god" or "devil" term—and public discussion of the 


\section{Rita L. Rahoi-Gilchrest}

act-becomes far muddier. Consider the discourse surrounding whistleblowing in the daily headlines of the past decade. There, we can see a linguistic tug-of-war between "god" and "devil" terms as a split develops between those who view whistleblowing as an unpatriotic act (attacking, for instance, the motives of Edward Snowden and Chelsea Manning) and those who staunchly defend the right of whistleblowers to be protected for their patriotic or moral acts (most recently, in 2019, the CIA official whose White House whistleblower complaint triggered presidential impeachment hearings).

Perhaps another key to deeper understanding of the social meaningmaking in whistleblowing lies in Greene, Horvath, and Browning's presentation of Charles Redding's differentiation between "boat rockers" and "whistleblowers"-implying that their motivation, as we perceive it, might lead to a wider definition of a whistleblowing act as being on one side or the other of the "god/devil" dialectic. We also can take into consideration Corey Bruno and Charles Conrad's observation that once people have been "de-humanized through existing rhetoric" (perhaps through the application of "devil terms"), they are less likely to be dissenters at all.

\section{Whistleblowing as Dialectic Tensions}

The dialectic tensions in our very talking about whistleblowing lead us back to the opening chapter of this volume. There, in his own account of his whistleblowing experience, we find Peer Jacob Svenkerud (PJS) reflecting on his personal and professional struggles to navigate the competing forces of self-preservation and self-sacrifice. PJS poignantly describes feeling, for much of his life, a "stranger in a strange land," moving from company to company in search of a professional home that truly aligned with his values, his training as a scholar of social structures and diffusion theory, and his day-to-day work as a corporate leader.

Organizational assimilation is a powerful force, especially for someone who has long sought the ideal fit for his skills, temperament, and experience. PJS, as just such a person, likely felt especially susceptible to its influence; Bruno and Conrad agree that "self-knowledge and selfperception at a given point in time/space guides and constrains actors' symbolic action and their identity narratives," which implies that the forces of organizational assimilation can strongly affect an individual's decision to delay whistleblowing.

Further, as PJS describes, NT had an authoritarian corporate culture in which anyone daring to speak out about unethical practices had repeatedly and quickly been sanctioned. Such a repressive culture, Bruno and Conrad point out, often leads to co-workers perceiving the dissenter as a threat to their own well-being. In one particular meeting, only one of many in which he tried to voice his concerns about unethical practices and 
the growing attention they were getting in the media, PJS was christened "The Prince of Darkness"-a "devil term" in all senses of the phrase. And just a few short months later, when he had expressed his concerns to another top leader, the vice CEO introduced another "devil term," telling the group, "We have an unfaithful servant ... do any of you know who this individual is?" As PJS then reveals, his identity was outed nearly three years later, and despite a new CEO's promises to "clean up" after the scandal, PJS was essentially removed from an active role as director for communications and external affairs. He then hired an attorney, settled with the company, and began a new career just days after terminating his relationship with NT. What began as informed self-sacrifice for the public good then became nearly a life-and-death (or life-and-health) issue of self-preservation. What PJS does not discuss in depth but is also relevant, is his identity as the son and grandson of a socially and politically prominent family in Norway. Knowing this helps us understand even better the deeper dimensions of the personal and professional risks he took in this case.

Along these same lines, Karl E. Weick's chapter addresses such dialectic tensions as "surfaces of apprehension" (citing Taylor \& Van Every, 2000)— "opposed ideas that become increasingly difficult to manage"and delves more deeply into the sensemaking that PJS needed to do in his particular circumstances. Weick says that "whistleblowing can be treated as a deepening struggle to make sense under conditions where a growing set of implications, tied to a generative cognition, become increasingly incompatible" and adds that while some people are able (or acculturated) to adapt to modest dissonance, others have a "fixation with stronger dissonance that edits sensemaking more severely." Returning to PJS's story and viewing it from this sensemaking perspective, it appears his personal vulnerability in feeling a lack of belongingness or satisfaction despite his successful career might well have been a hidden strength - not only to call out the dissonances between organizational messaging and practice, but also to brave the risks of the whistleblowing act.

At this point, then, we have a sense of how rhetorical, multidisciplinary, intercultural/international, and historical views inform a keener understanding of whistleblowing. For me personally, however, as a passionate lifelong student of organizational/corporate communication and rhetoric, the finest value of this collection is how it inspires future directions for research in these fields-with whistleblowing as the centerpiece of a vital discursive community.

\section{Whistleblowing as Research and Practice in Organizational Communication}

The idea of personal and organizational risk-taking that I discussed in the previous section ties closely to the final topic of this epilogue-the 


\section{Rita L. Rahoi-Gilchrest}

idea that whistleblowing might be a more inclusive, and more promising, topic for research and practice in organizational communication than previously realized. Authors Greene, Horvath, and Browning discuss the unique nature of whistleblowing as organizational communication. They suggest we move beyond established definitions of whistleblowing (i.e., as a public act or an act against one's superiors) and instead view it as a way to "negotiate asymmetrical relationships of power." They contend that both organizations and individuals might benefit from organizations actively encouraging collective action and upward communication on whistleblowing, keeping discussions internal and therefore resulting in positive correction that remains under organizational control.

I discussed earlier the dialectic tension resulting in the use of "legal" vs. "scholarly" definitions of whistleblowing. Another reason to examine whistleblowing as a unique form of organizational communication comes from law professor Anne Oline Haugen, who says: "In this story, the whistleblower blew the whistle about the use of public funds that he considered illegitimate. No one disputed the justness of his charges, but he still received no protection from recrimination. How could this happen?” Indeed. It's especially puzzling given Bjørn T. Bakken and Thorvald Hærem's observation that whistleblowing cases are "high on the public agenda in Norway." Essentially, Haugen goes on to explain, there are differences in Norway's legal statutes and practice. Norwegian law, for instance, determines that some immoral practices are not punishable within the scope of whistleblowing statutes. But regardless of context or culture, the law can be flawed.

Norwegian scholars Einar Øverenget and Åse Storhaug Hole, in their discussions of ethical blindness and the lack of reporting organizational wrongdoing, offer another intriguing possibility for future research. What can we investigate further to improve risk assessment for ethical blindness in the organizational cultures we study? These authors identify several likely subjects: fear of retaliation, beliefs of inaction, difficulty in assessing the wrongdoing, and lacking trusted confidants.

But the case of NT reveals other factors that might influence nonreportage, such as the prestige and value structures of the organizationfactors building a strong sense of organizational identification and pride. Joseph McGlynn reminds us in his chapter on whistleblowing and risk that from the perspective of prospect theory, people "place a greater emphasis on potential losses than they do gains." Thus, where they occupy a comfortable place in a successful organization, people are more apt to be risk-averse. And any organization that enjoys a positive reputation, as Audra Diers-Larson points out, suffers from the "vulnerability of complacency." The stronger and more accomplished the organization, then, the greater the risk might be of failure to address unethical actions unless the kind of "mindful management" discussed by Bakken and Hærem is in place. If these principles are followed, whistleblowers 
are not needed to amplify weaker signals of wrongdoing to management, which of course is what PJS eventually decided he had to do. As William Rothel Smith III, Jeffrey W. Treem, and Joshua B. Barbour remind us in their chapter on reconstituting organizations, whistleblowing is a signal of the "need to reconstitute the organization ... and ... marshal constitutive resources to do so," as PJS experienced in the NT case.

Contributors Åse Storhaug Hole and Therese E. Sverdrup offer another valuable perspective from the field of organizational behavior regarding decision-making, sensemaking, and whether or not dialectic tensions are addressed and resolved. Their discussion of psychological contracts resonates with PJS's discussion of the many pressures weighing on him at NT. $\mathrm{He}$ certainly had long-standing relational contracts based on trust and loyalty (reinforced by considerable organizational messaging that loyalty was a priority), as well as ideological contracts based on the stated values of the organization. In fact, it was only when these ideological contracts were so repeatedly and egregiously violated that he could break the relational contract keeping him from whistleblowing.

If whistleblowers cannot be guaranteed legal protection, and if individuals struggle with organizational identification, perceived loss vs. gain, and their own unwritten psychological contracts, does this mean that whistleblowing will most likely occur only when it raises the lowest risks for all and can be managed internally within organizations? Consider the point made by Bruno and Conrad that not only PJS's story, but also his status, allowed him to engage in whistleblowing. (He was, we recall, an insider in upper management, tasked with looking after his company's image and strategy, and someone who maintained secrecy and anonymity for nearly three years.) This view is echoed in writer Amira de la Garza's observation that PJS was able to "elegantly navigate events due largely in part to the power that accompanied his experience and position, as well as the power of having governmental agencies collaborating to investigate." So, do we infer from this narrative and these discussions that whistleblowing is most likely to be carried out by those who are already well connected and/or protected?

Several of the scholars invited to this colloquy addressed the issue of voice and how it's expressed or suppressed in the meaning-making that accompanies the act of whistleblowing. In terms of its implications for organizational research, Diers-Lawson makes a poignant point in her chapter on the "loneliest stakeholder." She notes a lack of attention to "narrative about transgressions in organizations-the emotional journey that employees take through the crisis, no matter whether they are whistleblowers or trying to make sense of the events as they unfold." Contributors Storhaug Hole and Sverdrup agree, noting, "We think it no less important to focus on non-reporting behavior because most employees stand by in silence." This might well be worth consideration in future research on both organizations generally and crisis communication specifically. 
Additionally, where does the sensemaking of stakeholders fit into the dynamic of risk, decision-making, and dialectic tensions involved in whistleblowing? After all, the perceived opinion of the board of directors came into play in the NT case when PJS was told that his voice would carry more weight than that of someone less highly ranked in the company. Yet, he recalls, when he met with the chair and vice chair of the board in Oslo, "case after case was dismissed with the explanation that it was impossible to prove, that they lacked written evidence, that, yes, it was serious and warranted a 'warning' and change of practice, but that no further action was required." Although this was not the final decision by the board, it was certainly a stunning first reaction to PJS's attempt to share his concerns.

The significance of this action, contributor Brian K. Richardson explains, is that whistleblowers rarely win their case if stakeholders don't, or won't, get involved in the issue. And, applying attribution theory, they are generally apt to have "more negative perceptions about whistleblowers who were engaged in the wrongdoing they are now reporting." Yet, at the other end of the spectrum, the "saint whistleblower will face greater retaliation ... in an attempt to reduce their credibility and legitimacy." Diers-Lawson affirms that in the NT situation, "blame attribution [was] less of a question of the facts of a situation and more of a question of perception and competing interests." This takes us back to our earlier discussion of the "god"/“devil" dialectic. Richardson poses the question of whether stakeholders would consider PJS to have been a hero or a prince of darkness.

This discussion fully acknowledges the difficulties inherent in changing any organization's culture, particularly when its potential losses may exceed any gains. Nord University Professor June Borge Doornich reminds us of companies such as Enron, WorldCom, and Tyco that were forced to implement change after their white-collar scandals made the news but wonders whether such forced change as a result of publicized crises is actually effective in the long term. She concedes that the judicial frameworks in certain countries "force companies to implement a management control system that both eases the threshold for blowing the whistle and protects the whistleblower afterwards." But as we have already discussed, a legal paradigm isn't always the most effective one for understanding and managing whistleblowing.

At the start of this epilogue, you'll recall my coining the phrase "paracorporate communication," with the prefix "para" denoting "beside, alongside of, beyond, aside from" (Merriam-Webster, 2019). I meant "paracorporate" to reference the broader, multidisciplinary field of study that surrounds and supplements our studies of corporate communication. In this very volume, perspectives ranging from organizational to interpersonal to rhetorical theory offer varied perceptual lenses trained on a single, significant, value-laden act, one that calls out corporate 
wrongdoing. To help navigate the difficult cultural, social, and organizational changes such an act carries with it, we might well have to draw on many different tools as scholars.

Ultimately, the narrative offered by PJS in the NT case-indeed, this entire volume-challenges us to examine our own values as scholars and practitioners. As we pursue these lines of paracorporate research, do we believe the need for self-identity, the need to tell a story until it is heard, and the innate drive for sensemaking will be enough for aggrieved individuals to overcome the pressures of organizational culture, identification, and assimilation and find the courage to report wrongdoing? Can we take our skills at risk assessment and employ them to make organizations stronger and safer for (and perhaps through) whistleblowing? Do we believe organizations can evolve cultures actually welcoming the whistleblowing act as a means of rewriting the organization's story on the way to fulfilling its own manifest destiny?

As in the act of whistleblowing itself, our future goals as scholars and practitioners might well be to come together into the kind of community of practice represented in this collection, studying the "communicative constitution of organizations" suggested by Rothel Smith III, Treem, and Barbour, and using our shared wisdom and insights to draw belief and action together.

\section{References}

Hagens Berman Sobol Shapiro LLP. (2016, July 20). Five of the most common types of whistleblower fraud. Retrieved from www.hbsslaw.com/blog/hagensberman-blog/whistleblower/5-of-the-most-common-types-of-whistleblowerfraud

Kperogi, F. A. (2016, September 25). Transformation of "change" from God term to Devil term in Nigeria. Retrieved from www.farooqkperogi.com/2016/09/ transformation-of-change-from-god-term.html

The Law Dictionary. What is whistleblower? Retrieved from https://thelawdic tionary.org/whistleblower/

Merriam-Webster, Incorporated. (2019). Para. Retrieved from www.merriamwebster.com/dictionary/para

Miceli, M. P., \& Near, J. P. (1985). Characteristics of organizational climate and perceived wrongdoing associated with whistle-blowing decisions. Personnel Psychology, 38(3), 525-544.

Naylor, B. (2019). "Whistleblowing is really in our DNA": A history of reporting wrongdoing. Politics, September 25. Retrieved from www.npr.org/2019/09/25/ 764010989/whistleblowing-is-really-in-our-dna-a-history-of-reporting-wrongdoing.

Taylor, J. R., \& Van Every, E. J. (2000). The emergent organization: Communication as its site and surface. Mahwah, NJ: Erlbaum.

Weaver, R. (2009/1953). The ethics of rhetoric. New York: Routledge. 


\section{Index}

Note: Page numbers in italics indicate a figure and page numbers in bold indicate a table on the corresponding page.

$\mathrm{ABC}$ see Activity Based Costing (ABC) accentuation 82-83, 90 Activity Based Costing (ABC) 130-131

administrative control 201-202, 204; culture effect on 207-208; mechanisms 201-202, 206, 211

affective responses 119,140

altruistic motivations 154,159 altruistic reasons $154-155,157-158$, 160

Ansoff, Igor 124-125

anticipation 132-133, 175

anti-discrimination practices 63 appropriateness, authority and criteria of 217

Aronson, E. 85

Athenian Assembly 35

attributions-based typology of whistleblowers 151, 153-154, 154; attribution theory 153-154; definitions and 151-152; locating PJS within 157-159; motives 152; propositions 155-157; stakeholders and whistleblowing cases 152-153; typology of 154-155

authentic leadership 106

authoritative texts 216-217; NT 218; shared 222

authority $21,49,96-97,105,189$, 204, 221-226

Bakhtin, M. M. 111-122

Bakken, Bjørn T. 122

balancing 90; dynamic image of 89-90; firms place on 89-90 banality of evil 96

Bandura, A. 97

Barbour, Joshua B. 214

Bazerman, M. H. 97, 126-127

Beck, T. E. 126

blame attribution 165, 172, 238

blame or responsibility attribution 172

board of directors (BOD) 31, 34, 39

boat rocker 33, 41-42, 63, 234

boat-rocking 33

BOD see board of directors (BOD)

Bourdieu, P. 111, 115-116, 118

bracketing 82

Brief, A. P. 105

Brown, D. A. 204-205

Browning, Larry 15, 31

Bruno, Corey 61

budget $6,24,62,112,114-115,130$, $192,209,218$

business expenditures 218

bystander effect 128

Callahan, E. S. 208

Campbell, J. 16, 20

Campbell's Monomyth 22

Caspersz, D. 152

CCO see communicative constitution of organizations (CCO)

censorship 53

CEO see chief executive officer (CEO)

chairman of the board (COB) 40, 191-192, 193, 195

Chartered Institute of Internal Auditors 208

Chen, C. P. 167, 175 
chief executive officer (CEO) 3 , 6-8, 11-12, 31, 39, 55-56, 124, 144-145, 158-159, 171-174, 176, 191-192, 194-195, 207; behavior 9; charismatic reputation of 221 ; decision-making 178; descriptions of 221-222; execution of role and responsibility 102; handling of financial issues 178; liaisons of 10 ; narrative and sensemaking 169; performative aspects of 222; personal gardening expenses 129 ; self-serving actions of 221

Christianson, M. 82

chronotopes: function 112; methodology of 119

chronotopic distinctions 110-112; I 112; II 112-113; III 113; IV 113-114; V 114; VI 114; VII 115; X-rays $115-120$

Chugh, D. 97

Clair, J. A. 166

clan control 204-205

clan culture, effect on whistleblowing 208-211

clear association 173

close liaison 10

COB see chairman of the board (COB)

collective activity 215

Commers, M. R. 190-191

commitment to resilience principle 131-133

communication 40; choice of 61 ; consultants 159; crises and crisis 165; effectiveness of 222 ; internal and external 88; strategies 221 communicative constitution of organizations (CCO) 214-215, 221-222, 226; concern of 215; perspectives 220; scholarly movement of 215

communicative products 215 company secrets 8 company values 204-205 compensation packages 72 concrete texts 219

Confessors 154-156, 158

conformity 96-97

Conrad, Charles 61

constant practical rationality 97

containment 132-133

continuity of experience 86 contracts, types of 190

control, types of 201

conversations 215-216; producing texts

219; shared interpretation of 216

Coombs, W. T. 177

corporate culture 65,211

corporate environment 205

corporate governance 206

corporate social responsibility (CSR)

4, 16, 66, 85, 101, 172, 192

corruption 10, 145-146

credibility 155-156

crisis: definition of 166 ; management 128,173 ; understanding of 166

critical information 36

cultural controls 201-202, 208; effectiveness of 208; forms of 204

culture: effects of 202; sustaining values of 120; of trust and openness 191

Cunha, M. P. 128

cybernetic controls 201-202

deaf effect 103

decision-making in whistleblowing processes 185 , 187-189; blowing the whistle 192-194; choosing to go public 192-195; choosing to resign 195; discussion 195-196; psychological contract 186 , 189-192

decision-making process 167 deference to expertise principle 132-133

degree of retaliation 207

Deloitte 26, 67

Denzin, N. 15

descriptive approach 96

Dewey, J. 15-16, 82, 86

Diers-Lawson, Audra 164

discrimination 48,52

disenchantment 66

dissemination of stories 90

dissent/intransigence 64

dissertation 110, 113-115, 117

dissonance $67,73,85-87,90,235$

distinction, methodology of 119

diversity 118, 165

donated labor 71

Doornich, June Borge 201

Douglas, S. C. 190

Drucker, P. 211

dynamic equilibrium model 90 


\section{Index}

emotional discontent 144

emotional significance 70

emotions influence 141

employees/employment 48, 50-51, 55,

185,205 ; appropriate procedure

for 52; behavior and actions 201;

contract, mutual obligations 186 ;

freedom of speech 49; protection of 48; responsibility 93-94; selfsacrificing 122

Enron 64, 68, 201, 238

ethical blindness 93-94, 97-98; ethics and practical rationality $95-97$; frames and rigid framing 98-103; managerial implications 105-106; temporary state of 94; wrongdoing 94-95

ethical decision-making 96-97;

models 94; processes 106

ethical fading 94, 97

ethical failure 95-96

ethical inconsistency 93

ethical issues, informal discussions of 67

ethicality 70, 97

ethical standards 71-72

ethical theories 95

European Convention of Human Rights 48-49

European Union (EU) convention 47 exceptional autonomy 65

executive compensation, elements of 72

exit 16,19

Exit, Voice, and Loyalty: Responses to Decline in Firms, Organizations, and States (Hirschman) 16

experience 115-116

Extended Parallel Process Model (EPPM) 141

external whistleblowing 18, 54-55

figurative texts 219

Fombrun, C. J. 170

formal policies 204

formal reporting system 206

foster flexible framing 105

Foucault, M. 35-37

framing 98

Frandsen, F. 164, 170

Frank, J. 47

frankness 35-37, 39, 42

freedom of expression 48-49

freedom of speech $48-49$
Gabriel, Y. 35

Garza, Sarah Amira de la 110

generative cognition 85

"generative" organizational culture 127-128

Gentile, M. C. 211

Gossett, L. M. 224

governance 204, 206, 208, 211

grand ideologies 217

grand theory 111, 118

Grant, C. 152

Greene, Ronald Walter 31

groupthink 111

Guattari, F. 116

Gundlach, M. J. 190

Hærem, Thorvald 122

harassment 48, 52, 55, 64, 68, 123

Haugen, Anne Olin 46

Heath, R. L. 170-171

Hero with a Thousand Faces

(Campbell) 20

Hero with a Thousand Faces, The

(Campbell) 16

Heumann, M. 152-153

Hirschman, A. O. 33-34, 223

history of interaction 168

Holladay, S. J. 177

Hole, Åse Storhaug 93, 185

horizontal contract 190, 193-196

Horvath, Daniel 31

human behavior 46-47

human grouping 89

human rights 47,62

hygiene-motivation theory $172-173$

identity 84; narrativizing 69-70; statements 157

ideological contract 190, 192-193, 237

ideological psychological contract 192

images: creation of 83; values of 117

impatience 3

individual ethical concerns 64

informal interactions 66

instrumentality 96-97

insubordination 34-35

intention 62, 94, 104, 116, 133 , 172-173, 178

intercultural competence 4

internal commotion 8

Internal Review Board (IRB)

requirements 110

internal whistleblowing 18 
internationalization in crisis communication 165

international leadership competence 4 interpersonal relationships 171

intolerable evils 34

James, William 86

Jilted Lover 154-157

job satisfaction 17, 62

Johansen, W. 164, 170

Johnson, C. E. 156-157

Kaptein, M. 209

Kenny, K. 31, 40

Kilker, J. 224

Kuhn, T. 216

labor law 47-48

labor markets 124

Lai, C. T. 167, 175

Langenberg, S. 40

language choices 140

Lay, K. 68

leadership 105, 221, 224; actions of 220; classes 7

leading scholarship 39

legitimacy 156, 168

Lewis, M. W. 90

$\log 036$

love triangle 171

loyalty 16, 19, 223; to employer 49; psychological contract of 191

macro-level of institutions 217

Maitlis, S. 82

Malmi, T. 204-205

management control system (MCS) 201-202; administrative control mechanisms for whistleblowing 206; clan culture's effect on whistleblowing 208-211; culture effect on administrative controls 207-208; effectiveness of 201; framework 210; as package 202-206, 203

managerial blindness 125

managers 46, 195; defensive action

122 ; as role models for employees 133

Mansbach, A. 39, 41

Markovits, E. 37

Martinko, M. J. 190

McGlynn, Joseph 139

McKenna, B. 9
MCS see management control system (MCS)

Messick, D. M. 97

Miceli, M. P. 17, 31, 105-106, 187

micro-level of interaction 217

middle management, involvement of 126

Miethe, T. D. 187

mindful management 129

mindful organizing 126, 132

misconduct 211; continuous 209; risks of 208-209; whistle on 209

misidentification 89

mis-specification 89

Monoson, S. 37

monstrous abridgement 86

moral disengagement 97

Mueller, R. 68

Mumby, D. K. 39

national monopoly 219

Near, J. P. 17, 31, 105-106, 187

negative affect 144

neglect 223

non-reporting behavior 185

non-responsive organization 33

Nordic labor-market model 49-50

normative contracts 190

Norsk Tipping (NT) 5, 9, 40, 67, 110, 116-117, 129-131, 158, 185, 206, 211, 214, 226; annual reports 219; appropriateness of actions 223; athletic organizations and events 218; attempted reconstruction of 221-223; attitudes about 175; authoritative text at 217-218; behaviors 171; "boys club" at 210; "business as usual" ethos 220; characterized 220; communication professionals at 221; communicative constitution of 218 ; conflicts at 16; constitution of 218 ; crisis for 166,175 ; culture 89-90; decisionmaking at 222; employees 194; form of annual reports 220; fraud at 218; glowing view of 221 ; image 195; leadership 15-16, 152 ; levels 218 ; liability for 167 ; macro-level discourse of 218-220; malfeasance at 222; management 220; micro-level discourse at 220-221; mismanagement issues 174; model for 221; opportunity for 176; reputation 101, 194; scandal 


\section{Index}

164; sensemaking interpretation of 81 ; social performance 175 ; stakeholders 169, 169; transparency 219; virtual autonomy 101; voice as means of legitimate resistance to authority 223-224; whistleblower in 202; whistleblowing 110-111; wrongdoing at 145

Norway/Norwegian 206; corporate culture in 208; culture 202; law 47; legislation 50; media 35; national lottery 123; sports activities 192; whistleblowers 51; whistleblowing legislation 47-48; Working Environment Act (WEA) 48; working life in 4; workplaces 207

Norwegian Athletic Association (NAA) 159

notice of dismissal 48

NT see Norsk Tipping (NT)

oceanic stewardship 216-217

openness, culture of 191

Opportunists 154-156

options 88

organizational communication 216; active approach to 34 ; presumption in 36; theoretical analysis of 110-111; whistleblowing as 32-35 organization, (re)constituting 214-215; CCO 215-217; to organize itself $214-215$; reconstituting 214; scholarly studies of 214; whistleblowing 224-226; see also Norsk Tipping (NT) organization/organizational: against allegations 73; behavior 186; challenges 167; characteristics of 217; chorus 215; complacency for 176; control 35; crises 171; culture 63 , 88; environments 169-170; ethics 71 ; identity 72 ; member voice 223 ; memory 63 ; messaging 216 ; performance 72 ; practices 62 ; procedures 53-55; reputation 173 ; socialization 73 ; and stakeholders 176-178; structures 204, 208, 216, 224 ; theory 114 ; values 118,204 ; well-being 168-169; wrongdoing 31, 46, 139, 142

Øverenget, Einar 93

Palazzo, G. 97

parrhesia: constitutive elements 39; movement of 35 ; speaking truth to power 35-38; subjective elements of 41; whistleblowing 39-41

parrhesiastic relationship 40

Pascoe, J. 211

Pearson, C. M. 166

perceptions $88,141,158$

Perrow, C. 68

personal development 147

personal relations 37

Persson, G. 5

PJS see Svenkerud, Peer Jacob (PJS)

planning 201-202

plausible meanings 84

Plowman, D. A. 126

policies and procedures 204

positive intention 172-173

power 168; institutional and political

grammars of 116; relations 119

predictable surprises 126

preoccupation with failure principle

129-130, 133

preparedness 127

pre-reflexive practical coping 96

prescriptive approach 96

pre-whistleblowing time frame 219

prince of darkness 152

principled dissent 61

Privacy Protection authorities 46

procedural violation 130

production of subjectivity 120

project budget 115

prosocial behavior 187

prospect theory 139-141

protection, conditions for 51-53

psychological contract $186,188,191$, 195-197; breach of 189; ideological 192; individual 190; of loyalty

191; normative 196; perspective

191-192; research on 189 ; theory

$186,188-191$; violation of 188 ,

194

public decision-making system 50

public discourse 219

public expectations 8

public funds, misuse of 49

public interest $170,172-173$

public sector 48

Radiation Protection Regulations 52 radical change 147

Rahoi-Gilchrest, Rita L. 231

rational-ethical decision-making 175

rational human beings 96

Reason, J. 125-126, 133

Redding, C. 33, 41-42 
regulatory agencies 153

regulatory capture $66,71-72$

relational contracts 186, 189, 193

relational valence 168

relationship: among stakeholders

174-175; evaluation of 172 ;

between stakeholders 175 ; web of 170

reluctance to simplify principle

130-133

resilience, commitment to 131-133

response efficacy 141

retaliation 51, 55, 64, 157, 196

retrospect for meaning 84

reward and compensation 201-202

Richardson, Brian K. 151

rigid framing 98, 105; consequence of 99; examples of 99-100

risk 139-140; as analysis 140; in case of PJS 142-144; decisions 141,

144; Extended Parallel Process

Model (EPPM) 141; as feelings

140 ; isolation and duality of

support 144-146; management

127; outcomes 147; perceptions

and judgments 140; prospect

theory 140-141; responsibility

140 ; severity of 140 ; social stigma

146-147; theories, concepts and dimensions of 139-140; types of 143; whistleblowing and 142

Roe, E. 88

Russo, J. E. 105

safety management $125-126$

Saint whistleblower 154-155, 157, 159

Samuelson, J. 211

Sawyer, K. R. 152-153, 155

Saxonhouse, A. 37

Schein, E. H. 128

Schoemaker, P. J. H. 105

scholarship 225

Schulman, P. S. 88-89

scientific rationality 96

self-approval 143

self-construction process $70-73$

self-criticism 214

self-discovery, process of 147

self-efficacy 141

self-knowledge 61

self-perception 61

self-respect 143

sensemaking 81-83, 111, 126-127;

conceptual resources of $86-87$; in context of whistleblowing

86-87; culture 88-90; definition

of 83 ; dissonance 87 ; errors of 89 ;

management of 81 ; mechanism

of $87-88$; process of $68,87-88$,

128 ; properties of 83 ; in service of

whistleblowing 83-86

sense of shared meaning 83

sensitivity to operations principle

130-131, 133

shared authoritative text 222

shared interpretation of conversation

216

shared meanings 83

sharing of risks 128

SIR-COPE 84, 88, 90

situational crisis communication

theory 172

situation assessment 128

Skivenes, M. 95, 187

Smith, William Rothel, III 214

Smith, W. K. 90

social context 84

social integration 190

social isolation $174-175$

socialization 205,221

social psychology 128

social responsibility 170,172

social stigma 146-147

societal values 204-205

Sørnes, Jan-Oddvar 15

speaking 142-143

speech act of resistance 39

Stakeholder Relationship

Management (SRM) Model 171, 171,177

stakeholders 158, 164-165, 194;

attitudes 175-176; emotional

involvement 173; external 195;

framework 167-168; and issues

173-176; judgments 171-172;

kinds of 153; organizational

environments 169-170;

organization and 170, 172-173, 176-178; perceived knowledge 177; primary functions 151 ; relationship management 165 , 167-172; theory in organizational communication 168 ; voices and perspectives 164; whistleblowing 165-169

Standing Committee on Scrutiny and Constitutional Affairs 102

Stewart, L. P. 33

strategic communication 61 


\section{Index}

strategic meetings 222-223

strategic planning technology 125

stress management 174

subjective probability 94

support: isolation and duality of 144-146; types and quality of 146

surfaces of apprehension 81

Sutcliffe, K. M. 126, 129, 132

Svenkerud, Peer Jacob (PJS) 3, 15, 17, 21, 31, 46-47, 55-56, 61, 67, 73, 84-85, 89, 98, 102, 116-118, 122-123, 128-129, 131, 139, 141, 143, 146-147, 151, 158-159, 164, $169,172,174,185,192,194-195$, 202, 214-215, 218-223, 225-226; accounts of whistleblowing 119 ; actions of 224; blowing the whistle 192; CSR agenda 85; decisionmaking 50; decision to blow the whistle 144; disclosures 124; experience 169; interviews 218; key aspects of 215; narratives 191; observations 102-103; retaliation 207; story as self-construction 70-73; whistleblowing 16, 130, 206, 225

Sverdrup, Therese E. 185, 194

symbol-based controls 204-205

Taylor, J. R. 215

technical knowledge 38

Tenbrunsel, A. E. 97

Teo, H. 152

threatening 63

trade union 48

transactional contracts 186,189 , 192-193

transgressions 116, 165, 167, 225

transparent culture 209

Treem, Jeffrey W. 214

Trevino, L. K. 191

trust, culture of 191

truth, contextual character of 41

truth-telling and organizational

democracy 31-32; regimes of 41-43; rhetoric of danger 41-43; whistleblowing as organizational communication 32-35;

whistleblowing as parrhesia $35-41$

Trygstad, S. 95, 187

uncertainty 140, 144, 185, 206

unethical behavior 153
United Nations International Covenant on Civil and Political Rights 49

urgency of stakeholder interest 168-169

value-based contracts 190

value-based controls 204, 208, 211

values $167,204-205$

Vandekerckhove, W. 40, 106, 190-191

Victor, B. 191

voice 16-17, 19, 223-224

volatility 88

Watkins, M. 126-127

weak signals 124, 129

Weick, Karl E. 81, 126, 129, 132

well-being 3-4

Welsh, M. 211

whistleblowers/whistleblowing 33-34, 61, 81, 122-124, 142, 165, 224; activity and effectiveness 49-50; annual reports 24-25; attributions of 62,154 ; audience of 40; to auditors 158; Campbell's monomyth 19-21; chronotopic view of 117; clan culture effect on 208-211; classic case of 110; commitment to resilience 131-132; complaints 34; concept of 187-189; conditions for 122; Confessor 154-155; context of 172 ; crisis 166 ; deference to expertise 132 ; definition of 31,187 ; disclosures 116-117; discussion of 132-134; double trouble of 128-129; effectiveness, definition of 188 ; empirical research on 94 ; events 15-16, 129; exit, voice, loyalty, and monomythology 16-19; external reviews 26-27; grounds for 89 ; internal 122; interviews 23-24; Jilted Lover 154-155; legal protection 50; legislation of 46, 48-51, 53; listening to 105-106; meaning and effectiveness of 224 ; of misappropriation of funds 117 ; motives of 152 ; news articles 25; Opportunists 154-155; as organizational communication 32-35; organizational role of 224; photographs 25-26; power 
and position of 188 ; precarious authority 225-226; as precarious authority 225-226; preoccupation with failure 129-130; primary defense of 41 ; private perceptions 95; and procedures 207; process 187-189, 188, 194, 196; promoting and protecting 206, 208, 211; proportion of 64 ; protection 64 ; protest against norms of organizing 214; psychological contracts on 185; relevance to 127-128; reluctance to simplify 130 ; research 193; rhetorical character of 41 ; routines 94; Saint 154-155; sensitivity to operations 130-131; storytelling 69-70; support and promote 191; syntactic structure of 118 ; theory $124-127$; by time and place 224-225; types of 152,154 ; typology of 154,154 white-collar scandals 201, 238 Working Environment Act (WEA) 206 workplace 193-194, 201

World Lottery Association 221 wrongdoing 47, 94-95, 97, 187, 209; benefitting from 158; claim of 41; disclosure of 34; involvement in 158; myriad perceptions of 95; observation of 187-188; organizational 46; of peers 191 ; PJS's assessments of 67; public circulation of 41 ; reporting of 187 ; revelation of 41; seriousness of 63 , 94-95, 197; solid proof of 95

"x-ray" capability of chronotope 115-120 


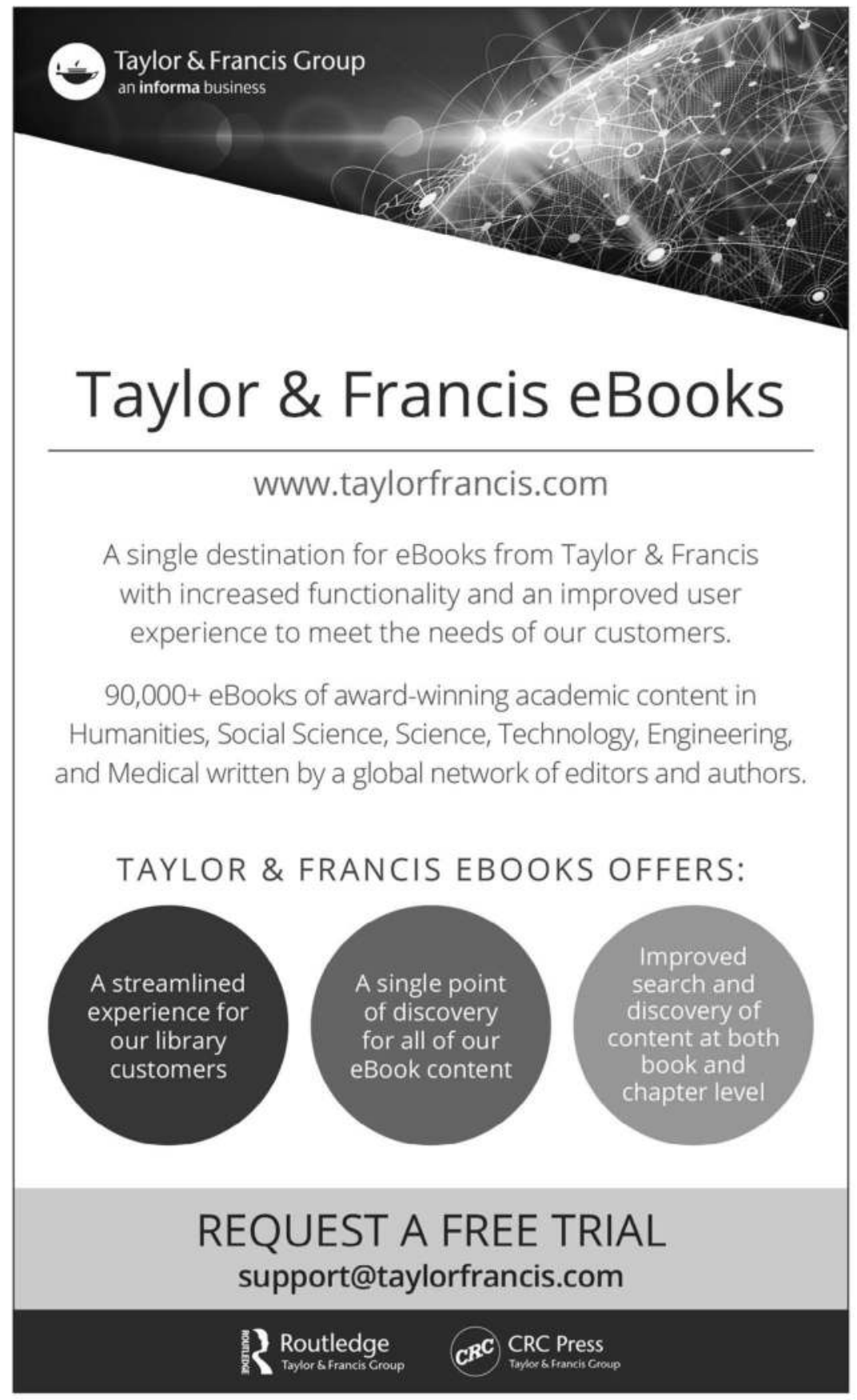

